Historic, Archive Document

Do not assume content reflects current scientific knowledge, policies, or practices. 



\section{$F 7632 \mathrm{U}$}

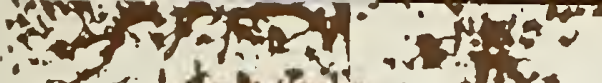

Con. 3

JSDA Forest Service

lesearch Paper RM-84

'ebruary 1972

scky Mountain Forest and ange Experiment Station

prest Service

S. Department of Agriculture

int Collins, Colorado

ind

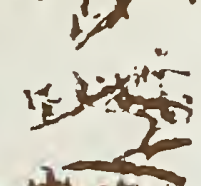
$1+100$

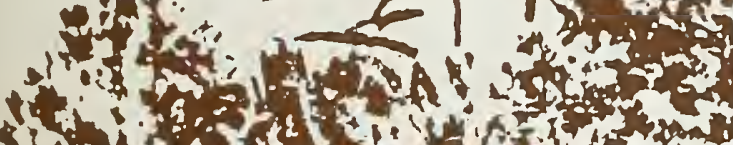

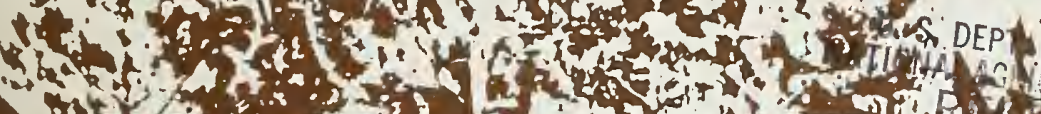

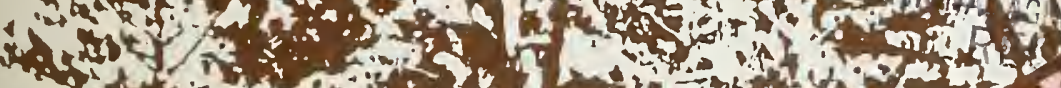

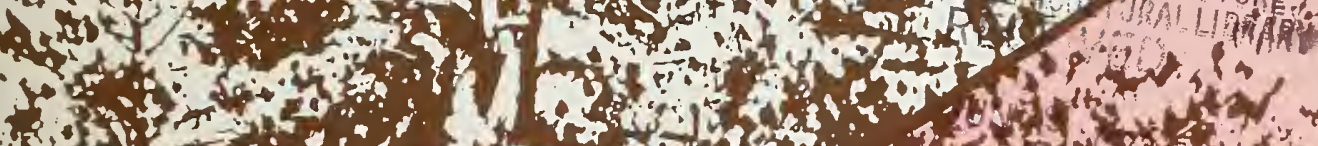
(n)

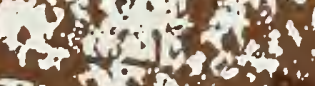
Fis

\section{NATIONAL \\ FIRE-DANGER} RATING SYSTEM

by John E. Deeming, James W. Lancaster, Michael A. Fosberg, and Mark J. Schroeder R. William Furman, (n)

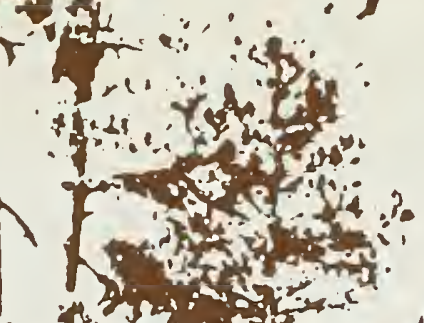

\section{ane dertint} ity 69.

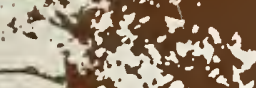

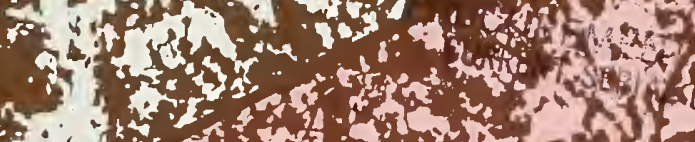
ats atiog 2118 $x^{2}$ iii 195 is $15 y=15$

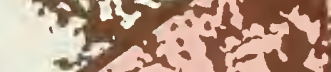
ans it it.

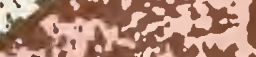
is:i $\rightarrow 2,2)$ ह 1

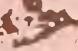
$x+2,254^{2}$ D: a dit? (1)

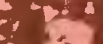

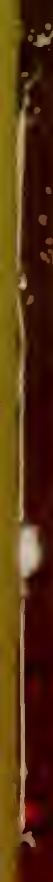
and on

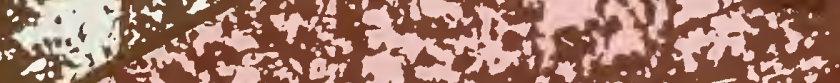

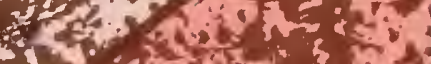

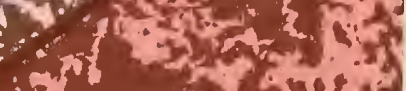
sitis. is 1. $2,12=2$ IN:-

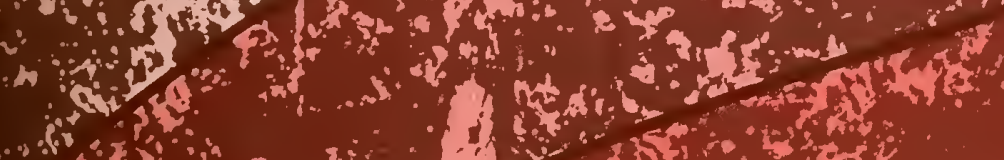

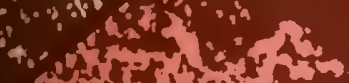
Thistery

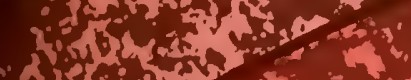
$\therefore 3$ is

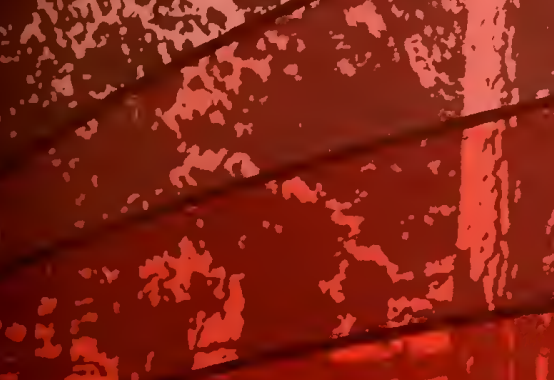

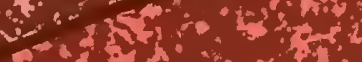

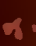




\section{ABSTRACT}

The National Fire-Danger Rating (NFDR) System produces three indexes-Occurrence, Burning, and Fire Load-that measare relative fire potentials. These indexes are derived from the fire behavior components-Spread, Energy Release, and Ignitionplus a consideration of Risk.

Three innovations in fire-danger rating are introduced in the NFDR System. First, it is solidly based on the physics of fire behavior-it is not empirical or statistical. Second, it makes use of the fuel model, an open-ended means of treating the myriad of naturally occurring fuel situations. Third, the system is designed so that improvements can be incorporated with a minimum of impact on the users.

Fuel moisture, wind, and risk are the principal variables accounting for the day-to-day fluctuations of fire danger. In the NFDR System, three classes of dead fuels and two of live fuels are recognized. Rainfall duration is the best predictor of the effect of rainfall on the moisture content of dead fuels. Very important, also, is the time fuels are exposed to solar radiation (sunshine).

Nine fuel models are introduced; each represents a broad grouping of fuel types with common characteristics. These characteristics, when evaluated, are the numerical fuel inputs required to solve the mathematical equations which yield the Spread and Energy Release components. The number of fuel models can be increased to provide the resolution necessary to meet the future needs of fire management organizations.

Risk is evaluated for lightning and man-caused fires. Both evaluations are subjective, but the schemes presented are considered adequate until more objective approaches can be developed.

Instructions and tables necessary to manually compute the indexes and components for all nine fuel models are presented. The format is designed so that agencies can incorporate these instructions into directives as a technical supplement.

Key words: Forest fire hazard, forest fire behavior, forest fire risk. 


\title{
The National Fire-Danger Rating System
}

\author{
by \\ John E. Deeming, James W. Lancaster, \\ Michael A. Fosberg, R. William Furman, $\underline{\text { / }}$ \\ and \\ Mark J. Schroeder 2 /
}

I The authors are, respectively, Associate Forester, Principal Forester, Principal Meteorologist, and Associate Meteorologist, at the Rocky Mountain Forest and Range Experiment Station, USDA Forest Service. The Station's central headquarters is maintained at Fort Collins, Colorado, in cooperation with Colorado State University.

2/ Chief Meteorologist, Pacific Southwest Forest and Range Experiment Station, USDA Forest Fire Laboratory, Riverside, California. The Station's central headquarters is at Berkeley, California. 


\section{PREFACE}

This Research Paper was prepared to provide field personnel with the information necessary to understand and apply the National Fire-Danger Rating System, and to provide a basic handbook for use in calculating the rating values.

The NFDR System is the result of 4 years of development work, which included two seasons of field trials. Numerous changes have been made since the field trials in 1970 and 1971. To avoid confusion, copies of the 1970 and 1971 field-trial instructions should be destroyed. This Research Paper, RM-84, supersedes all previous versions of the National Fire-Danger Rating System.

\section{ACKNOWLEDGMENTS}

Much of the work which made the development of this National Fire-Danger Rating System possible was done by USDA Forest Service fire research personnel other than those listed as authors. Special recognition is due the following:

Hal E. Anderson, Project L،ader, and James K. Brown, Fuels Science Project, Northern Forest Fire Laboratory, Missoula, for their assistance in developing the fuel model concept and the nine models presently used in the system.

Richard C. Rothermel, Project L,eader, Fire Physics Project, Northern Forest Fire Laboratory, for the development of the heterogeneous fire spread mathematical model, which is the basis for calculating the principal fire behavior indicators of the system.

John J. Keetch, Scientist, Fire Control, Southeastern Forest Experimental Station, for his advice and counsel. 


\section{CONTENTS}

Page

HISTORY AND BACKGROUND OF THE NATIONAL

FIRE-DANGER RATING SYSTEM ........................................... 1

PHILOSOPHY OF THE NATIONAL FIRE-DANGER RATING SYSTEM ............. 2

STRUCTURE OF THE NATIONAL FIRE-DANGER RATING SYSTEM............... 3

OPERATIONAL APPLICATIONS OF FIRE-DANGER RATING VAI.UES ........... 5

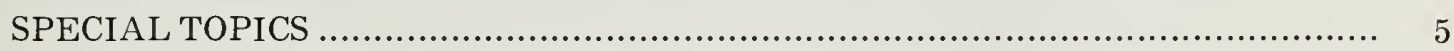

Fuels in the National Fire-Danger Rating System ............................... 5

Risk in the National Fire-Danger Rating System ............................... 7

INSTRUMENTAL، AND OBSERVATIONAL REQUIREMENTS ...................... 10

COMPUTATIONAL PROCEDURES ............................................. 11

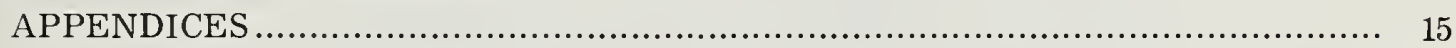

A Glossary .......................................................................... 15

B Selection of Fuel Models ..................................................... 19

C Selection of Slope Class ................................................ 22

D Evaluation of Herbaceous Vegetation Condition ................................ 22

E Evaluation of Risk ............................................................. 23

F Evaluation of the Woody Vegetation Condition............................... 28

G Estimation of the Maximum and Minimum Relative Humidities ............... 28

$\mathrm{H}$ Estimation of the 10-Hr. TL Fuel Moisture ................................... 30

I One-Half Inch Fuel Moisture Sticks .......................................... 32

J 10-Day Fire Danger and Weather Record (WS D-9a) ....................... 32

General Instructions ..................................................... 34

Punch Card Format ...................................................... 37

K Commonly Committed Computational Errors .................................. 38

I. Tables for Operational Use of the NFDR System ............................. 39

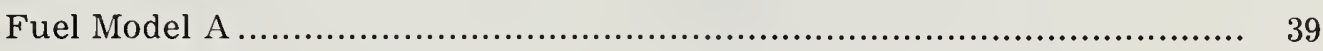

Fuel Model B .................................................................. 51

Fuel Model C .............................................................. 67

Fuel Model D ............................................................. 79

Fuel Model E ................................................................. 95

Fuel Model F ............................................................... 107

Fuel Model G ................................................................. 119

Fuel Model H ............................................................... 135

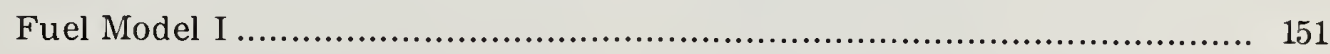




\section{LIST OF ABBREVIATIONS}

\begin{tabular}{|c|c|}
\hline BI & Burning Index \\
\hline comp. & component \\
\hline DST & daylight savings time \\
\hline $\mathrm{ERC}$ & Energy Release Component \\
\hline FFM & fine fuel moisture \\
\hline FLI & Fire Load Index \\
\hline FM & fuel moisture \\
\hline hum. & humidity \\
\hline IC & Ignition Component \\
\hline LR & Lightning Risk \\
\hline LST & local standard time \\
\hline MCR & Man-Caused Risk \\
\hline MPH & miles per hour \\
\hline NFDR & National Fire-Danger Rating \\
\hline OI & Occurrence Index \\
\hline $\begin{array}{l}\text { prec } \\
\text { RH }\end{array}$ & $\begin{array}{l}\text { precipitation } \\
\text { relative humidity }\end{array}$ \\
\hline $\mathrm{SC}$ & Spread Component \\
\hline SSI & Seasonal Severity Index \\
\hline TI & timelag \\
\hline eg. & vegetation \\
\hline & weather \\
\hline & yesterday's \\
\hline Hr. TL & 1-hour timelag \\
\hline 10-Hr. TL & 10-hour timelag \\
\hline 0-Hr. TL & 100-hour timelag \\
\hline
\end{tabular}




\title{
NATIONAL FIRE-DANGER RATING SYSTEM
}

\author{
John E. Deeming, James W. Lancaster, Michael A. Fosberg, \\ R. William Furman, and Mark J. Schroeder
}

\section{HISTORY AND BACKGROUND OF THE NATIONAL FIRE-DANGER RATING SYSTEM}

At fire control conferences called by the USDA Forest Service in Ogden, Utah in 1940 and 1954, the need for a nationally uniform fire-danger rating system was emphasized. Conference committees made the following recommendations concerning such a system:

1. It should be based on those environmental factors which control the moisture content of fuels;

2. It should apply nationwide.

In 1954 there were eight different fire-danger rating systems in use across the country. Better communication and better transportation were beginning to make mutual assistance agreements between fire control organizations practical. State compacts, and in the case of the Federal government, interagency and interregional agreements, were bringing fire control teams together from widely separated areas of the country. It was necessary that a national system of rating fire danger and fire behavior be established to improve and simplify communications among all people concerned with wildland fires.

In 1958 , a joint committee composed of fire research and fire control personnel of the Forest Service met and decided that development of a national system was feasible. In June, the Washington Office, Division of Fire Research, organized a team to formulate and carry out the development program; a year later, full-time work on the project began. By 1961 the basic structure for a four-phase rating system had been outlined and the first, the spread phase, was ready for field testing. The spread phase provided two indexes which predicted the relative forward spread of a fireone for fires burning in the comparative closed environment under a timber canopy, and the other for fires burning in the open in fine fuels. A third index, the buildup index, which was utilized in the computation of the "timber" spread index, was a number which reflected the cumulative drying of the heavier fuels. The spread phase was field tested in 1962 and 1963; in 1964 a Forest Service Handbook (FSH 5109.11) covering the spread phase was issued for field use.

Since the remaining phases-ignition, risk, and fuel energy-were not available, a number of fire control agencies did not adopt the new system but preferred instead to remain with the systems then in use. User adaptations, interpretations, and additions quickly followed, making it obvious that the spread phase was not uniformly applicable across the country. Continued development was urgently needed. By 1965, however, most fire control organizations in the United States were using at least a modified version of the spread phase.

In 1965 , a research project headquartered at Seattle was established to provide a fresh look at the needs and requirements for a national system. The Seattle project canvassed many fire control agencies across the country, analyzed their requirements, and recommended direction for research which would lead to the development of a complete National Fire-Danger Rating System.

In March 1968 the present National FireDanger Rating Research Work Unit was established at Fort Collins, Colorado.

As part of the organization phase, the following points were formulated:

1. A target date of 1972 was established for getting a completed system ready for operational field use. It was the consensus of numerous fire researchers that a fire-danger rating system superior to any in use at the time could be developed from current "state of the art" knowledge, and that it was not necessary to wait until that hypothetical day when "all research" pertinent to firedanger rating was completed.

2. Closely related to (1), the basic structure of the system would be designed so that new knowledge such as better prediction equations and improved fuel information could be incorporated readily. Such refinements would take the form of updated computer programs or new tables supplied to the users; the basic format and definitions would remain unchanged. 
3. The system would not be introduced "piecemeal" but would be implemented as a complete, comprehensive package.

4. The complete system would include a subjective evaluation of "risk." The development of an objective method would be deferred until the physics of fuel moisture relationships and fire behavior had been developed sufficiently to meet the needs of the system.

5. Ultimately, the system would be purely analytical, being based on the physics of moisture exchange, heat transfer, and other known aspects of the problem. Laboratory and field checks would be made. Some experimentation would be necessary to establish basic relationships, but the system would not be empirically or statistically based.

The preliminary version of the system was inaugurated in May 1970, in Arizona and New Mexico. Stations on eight National Forests. one Bureau of Land Management district, two National Park Service units, and in the State of Georgia participated. In 1971, an improved version of the system was used operationally in the Southwest. Field trials were also conducted elsewhere by the Forest Service, Bureau of Land Management, National Park Service, Bureau of Indian Affairs, and on many stations administered by State agencies. Trials were conducted at selected locations from Maine to California and from Florida to Alaska. In all, nearly 150 stations operated the system; feedback from the users was plentiful and helpful.

\section{PHILOSOPHY OF THE NATIONAL FIRE-DANGER RATING SYSTEM}

Before actual work could begin, a framework within which the development could proceed had to be built; this constituted what is now called the "philosophy" of the NFDR System (Deeming and Lancaster 1971). It can be summarized as follows:

1. The system would consider only the "initiating fire." This is defined as a fire which is not behaving erratically; it is spreading without spotting through fuels which are continuous with the ground (no crowning). The "state of the art" cannot yet consider fires which exhibit erratic behavior other than to show that extreme behavior is correlated with increasing fire danger.

2. The system would provide a measure of that portion of the potential job of con- tainment which is attributable to fire behavior. The concept of containment as opposed to extinguishment is basic since it limited the scope of the fire behavior prediction problem to the head fire. Those portions of the containment job dealing with accessibility, soil condition, and resistance to line construction must still be evaluated by other means.

3. The length of the flames at the head of the fire was assumed to be directly related to the contribution that fire behavior makes to the job of containment.

4. The system would attempt to evaluate the "worst" conditions on a rating area by (a) taking the measurements when fire danger is normally the highest (usually in the early afternoon), (b) measuring fire danger in the open, and (c) where possible, measuring fire danger on extreme (southerly or westerly) exposures. This means that extrapolation of fire-danger values to areas other than those immediately in the vicisity of the fire-danger station would involve scaling the values down, not up.

5. The system would provide ratings which would be physically interpretable in terms of fire occurrence and behavior. These evaluations could then be used alone or in combinations, giving the system the flexibility needed to deal with the entire spectrum of fire control planning and dispatch problems.

6. Ratings would be relative, not absolute. The ratings would be linearly related to the activity being evaluated. This means that when a component or index doubles, a doubling of the rated activity relative to what has previously been observed should be anticipated. Because of the many variables in the computations, the inexactness of our understanding of some relationships, and the variability of fire danger within a rating area, it is not feasible to attempt to predict exactly what will happen in a given situation.

\section{STRUCTURE OF THE NATIONAL FIRE-DANGER RATING SYSTEM}

The basic structure of the system (fig. 1) provides three indexes designed to aid in planning and supervising fire control activities on a fire protection unit. These indexes are derived from the three fire behavior componentsSpread Component (SC), Energy Release Component (ERC), and Ignition Component (IC). 


\section{NATIONAL FIRE DANGER RATING SYSTEM}

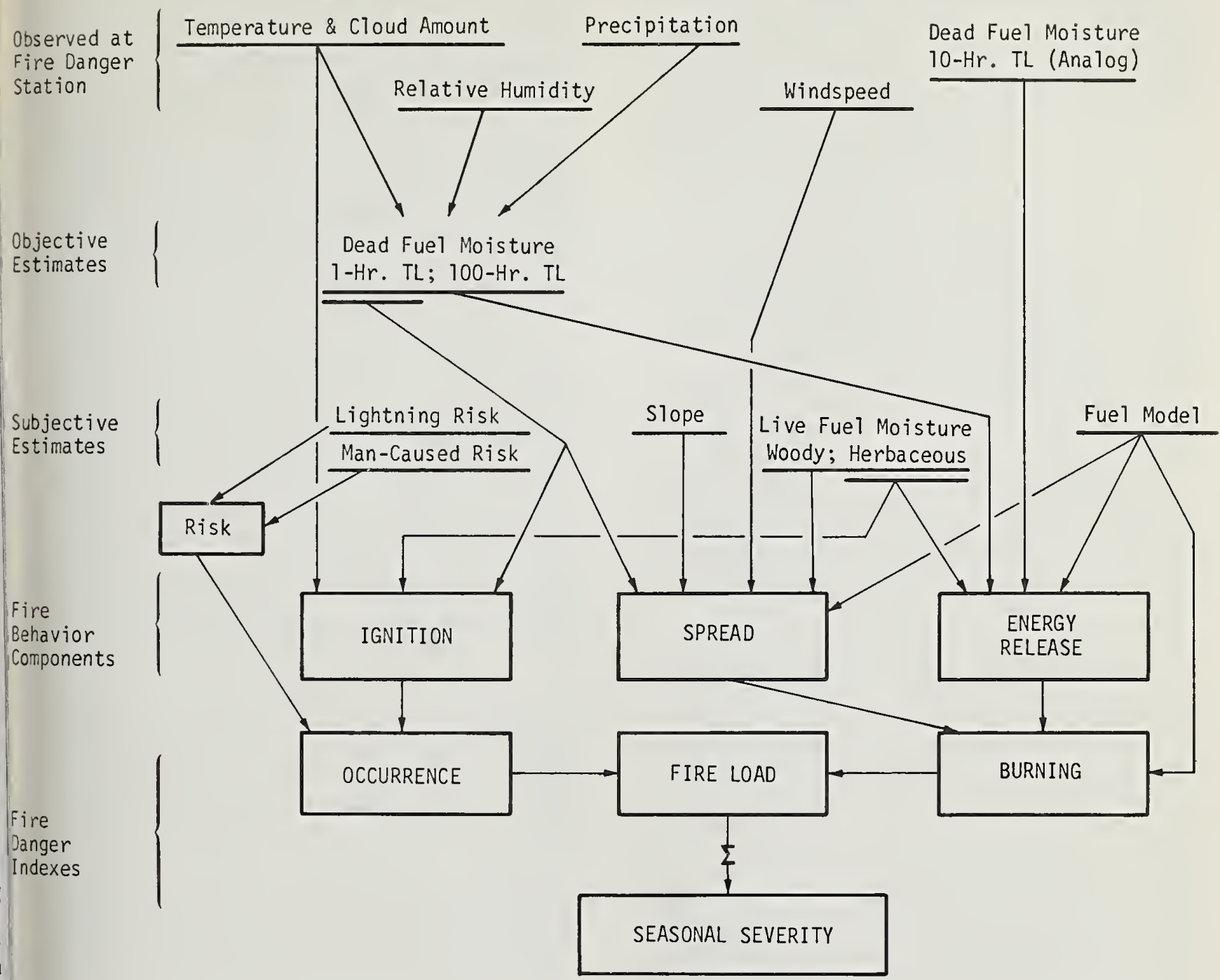

Figure 1.-Structure of the National Fire-Danger-Rating System.

Each is evaluated on a scale of 0 to 100 . The indexes are defined as follows:

Occurrence Index (OI). A number related to the potential fire incidence within a rating area.

Burning Index (BI). A number related to the potential amount of effort needed to contain a fire in a particular fuel type within a rating area.
Fire Load Index (FLI). A number related to the total amount of effort required to contain all probable fires occurring within a rating area during a specified period.

The OI is derived from Risk, the degree to which an area will be exposed to ignition sources, and the Ignition Component, the likelihood that a spreading fire will result if a firebrand is introduced into fine fuels. 
The BI is derived from the Spread and Energy Release Components. Indications of how fast a fire is likely to spread, the rate of combustion per unit area within the flaming front and the width of the flaming zone when considered together, give a measure of the potential difficulty of the containment job. In the calculation of the BI, the SC and ERC are combined in an equation originally developed by Byram for calculating flame length (Davis 1959, p. 82). A unique BI table is required for each fuel model.

The difficulty of containing a single fire (BI), multiplied by the probable number of fires (OI), gives a measure of the potential fire containment job on the protection unit for the day; this is the FLI. Like the BI, an FLI table unique to each fuel model is necessary.

In addition, the Seasonal Severity Index (SSI) may be computed by summing the FLI's recorded during a given period. The SSI is useful as an administrative tool to estimate the potential fire control job experienced on a protection unit during a fire season.

The importance of the basic aspects of fire behavior-ease of ignition, rate of spread, and rate of combustion-cannot be overemphasized since they dictate what is needed for control. Any system or scheme which attempts to rate fire danger should provide accurate and reliable predictions of these three variables. This is the reason why the fire behavior components, IC, SC, and ERC, are shown as they are in figure 1. The fire behavior components are the principal keys to fire-danger rating since they integrate the effects of fuels, weather, and topography into a set of numbers which the fire manager can use to meet his needs. Because they are so important, a more detailed look at their derivation is warranted.

Ignition Component (IC). The IC represents the ease with which fine fuels are ignited. Ignition normally takes place in the dead component of the fine fuels. The three distinct steps that must be considered are (1) the firebrand must come in contact with the dead fuel, (2) the fuel particle must be dried, and (3) the temperature of the fuel particle must be raised to the kindling point, about $380^{\circ} \mathrm{C}$. $\left(716^{\circ} \mathrm{F}\right.$. $)$.

Living material in the fine fuel complex shields the dead fuel from the firebrand or otherwise reduces its efficiency. Therefore an adjustment dependent on the percent of the fine fuels which is living (herbaceous vegetation condition) is made.
The moisture content of the dead component of the fine fuel-1-hour timelag fuel moisture (1-Hr. TL FM)-depends on the temperature and humidity of the air immediately in contact with the fuel particle. In the calculation of the 1-Hr. TL FM, temperature and humidity values measured in the instrument shelter (4.5 feet above the ground) are automatically adjusted in the tables to fuel level values. The extent of the adjustment is dependent on insolation; two conditions, sunny (5 10th or less cloud amount) and cloudy ( 6,10 ths or more cloud amount) are recognized (Fosberg and Deeming 1971).

Herbaceous vegetation condition and the 1-Hr. TL FM are integrated in the calculation of the fine fuel moisture (FFM) which expresses the effective moisture content of the fine fuels.

The closer the initial temperature of the fuel to the ignition temperature, the more likely a fire will result, since not as much energy is needed to raise the temperature of the fuel particle to $380^{\circ} \mathrm{C}$. As in the calculation of the 1-Hr. TL FM, relationships between the fuel temperature and the instrument shelter temperature for sunny and cloudy days are handled automatically in the IC table.

Spread Component (SC). The SC is derived from the mathematical model developed at the Northern Forest Fire Laboratory. This model integrates the effects of wind and slope, together with fuel bed and fuel particle properties to compute the fire spread rate (Rothermel 1972).

Since the characteristics of the fuels through which the fire is burning are so basic in determining the rate at which the fire front moves, a unique SC table is necessary for each of the nine fuel type groups recognized by the system (appendix B).

In the calculation of the $\mathrm{SC}$ the inputs used are windspeed, slope, fine fuel moisture (includes the effect of green herbaceous plant material), and the moisture content of the foliage and twigs of living woody plants (woody vegetation condition).

Energy Release Component (ERC). Like the SC, the ERC is calculated using a table unique to each fuel model. The combustion rate is almost wholly dependent on the same fuel properties as are considered in the equations which calculate the SC. A principal difference is that, whereas the SC is determined primarily by the finer fuels, the ERC calculation also requires moisture content inputs for the 10-Hr. and $100-\mathrm{Hr}$. TL fuels. 
OPERATIONAL APPLICATION OF

FIRE-DANGER RATING VALUES

To give the user a better understanding of the ratings generated by the NFDR System, some of the uses that designers of the system envisioned the ratings being used for are summarized here.

The Occurrence Index (OI) is an indicator of the potential fire incidence on a protection unit during a rating period. A high OI would indicate that the detection system should be brought to a high level of readiness. Then, looking at Risk, the fire control manager will know whether to concentrate detection efforts in the lightning belts on their protection unit or in the areas frequented by man. If the probability of man-caused fires is high, some additional resources of the unit probably should be diverted to patrol and prevention work.

Though further development work is needed, the Ignition Component (IC) has potential in several areas. Two of the most important are (1) as an indicator of spotting, and (2) in combination with the BI, as a means of determining the adjective fire-danger class for public information.

The Burning Index (BI) integrates the effects of weather, fuels, and topography on fire behavior. It will indicate the level of manning and the amount and kind of equipment which should be directed to a single fire. However, since the BI is made up of the Spread Component (SC) and the Energy Release Component (ERC), a more precise estimate of the requirements for the prompt containment of a particular fire can be made by examining both of these values. If a fire-control organization does not want to consider Risk, the BI can be used as a basis for manning and readiness plans.

The ERC should be used as a guide to the kind of attack forces that will be most effective. For low values, direct attack methods should be practical. If the fuel, soil, and topographic conditions allow, hand crews may be adequate. On the other hand, when the ERC is high, it is likely that heavy equipment may be needed for direct attack. If the ERC is very high, direct attack by any means will frequently be impossible and indirect attack methods should be used. With experience, the effectiveness and practicability of using chemicals, ground or air delivered, may be indicated by the ERC. It may also be used as a general indicator of the potential for certain types of fire damage.
The SC, since it indicates the rate of forward spread of the fire, will give an indication of the time within which a fire must be contained to prevent it from exceeding an acceptable size. It can also be a guide to the prepositioning of units to keep travel time within necessary limits. Travel time and the rate of line construction by the various mixes of men and machines are key factors.

The Fire Load Index (FLI) is the number to which readiness plans will be keyed. ${ }^{3}$ It will indicate the level of readiness at which suppression forces on a protection unit should be maintained to handle the potential fire situation. The other indexes and components will give more specific direction for determining pre-positioning, detection, and prevention.

The Seasonal Severity Index (SSI) will provide a yardstick for comparing the potential fire problem of one protection unit against another, or for evaluating accomplishments. When considered with actual fire occurrence, the SSI will provide decision aids for such administrative tasks as allocating monies, changing authorized manning levels, and so forth.

The NFDR System was designed so the individual components or indexes could stand alone, if desired. Thus the system can be tailored to meet the needs of the individual fire control agency. The increased flexibility of the multiple index approach gives the fire manager a wide range of choices, allowing him to balance his needs against the capabilities of the system.

If the user anticipates applying the indexes and components in ways other than those discussed above, consultation with the authors is suggested. Work in the applications of firedanger information will continue and the results will be presented in future publications.

\section{SPECIAL TOPICS}

\section{Fuels in the \\ National Fire-Danger Rating System}

\section{Classification of Wildland Fuels}

Five classes of fuels, three dead and two living, are considered by the NFDR System. Since the system is designed to measure the job of containment-not extinguishment-of the

\footnotetext{
3 Until Risk can be more objectively assessed, Burning Index is recommended for this application. However, users should evaluate Risk and compute the 0 I and FLI because it will provide experience and data for further Risk explorations.
} 
fire, only those fuels involved in combustion within the immediate flaming front need be considered. Because moisture content, to a large extent, determines the flammability of fuels, the separation of dead fuels into classes was based on the rapidity of the moisture content response of individual fuel particles to changes in relative humidity (Lancaster 1970). Living fuels are classified according to whether they are herbaceous or woody.

Four generally recognized weather cycles were considered: the diurnal, synoptic, planetary, and annual cycles. Studies indicated that fuels with timelags of 200 hours or less would satisfactorily reflect the effects of weather on fire danger. Accordingly, three classes of dead fuels, 1-, 10-, and 100-Hr. TL, were designated:

Timelag class

1-Hr. 10-Hr. $100-\mathrm{Hr}$.

Timelag

class interval

0-2 hrs. $\quad 2-20$ hrs.

20-200 hrs.

Approximate

equivalent

fuel dimensions: ${ }^{4}$

$\begin{array}{llll}\text { Roundwood } & \begin{array}{l}\text { Less than } \\ 1 / 4 \text {-inch }\end{array} & \begin{array}{l}1 / 4- \\ 1 \text { inch }\end{array} & \begin{array}{l}1+- \\ 3 \text { inches }\end{array} \\ \begin{array}{l}\text { Litter and/or } \\ \text { duff }\end{array} & \begin{array}{l}\text { Surface } \\ \text { layer } \\ \text { only }\end{array} & \begin{array}{l}\text { Surface }- \\ 3 / 4 \text {-inch }\end{array} & \begin{array}{l}3 / 4+- \\ 4 \text { inches }\end{array}\end{array}$

Two classes of living fuels are considered. They are (1) grass and other herbaceous plants, and (2) twigs less than one-fourth inch in diameter and the foliage of woody plants. Onefourth inch is considered to be the upper size limit of living woody material which can be desiccated and consumed within the flaming front of an initiating fire.

How living fuels affect' fire behavior is inadequately understood; further research is needed before their role in fire-danger rating can be fully evaluated. As of this time, living herbaceous material is considered only as it changes the effective moisture content of the fine fuels. The living woody material is treated

\footnotetext{
4 Though the timelag of an individual fuel particle can be determined exactly, correlating timelag with size is not reliable because the relationship is inexact. Timelag in natural fuels of the same size and species varies duc to structural differences, surface weathering, density, and so forth. The figures given for roundwood are reasonable and are considered acceptable. Because physical properties of litter vary over a wider range, however, the figures are only "best guesses."
}

both as a heat sink (it takes a considerable amount of energy to desiccate this material) and as a heat source (after it has been desiccated, it burns and contributes energy just as dead fuel does) (Fosberg and Schroeder 1971).

\section{Fuel Models - the Concept}

The rating of fire danger, in its simplest form, is the prediction of the behavior of a potential fire. Principal determinants of fire behavior can be classified as being variable or constant in time. Variable determinants are weather dependent; they are wind, fuel moisture, and fuel temperature. The more constant determinants are topography and fuels.

Wind affects fire behavior by increasing the flow of oxygen to the fire. Also, wind bends the flames over the unburned fuel and increases the flow of hot gases from the combustion zone; both processes contribute to the preheating of the unburned fuels. Fuel moisture is governed by insolation, air temperature, humidity, and precipitation. The lower the fuel moisture, the less energy is required to dry and ignite fuel particles. Fuel temperature is dictated by air temperature and insolation. The higher the fuel temperature, the less energy is required to raise the fuel to the ignition point.

All of these factors are accounted for in the NFDR System and are evaluated daily.

Increasing slope accelerates burning. The steeper the slope, the closer the flames are to unburned fuels, with the result that drying and preheating is more efficient. The effect of slope on fire behavior has been recognized for years and is accounted for in the NFDR System.

But how about fuels, a most important factor?

In the past, fire-danger rating systems considered the variability of fuels only to a very limited extent. The 1964 spread phase of the NFDR System recognized only open and timbered types; the California Wildland System recognizes three-timber, brush, and grass. ${ }^{5}$ The principal problem was that there were no means of quantifying the effects of the various fuel properties on fire behavior.

The development of Rothermel's (1972) mathematical spread model provided a means for incorporating fuels information into firedanger rating to a degree never before possible.

5 USDA Forest Service. Wildland fire-danger rating. Unpublislied report on file at Pac. Southwest Foresi and Range Exp. Sta., Berkelcy, Calif. 
The mathematical model considers such fuel bed properties as compactness (bulk density), and loadings (weight per unit area) by classes of living and dead fuel particles. It also considers fuel particle properties such as density, heat content, mineral content, moisture content, and geometry.

For the NFDR System, fuel models were devised as a means for organizing the required fuels information for input into the mathematical model. The fuel model is a simulated fuel complex for which all the required fuel descriptors have been determined; it consists of a complete set of the fuel parameters required for solution of the mathematical model.

In the formulation of the fuel models, typical values for the loadings by fuel classes, surface area to volume ratios, and bed depths were determined for the fuel situations to be represented by the fuel model. Fuel particle properties such as density, heat content, and mineral content are assigned constant values. The remaining inputs, the moisture content by fuel classes, are variables determined by physiological and meteorological processes. Hence, they must be evaluated daily. Fuel moisture contents, wind, and fuel temperature account for the short-term variation of fire danger.

In the NFDR System the Spread Component (SC), Energy Release Component (ERC), and Burning Index (BI) are fuel model dependent. For instance, for a given set of burning conditions, the value of the SC, ERC, and BI will depend on which fuel model is being used. In other words, at a given fuel moisture, windspeed, and slope, the SC for fuel model A (grass) is higher than for $\mathrm{E}$ (oak-hickory and pine). Figures 2, 3, 4, and 5 illustrate the response of these ratings to changes in burning conditions.

As of this time, nine models have been generated for use in the NFDR System. They are described in detail in appendix B. Because only nine models are being used to represent all the wildland fuels situations found from Florida to Alaska, they are necessarily quite general.

There are three primary reasons for not introducing more models initially: (1) it was felt that the impact of an already complex system would be eased; (2) the amount of fuels information required for more specific fuels situations is very limited; (3) the mathematical model has not been developed to a high enough level of precision. Until these situations are rectified, additional, meaningful resolution is not possible.

\section{Risk in the \\ National Fire-Danger Rating System}

Fire incidence is predicted by the NFDR System by anticipating Risk, the number of ignition sources that a protection unit will be exposed to, and the Ignition Component (IC), the probability that each ignition source will produce a spreading fire if it lands on receptive fuels. The $\mathrm{IC}$ is derived objectively from equations which consider the temperature and moisture content of the 1-hour timelag (1-Hr. TL) fuels and the amount of green herbaceous plant material in the fine fuel complex. Risk, however, cannot be arrived at as neatly or as easily.

Two sources of Risk are considered, Lightning Risk (LR) and Man-Caused Risk (MCR). Each is evaluated on a scale of 0 to 100; when added together (Total Risk) their sum cannot exceed 100 .

\section{Lightning Risk (LR)}

LR can be defined as a number related to the number of potential fire setting strikes a protection unit will be exposed to during a rating period.

In the past, lightning forecasts have been issued by fire-weather forecasters in probability terms. The major problem with this forecast format has been the difficulty of incorporating probability values into the decisionmaking process which determines the level of readiness of fire suppression and detection forces.

With the implementation of the NFDR System, forecasts of lightning activity level on a 1 to 5 scale are needed. The proposed scale is exponential, based on powers of 2 . Beginning at level 3 , each level indicates twice the amount of lightning expected at the level immediately below; an activity level of 3 indicates twice the lightning as a 2; an activity level of 4 twice that of 3 ; and an activity level of 5 twice that of 4 .

Since lightning fires are not always discovered and suppression action taken on the day they were set, the incipient or "holdover" fire is also considered. Taylor ${ }^{6}$ concluded that 25 percent of all lightning fires remain undetected 24 hours after origin. A correction commensurate with this figure is contained in the current day's LR value to account for holdover fires.

\footnotetext{
6 Taylor, Alan R. Lightning as a factor in for est fuel ignition and forest protection. Problem analys is on file at the N. Forest Fire Lab., Missoula, Mont.
} 

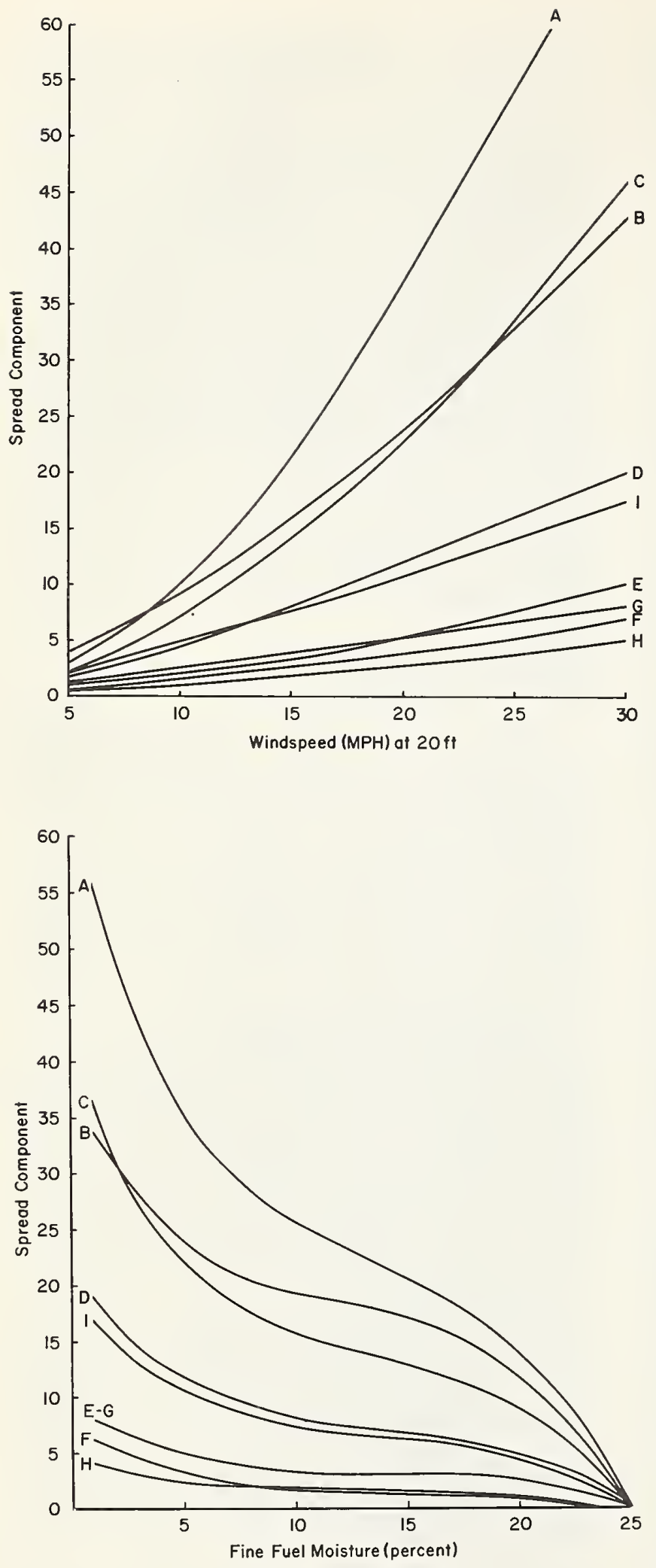

Figure 2.-Spread Component vs. Windspeed. In order to illustrate the effect of windspeed on the SC, a plot for each fuel model is presented. The following constants were assigned: slope, class I; FFM, 5 percent; herbaceous vegetation condition, zero (0) percent green; woody vegetation condition, slow growth (code 7 ).
Figure 3.-Spread Component vs. Fine Fuel Moisture. As in figure 2, constants were assigned for slope and conditions of herbaceous and woody vegetation. Windspeed is $20 \mathrm{MPH}$, leaving the FFM as the only variable. 


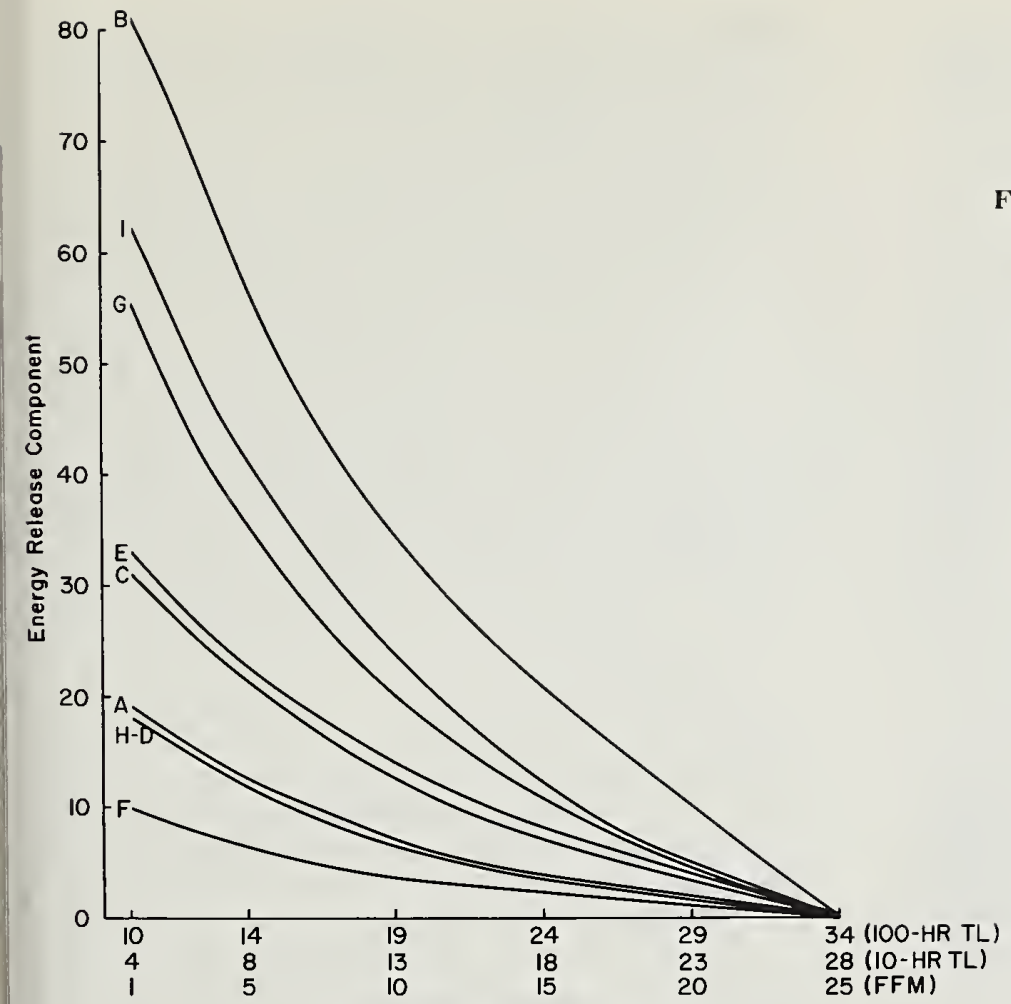

Fuel Moisture (percent)

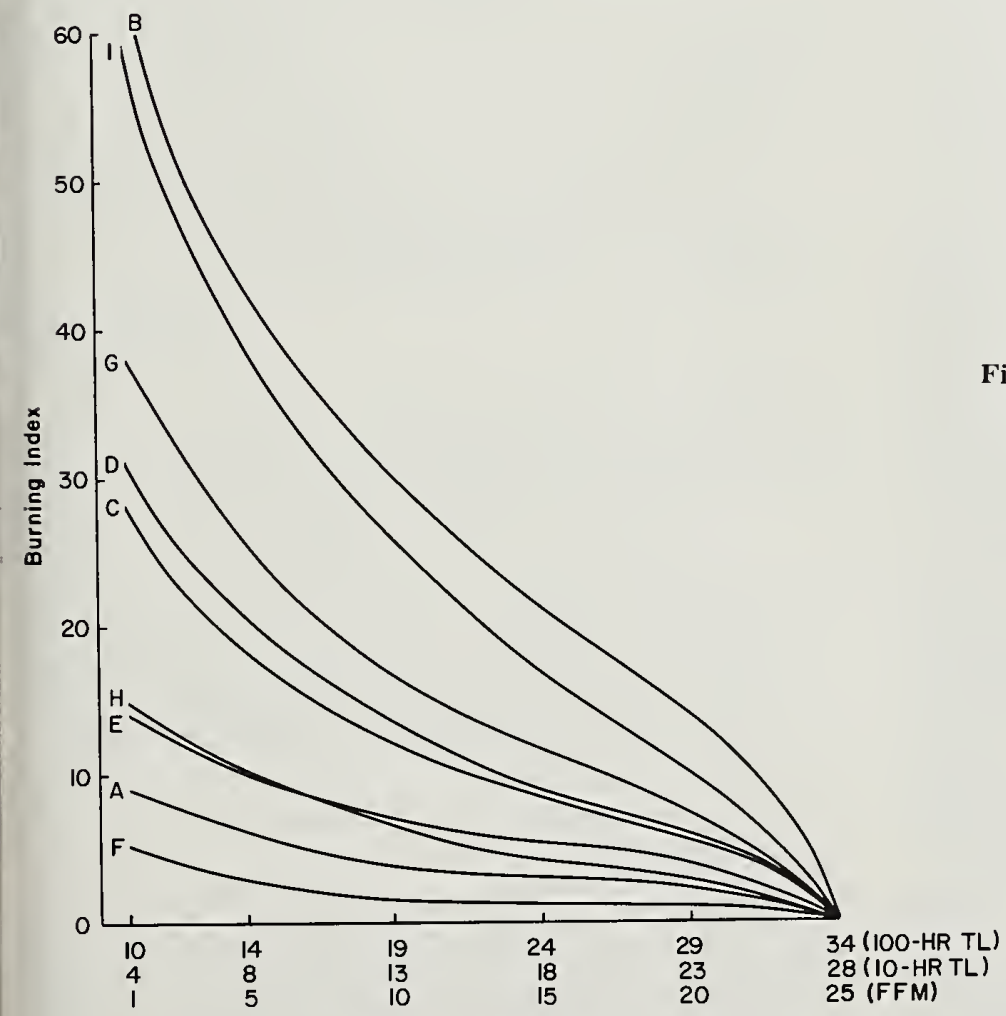

Fuel Moisture (percent)
Figure 4.-Energy Release Component vs. Fuel Moisture. The ERC is a function of fuel moisture only-windspeed and slope are not considered in its evaluation. For this illustration, simple relationships between the FFM and the 10-IIr. and 100-Hr. TI, FM were assigned. These are: $10-\mathrm{Hr}$. TL FM $=\mathrm{FFM}+3 ; 100-\mathrm{Hr}$. TL FM $=\mathrm{FFM}+9$. This was considered preferable to a very artificial situation where the moisture contents of all classes of dead fuels were the same.
Figure 5.-Burning Index vs. Fuel Moisture. These curves show the relative amounts of effort attributable to fire behavior needed to contain fires in types represented by each fuel model. The constants assigned are the same as those in figures 3 and 4 . 
To incorporate a correction for holdover fires into the LR, the lightning activity level actually experienced on the protection unit the preceding day must be determined. How this is done depends a great deal on the type of intelligence available. If weather radar or other radar coverage is good, composite maps may be used to determine the total area af fected by thunderstorms during the previous 24 hours. This can be translated into lightning activity level as suggested in the Lightning Activity Level Guide (appendix E). If ground observers, lookouts, or aerial patrol are used, the narrative descriptions in the Lightning Activity Level Guide may be used.

Details and procedures will have to be worked out between the users and the fireweather forecaster responsible for operational forecasts. Additional directives shall be provided through the agency concerned.

Once the user knows what lightning activity level is expected, and what lightning activity level was experienced the previous day, an LR value may be obtained directly from a simple two-way look up table. This value is entered directly into the fire-danger calculations.

Examples are given in appendix E.

\section{Man-Caused Risk (MCR)}

No objective means are available for determining an MCR value for a protection unit. A workable scheme has been formulated, however, based on subjective estimates made by an officer familiar with the man-caused fire problem on the protection unit.

In principle and in practice, the scheme is reasonably simple. It requires that a rating on a scale of 1 through 5 (daily activity level) be assigned to each of several of man's activities which historically have been important sources of man-caused fires in the rating area (risk sources). The rating scale is calibrated to what is normal for a specific risk source on that rating area. If for some reason a particular risk source is less active than normal, a "None" or "Low" daily activity level may be assigned; if it is more active, a "High" or "Extreme" daily activity level may be assigned.

The contribution that a particular risk source makes to the final MCR value is weighted according to the proportion of the man-caused fires which historically have been attributable to that particular risk source (risk source ratio).

The principal risk sources must be identified for each month of the fire season by analyzing fire occurrence records. They must be identified on a monthly basis because their importance may change with the season. Hunters, campers, and debris burning, for instance, are very seasonal.

A complicating consideration is that a normal daily activity level of risk for one protection unit probably is not normal for another. For administrative purposes, it is necessary to determine the relative levels of the "normals" of the units being grouped together. This will allow units which historically have a more serious man-caused fire problem to reach higher risk values. This normalization can be done on any scale for which comparability is desired. Examples: between counties within a State; between National Parks within a State, a region, or the Nation; between ranger districts in a region, or across the Nation, and so forth.

In summary, the evaluation of MCR can be divided into two phases. Phase one is the analysis of fire occurrence records for (1) identifying the principal risk sources on a monthly basis, and (2) determining the seasonal monthly average and the peak monthly average incidence of man-caused fires during the fire season. The analysis of (2) provides the basis for the "normalization" of risk between units with very different man-caused fire problems.

Phase two consists of (1) an evaluation on a five-point scale of the daily activity level for each of the principal risk sources identified in phase one, and (2) the computation of the MCR value. The procedure is presented in detail with examples in appendix $\mathrm{E}$.

\section{INSTRUMENTAL AND OBSERVATIONAL REQUIREMENTS}

The NFDR System is quite complex, and requires weather information not required by previous fire-danger rating systems. This includes 24-hour maximum and minimum relative humidities and temperatures, rainfall beginning and ending times, and rainfall duration.

Best estimates of the beginning and ending times and the duration of rainfall are considered adequate. The 24-hour extreme values for temperature and relative humidity can be obtained from a hygrothermograph if available. If not, the maximum and minimum relative humidities can be estimated to an acceptable degree of accuracy when the 24-hour temperature extremes are known.

Fuel conditions must also be observed. To obtain best accuracy, fuel moisture sticks should be used for determining the 10-hour timelag fuel moisture (10-Hr. TL FM) (appendix I). For users who do not want to use fuel 
moisture sticks and feel that they can accept less reliable numbers, a means of estimating the $10-\mathrm{Hr}$. TL FM is presented in appendix $\mathrm{H}$.

As in the 1964 rating system, an evaluation of the amount of green herbaceous material in the fine fuel complex is required (appendix D). In addition, if woody perennial plants are considered by the fuel model, a subjective estimate of the moisture content of their twigs and foliage is required (appendix $F$ ). The latter two evaluations must be made by the fire control officer or under his supervision.

The following is a list of the required inputs for the NFDR System which should be recorded on the WS Form D-9a, 10-Day Fire Danger and Weather Record (appendix K). Exceptions and options are footnoted.

Station number

Station elevation

Fuel Model (appendix B)

Slope class (appendix C)

Date (year, month, day)

State of weather

Herbaceous vegetation condition (appendix D)

Woody vegetation condition ${ }^{7}$

Dry and wet bulb temperatures

Risk, lightning and man-caused (appendix E)

Windspeed - 10 minute average

Wind direction

Precipitation kind

Precipitation amount

Precipitation duration

Precipitation beginning and ending times

Lightning activity level (appendix E)

24-hour maximum and minimum temperatures

24-hour maximum and minimum relative humidities $^{8}$

10-Hr. TL FM ${ }^{9}$

Instrumentation required in addition to the anemometer, rain gage, and wet and dry bulb thermometers which should already be in place at the fire danger station are:

1. Fuel moisture scales (if fuel moisture sticks are to be used) $;^{10}$

2. A hygrothermograph (preferred) or a maximum-minimum thermometer."

7 For models $B$ and $F$ only; sec appendix $F$.

8 If a recording instrument for relative humidity is not available, see appendix 6 .

9 If fuel moisture sticks are not used, see appendix II.

10 An adequate beam balance of 1,000 grams capacity can be purchased for under $\$ 40$.

11 A maximum-minimum thermometer of the " $U$ " tube or dial type is adequate and can be purchased for under $\$ 15$.
Not all fuel models require a complete set of the observational information for the computation of the fire-danger indexes, but it is important that all observations be made and recorded. The reasons may not be obvious to field personnel, but they are important. For instance, the additional information may be used to determine fire-danger rating areas or climatological zones or it may be used for research purposes. Users may wish to compute ratings for adjacent areas using fuel models requiring more input than the one originally used. Certainly, as more sophisticated fuel models become available, their requirements will be greater.

\section{COMPUTATIONAL PROCEDURES}

In appendix $\mathrm{L}$, a section is devoted to each of the nine fuel models used in the NFDR System. All of the tables necessary for the computation of the NFDR values, except those used in evaluating Risk, are arranged sequentially for each fuel model. In addition, at the beginning of each section there is a flow chart showing precisely the steps to be followed in the calculation (fig. 6), and a sample WS Form D-9a, 10-Day Fire Danger Weather Record, with worked examples for that fuel model (fig. 7).

Included with each table are instructions and reminders of the key points that are important to consider when using that table.

Appendix $\mathrm{K}$ is a listing of the errors most commonly committed during the field trials in 1970 amd 1971. It is hoped that by emphasizing these troublesome items, repeated errors of these same kinds may be avoided.

The following is the sequence suggested for computing the NFDR values:

1. Complete the station identification and date entries in the heading.

2. Make the following entries as directed by the unit fire control officer:

\begin{tabular}{lll} 
Column $^{12}$ & \multicolumn{1}{c}{ Entry } & $\begin{array}{c}\text { Instruction } \\
\text { Heading }\end{array}$ \\
Heading & $\begin{array}{l}\text { Fuel model designation } \\
\text { Slope class }\end{array}$ & $\begin{array}{l}\text { Appendix B } \\
\text { Appendix C }\end{array}$ \\
8 & $\begin{array}{l}\text { Herbaceous vegetation } \\
\text { condition }\end{array}$ & Appendix D \\
$11,12,13$ & $\begin{array}{l}\text { Risk } \\
\text { Woody vegetation } \\
17\end{array}$ & $\begin{array}{l}\text { Appendix E } \\
\text { Appendix F }\end{array}$ \\
37 & Lightning activity level & Appendix E
\end{tabular}

12 All columns referred to are those on the WS Form D-9a, 10-Ilay Fire Ilanger and Weather Record (see figs. 7, 9). 
(1)

(2)

(4)

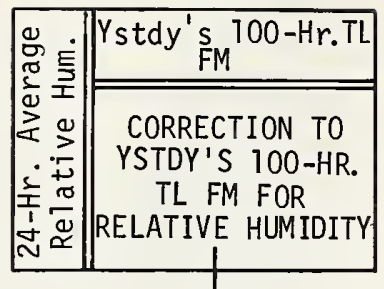

(3)

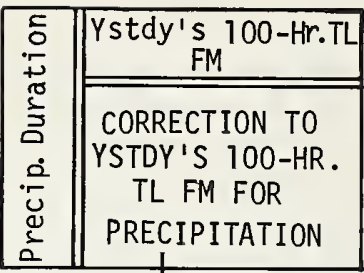

(3)

Today's 100-Hr. TL FM

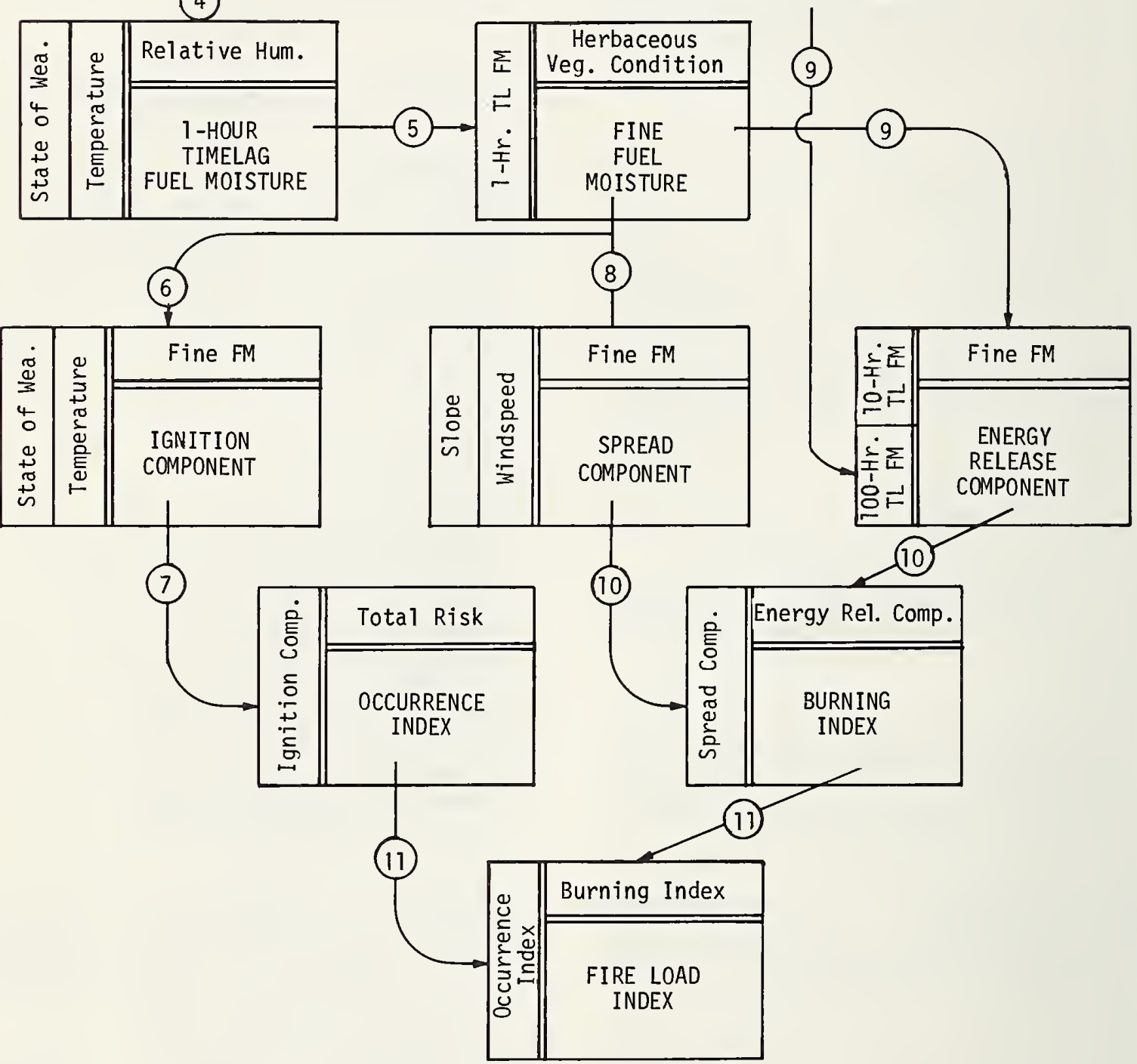

Figure 6.-Computation Flow Chart for Fuel Model I. The circled numbers indicate the sequence of each step in the calculation. Each box represents a table; the title of the table is in the lower right and the variables used as inputs to that table are shown at the top and left. 


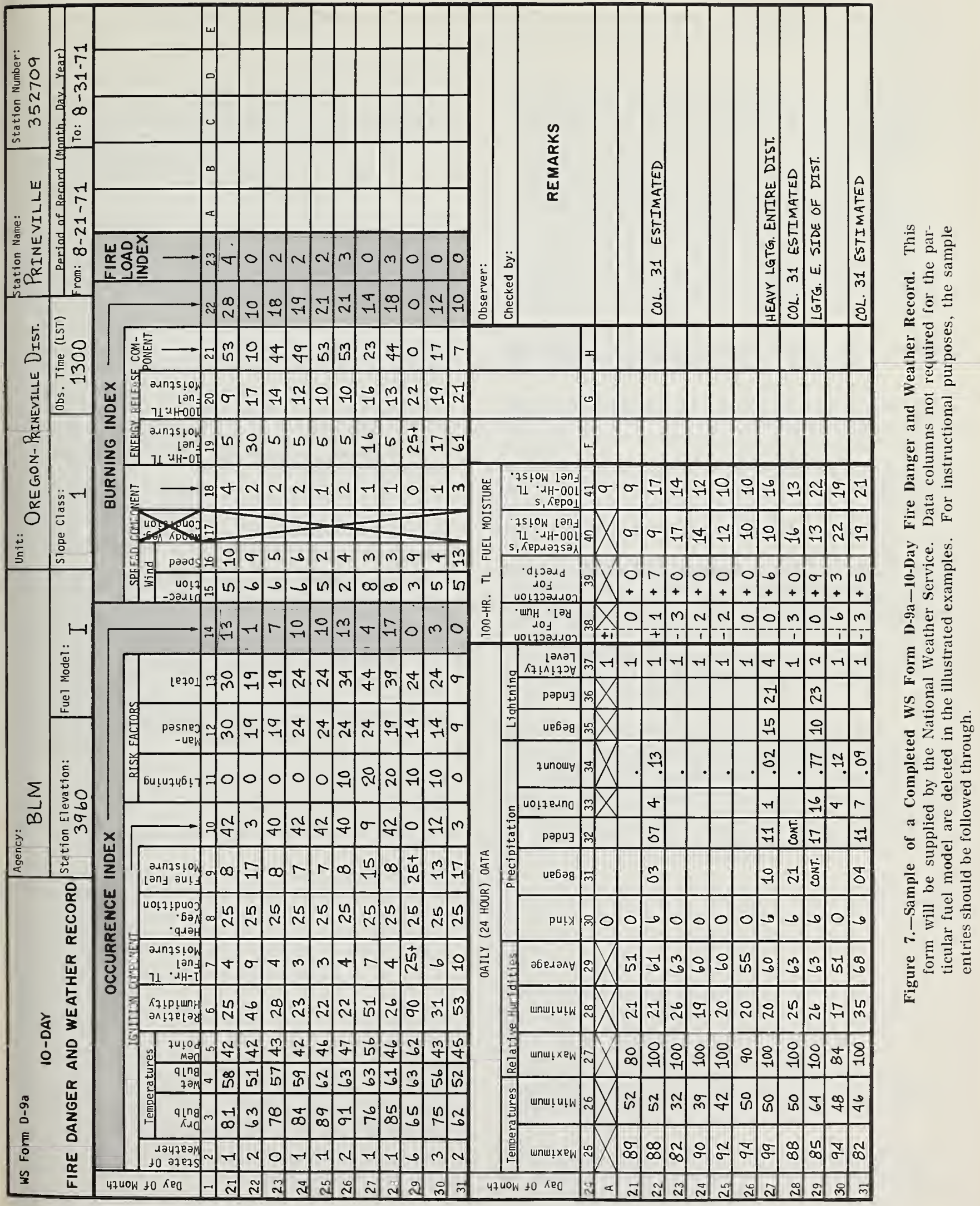


3. Make the appropriate weather observational entries in columns $2-4,15,16,25-28$, and 30-37.

4. Weigh the fuel moisture sticks ( $1 / 2$-inch dowels) or estimate the $10-\mathrm{Hr}$. TL FM in accordance with appendix $\mathrm{H}$ and record in column 19.

5. Make the dew point and relative humidity calculations and record in columns 5 and 6 .

6. Compute the average relative humidity and record in column $29 .^{13}$

7. Record yesterday's 100-Hr. TL FM in column $40 .^{13}$

8. Make the fire-danger computations as follows:

\begin{tabular}{|c|c|c|}
\hline Step & Table & Column \\
\hline 1 & $\begin{array}{l}\text { Correction to } 100-\mathrm{Hr} \text {. TL FM for } \\
\text { relative humidity }{ }^{33}\end{array}$ & 38 \\
\hline 2 & $\begin{array}{l}\text { Correction to } 100 \text {-Hr. TL FM for } \\
\text { precipitation } 13\end{array}$ & 39 \\
\hline 3 & Today's $100-\mathrm{Hr}$. TL FM ${ }^{13}$ & 41,20 \\
\hline 4 & 1-Hr. TL FM & \\
\hline 5 & Fine fuel moisture & \\
\hline 6 & Ignition Component & 10 \\
\hline 7 & Occurrence Index & 1 \\
\hline 8 & Spread Component & 1 \\
\hline 9 & Energy Release Component & 21 \\
\hline 10 & Burning Index & \\
\hline 11 & Fire Load Index & 23 \\
\hline
\end{tabular}

13 I or fucl model- I. II. f. II. and I only.

\section{LITERATURE CITED}

Davis, Kenneth P.

1959. Forest fire: control and use. 584 p. N. Y.: McGraw-Hill.

Deeming, John E., and James W. Lancaster.

1971. Background, philosophy, implementation-national fire danger rating system. USDA Forest Serv. Fire Control Notes 32(2): 4-8.

Fosberg, Michael A., and John E. Deeming.

1971. Derivation of the 1 - and 10-hour timelag fuel moisture calculations for fire-danger rating. USDA Forest Serv. Res. Note RM-207. 8 p. Rocky Mt. Forest and Range Exp. Sta., Fort Collins, Colo. and Mark J. Schroeder.

1971. Fine herbaceous fuels in fire-danger rating. USDA Forest Serv. Res. Note RM-185. 8 p. Rocky Mt. Forest and Range Exp. Sta., Fort Collins, Colo. Lancaster, James W.

1970. Timelag useful in fire danger rating. USDA Forest Serv. Fire Control Notes 31(3): 6-8, 10.

Rothermel, Richard C.

1972. A mathematical model for fire spread predictions in wildland fuels. USDA Forest Serv. Res. Pap. INT-115. 40 p. Intermt. Forest and Range Exp. Sta., Ogden, Utah.

U. S. Department of Agriculture. Forest Service. 1964. Handbook on national fire-danger rating system. USDA Forest Serv. Handb. FSH 5109.11. 


\section{APPENDIX A}

\section{Glossary}

Ambient - Surrounding, enveloping conditions. As it pertains to weather at the earth's surface, the conditions measured in the instrument shelter are considered as ambient.

Analog - See fuel moisture analog.

Average relative humidity - The mathematical average of the maximum and minimum relative humidities measured at a fire-danger station from one Basic Observation Time to the next.

Average temperature - The mathematical aver age of the maximum and minimum dry-bulb temperatures measured at a fire-danger station from one Basic Observation Time to the next.

Base area - A zone which is representative of the major fire problem areas on a protection unit. From this area, the base fuel model and slope class used to calculate the unit's firedanger ratings are chosen. Not to be confused with fire-danger rating area.

Base fuel model - The fuel model which represents the cover on the base area. The base fuel model is used in the calculation of the fire-danger ratings which are the bases for the unit's suppression readiness.

Basic Observation Time - The time established to take the fire-danger observation which rates the day.

Brush - Scrub vegetation and stands of tree species that do not produce merchantable timber. (Not a synonym for slash.)

Burning Index (BI) - A number related to the amount of effort needed to contain a fire in a particular fuel type within a rating area. A doubling of the BI indicates that twice the effort will be needed to contain a fire in that fuel type as was previously required.

Cloudy - The adjective classification of the sky when $6 / 10$ ths or more of the sky is obscured by clouds.

Daily activity level - A subjective estimate of the degree of activity of a potential mancaused fire source relative to that which is normally experienced. Five activity levels are defined: None, Low, Normal, High and Extreme (appendix E).
Dead fuels - Naturally occurring fuels in which the moisture content is governed almost entirely by atmospheric moisture (relative humidity and precipitation).

Dew point - The temperature to which a parcel of air must be cooled to reach saturation.

Diurnal - Daily; pertains to daily cycles of temperature, relative humidity, wind, and stability.

Drought - A period of moisture deficiency, extensive in area and time.

Dry-bulb temperature - The temperature of the air.

Duff - The partially decomposed organic material of the forest floor beneath the litter of freshly fallen twigs, needles, and leaves. (The $F$ and $\mathrm{H}$ layers of the forest floor.)

Energy Release Component (ERC) - A number related to the rate of heat release (BTU per second) per unit area (square foot) within the flaming front at the head of a moving fire. The expression differs from that of intensity (see intensity) but is indicative of how "hot" a fire is burning.

Equilibrium moisture content (EMC) - The moisture content that a fuel particle would attain if exposed for an infinite period in an environment of specified constant temperature and humidity. When a fuel particle has reached its EMC there is no net exchange of moisture between it and its environment.

Fine fuel moisture (FFM) - An adjustment to the 1-Hr. TL FM which compensates for the presence of living plant material in fine fuels.

Fine fuels - The complex of living and dead herbaceous plants and dead woody plant materials less than one-fourth inch in diameter.

Firebrand - Any source of heat, natural or manmade, which is capable of igniting wildland fuels.

Fire-danger rating area - A geographical area where the fire danger throughout is adequately represented by that measured at a single fire- 
danger station. It is relatively homogeneous in climate, fuels, and topography.

Fire Load Index (FLI) - A number related to the total amount of effort required during a rating period to contain all probable fires occurring within a rating area.

Flaming front - That zone of a moving fire within which the combustion is primarily flaming. Behind the flaming front combustion is primarily glowing.

Forb - A nongrasslike herbaceous plant.

Fuel class - A group of fuels possessing common characteristics. In the NFDR System, dead fuels are grouped according to their timelag (1-, 10-, and 100-Hr.) and living fuels by whether they are herbaceous or woody.

Fuel model - A simulated fuel complex for which all the fuel descriptors required for the solution of the mathematical fire spread model have been specified (appendix B).

Fuel moisture - See fuel moisture content.

Fuel moisture analog - A device which simulates the response of the moisture content of specific classes of dead fuels when exposed in the same environment. Examples are basswood slats which respond like $1-\mathrm{Hr}$. TL fuels and half-inch ponderosa pine dowels which react like 10-Hr. TL fuels. An analog may also be constructed of inorganic materials or, in a broad sense, may consist of a computational procedure such as used in the NFDR System to determine the 1-, 10-, and $100-\mathrm{Hr}$. TL FM.

Fuel moisture content (also fuel moisture) - The quantity of water in a fuel particle expressed as a percent of the ovendry weight of the fuel particle.

Herb - A plant which does not develop woody, persistent tissue but is relatively soft or succulent and sprouts from the base or develops from seed (annuals) each year. Included are grasses, forbs, and ferns.

Herbaceous fuels - Undecomposed material, living or dead, derived from herbaceous plants.

Herbaceous vegetation condition - The percent, by volume, of the fine fuels which is living (appendix D).
Humidity - A measure of the water-vapor content of the air.

Ignition Component (IC) - A number related to the probability that a spreading fire will result if a firebrand encounters fine fuel.

Initiating fire - A wildfire which exhibits reasonably predictable behavior (no crowning or spotting).

Insolation - Solar radiation received at the earth's surface.

Instrument shelter (also thermoscreen) - A naturally or artificially ventilated structure, the purpose of which is to shield temperature measuring instruments from direct sunshine and precipitation.

Intensity - The rate of heat release (BTU/second) per unit length of fire front (foot).

Lightning activity level - A number, on a scale of 1 to 5 , which reflects the frequency and character of cloud-to-ground lightning either forecasted or observed. The scale is exponential, based on powers of 2; a lightning activity level of 3 indicates twice the lightning as 2, a 4 twice that of 3 , and so forth.

Lightning Risk (LR) - A number related to the expected number of cloud-to-ground lightning strikes that a protection unit is expected to be exposed to during the rating day. The lightning risk value used in the calculation of the OI includes an adjustment for lightning activity experienced during the previous day to account for possible "holdover" fires (appendix E).

Litter - The top layer of the forest floor, composed of loose debris including dead sticks, branches, twigs, and recently fallen leaves or needles; little altered in structure by decomposition. (The L layer of the forest floor.)

Living fuels - Naturally occurring fuels in which the moisture content is physiologically controlled within the living plant. The NFDR System considers only herbaceous plants and woody plant material which is small enough (leaves and needles, and twigs less than one-fourth inch in diameter) to be consumed in the flaming front of an initiating fire.

Man-Caused Risk (MCR) - A number related to the expected number of firebrands originating 
from human activities which a protection unit will be exposed to during the rating day (appendix E).

Monthly average - Historically, the average number of man-caused fires occurring on a protection unit during a specific calendar month (appendix E).

Occurrence Index (OI) - A number related to the potential fire incidence within a protection unit.

One-hour timelag fuel moisture (1-Hr. TL FM) The moisture content of the 1-hour timelag fuels.

one-hour timelag fuels - Fuels consisting of dead herbaceous plants and roundwood less than about one-fourth inch in diameter. Also included is the uppermost layer of needles or leaves on the forest floor.

one-hundred hour timelag fuel moisture (100Hr. TL FM) - The moisture content of the 100-hour timelag fuels.

One-hundred hour timelag fuels - Dead fuels consisting of roundwood in the size range of 1 to 3 inches in diameter and very roughly the layer of litter extending from approximately three-fourths inch to 4 inches below the surface.

Partial risk factor - The contribution to the Man-Caused Risk made by a specific risk source. The partial risk factor is a function of the daily activity level assigned that risk source and the appropriate risk source ratio.

Peak monthly average - The highest monthly average calculated for a protection unit (see monthly average) (appendix E).

Precipitation - Any or all the forms of water particles, liquid or solid, that fall from the atmosphere and reach the ground. (Usually measured to the nearest one-hundredth of an inch.)

Probability - The chance that a specific event will occur.

Protection unit - A geographical area which is administratively defined and which is the smallest area for which organized fire suppression activities are formally planned.

Rating period - The period of time during which a fire-danger rating value is considered valid or representative for administrative or other purposes. Normally it is 24 hours extending from midnight to midnight.

Relative humidity (RH) - The ratio of the actual amount of water vapor in the air to the amount necessary to saturate the air at that temperature expressed as a percentage.

Residence time - (1) The time required for the flaming zone of a fire to pass a stationary point, (2) The width of the flaming zone divided by the rate of spread of the fire.

Risk - A number related to the potential number of firebrands to which a given area will be exposed during the rating day (appendix $\mathrm{E}$ ).

Risk source - An identifiable human activity which historically has been a major cause of wildfires on a protection unit (appendix E).

Risk source ratio - That percent of the mancaused fires which have occurred on a protection unit that can be charged to a specific risk source (appendix E).

Roundwood - Boles, stems, or limbs of woody material; that portion of the dead wildland fuels which are roughly cylindrical in shape.

Seasonal monthly average - Historically, the average number of man-caused fires occurring on a protection unit per month during the established fire season (appendix E).

Seasonal risk class - An objective ranking of protection units within an administrative group, based on the incidence of man-caused fires for at least the past 5 years (appendix E).

Shrub - A woody perennial plant differing from a perennial herb by its persistent and woody stem, and from a tree by its low stature and habit of branching from the base.

Slash - Branches, bark, tops, chunks, cull logs, uprooted stumps, and broken or uprooted trees left on the ground after logging; also debris resulting from thinnings, wind, or fire.

Slope - The variation of terrain from the horizontal; the number of feet rise or fall per 100 feet measured horizontally, expressed as a percentage.

Slope class - A code which designates the most common slope encountered in the primary 
fire problem area on a protection unit (appendix C).

Spread Component (SC) - A number related to the forward rate of spread of the head of a fire.

Standard drying day - A day which produces the same net drying as experienced during a 24-hour period under laboratory conditions where the dry-bulb temperature is maintained at $80^{\circ} \mathrm{F}$. and the relative humidity at 20 percent.

State of weather - A code used for the entry in column 2 of the 10-Day Fire Danger Weather Record Form which expresses the amount of cloud cover, kind of precipitation, and/or restrictions to visibility being observed at the fire-danger station at Basic Observation Time. In the NFDR calculations it is significant because it indicates whether fuel moisture values should be corrected to compensate for the effects of additional heating on sumny days.

Sunny - The adjective classification of the sky when $5 / 10$ ths or less of the sky is obscured by clouds.

Ten-hour timelag fuel moisture (10-Hr. TLFM) The moisture content of the 10-hour timelag roundwood fuels.

Ten-hour timelag fuels - Dead fuels consisting of roundwood in the size range of one-fourth to 1 inch and very roughly the layer of litter extending from just below the surface to approximately three fourths inch below the surface.
Thermoscreen - See Instrument Shelter.

Timelag (TL) - The time necessary for a fuel particle to lose approximately 63 percent of the difference between its initial moisture content and its equilibrium moisture content.

Total risk - The sum of Lightning- and ManCaused Risk values. It cannot exceed a value of 100 .

Unnormalized man-caused risk - The sum of the partial risk factors computed for the risk sources active on a protection unit (appendix E).

Volatiles - Readily vaporized organic materials which, when mixed with oxygen, are easily ignited.

Weighted monthly occurrence - A number used to determine the seasonal risk class for a protection unit. It is calculated by multiplying the peak monthly average by two and adding that product to the seasonal monthly average (appendix E).

Wet-bulb temperature - The temperature of a properly ventilated wet-bulb thermometer.

Windspeed - Wind, in miles per hour, measured at 20 feet above the ground or the average height of the vegetative cover, and averaged over at least a 10-minute period.

Woody vegetation condition - A code which reflects the moisture content of the foliage and small twigs (less than one-fourth inch) of living woody plants (appendix F). 


\section{APPENDIX B}

\section{Selection of Fuel Models}

Ideally, a protection unit should be subdivided into fire-danger rating areas with relatively homogeneous climate, fuels, and topography. In such a situation, fire-danger rating values would be calculated for each rating area; a weighted average of these numbers would then determine the readiness plan to be followed during that rating period.

At the present time, however, with only a few exceptions, the protection unit is the smallest geographical division recognized. The protection unit may, as in many range or prairie lands, be quite homogeneous and may satisfy the criteria for a fire-danger rating area. Many units, however, are heterogeneous. For the management of fire suppression activities on such a unit, the most practical approach is for the fire control manager to pick an area he considers representative of the fire problem on the unit. This area we will call the base area-not to be confused with a firedanger rating area.

Several options may be considered as a basis for selecting the base area. Agency directives should provide guidance. The base area may be chosen on the basis of:

1. Where the most fires occur,

2. Where the potential cost of suppression plus loss of resource or manmade structures is greatest,

3. Where the fire control personnel feel there is a "key" area to which they are able to relate fire danger across the protection unit.

Regardless of which of the above options is used, a careful analysis of the fire history on the protection unit is absolutely essential.

Once the base area has been chosen, the next step is to select the fuel model which best represents the fuels found there. Nine fuel models have been formulated for use with the NFDR System at this time; however, it is unlikely that more than two or three will be usable on any one protection unit. Besides the one selected for the base area (base fuel model), other applicable models should be determined for dispatch purposes for fires in fuels other than those covered by the base fuel model.

The following key and narrative descriptions should help in selecting the correct fuel model. Keep in mind that the models are not based on cover types, but on how much fuel, by classes, is present and how it is arranged. Rather diverse cover types are grouped together because they have similar fuel properties.

Because data were lacking, fuel models could not be constructed for several common wildland situations. In the following key, such situations are designated with an asterisk (*) and a "best fit" model is suggested.

\section{Fuel Model Key - 1972}

I. The orea is not timbered; less than onethird of the oreo is occupied by trees. (Stunted tree species and conifer reproduction are grouped with shrubs and called brush. Slash is not considered as brush.)

A. Gross and other herbaceous plonts, or mosses and lichens are the predominont fuel. Brush, slosh and trees together occupy less than one-third of the area ..............Model A

B. Gross ond other herbace ous plants are not the predominont fuel.

1. Brush or tree reproduction makes up the predominant plont cover; occupies one-third or more of the orea.

o. The foliage of the predominant woody cover species burns reodily.

(1) The predominant cover occupies two-thirds or more of the areo.

(a) One-third or more of the woody portion of plants is dead; much of it 2 inches in diameter or larger, or there is o duff/litter layer at leost 3 inches deep. Cover must averoge 6 feet or more in height......Model B

(b) The cover contains little dead woody fuel larger than 2 inches in diometer, ond the duff/litter layer is less than 3 inches deep.........Model D

(2) The predominant cover occupies one-third but less thon two-thirds

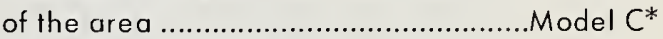

b. The foliage of the predominant cover species does not burn eosily. Model F

2. Slash is the predominant fuel.

a. The foliage is still ottached to the slosh.

(1) Coniferous slosh Model I

(2) Hardwood slash Model D*

b. The foliage is no longer oftached to the slash; settling is evident.

(1) Herboceous plants have invaded the orea. Model C*

(2) Brush has invoded the areo Model D* 
II. The oreo is timbered. One-third or more of the area is accupied by trees.

A. The area has been thinned or portially cut, leaving slosh os the major fuel camponent.

1. Coniferaus slash with needles attached....Madel B*

2. All hardwaad slosh or coniferaus slash with needles no longer attached....

B. The oreo hos nat been thinned ar partiolly cut.

1. Grass and ather herbaceous plants are o common ground fuel; the canapy af the overstory is commonly "open" .......Model C

2. Duff/litter, branchwaod and tree boles are the primary graund fuel; the canapy af the overstary is "closed" thaugh openings moy be common in the stond. a. Twa-thirds or more of the overstory consists of deciduaus species.

(1) The overstory is dormant; the leoves hove follen and the leof litter is not compoct. Model E

(2) The averstary is nat darmant; or the leaf litter has been compacted by rain or snaw Model $\mathrm{H}$

b. One-third or mare of the overstory consists of evergreen species.

(1) The overstory is moture or overmature and is aften decadent. There is on exceptianolly heavy accumulotion of bronchwoad, downed trees, ond duff/litter on the forest floor Model G

(2) The overstory is immoture ar mature. There is only a nominal accumulatian af debris on the forestfloor.

(o) Brush or reproduction occupies less than ane-third af the orea.

(oo) The ground fuel is primorily needles 2 inches or more long (mast pines) ...................................Madel E* (bb) The ground fuel is primarily needles less thon 2 inches long ......Model H

(b) Brush or reproduction accupies one-third or mare of the oreo.

(oo) The folioge af the understary burns readily ar needle drape is prevalent ..................................Madel D*

(bb) The foliage of the understary daes nat burn readily and there is little ar no needle drope Model F

\section{Fuel Model A}

Cover types represented here are grasslands and others such as tundra, where the primary carrier of fire is a continuous bed of fine fuels. Brush or trees may be present, but the crowns should not occupy more than one-third of the area. Concentrations of brush or trees within the type are such that control lines need not be placed close to them. Examples of types covered by fuel model $A$ are western grasslands, the savannah, and tundra. Open stands of pinyon-juniper and desert shrubs such as mesquite, creosotebush, and palo verde may be included, but fire spread will be overrated during those periods when grazing or lack of rain prevents herbaceous ground fuels from developing.

\section{Fuel Model B}

This model represents chaparral or other dense brush, and recently partially cut or thinned conifer stands where slash is a serious fuel problem. These situations are characterized by heavy loadings of dead woody material over 2 inches in diameter, or duff/litter layers 3 inches or more deep. In the brush, the primary cover plants must average 6 feet or more in height. Foliage of brush plants typically becomes easily involved in the fire. Individual plants in these associations almost always form a dense, continuous fuel bed occupying twothirds or more of the area. Typical cover types are mature California and some other southwest chaparral, the pine barrens of New Jersey, and the high pocosins of the central Atlantic Coast.

\section{Fuel Model C}

Apply this model where grass or other herbaceous plants are the primary carrier of the fire. The overstory is typically open, occupying one-third but not more than two-thirds of the area. Usually enough branch material is on the ground to contribute significantly to fire intensity. In the more open areas, concentrations of brush or trees are such that it is difficult to avoid placing control lines close to them. Types included may be young conifer plantations where the trees occupy less than two-thirds of the area, open ponderosa, sugar, longleaf, slash, and sand pines, wiregrass-scrub oak, and timber-sagebrush-grass associations. Desert shrubs and pinyon-juniper stands are included where a continuous ground fuel develops most years, and where pinyon makes up more than one-third of the stand. 


\section{Fuel Model D}

Use this model where there is a heavy loading of fuels 1 inch or less in diameter and little or no material greater than 2 inches in diameter. Usually the living foliage burns readily. Examples of types to which this model apply are the low pocosins of the Atlantic Coast, palmetto-gallberry, sagebrush and conifer plantations, and other situations where the woody plants occupy two-thirds or more of the area. Also covered here are black spruce and the black spruce-aspen-poplar types of Alaska; but the latter only where the spruce makes up one-third or more of the overstory. This model covers those chaparral situations which are not dense enough or heavy enough to qualify for model $\mathrm{B}$.

\section{Fuel Model E}

Use this model in hardwood and mixed conifer-hardwood stands when the hardwoods are dormant and before the leaf litter has been compacted by rain or snow (when hardwoods are leafed out, use model $\mathrm{H}$ ). This model was constructed primarily for the oak-hickory type where the litter consists of large, coarse leaves which do not compress readily as do the leaves of such species as maple, tulip poplar, aspen, and similar species. Under very high wind conditions, this model will underrate fire danger since it cannot account for the increase in spread due to rolling or blowing leaves. This model also covers closed stands of conifers with needles 2 inches or more in length (most pines). (The short-needled conifers produce a much denser, more compact litter bed which is better covered by model H.)

\section{Fuel Model F}

This model represents situations where there is a fairly continuous cover of young brush or shrub species which contain little or no dead material and the foliage does not burn readily. Types covered by fuel model $F$ are laurel, salal, vine maple, alder, and mountainmahogany. Also included are young stands of chamise and manzanita. Grass, ferns, and other herbaceous plants may be present, but if there is a continuous cover of ground fuels, model A should be used.

\section{Fuel Model G}

This model applies primarily to dense conifer stands where a heavy buildup of downed tree material has accumulated. Natural breakup of overmature stands, insect and disease damage, wind or ice storms, and thinnings or partial cuts are typical events that create the heavy amounts of fuel which typify this model. The canopies of these stands are usually closed, but large openings, the result of the downing of timber, are common. Deep litter and a very high loading of dead fuels larger than 1 inch in diameter are also characteristic. The amount of undergrowth may be quite varied. Types covered by fuel model $G$ are hemlock-Sitka spruce, coastal Douglas-fir, or windthrown or bug-killed lodgepole pine and spruce; also, thinned or partially cut conifer stands where there is heavy slash after the fines have dropped off and the slash has settled. While the slash is fresh, fuel model B should be used.

\section{Fuel Model H}

Most closed short-needled conifer types and hardwoods, when in leaf or after compaction of the leaf litter by rain or snow, are represented here. These associations contain a variable amount of undergrowth, but initiating fires seldom burn other than on the ground through a shallow, dense litter layer which contains only a small amount of dead branchwood. Pine and pine-hardwood associations (where pines make up one-third or more of the overstory) and dormant hardwoods (before the litter has been compacted) are best covered by model E.

\section{Fuel Model I}

This model was designed to satisfy the need for determining fire-danger ratings for clearcut conifer areas. The loadings used are highest of all fuel models, but represent midrange values for most such areas in the West. Exceptions are (1) for clearcuts in the southern pines, model $\mathrm{C}$ is more appropriate, and (2) in ponderosa and other pines of similar growth characteristics, use model D. 


\section{APPENDIX C}

\section{Selection of Slope Class}

Like the fuel model, the slope class for a protection unit should be selected carefully. The basic consideration for the assignment of the slope class is the topography in that portion of the base area where initial attack is commonly initiated. Once again, knowledge of the fire history in the protection unit is essential.

\author{
Slope class \\ 1 \\ 2 \\ 3
}

Slope (percent)

0 to 20

21 to 40

Greater than 40

The slope class should not be selected to represent the "average" slope, but the most commonly encountered slope in the base area.

\section{APPENDIX D}

\section{Evaluation of the Herbaceous Vegetation Condition (column 8)}

The flammability of a fine fuel complex is affected by the proportion of the fuel which is living. The percent of the grass and other herbaceous plants which is green will usually increase throughout the growing season; rapidly at first, then more slowly.

In the 1964 version of the NFDR System, only three broad classes were recognized; cured ( 0 to 25 percent green), transition (26 to 75 percent green), and green (76 to 100 percent green). Recent research has shown that fire behavior is very sensitive to this factor, so a much more rigorous evaluation is necessary. It is best done with a range forage volume transect conducted on a representative site within the base area. This should be done by, or under the supervision of, the unit fire control officer.

For users who are not familiar with the range forage volume transect, a brief description follows.

A permanent transect, 300 feet or more in length, should be located in a portion of a major extensive herbaceous type within the base area. It should be representative of the slope and cover type of that portion of the base area where most fires occur. The transect should be marked with a steel post at each end. A permanent installation will allow valid comparisons to be made not only during a season, but also from one fire season to another.

The sampling should be done by the same person. In the spring and fall, or during other periods of rapid change, sampling maybe necessary every week or 10 days; however, during periods of little or no change such as midsummer, once a month or even less frequently may suffice. The unit fire control officer will determine the frequency of sampling.

Ten evenly spaced samples are evaluated along the transect line. Pacing is sufficiently accurate for locating the sampling points. The sampling circle is located on the ground by placing a hoop, about 1 foot in diameter, immediately in front of the toe when the sampler has paced the required distance. Mentally divide the circle into quadrants and estimate, by volume, the percent green material in each. The average of these four estimates is the percent green for that sample point.

Repeat this procedure until a total of 10 points has been sampled. The average of these 10 values is the herbaceous vegetation condition; enter in column 8 on the 10-Day Fire Danger and Weather Record Form.

Initially, when the observer is "calibrating" his judgment, and then periodically, as a check, plots should be clipped; the dead and live material separated and the volume of each measured by any convenient means. The percent green is then the ratio

\section{Volume Green \\ X 100 \\ Volume Green + Volume Dead}

Remember that all fuels in the 1-Hr. TL class should be considered. Litter should be included with any dead stems still standing. Estimates of green material in excess of 50 percent should be considered very carefully. These situations are very rare except where no litter or standing dead stems remain from the previous growth. 


\section{APPENDIX E}

\section{Evaluation of Risk}

\section{Lightning Risk (LR) (Column 11)}

In the computation of LR, not only the amount of lightning expected during the current day is considered, but also the amount experienced during the preceding day. The latter is necessary to account for undiscovered (holdover or sleeper) fires.

The LR is computed in the following steps:

1. From the Lightning Activity Level Guide, the fire control officer assigns a lightning activity level for the current day. His primary guide is the current lightning activity level forecast provided by the fire-weather forcaster.

\section{LIGHTNING ACTIVITY LEVEL GUIDE}

\begin{tabular}{|c|c|c|}
\hline \multirow[b]{2}{*}{$\begin{array}{l}\text { Lightning } \\
\text { activity } \\
\text { level }\end{array}$} & \multicolumn{2}{|c|}{ Type of observation } \\
\hline & $\begin{array}{l}\text { Ground or aerial } \\
\text { (narrative } \\
\text { description) }\end{array}$ & $\begin{array}{l}\text { Radar-total area } \\
\text { affected (percent } \\
\text { coverage, } 24 \text { hours) }\end{array}$ \\
\hline
\end{tabular}

$1 \quad$ No thunderstorms or building 0 cumulus observed.

2 A few building cumulus with only $1-14$ on occasional one reaching thunderstorm intensity typify this activity level. Thunderstorms or lightning need not be observed for this activity level to be assigned; however, large cumulus must be present.

3 Building cumulus are common; thunderstorms are widely scattered, but their presence must be verified in order for this activity level to be assigned. Lightning need not be observed.

4 Thunderstorms are common, but do not obscure the sky. Lightning is primarily cloud-to-cloud or in-cloud, but cloud-to-ground lightning will be observed.

5 Thunderstorms are common, occasionally obscuring the sky. Lightning of all kinds occurs frequently and is characteristically persistent.

2. The LR is determined by entering table E-1 with the current day's expected lightning activity level and the preceding day's observed lightning activity level (column 37). Enter the resulting value in column 11 of the 10-Day Fire Danger and Weather Record Form.

Example.-For District B of the Big Pine National Forest a lightning activity level of 4 was forecast for the 17th of August by the fire-weather forecaster. The fire control officer, at the Basic Observation Time, felt that observed conditions thus far that day definitely indicated that a 4 was appropriate. For the 16th, observed lightning warranted the assignment of a lightning activity level of 3 .

From table E-I, at the intersection of the column indexed by the forecasted lightning activity level of 4 and the row indexed by the lightning activity level for the previous day, 3 , is 45 -the LR.

Table E-1. — LIGHTNING RISK

Col. 11

\begin{tabular}{|c||r|rrr|r|r|r|r|}
\hline $\begin{array}{c}\text { Yesterday's Observed } \\
\text { Lightning Activity } \\
\text { Level } \\
\text { (Col. 37) }\end{array}$ & \multicolumn{6}{|c|}{ Forecasted Lightning Activity Level } \\
\hline 1 & 1 & 2 & 3 & 4 & 5 \\
\hline 2 & 0 & 10 & 20 & 40 & 80 \\
3 & 3 & 13 & 23 & 43 & 83 \\
4 & 5 & 15 & 25 & 45 & 85 \\
5 & 10 & 20 & 30 & 50 & 90 \\
\hline
\end{tabular}


Man-Caused Risk (MCR) (column 12)

General.-The contribution that man's activities make to risk is evaluated from three inputs. The first is a semipermanent number which ranks the man-caused fire potential of the individual protection unit relative to that of the other protection units; it is called the seasonal risk class. The second, the risk source ratio, is that portion of the potential man-caused fire problem which can be charged to a specific, identifiable cause. The third is the fire control officer's estimate of how active each of these sources is. This is called the daily activity level. The seasonal risk class and the risk source ratio are derived from analysis of fire occurrence records; the daily activity level, as its name implies, is evaluated subjectively each day.
The procedure for determining the MCR for a protection unit requires the following steps:

1. For each risk source, evaluate its daily activity level. Enter table E-2 with the daily activity level and the risk source ratio; the resulting number is the partial risk factor.

2. Sum up the partial risk factors, one for each risk source, to get the unnormalized mancaused risk.

3. Enter table E-3 with the results from step 2 and the unit's seasonal risk class; the resulting number is the MCR.

Keyed to the flow diagram in figure 8 are guidelines $\mathrm{A}$ through $\mathrm{E}$ which cover the details necessary for determining the inputs and carrying out the calculation of MCR.
Risk Source A

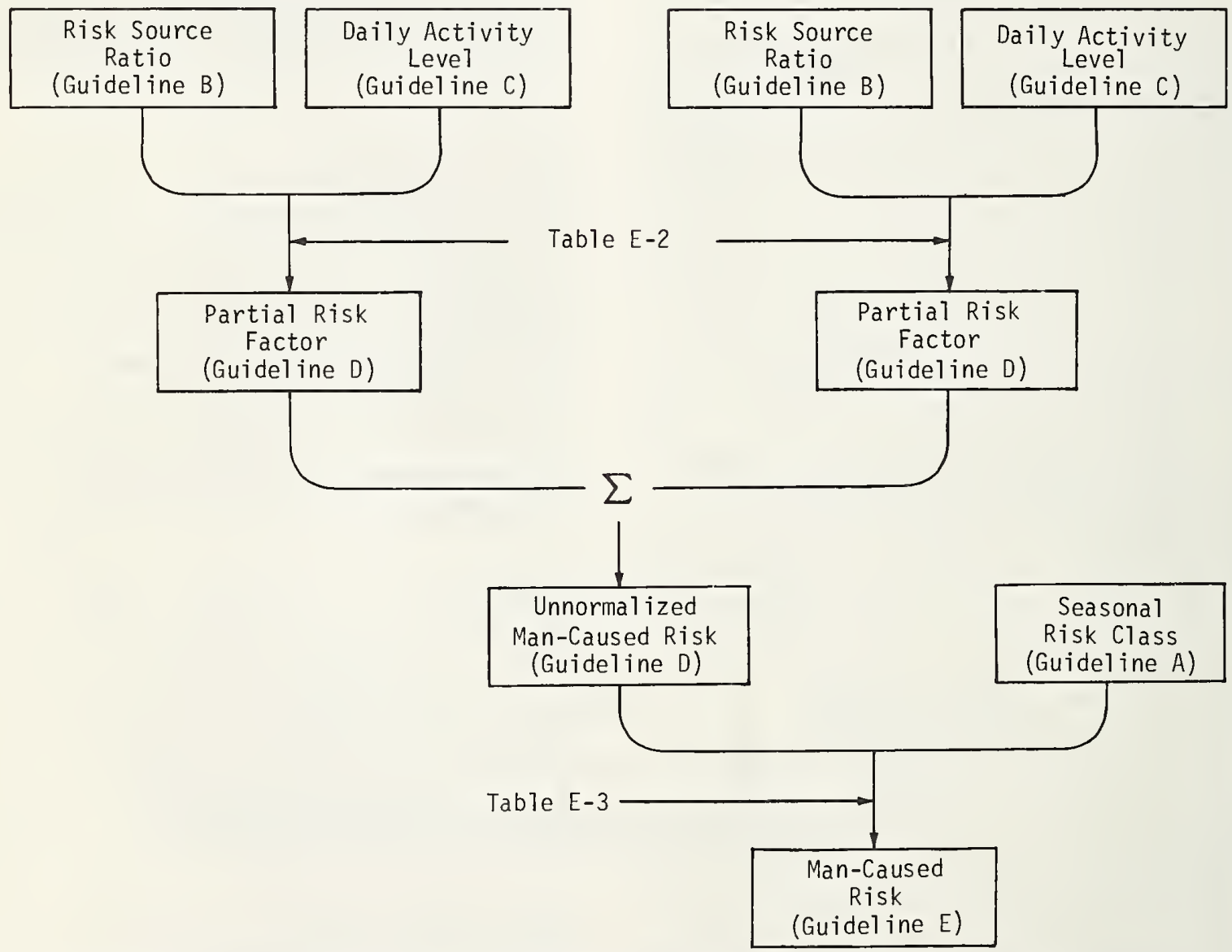

Figure 8.-Computational Flow Chart for Determining Man-Caused Risk. This chart, as an illustration, shows only two risk sources, $\mathrm{A}$ and $\mathrm{B}$. In reality, three to five will be used and the partial risk factors for all will be summed to give the unnormalized MCR. 
Guideline A - Evaluation of the Seasonal Risk Class. - The seasonal risk class reflects the ranking of the potential level of MCR of a protection unit relative to that of other units in that administrative group. A basic assumption is that the potential level of risk is correlated directly with the experienced level of fire incidence. At least 5 years of fire occurrence records for the established fire season are necessary for this analysis; 10 years is preferable.

Besides the seasonal monthly average fire incidence, the peak monthly average must be considered in establishing the seasonal risk class. For instance, Unit A averages three man-caused fires per month during a 6-month season, but in July, the average is 10 fires. Unit B averages five fires per month during the season with the worst month averaging only seven fires. Which unit has the worst potential man-caused fire problem? Twice the weight is given to the peak monthly average than to the seasonal monthly average in the ranking procedure. Thus, Unit A ranks the highest.

The seasonal risk class is determined as follows:

1. Divide the total number of fires experienced during the period of record by the number of months in the record (years of record multiplied by the length of fire season in months). This value is the seasonal monthly average.

2. Summarize the occurrence records by months.

3. Divide the totals for each month by the number of years of record. The largest of these monthly averages is the peak monthly average.

4. Multiply the peak monthly average by 2 and add to the seasonal monthly average. You now have a weighted monthly occurrence.

5. Divide 10 by the highest weighted monthly occurrence of those calculated for the units being ranked together.

6. When the weighted monthly occurrences for all units are multiplied by this factor, the resulting numbers rounded up to the next highest whole number are the seasonal risk classes for those units.
Example.-On the Big Pine National Forest, the seasan is 4 months lang for all districts, extending from February through May. The seasonal risk class far the districts will be determined as follaws:

Five-year man-caused fire occurrence recordby manth

\begin{tabular}{lccccr} 
& Feb. & Mar. & Apr. & May & Total \\
\hline District A & 21 & 14 & 8 & 6 & 49 \\
District B & 4 & 16 & 5 & 5 & 30 \\
District C & 8 & 12 & 10 & 6 & 36 \\
District D & 5 & 18 & 70 & 4 & 37
\end{tabular}

For each district, the manthly totals are divided by 5 (5 Februarys, 5 Marches, and so forth) ta get a monthly average and the total number of fires by 20 (5 years of 4 months each equals 20 months) to get a seasonal monthly average.

\begin{tabular}{llllll} 
& \multicolumn{3}{c}{ Five-year monthly average } & $\begin{array}{r}\text { Seasonal } \\
\text { manthly } \\
\text { average }\end{array}$ \\
& Feb. & Mar. & Apr. & May & 2.5 \\
\hline District A & $4.2^{*}$ & 2.8 & 1.6 & 1.2 & 1.5 \\
District B & 0.8 & $3.2^{*}$ & 1.0 & 1.0 & 1.8 \\
District C & 1.6 & $2.4^{*}$ & 2.0 & 1.2 & 1.9 \\
District D & 1.0 & $3.6^{*}$ & 2.0 & 0.8 &
\end{tabular}

*Peak monthly average

\begin{tabular}{lrr} 
& & $\begin{array}{r}\text { Weighted } \\
\text { manthly } \\
\text { accurrence }\end{array}$ \\
\hline District A & $4.2 \times 2+2.5=$ & 10.9 \\
District B & $3.2 \times 2+1.5=$ & 7.9 \\
District C & $2.4 \times 2+1.8=$ & 6.6 \\
District D & $3.6 \times 2+1.9=$ & 9.1
\end{tabular}

10.9 is the highest; the normalizing factor then is $10 \div 10.9=0.92$

Seasonal risk class

\begin{tabular}{llr}
\hline District A & $10.9 \times 0.92=10.0$ & 10 \\
District B & $7.9 \times .92=7.3^{* *}$ & 8 \\
District C & $6.6 \times .92=6.1^{* *}$ & 7 \\
District D & $9.1 \times .92=8.4^{* *}$ & 9
\end{tabular}

**If a decimal results, the next highest whole number is the seasanal risk class.

Instructions for the seasonal risk class are given in Guideline E. 
Guideline B - Risk Source Ratio.-The risk source ratio is that portion of the fires occurring during the period of record which is attributable to a specific cause.

To calculate the risk source ratios, the major causes of fires by months during the fire season must be identified. Risk sources are tabulated on a monthly basis because the contribution of a particular source to the fire problem will likely change as the fire season progresses. For instance, in some areas debris burning during the spring is usually a major source of fires, but in the summer, its importance diminishes.

It is not necessary, or desirable, to isolate all possible fire causes. The risk sources selected should, at a minimum, account for 70 percent of the historical fires. In most cases, four or five of the most important risk sources will satisfy the 70 percent rule.

Example.-In the following example, the major risk sources are identified, and the risk source ratios calculated for District B of the Big Pine National Forest for February.

\begin{tabular}{lcc} 
Risk source & $\begin{array}{c}\text { Number of fires } \\
\text { (5-year total) }\end{array}$ & $\begin{array}{c}\text { Risk source ratio } \\
\text { (Percent) }\end{array}$ \\
\hline Incendiary & 7 & 33 \\
Debris burning & 6 & 29 \\
Campfire & 3 & 14 \\
Machine use & 2 & 10 \\
All other & 3 & 14 \\
\multicolumn{1}{c}{ All sources } & 21 &
\end{tabular}

The first four risk sources account for 86 percent of the fires. The remainder are combined and designated as "all other."

Instructions for using the risk source ratios are given in Guideline D.
Guideline C - Daily Activity Level. - Unlike the risk source ratio and seasonal risk class, which are semi-permanent, objectively derived numbers, the daily activity level is evaluated subjectively each day. Because the daily activity level must be estimated rather than calculated, it requires some careful consideration. The actual level may vary over a considerable range, particularly for the principal sources of risk, but only five levels are needed for application. These are: None, Low, Normal, High, and Extreme.

\section{DAILY ACTIVITY LEVEL GUIDE-MAN-CAUSED RISK}

Daily activity level Description

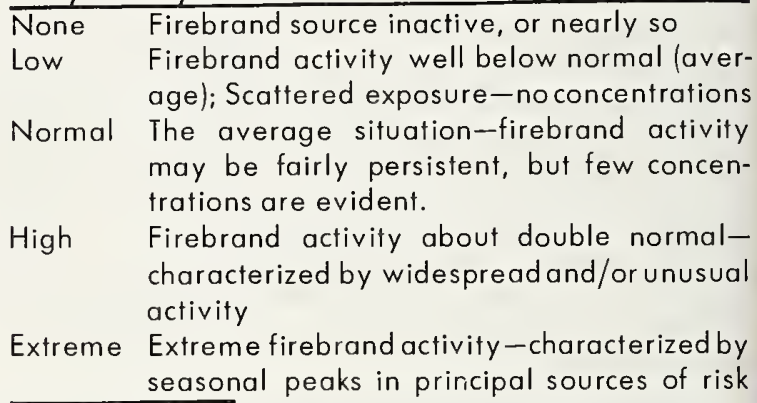

Key points in estimating the current (or predicted) daily activity level:

1. A daily activity level must be assigned to each risk source for which a risk source ratio has been computed. The evaluation is relative to what is normal for that particular risk source in that rating area.

2. Select the daily activity level that best fits the general description of firebrand activity given in the Daily Activity Level Guide. If winds in excess of $12 \mathrm{MPH}$ are expected or are being experienced, raise the daily activity level for all risk sources one category.

Table E-2. - PARTIAL RISK FACTOR

\begin{tabular}{|c|c|c|c|c|c|c|c|c|c|c|c|c|c|c|c|c|c|c|c|c|}
\hline \multirow[b]{2}{*}{$\begin{array}{l}\text { Daily } \\
\text { Activity } \\
\text { Level }\end{array}$} & \multicolumn{20}{|c|}{ Risk Source Ratio } \\
\hline & $\begin{array}{l}1 \\
5\end{array}$ & $\begin{array}{r}6 \\
1 \\
10\end{array}$ & $\begin{array}{r}11 \\
\downarrow \\
15\end{array}$ & $\begin{array}{r}16 \\
\downarrow \\
20\end{array}$ & $\begin{array}{r}21 \\
\downarrow \\
25\end{array}$ & $\begin{array}{l}26 \\
1 \\
1 \\
1 \\
130\end{array}$ & $\begin{array}{r}31 \\
\downarrow \\
35\end{array}$ & $\begin{array}{r}36 \\
1 \\
40\end{array}$ & $\begin{array}{r}41 \\
\downarrow \\
45\end{array}$ & $\begin{array}{r}46 \\
\downarrow \\
50\end{array}$ & $\left\{\begin{array}{l}51 \\
1 \\
1 \\
155\end{array}\right.$ & $\begin{array}{r}56 \\
\downarrow \\
60\end{array}$ & $\begin{array}{r}61 \\
\downarrow \\
65\end{array}$ & $\begin{array}{r}66 \\
\downarrow \\
70\end{array}$ & $\begin{array}{r}71 \\
\downarrow \\
75\end{array}$ & $\begin{array}{l}176 \\
1 \\
1 \\
1 \\
1\end{array}$ & $\begin{array}{r}81 \\
\downarrow \\
85\end{array}$ & $\begin{array}{r}86 \\
\downarrow \\
90\end{array}$ & $\begin{array}{r}91 \\
\downarrow \\
95\end{array}$ & $\begin{array}{rr}1 & 96 \\
\downarrow & \downarrow \\
5 & 100\end{array}$ \\
\hline None & 1 & 1 & 1 & 1 & 2 & 2 & 2 & 2 & 3 & 3 & 13 & 4 & 4 & 4 & 5 & 5 & 5 & 6 & 6 & 6 \\
\hline Low & 1 & 1 & 2 & 2 & 3 & i 4 & 4 & 5 & 5 & 6 & 17 & 7 & 8 & 9 & 9 & 10 & 11 & 11 & 12 & 212 \\
\hline Normal & 1 & 2 & 3 & 5 & 6 & 7 & 8 & 10 & 11 & 12 & 14 & 15 & 16 & 17 & 19 & 20 & 21 & 22 & 24 & $4 \quad 25$ \\
\hline High & 2 & 4 & 7 & 9 & 12 & 14 & 17 & 19 & 22 & 24 & 27 & 30 & 32 & 35 & 37 & 40 & 42 & 45 & & 750 \\
\hline Extreme & 3 & 8 & 13 & 18 & 23 & 29 & 34 & 39 & 44 & 49 & 54 & 59 & 64 & 69 & 74 & 80 & 85 & 90 & & 100 \\
\hline
\end{tabular}


3. Consider whether the most recent observed activity level for a risk source will continue for another 24 hours, or shift to a new level. a. Certain sources, such as debris burners, are weather related-very active at times, and nearly totally inactive at other times.

b. Certain sources, such as railroads, are fairly persistent regardless of weather, although some seasonal changes may be noted; for instance, transportation related to farming or logging activities.

c. Recreational activity peaks can often be pinpointed to holidays or weekends.

Instructions for using the daily activity levels are given in Guideline D.

Guideline D - Calculation of the Unnormalized Man-Caused Risk. - When the daily activity level and the risk source ratio for each risk source are entered in table E-2, the number resulting is called the partial risk factor. When the partial risk factors for all of the risk sources have been added together, the resulting number is the unnormalized man-caused risk.

Example.-For computing the unnormalized mancaused risk, let's look again at District B, Big Pine National Forest, for the third of February. The daily activity levels have been assigned as follows:

\begin{tabular}{llll} 
Risk source & $\begin{array}{c}\text { Risk source } \\
\text { ratio }\end{array}$ & $\begin{array}{c}\text { Daily activity } \\
\text { level }\end{array}$ & $\begin{array}{c}\text { Partial risk } \\
\text { factor }\end{array}$ \\
\hline Incendiary & 33 & Normal & 8 \\
Debris burning & 29 & Low & 4 \\
Campfires & 14 & Low & 2 \\
Machine use & 10 & Extreme & 8 \\
All other & 14 & Normal & 3 \\
\cline { 2 - 3 } & & & 25
\end{tabular}

*** The "all other" group is always carried through the procedure with an assigned daily activity level of "Normal."

Guideline E - Normalization of Man-Caused Risk. - Combining the unnormalized man-caused risk with the seasonal risk class in table E-3 gives the MCR value.

Example.-Again consider District $B$; if you enter table E-3 with an unnormalized man-caused risk of 25 and the seasonal risk class of 8 , the MCR is 19 .

\section{Total Risk (column 13)}

The sum of the LR and MCR is the Total Risk. Total Risk cannot exceed 100; if the sum of the LR and MCR values exceeds 100 , record 100 in column 13 .

Table E-3. - MAN-CAUSED RISK

Col. 12

\begin{tabular}{|c|c|c|c|c|c|c|c|c|c|c|c|c|c|c|c|c|c|c|c|c|}
\hline \multirow[b]{2}{*}{$\begin{array}{c}\text { Seasonal } \\
\text { Risk } \\
\text { Class }\end{array}$} & \multicolumn{20}{|c|}{ Unnormalized Man-Caused Risk } \\
\hline & $\begin{array}{l}0 \\
1 \\
5\end{array}$ & $\begin{array}{r}6 \\
\downarrow \\
10\end{array}$ & $\begin{array}{r}11 \\
\downarrow \\
15\end{array}$ & $\begin{array}{r}16 \\
\\
20\end{array}$ & $\begin{array}{r}21 \\
+ \\
25\end{array}$ & $\begin{array}{l}26 \\
1 \\
30\end{array}$ & $\begin{array}{r}1 \\
35\end{array}$ & $\begin{array}{r}36 \\
40\end{array}$ & $\begin{array}{r}41 \\
45\end{array}$ & $\begin{array}{r}46 \\
\downarrow \\
50\end{array}$ & 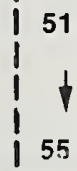 & $\begin{array}{r}56 \\
\downarrow \\
60\end{array}$ & $\begin{array}{r}61 \\
\downarrow \\
65\end{array}$ & $\begin{array}{r}66 \\
1 \\
70\end{array}$ & $\begin{array}{r}71 \\
\downarrow \\
75\end{array}$ & $\begin{array}{l}176 \\
1 \\
1\end{array}$ & $\begin{array}{r}81 \\
\\
85\end{array}$ & $\begin{array}{r}86 \\
\downarrow \\
90\end{array}$ & & $\begin{array}{l}190 \\
+\quad 1 \\
+100\end{array}$ \\
\hline 1 & 1 & 1 & 1 & 2 & 2 & 3 & 3 & 4 & 4 & 5 & 5 & 6 & 6 & 7 & 7 & 8 & 8 & 9 & 9 & $\begin{array}{l}9 \\
9\end{array}$ \\
\hline 2 & 1 & 2 & 3 & 4 & 5 & 6 & 7 & 8 & 9 & 10 & 11 & 12 & 13 & 14 & 15 & 16 & 17 & 18 & 19 & 920 \\
\hline 3 & 1 & 2 & 4 & 6 & 7 & 19 & 10 & 12 & 13 & 15 & 16 & 18 & 19 & 21 & 22 & 24 & 25 & 27 & 28 & 30 \\
\hline 4 & 1 & 3 & 5 & 7 & 9 & 11 & 13 & 16 & 18 & 20 & 22 & 24 & 26 & 28 & 30 & 32 & 34 & 36 & 38 & 340 \\
\hline 5 & 2 & 4 & 7 & 9 & 12 & 14 & 17 & 19 & 22 & 24 & $\int^{i} 27$ & 30 & 32 & 35 & 37 & 40 & 42 & 45 & 47 & 750 \\
\hline 6 & 2 & 5 & 8 & 11 & 14 & 17 & 20 & 23 & 26 & 29 & 32 & 36 & 39 & 42 & 45 & 48 & 51 & 54 & 57 & $7 \quad 60$ \\
\hline 7 & 2 & 6 & 9 & 13 & 16 & 20 & 24 & 27 & 31 & 34 & 38 & 41 & 45 & 49 & 52 & 56 & 59 & 63 & 66 & 670 \\
\hline 8 & 2 & 7 & 11 & 15 & 19 & 23 & 27 & 31 & 35 & 39 & 43 & 47 & 51 & 56 & 60 & 64 & 68 & 72 & 76 & 80 \\
\hline 9 & 3 & 7 & 12 & 17 & 21 & 26 & 30 & 35 & 39 & 44 & 49 & 53 & 57 & 62 & 67 & 72 & 76 & 81 & 85 & 590 \\
\hline 10 & 3 & 8 & 13 & 18 & 23 & 29 & 34 & 39 & 44 & 49 & 54 & 59 & 64 & 69 & 74 & 80 & 85 & 90 & 95 & 100 \\
\hline
\end{tabular}




\section{APPENDIX F \\ Evaluation of the Woody \\ Vegetation Condition (column 17)}

The woody vegetation condition refers to the moisture content of the foliage and small twigs of woody perennial plants (reproduction of either conifer or broadleaf tree species, and shrub or brush species, evergreen or deciduous). Note that it does not refer to herbaceous fuels which grow from the base or from seed each year, such as grasses, forbs, and ferns. (These fuels are considered by the system through the herbaceous vegetation condition.)

The evaluation is necessary only for fuel models $B$ and $F$. Enter a code 5, 7, or 9 in column 17 of the 10-Day Fire Danger and Weather Record Form if these models are being used, otherwise leave blank. Record notes of drought observations in the Remarks section of the record form. The unit fire control officer is responsible for making this evaluation.

Three general levels of moisture in living woody plants are considered in the NFDR System.

\section{Rapid Growth Stage}

Code 9.-In the early part of the growing season, the rapid growth of new leaves, needles, and twigs indicates a high moisture content throughout the plant. The new growth is usually light green in color and succulent in appearance.

\section{Slow Growth or Maturing Stage}

Code 7.-After the initial period of rapid growth, growth continues but at a much re- duced rate. Leaves and needles are fully developed and are much darker. Twigs are still soft and generally of a lighter color than last year's growth. This stage will normally persist until fall when the deciduous species lose their leaves. In milder climates, evergreen species will normally remain in the slow growth stage through the winter season.

\section{Severe Drought}

Code 5.-Drought during any season is hard to detect in its incipient stages, especially in evergreen species. Deficiency of rainfall will warn of impending drought, but cannot pinpoint the occurrence of moisture stress in the living fuels.

Severe drought can occur during any season, but is not encountered every year. During what would normally be the rapid growth stage, symptoms may be a failure of buds to break and new leaves to appear. New growth, if it does emerge, may soon wilt.

During the slow growth stage, drought symptoms in evergreen species will not be evident; however, there are usually enough deciduous species associated with the evergreens to give some indication of moisture stress. In the evergreen brush, premature or excessive leaf fall is about the only indicator, and it only occurs under extreme drought conditions. In deciduous species, leaves wilt, exhibit tipburn, turn brown, or fall off. In extreme cases, branches or the entire plant may die.

\section{APPENDIX G \\ Estimation of the Maximum and Minimum Relative Humidities (columns 27 and 28)}

If your station is equipped with a properly adjusted and maintained hygrothermograph, the maximum and minimum $\mathrm{RH}$ for the 24-hour period ending at your Basic Observation Time is readily determined from the trace. If only the wet-dry bulb and maximum-minimum thermometers are available the following procedures apply:

\section{24-Hour Maximum Relative Humidity}

a. If frost or dew was observed on natural materials such as vegetation (not on glass or metal) or if precipitation or fog was observed during the preceding 24 hours, assume the maximum RH to be 100 percent. Record in column 27. b. If no frost, dew, precipitation, or fog was observed, read the 24-hour maximum $\mathrm{RH}$ from the accompanying table at the intersection of the row indexed by the 24 -hour minimum temperature (column 26) and the column indexed by the dew point at today's Basic Observation Time (column 5). Record in column 27.

2. 24-Hour Minimum Relative Humidity

From the accompanying table, read the 24hour minimum $\mathrm{RH}$ at the intersection of the row indexed by the 24-hour maximum temperature (column 25) and the column indexed by the dewpoint at today's Basic Observation Time (column 5). Record in column 28. 


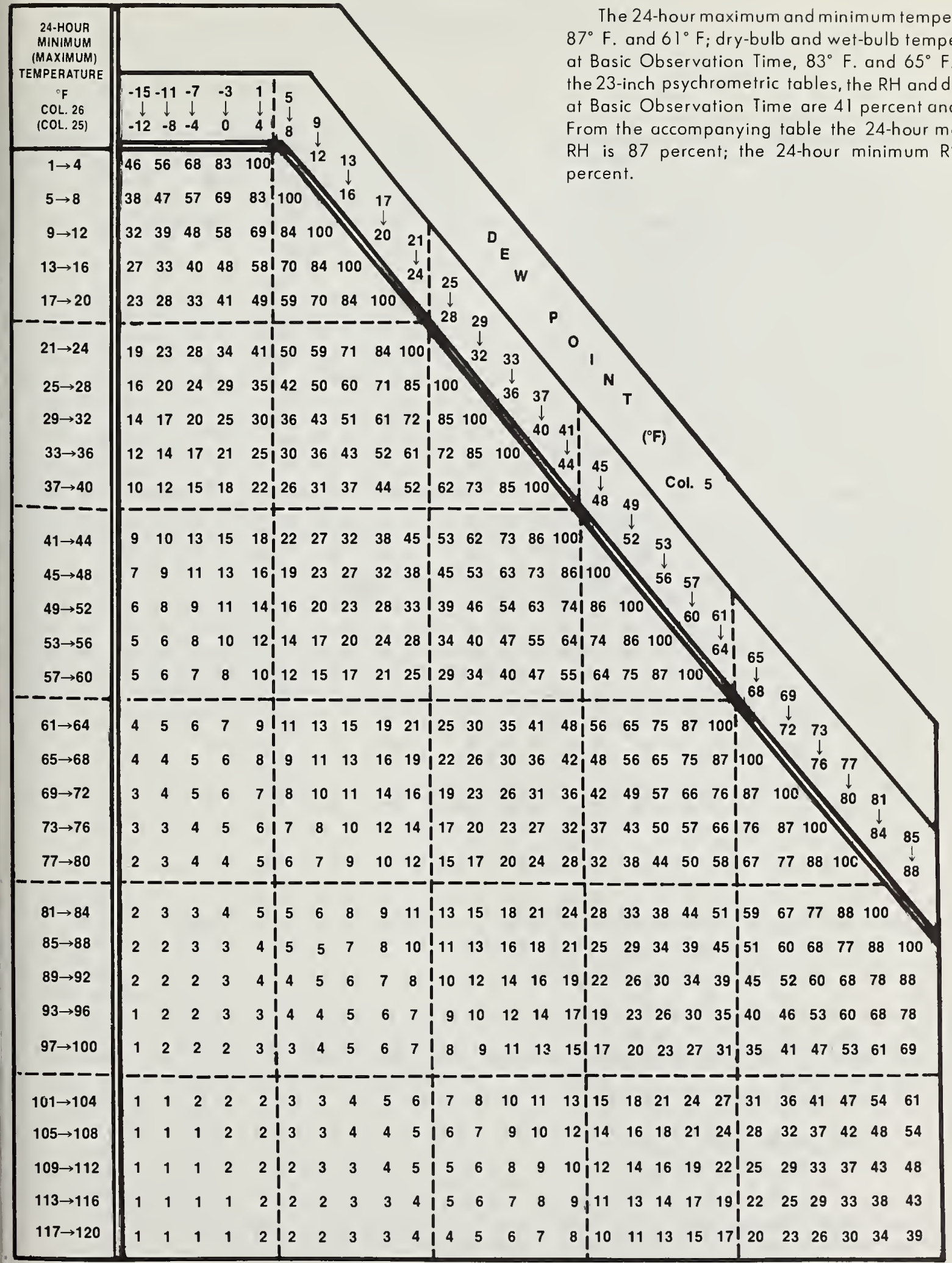




\section{APPENDIX H \\ Estimation of the 10-Hour Timelag \\ Fuel Moisture (column 19)}

For those organizations that do not choose to use the half-inch ponderosa pine fuel sticks for determining the 10-Hr. TL FM, the following alternate procedure must be used. The format of part $A$ of the accompanying table is the same as the format of the table used to determine the 1-Hr. TL FM. The procedure, then, is the same; enter the dry-bulb temperature at the left of the table in the column designated by the appropriate state of weather code. At the intersection of this row and the column indexed by the $\mathrm{RH}$ is the $10-\mathrm{Hr}$. TL FM.

If rain has occurred during the preceding 24 hours, part B must be used, and the results added to those obtained from part $A$. If the total exceeds 25, record $25+$ in column 19 of the WS Form D-9a.

In order to use part $B$, the duration of rainfall and the time that the rainfall occurred must be known. If the rain fell during the 16-hour period immediately after Basic Observation Time yesterday, use the top row of the table for the adjustment; if it fell during the 8 hours prior to Basic Observation Time today, use the bottom row.

If rain occurred during both periods, adjustments corresponding to the duration of the rainfall in each period should be determined, summed, and added to the results from part $\mathrm{A}$.

If it is raining at Basic Observation Time, record $25+$ for the $10-\mathrm{Hr}$. TL $\mathrm{FM}$.

\section{Exomple}

Bosic Observation Time, 1400 LST; temperoture ond humidity, $86^{\circ} \mathrm{F}$. and 24 percent; stote of weother, I (sunny). Rain began at 3:00 o.m. LST (0300) ond ended of 8:00 a.m. LST (0800).

From port $A$, the $10-\mathrm{Hr}$. TL FM uncorrected for precipitation is 5 percent. From port $B$, of the 5 hours of rainfall, 3 fell in the first period resulting in a correction of 7 percent ond 2 in the second period resulting in o correction of 15 percent. The totol correction for precipitotion then is 7 plus 15 or 22 percent. Adding 22 to the uncorrected value from port A gives a $10-\mathrm{Hr}$. TL FM of 27 percent; record $25+$ in column 19.

The importont thing in determining how the correction for precipitation is calculated is the hour of chonge. For instance, if the Basic Observotion Time is 1300 , then the observer is interested in whether the roin fell before 0500 or after 0500; for a Basic Observotion Time of 1400, 0600 is the cut off. 
PART A

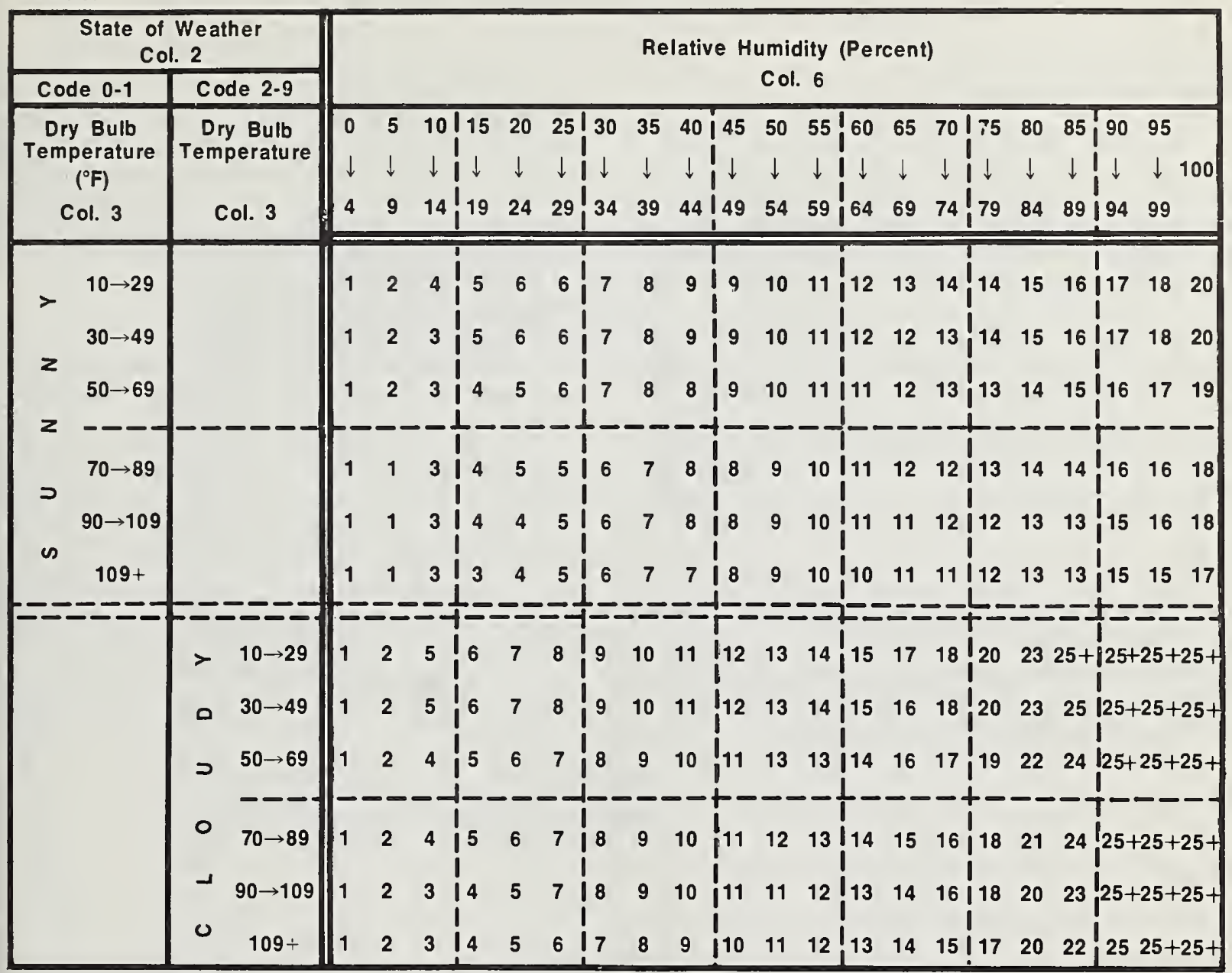

PART B

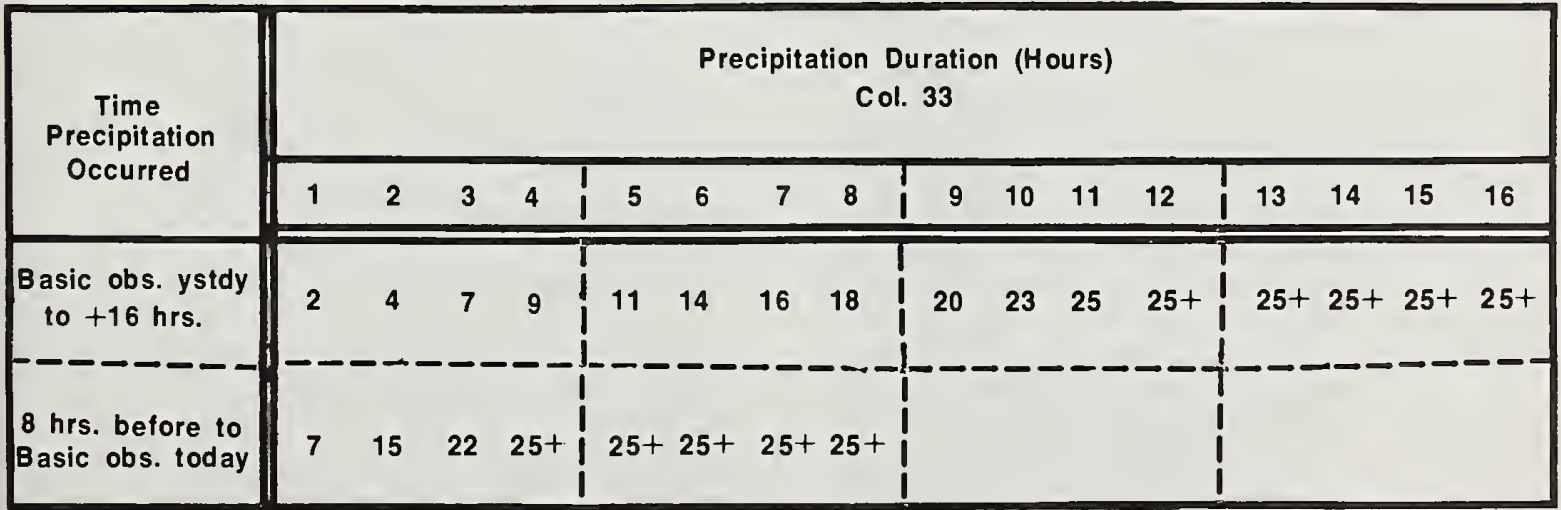




\section{APPENDIX I}

\section{One-Half Inch Fuel Moisture Sticks}

\section{Handling and Exposure}

The fuel moisture stick requires little maintenance, but should be replaced at least every 3 months. If the sticks are damaged, become noticeably discolored, or begin to check before 3 months have elapsed, they should be replaced. New sticks must be exposed for at least 5 days before accurate readings can be obtained.

The sticks should not be handled with bare hands because this will eventually leave a film of oil on the wood surface that would change the moisture response characteristics. A glove, cloth, paper, or tongs should be used in handling the sticks. If the sticks are splattered with mud, allow the mud to dry and brush off the dirt; be careful not to rub it into the wood.

The sticks should be exposed 10 inches above the ground on a wire rack. The rack should be located in the southern part of the instrument enclosure where it will not be shaded. The sticks should be oriented north-south, with the hook end to the north, brads down.
The bed under the sticks should prevent mud from being spattered on the sticks when it rains, and provide a standard reflecting surface. The bed can be constructed of natural litter or burlap, and should be kept free of grass, weeds, or other green material. Do not use gravel, plastic or roofing material.

\section{Scales and Weighing}

If commercial fuel moisture indicator scales are used, follow the instructions accompanying the scales for installation and use.

A less expensive alternative is a triplebeam balance of at least 200 grams capacity which can be read accurately to 0.5 gram.

After determining the weight of the fuel moisture sticks in grams, subtract 100 and the remainder is the moisture content-the value to be entered in column 19 of the 10-Day Fire Danger and Weather Record Form.

If it is raining at Basic Observation Time, do not disturb the sticks. Record $25+$ for the 10-Hr. TL FM.

\section{APPENDIX J}

10-Day Fire Danger and Weather Record

(WS Form D-9a)

The National Weather Service will print and distribute a form to be used with the NFDR System. It follows closely the format of the widely used WB Form D-9 (formerly the WB Form 612-17) which it will replace as the 1964 version of the NFDR System is phased out. The new form is designated the WS Form D-9a (fig. 9).

The D-9a will serve both as a recording form for the fire-danger observations and as a worksheet for those users who must do the calculations by hand. Even for those who have access to computers, it is recommended that the D-9a be used as a means for recording the basic observational data for permanent file and eventually for transfer to punch cards.

Following are the instructions as they appear on the cover of each tablet of forms, and suggested punch card format.

Instructions for Use of the WS Form D-9a

The form instructions are in two sections; the first deals with such general subjects as what to do with the completed forms, rounding of entries, and what to do when it is raining. The second section is more specific and deals with the entries in each column of the form; this is where coding instructions for state of weather, precipitation kind, etc., are found. 


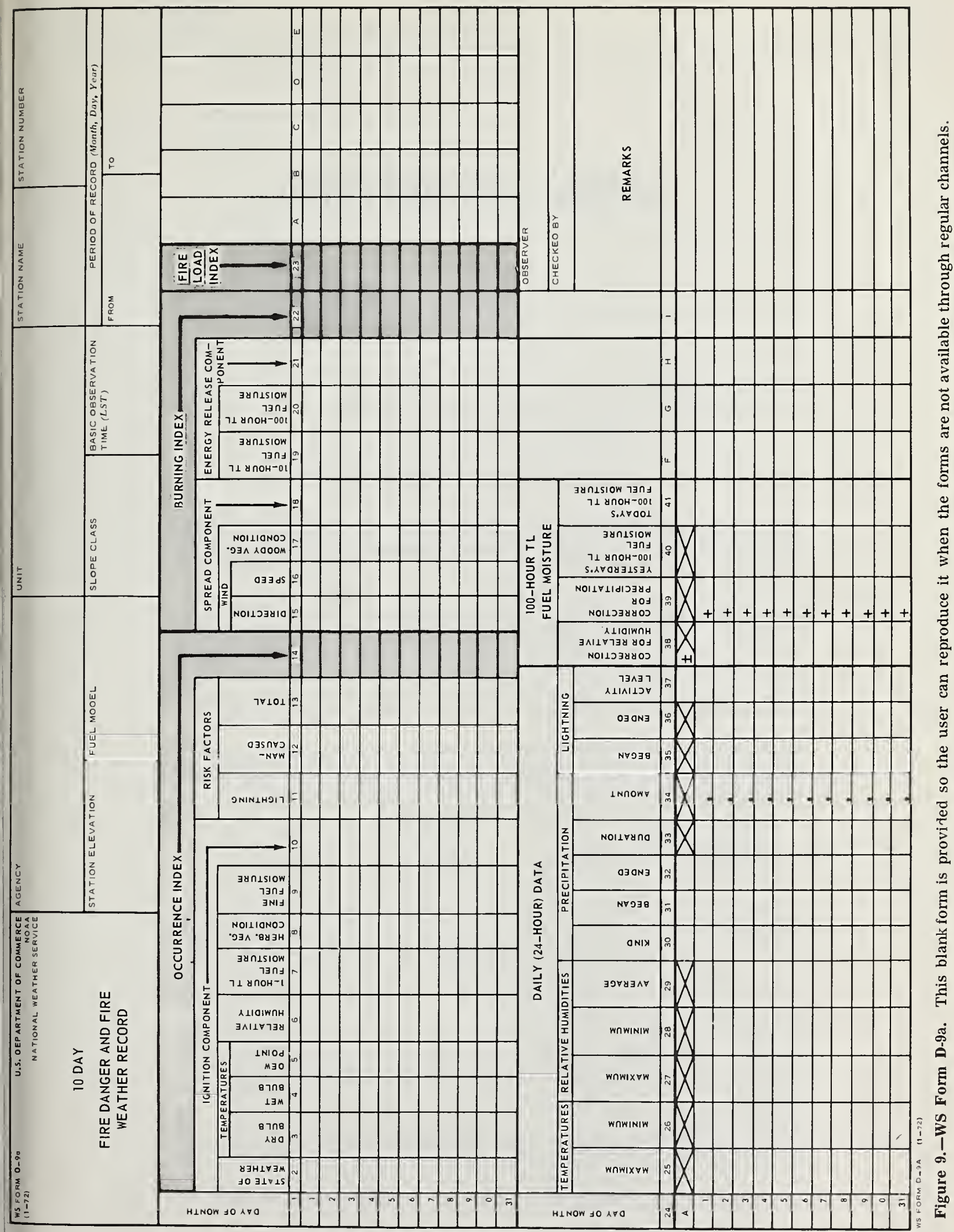




\section{GENERAL INSTRUCTIONS}

The WS Porm D-9a is designed to give uniformity to recordings of fire-weather and fire-danger rating data. Objectives are:

1. To provide a means for recording weather and fuels data necessary for calculation of fire-danger rating values.

2. To facilitate computation of the fire-danger rating values.

3. To provide a means for recording selected climatological information.

The time of BASIC observation will be established by fire control officials in consultation with your National Weather Service fire-weather forecaster. Once the BASIC observation time is established, it should not be changed; for example, if the BASIC observation is established at 1300 local standard time (LST), then it should be taken at 1400 whenever daylight saving time (DST) is observed.

The WS Form D-9a will be completed in duplicate, however, more or fewer copies may be required by your agency. Use fresh carbon paper and a hard pencil ( $23 / 4,3$, or $2 \mathrm{H}$ ) with a sharp but rounded point. Please DO NOT use a ballpoint pen or typewriter. Firies must be neat and legible. On the 1st, 11th, and 21 st days of each month, send the forms for the preceding ten days as your agency directs.

Questions conceming instructions, observations, or use of this form should be addressed to your fire-weather forecaster.

RECORDING READINGS FROM INSTRUMFNTS: ROONDING OF ENTRIES - In reading thermometers and other instruments, values will seldom fall exactly on a graduation. If the value is halfway or more than halfway between two graduations, record the next highest value; if less than halfway, record the lower value. Example:

Thermometer reads $82.5 \mathrm{deg}$.

Rain measures .055 in.

$10 \mathrm{~min}$. average wind is $2.5 \mathrm{mph}$

Fuel stick moisture content is $12.4 \%$

Average relative humidity is $42.5 \%$
Recoru 83

Record .06

Record 3

Record 12

Record 43

WHEN FUELS ARE WET OR COVERED WITH ICE OR SNOW - If it is raining or if it has rained enough at the station to thoroughly wet the surfaces of the fuels and the fuels are still wet at BASIC observation time, or if the fuels in the rating area are covered with ice or snow (regardless of whether the ice or snow is at the precise location of the fire-danger station), record 25+ for the "l-hour" and "l0-hour Timelag Fuel Moistures" (Cols. 7 and 19), zero (0) for the "Ignition", "Spread", and "Energy Release Components" (cols. 10, 18, and 21), and zero (0) for the "Occurrence", "Burning" and "Fire Load Indexes" (Cols. 14, 22, and 23). Treat hail as rain. Make an appropriate explanation in "Remarks".

START ING THE WS FORM D-9a - Pill in all heading spaces to ideniffy and locate your station; the name of your forest, district (BIM), county, etc., should be entered under "Unit". The "Station Number" will be provided by the fire-weather forecaster. The "Fuel Model" and "Slope Class" applicable to the rating area will be supplied by your local fire control officer. Using the 24 -hour clock, enter the "Basic Observation Time" in local standard time (LST) EVEN WHEN DAYIGHT SAVINGS TIME IS BETNG OBSERVED.

This form is a 10-day record to cover the period(s) 1-10, 11-20, and 21-end of month. Make the appropriate "Period of Record" entry. NEVER ENTER DATA FROM MORE THAN ONE OF THESE PERIODS ON THE SAME SHEET. LEAVE BLANK THOSE LINES FOR DAYS WHEN OBSERVATIONS ARE NOT TAKEN. In ColumnS $30,31,32,37$, and 41 on line A, copy the corresponding entries for the last day from the form just completed. AT THE BEGINNING OF THE SEASON, AN INITIAL VALUE OF 35 PERCENT CAN BE ASSUMEN FOR "YESTERDAY'S 100-HOUR TIMEIAG FUEL MOISTURE, (Col. 40 ). 
1 Day of the Month. In the first 10 days of the month (first decade) change the zero to 10. In the second decade insert figures so days will read 11 to 20 , and in the third decade, 21 to 30 . Line 31 is used only in months having 31 days.

State of Weather. Record highest applicable code number describing the weather at BASIC observation time from the table below:

Code

\section{State of Weather}

0 Clear (less than $1 / 10$ th of sky cloud covered).

Scattered clouds (1/10th to $5 / 10$ ths cloud covered).

Broken clouds (6/10ths to $9 / 10$ ths cloud covered).

Overcast (more than $9 / 10$ ths of sky cloud covered).

Foggy.

Drizzling (precipitation of numerous fine droplets; in some areas referred to as

"misting").

6 Raining.

7 Snowing or sleeting

8 Showering (showers in sight or occurring at station).

9 Thunderstorm in progress (lightning seen or thunder heard). At lookout stations and others having unrestricted visibility, record thunderstorm in progress only when activity is not more than 30 miles away.

$3 \& 4 \quad$ Dry and Wet Bulb Temperatures. Read thermometers to nearest whole degree.

5 \& 6 Dew Point and Relative Humidity. Determine from National Weather Service psychronetric tables, Series TA No. $454-0-1$ (A, B, C, D, or E, as appropriate for your elevation). Use a minus sign to indicate temperatures below zero.

7 1-Hour Timelag Fuel Moisture Content. Compute using the appropriate NFDR table.

8 Herbaceous Vegetation Condition. This entry will be supplied by your local fire control of ficer in accordance with NFDR System Instructions.

9 \& 10 Fine Fuel Moisture \& Ignition Component. Compute using the appropriate NFDR tables.

11, 12, Lightning Risk, Man-Caused Risk, Total Risk. These values will be supplied by the

\& 13 fire-weather forecaster and the local fire control officer in accordance with NFDR System Instructions.

14 Occurrence Index. Compute using the appropriate NFDR table.

15 Wind Direction. Enter the direction from which wind is blowing. Make entry using following code: NE, 1 ; E, 2; SE, 3; S, 4; SW, 5; W, 6; NW, 7; N, 8; Calm, 0 .

16 Wind Speed. Enter the 10-minute average speed to nearest whole M.P.H.

17 Woody Vegetation Condition. If required by your fuel model, this entry will be supplied by your local fire control officer in accordance with the NFDR Systern Instructions. model.

19 10-Hour Timelag Fuel Moisture. Determine to the nearest whole percent by weighing

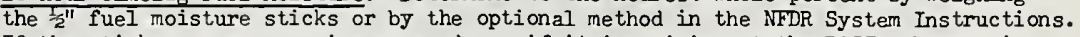
If the sticks are snow or ice covered, or if it is raining at the BASIC observation time, do not disturb, record at $25^{+}$.

20 100-Hour Timelag Ruel Moisture. Record the same value as found in Col. 41 if this calculation is required for your fuel model.

21 \& 22 Energy Release Component and Burning Index. Compute using the NFDR tables which are appropriate for your fuel model.

23 Fire Load Index. Compute using the appropriate NFDR table.

A - H These columns may be used for supplemental data, predictions, etc.

DAILY (24-Hour) DATA

Data in Cols. 25 through 29,33, and 34 cover the period from BASIC observation time yesterday to BASIC observation time today. Entries in Cols. 30, 31, 32, 35, 36, and 37 cover the period from 0001 to 2400 LST of the date of occurrence. (See example in Col. 34 instructions).

24

Day of the Month. See Col. 1 instructions.

$25 \& 26$ Temperatures, Maximum and Minimum. Record to the nearest whole degree. The maximum temperature (read today) cannot be lower than the dry bulb temperature at observation time yesterday or today. Your minimum temperature (read today) cannot be higher than the dry bulb temperature at observation time yesterday or today.

27 \& 28 Humidity, Maximum and Minimum*. If recording instrumentation is not available, determine in accordance with the NFDR System Instructions. 


\begin{tabular}{|c|c|c|}
\hline No precipitation & 7 & Snow or sleet \\
\hline Drizzle & 8 & Showers \\
\hline Rain & 9 & Hail \\
\hline
\end{tabular}

Note: If "zero" is entered in Col. 30, leave Cols. 31, 32, 33, and 34 blank.

31 \& 32 Time Precipitation Began and Time Ended nearest hour on the date line of occurrence. Use "Remarks" space for indicating more than one period of precipitation. If beginnings and endings are unknown, estimate and note in "Remarks". Use the entry "cont" to denote precipitation continuing past midnight.

Precipitation Duration*. This value should represent the tatal time that fuels were exposed to liquid water ( $r a i n$ ) since BASIC observation time yesterday. If several periods of rainfall occurred this value should represent the cumulative total of the durations of all occurrences rounded to the next highest full hour. If it is raining at the time of BASIC observation, the duration of rainfall up to that time is recorded; the remainder of the storm will be accounted for the following day, if, and only if, the total duration of the storm for both days exceeds 1 hour. Rains lasting less than Tr hour and producing only a trace amount should be disregarded. If more than a trace is received, a minimum of 1 hour should be entered in Col. 33. Hail and snow are treated as rain.

24-Hour Precipitation Amount*. Always empty the gage after taking the measurement. If no precipitation occurs, record a zero. If less than .005 inch occurs, record as a trace (T). .005 inch will be recorded as .01 inch. Melt snow and hail and measure as rain.

Examples:

$$
\text { Measured at BASIC }
$$

\begin{tabular}{|c|c|c|c|}
\hline $\begin{array}{ll}\text { July } & 2 \\
\text { July } & 2 \\
\text { July } & 2\end{array}$ & $\begin{array}{l}8: 30 \mathrm{a} \cdot \mathrm{m} . \\
\text { 3:00 p.m. } \\
8: 30 \mathrm{p} . \mathrm{m} .\end{array}$ & $\begin{array}{r}12: 15 \mathrm{p} \cdot \mathrm{m} . \\
\text { 5:30 p.m. } \\
\text { continued }\end{array}$ & .15 \\
\hline $2 y 3$ & continued & $2: 30 \mathrm{a} . \mathrm{m}$. & \\
\hline
\end{tabular}

Recording the above situation would be as follows:

\begin{tabular}{lcccccc}
\hline Date Kind & $\begin{array}{l}\text { Time } \\
\text { Began }\end{array}$ & $\begin{array}{l}\text { Time } \\
\text { Ended }\end{array}$ & Duration Amount & Remarks \\
\hline 2 & 6 & 08 & 12 & 4 & .15 & $\begin{array}{c}\text { Rain 15-18 \& } \\
21-\text { cont. }\end{array}$ \\
3 & 6 & cont. & 03 & 9 & .45 & \\
\hline
\end{tabular}

35 \& 36 Time Lightning Began and Time Ended. Use 24-hour clock, ma!ring entries to the nearest hour on the date line of occurrence. Record when lightning is first seen or thunder heard. At lookout stations and others having unrestricted visibility, consider only thunderstorns not more than 30 miles away.

37 Lightning Activity Level. Complete in accordance with NFDR System Instructions.

38 \& 39 100-Hour Timelag Fuel Moisture. (For use with Fuel Models B, D, G, H, and I.) Use the Correction for Relative Humidity table for computing the entry in Col. 38 ; record the appropriate arithmetic sign to the left of the vertical dashed line. If it has rained continuously for the past 24 hours, record a zero (0) in Col. 38 . If precipitation of duration less than 24 -hours has occurred, compute an entry for Col. 39 using the Correction for Precipitation table. If no rain has been experienced, record a zero (0) in Col. 39. The value entered in Col. 40 should be the same as the entry in Col. 41 for the previous day. Col. 41 is the algebraic sum of the entries in Cols. 38,39 , and 40 for the current day. +'s are already entered in Col. 39 because precipitation always makes a positive contribution to the net change in fuel moisture.

REMARKS Use remarks space for entries of more than one period of precipitation or thunderstorms; and for weather information which is not otherwise recorded such as "rain changed to snow". Also, explain entries or points not made clear in a column entry, referring to them by date and column. For example: on the 9 th at 1330, wind shifts abruptly from $5 W$ at $15 \mathrm{mph}$ to $\mathrm{NW}$ at $25 \mathrm{mph}$. Under remarks, enter "Col. 15--at 1330 wind shifted from SW--15 to NW--25". In addition, a note of "fuels wet or snow (or ice) covered" should be made when appropriate. Be sure entries begin on the line corresponding to the date of occurrence. Reasons for missing an observation should also be given. Make all entries as brief as possible.

* If observations for a day are missed, it is very important that these values be estimated using any information available to you. Make an appropriate explanation in "Remarks". 


\section{Punch Card Format for Use With the \\ WS Form D-9a}

The following punch card format has been designed on the assumption that the 10-Day Fire Danger and Weather Record form will be the document from which the key punch operators will work.

Notice that only observed data are punched. The computer will recalculate components and indexes when needed.
If, and only if, the dead fuel moisture contents (1-, 10-, and 100-Hr. TL) are observed are these values to be punched. For instance, only the $10-\mathrm{Hr}$. TL fuel analog is currently available (half-inch fuel moisture sticks). If the 10-Hr. TL FM is evaluated by weighing the sticks, it should be punched; if it is estimated (appendix H) leave card columns 33, 34 , and 35 blank.

\begin{tabular}{|c|c|c|c|c|c|}
\hline \multirow{2}{*}{$\begin{array}{c}\text { Field } \\
\text { no. }\end{array}$} & \multirow[t]{2}{*}{ Heading } & \multicolumn{2}{|c|}{ Columns } & \multirow{2}{*}{$\begin{array}{l}\text { No. } \\
\text { of } \\
\text { cols. }\end{array}$} & \multirow[t]{2}{*}{ Remarks } \\
\hline & & From & to & & \\
\hline & Station Number & 1 & 6 & 6 & Heading \\
\hline & Year & 7 & 8 & 2 & $"$ \\
\hline & Month & 9 & 10 & 2 & $"$ \\
\hline 1 & Day & 11 & 12 & 2 & \\
\hline 2 & State of Weather & & 13 & 1 & \\
\hline 3 & Dry Bulb Temperature & 14 & 16 & 3 & If - , Put - in column 14 \\
\hline 4 & Wet Bulb Temperature & 17 & 19 & 3 & If - , Put - in column 17 \\
\hline 7 & ${ }^{*} \mathrm{I}-\mathrm{Hr} . \mathrm{TLFM}$ & 20 & 22 & 3 & If $25+$, Put -25 in columns 20,21 and 22 \\
\hline 8 & Herb. Veg. Condition & 23 & 24 & 2 & If 100 , Put 99 in columns 23 and 24 \\
\hline 12 & Man Caused Risk & 25 & 27 & 3 & \\
\hline 15 & Wind Direction & & 28 & 1 & 8-PtCompass \\
\hline 16 & Wind Speed & 29 & 31 & 3 & \\
\hline 17 & Woody Veg. Condition & & 32 & 1 & \\
\hline 19 & "10-Hr. TL FM & 33 & 35 & 3 & If $25+$, Put -25 in columns 33,34 and 35 \\
\hline 20 & ${ }^{*} 100-\mathrm{Hr} . \mathrm{TL} F M$ & 36 & 38 & 3 & \\
\hline 25 & 24-Hr. Maximum Temperature & 39 & 41 & 3 & If - , Put - in column 39 \\
\hline 26 & 24-Hr. Minimum Temperature & 42 & 44 & 3 & If - , Put - in column 42 \\
\hline 27 & 24-Hr. Maximum RH & 45 & 47 & 3 & \\
\hline 28 & 24-Hr. Minimum RH & 48 & 50 & 3 & \\
\hline 30 & Precipitation Kind & & 51 & 1 & \\
\hline 33 & Precipitation Duration & 52 & 53 & 2 & During prev. 24 hrs. nearest whole hour \\
\hline 34 & Precipitation Amount & 54 & 57 & 4 & 2 Decimal Places \\
\hline 37 & Lightning Activity Level & 58 & 60 & 3 & \\
\hline
\end{tabular}




\section{APPENDIX K}

\section{Commonly Committed Computational Errors}

As a result of two seasons of field trials, many changes have been made in procedures, table format, and in the record form to make it easier for users to do error-free work. A list of errors commonly made by field personnel has been compiled to help those who will be doing the computations avoid making the same mistakes.

\section{0-Day Fire Danger and Weather Record (WS Form D-9a)}

Headings.-Make sure the station number, slope class, and fuel model entries are complete. The Basic Observation Time should be in local standard time (LST), even when daylight saving time (DST) is in effect.

Column 1.-When observations are not begun on the 1st, 11th, or 21st, make the initial entry on the line which corresponds to the date; that is, if the 25 th, start on the 5th line. -The bottom line, numbered 31 , is used for the 31st day of those months that have 31 days. Do not start a new form and put a 3 opposite the 1 on the first line.

Columns 7, 10, 14, 18, 19, 21, 22, and 23.-If precipitation is occurring at Basic Observation Time, the 1- and 10-Hr. TL FM should be recorded as 25+ and all components and indexes as zero.

Column 8.-Enter the herbaceous vegetation condition without decimals. The number should represent the percent, not the decimal fraction, of the fine fuels which are living.

Column 15.-Code the wind direction according to the instructions. Do not record the actual direction.

Column 29.-Be careful when adding the maximum and minimum relative humidities and dividing by 2 to get the average. Also, when a fraction results from the division, always round up, that is, 24.5 to $25,29.5$ to 30 .

Columns 31, 32, 35, and 36.-The beginning and ending times for precipitation and lightning should be entered in LST on the dateline of occurrence. If it starts on the 4 th and ends on the 5th, show the time of beginning opposite the 4 th and the time of ending opposite the 5th. Remember to record, "cont" under "ended" opposite the 4th and under "began" opposite the 5th to show that the rain continued past midnight.

Column 33.- If it is raining at the Basic Observation Time, the duration on that dateline should be the duration of rainfall up to Basic Observation Time. The duration recorded for the next day will account for the remainder of the storm.

Columns 38-41.-If it is raining at the Basic Observation Time, the $100-\mathrm{Hr}$. TL FM must be computed even though all other fire-danger rating values are zero. This is necessary because the $100-\mathrm{Hr}$. TL FM is cumulative, requiring a carryover value from the previous day. If observations are missed for some reason, the observer must recover this information so the computation can be completed each day.

\section{Tables}

General.-Be sure to use table for the correct fuel model.

- Read numbers from the table carefully. A straight edge or square is very helpful.

Fine Fuel Moisture and the Ignition Component.-Remember that the column used for the temperature on the left side of the table depends on the state-of-weather code. If the code is zero $(0)$ or 1 , use the left-hand column (sunny); if the code is 2 to 9 , use the righthand (cloudy).

Spread Component.-The windspeed is entered from the column corresponding to the assigned slope class. Since the slope class is not changed routinely, blanking out the unneeded columns will eliminate this problem.

Fine Fuel Moisture.--If the herbaceous vegetation condition is less than 5 , the fine fuel moisture is the same as the 1-Hr. TL FM. 


\section{APPENDIX L}

Tables for Operational Use of the NFDR System

Fuel Model A 


\section{COMPUTATIONAL FLOW CHART \\ FUEL MODEL A}

(1)

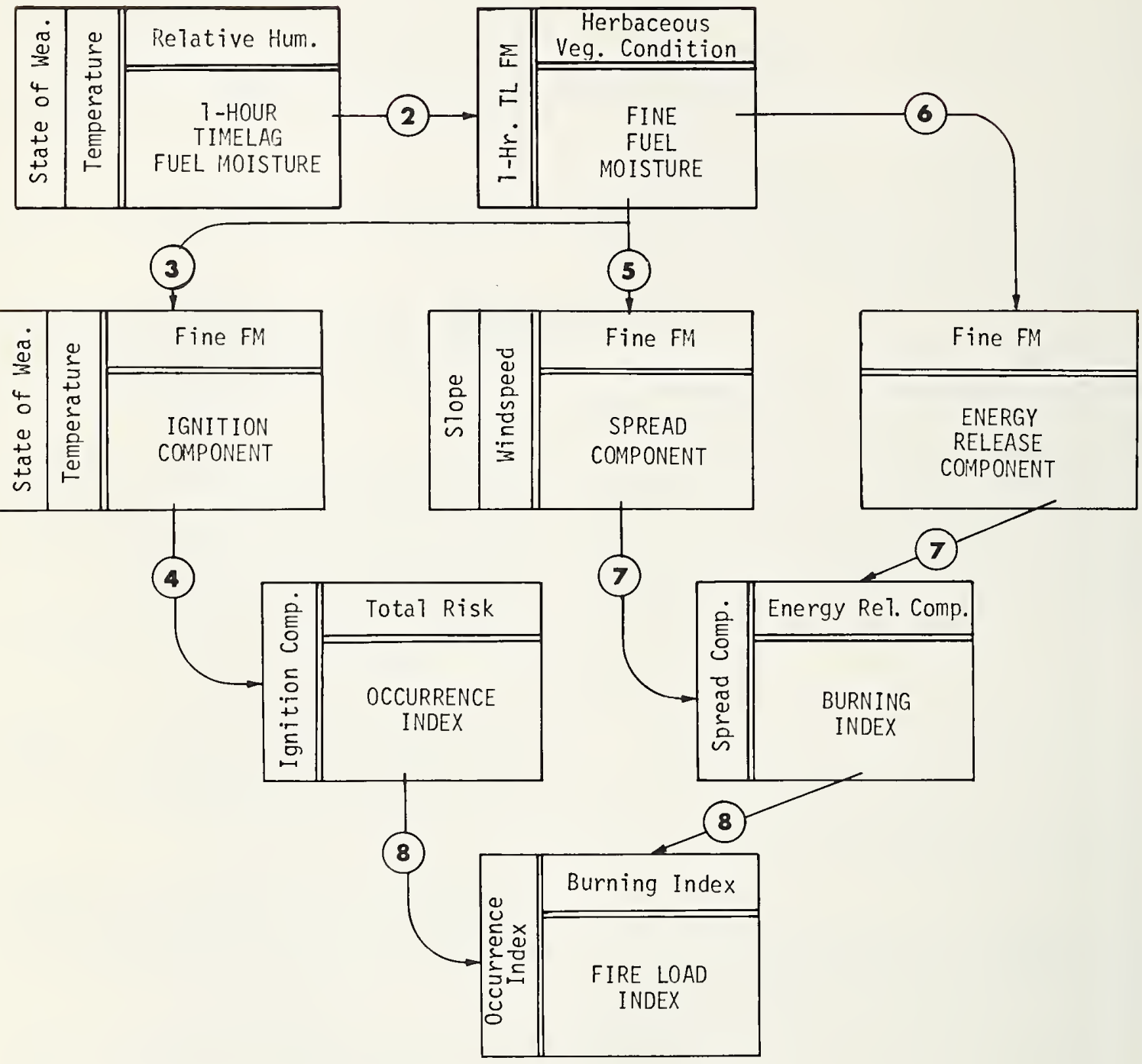




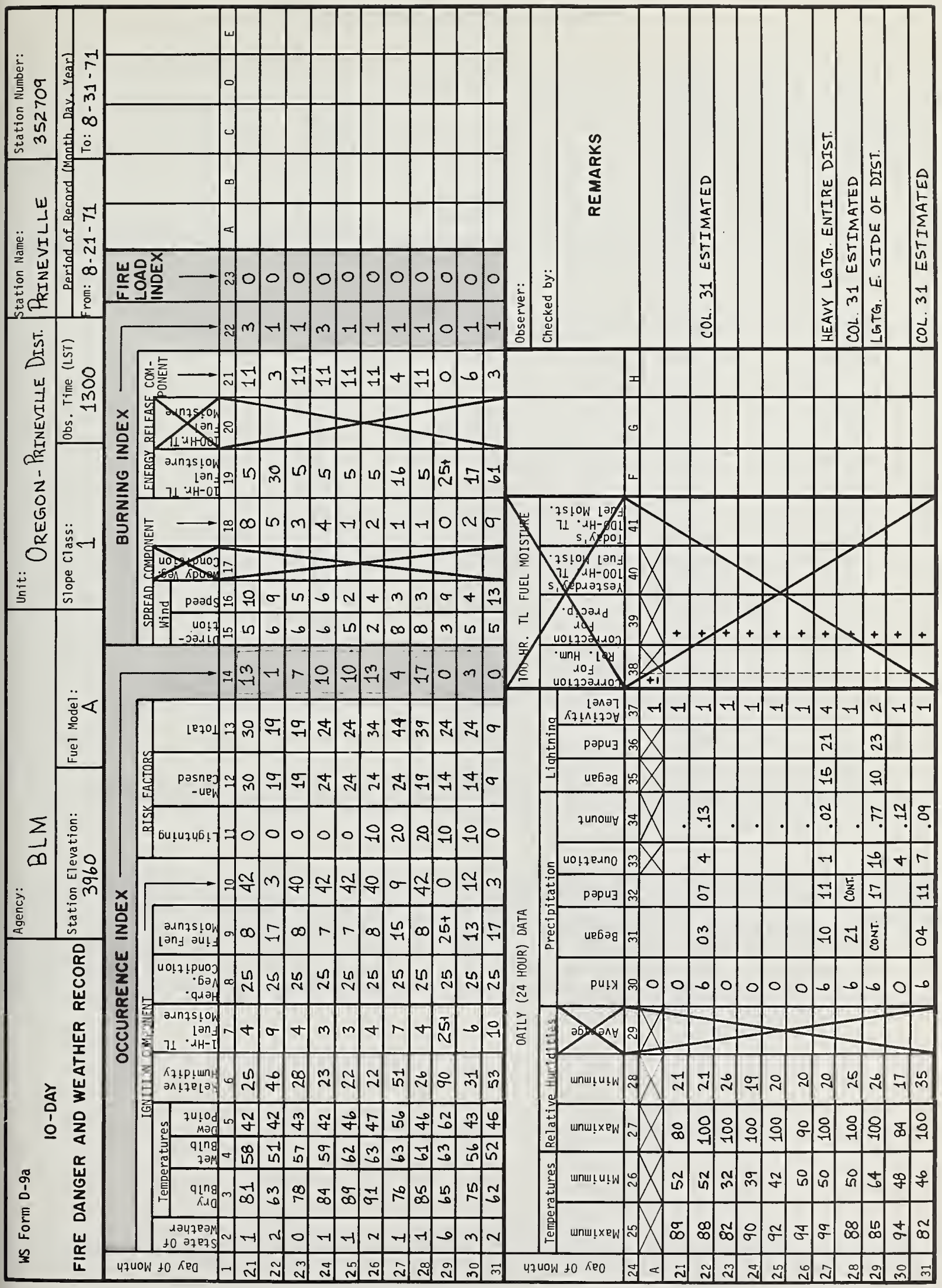




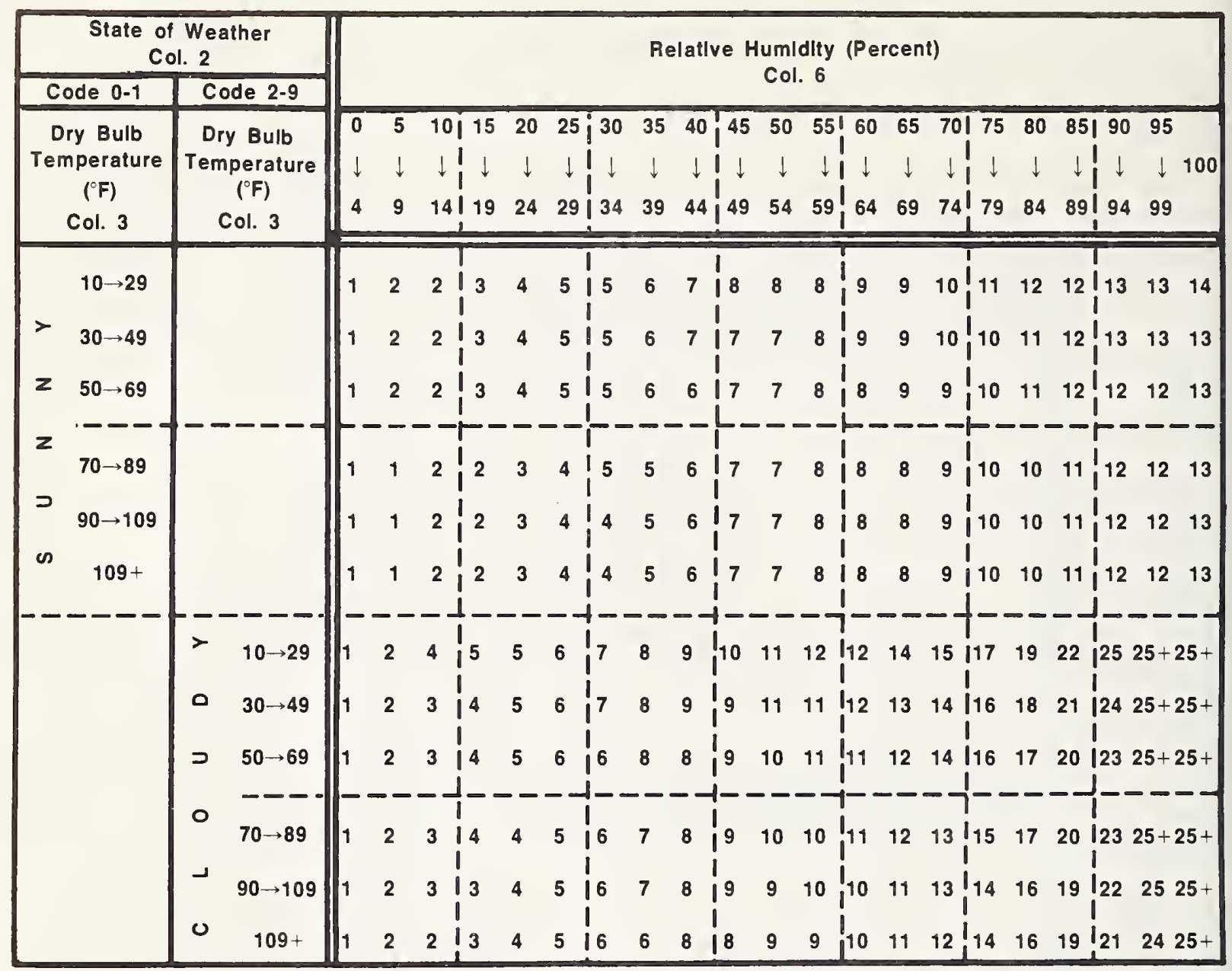

Purpose: To compute the moisture content of dead fuels one-quarter inch and less in diameter.* Procedure: If the state of the weather is coded 2, 3, 4, 8, or 9 (column 2), or if the observation is being taken before 1000 or after 1500 LST, the dry-bulb temperature is entered to the left in that section of the table labeled "cloudy." Otherwise enter the temperature in the section labeled "sunny." Read the 1-Hr. TL FM at the intersection of this row and the column indexed by the appropriate value for relative humidity (column 6); record in column 7 .

* If it is raining (state of weather codes 5, 6, or 7) or there is snow or ice on the ground fuels, record $25+$ in column 7 . 
FINE FUEL MOISTURE (PERCENT)

Col. 9

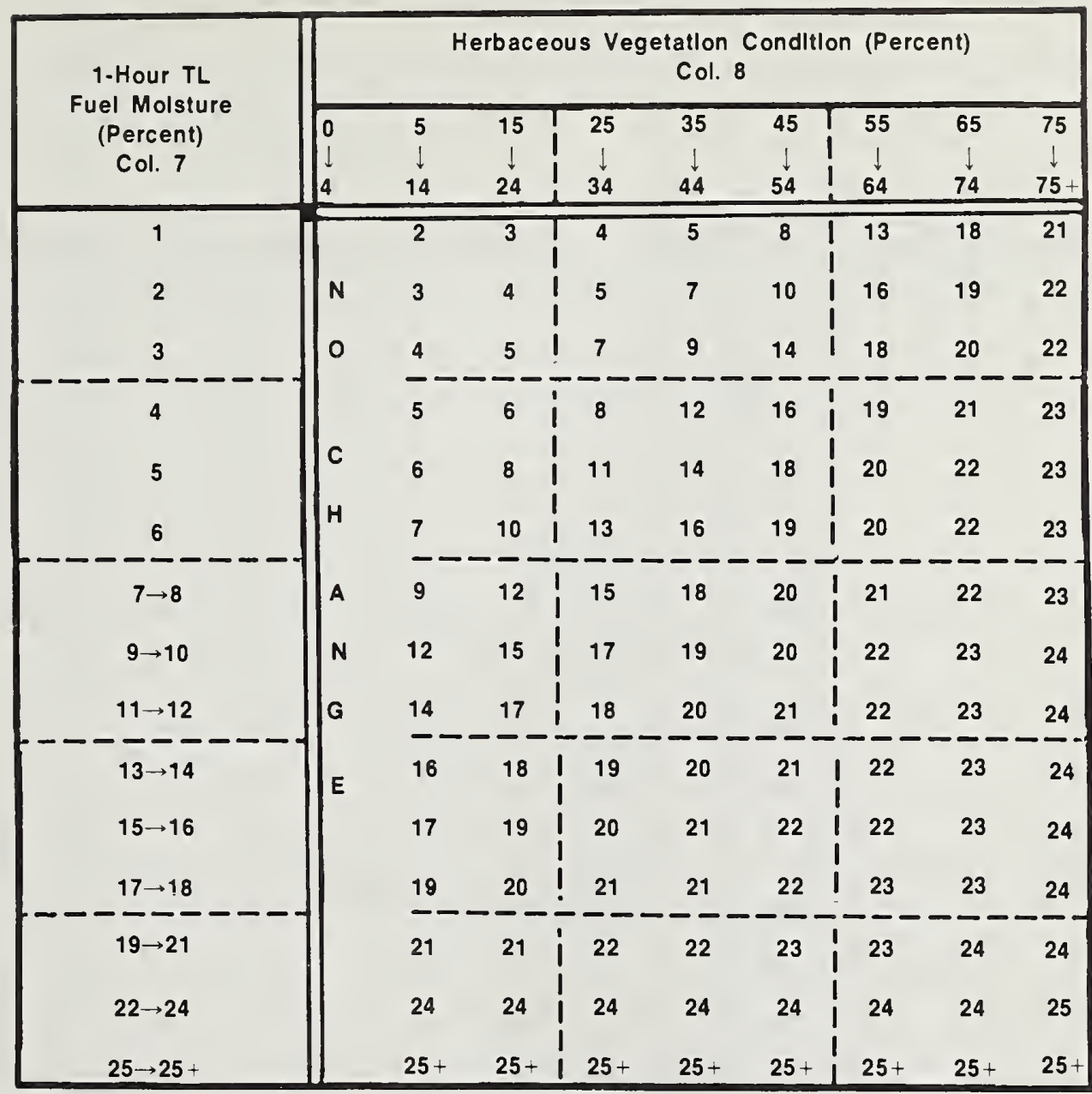

Purpose: To adjust the 1-Hr. TL FM to account for the reduced flammability of the lesser fuels due to the presence of living herbaceous plant material.*

Procedure: Read the FFM at the intersection of the row indexed by the 1-Hr. TI, FM (column 7) and the column indexed by herbaceous vegetation condition (column 8); record in column 9.

* If the herbaceous vegetation condition is 4 or less, enter the value of the 1-Hr. TL FM directly into column 9. 


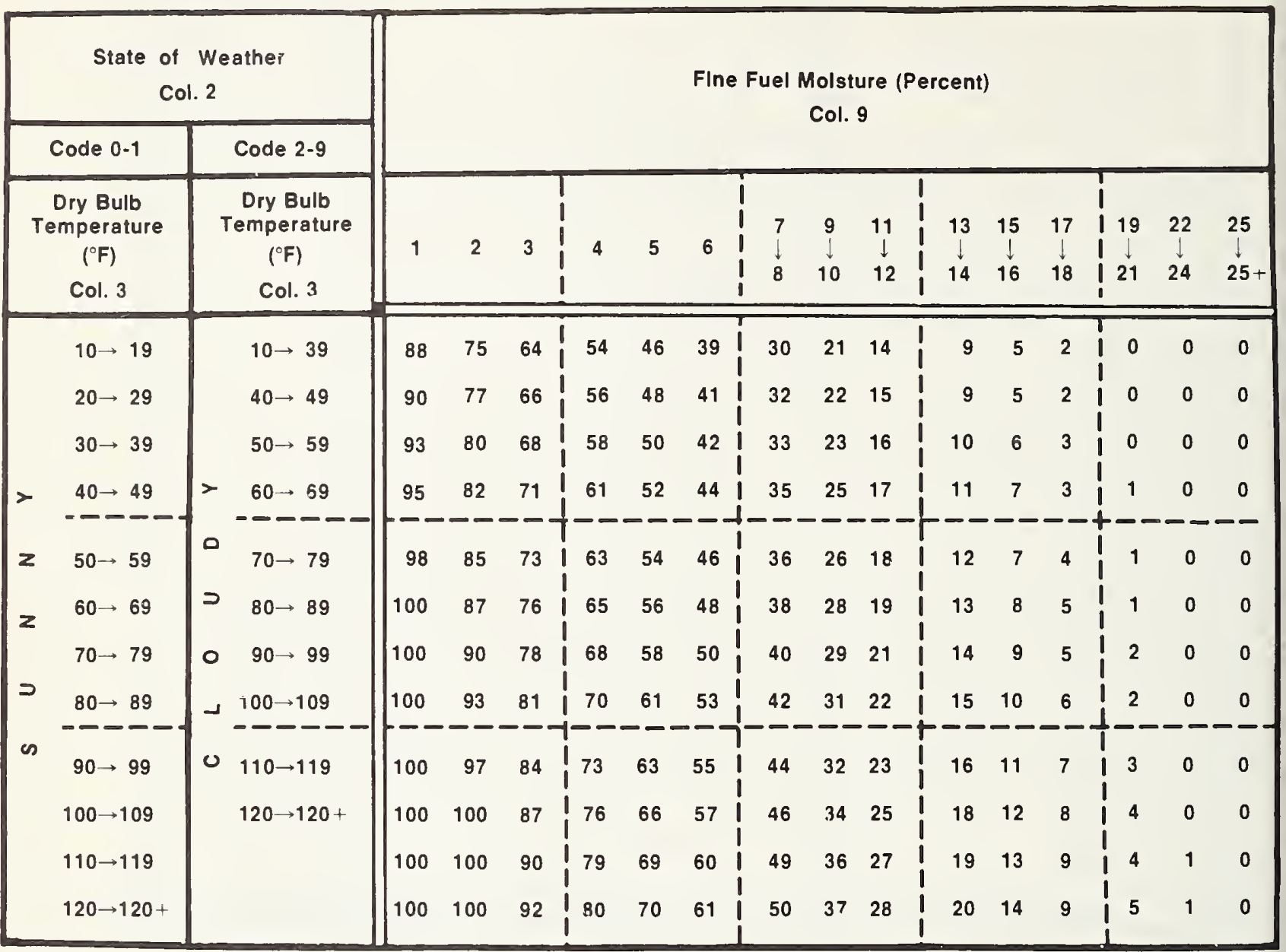

Purpose: To compute a number related to the probability that a fire will result if a firebrand is introduced into the fine fuel complex.*

Procedure: If the state of the weather is coded 2, 3, 4, 8, or 9 (column 2), or if the observation is being taken before 1000 or after 1500 LST, the dry-bulb temperature (column 3) is entered to the left in that section of the table labeled "cloudy." Otherwise, enter the temperature in the section labeled "sunny." Read the IC at the intersection of the column indexed by the FFM (column 9) and the row indexed by the dry-bulb temperature (column 3 ); record in column 10.

* If it is raining (state of the weather code 5,6, or 7) or there is snow or ice on the ground fuels, record a zero (0) in column 10. 


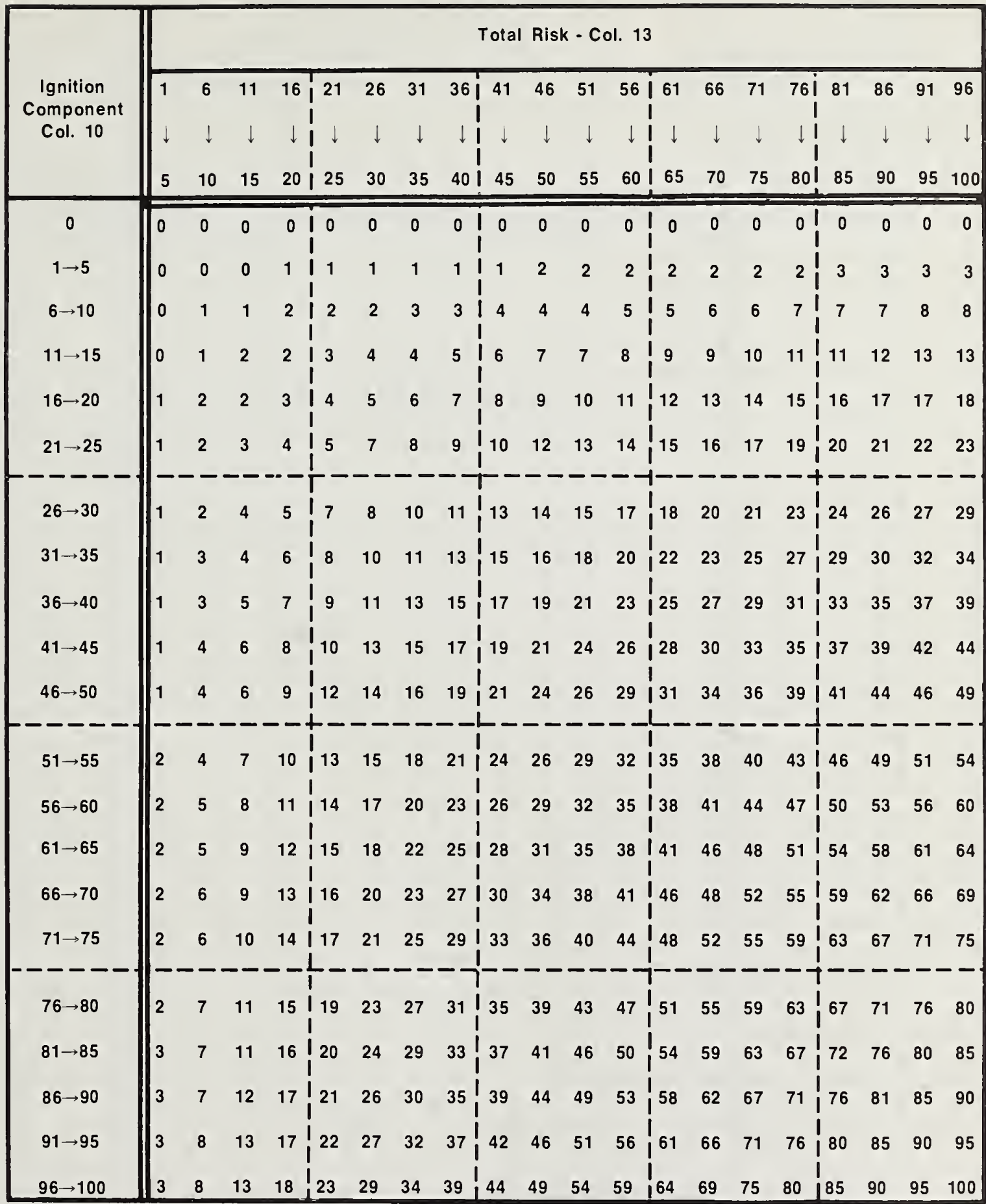

Purpose: To compute a number related to the probable level of fire incidence on the rating area.*

Procedure: At the intersection of the row indexed by the IC (column 10) and the column indexed by total Risk (column 13) is the OI; record in column 14.

* If it is raining (state of weather code 5, 6, or 7) or there is snow or ice on the ground fuels, record a zero (0) in column 14. 
SPREAD COMPONENT - FUEL MODEL A

Col. 18

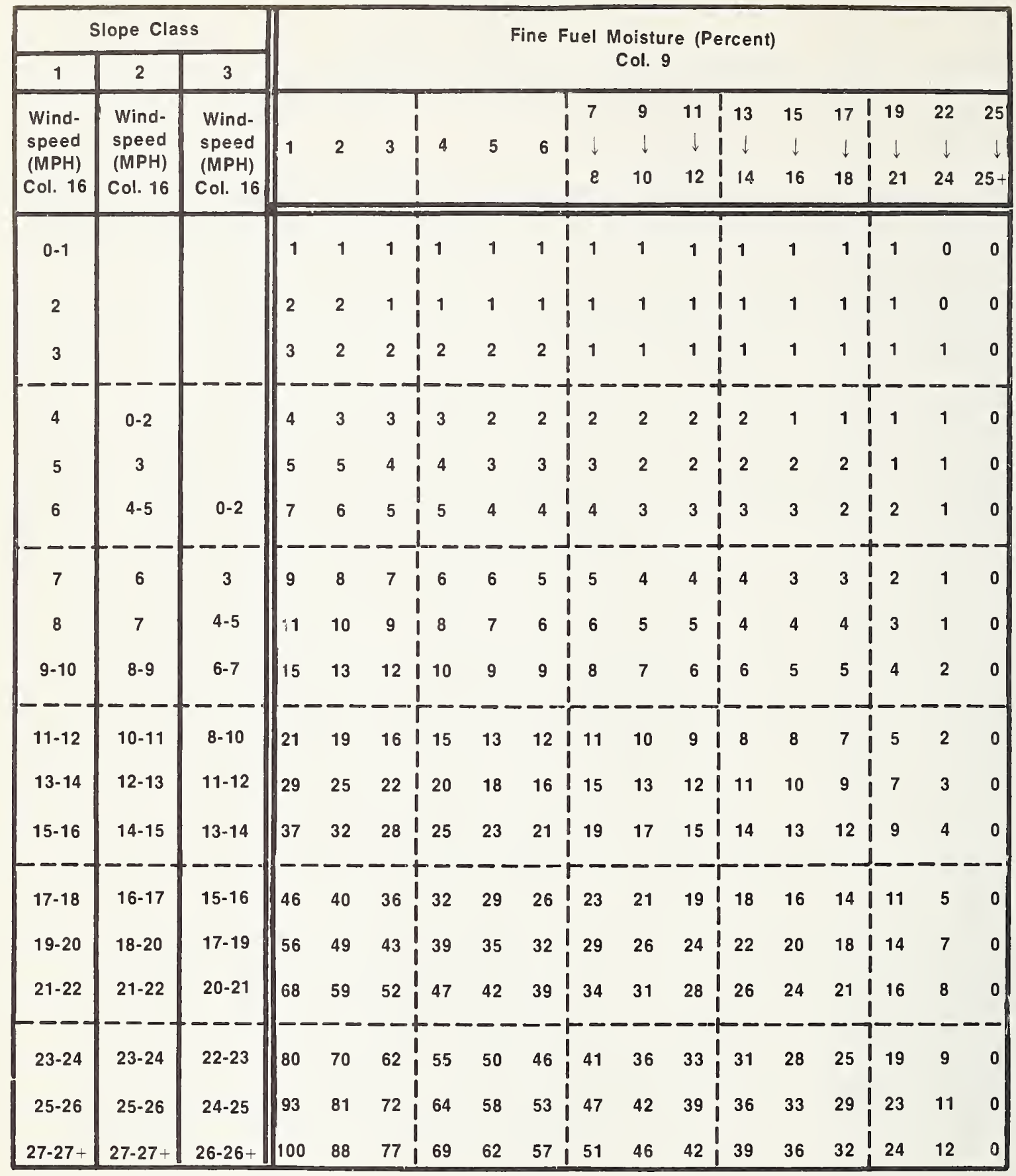

Purpose: To compute a number related to the forward rate of spread of the head of a fire burning in fuels represented by this fuel model.*

Procedure: The windspeed (column 16) is entered into the table from the column headed by the slope class assigned to the rating area. At the intersection of this row and the column indexed by the FFM (column 9) is the SC; record in column 18.

* If it is raining (state of weather code 5, 6, or 7) or there is snow or ice on the ground fuels, record a zero $(0)$ in column 18. 
ENERGY RELEASE COMPONENT - FUEL MODEL A

Col. 21

\begin{tabular}{|c|c|c|c|c|c|c|c|c|c|c|c|c|c|c|}
\hline \multicolumn{15}{|c|}{$\begin{array}{c}\text { Fine Fuel Moisture (Percent) } \\
\text { Col. } 9\end{array}$} \\
\hline 1 & 2 & 3 & 4 & 5 & 6 & $\begin{array}{l}7 \\
\downarrow \\
8\end{array}$ & $\begin{array}{c}9 \\
\downarrow \\
10\end{array}$ & $\begin{array}{c}11 \\
\downarrow \\
12\end{array}$ & $\begin{array}{c}13 \\
\downarrow \\
14\end{array}$ & $\begin{array}{c}15 \\
\downarrow \\
16\end{array}$ & $\begin{array}{c}17 \\
\downarrow \\
18\end{array}$ & $\begin{array}{c}19 \\
\downarrow \\
21\end{array}$ & $\begin{array}{c}22 \\
\downarrow \\
24\end{array}$ & $\begin{array}{r}25 \\
\downarrow \\
25+\end{array}$ \\
\hline 19 & 17 & 16 & 15 & 13 & 12 & 11 & 9 & 7 & 6 & 4 & 3 & 2 & 1 & 0 \\
\hline
\end{tabular}

Purpose: To compute a number related to the rate of combustion at the head of a fire burning in fuels represented by this fuel model.*

Procedure: Read the ERC immediately below the appropriate value of the FFM (column 9); record in column 21 .

* If it is raining (state of weather code 5,6, or 7) or there is snow or ice on the ground fuels, record a zero (0) in column 21. 
BURNING INDEX - FUEL MODEL A

Col. 22

\begin{tabular}{|c|c|c|c|c|c|c|c|c|c|c|c|c|c|c|c|c|c|c|c|c|c|}
\hline \multirow{2}{*}{$\begin{array}{l}\text { Spread } \\
\text { Component } \\
\text { Col. } 18\end{array}$} & \multicolumn{21}{|c|}{$\begin{array}{l}\text { Energy Release Component } \\
\text { Col. } 21\end{array}$} \\
\hline & 0 & 1 & 2 & 3 & 4 & 5 & 6 & 7 & & 8 & 9 & 10 & 11 & 12 & 13 & 14 & 15 & i 16 & 17 & 18 & 19 \\
\hline 0 & 0 & 0 & 0 & 0 & 0 & 0 & 0 & 0 & & 0 & 0 & 0 & 0 & 0 & 0 & 0 & 0 & 10 & 0 & 0 & 0 \\
\hline $1 \rightarrow 3$ & 0 & 0 & 0 & 0 & 1 & 1 & 1 & 1 & & 1 & 1 & 1 & 1 & 1 & 1 & 1 & 1 & $\begin{array}{l}1 \\
1\end{array}$ & 1 & 1 & 1 \\
\hline $4 \rightarrow 9$ & 0 & 1 & 1 & 1 & 2 & 2 & 2 & 2 & & 2 & 2 & 2 & 3 & 3 & 3 & 3 & 3 & $1_{1}^{1} 3$ & 3 & 3 & 3 \\
\hline $10 \rightarrow 15$ & 0 & 1 & 2 & 2 & 2 & 2 & 3 & 3 & & 3 & 3 & 3 & 3 & 4 & 4 & 4 & 4 & 14 & 4 & 4 & 4 \\
\hline--- & - & & & & & & & & & & & & & & - & - & - & -4 & - & -- & - \\
\hline $16 \rightarrow 21$ & 0 & 1 & 2 & 2 & 3 & 3 & 3 & 3 & & 4 & 4 & 4 & 4 & 4 & 4 & 5 & 5 & 5 & 5 & 5 & 5 \\
\hline $22 \rightarrow 27$ & 0 & 2 & 2 & 3 & 3 & 3 & 4 & 4 & & 4 & 4 & 5 & 5 & 5 & 5 & 5 & 5 & 6 & 6 & 6 & 6 \\
\hline $28 \rightarrow 33$ & 0 & 2 & 2 & 3 & 3 & 4 & 4 & 4 & & 5 & 5 & 5 & 5 & 5 & 6 & 6 & 6 & 6 & 6 & 7 & 7 \\
\hline $34 \rightarrow 39$ & 0 & 2 & 3 & 3 & 4 & 4 & 4 & 5 & 1 & 5 & 5 & 5 & 6 & 6 & 6 & 6 & 7 & 7 & 7 & 7 & 7 \\
\hline--- & 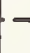 & & & & & & & & & & & & & & & & & - & - & -- & - \\
\hline $40 \rightarrow 45$ & 0 & 2 & 3 & 3 & 4 & 4 & 5 & 5 & & 5 & 6 & 6 & 6 & 6 & 7 & 7 & 7 & 7 & 7 & 8 & 8 \\
\hline $46 \rightarrow 51$ & 0 & 2 & 3 & 4 & 4 & 5 & 5 & 5 & & 6 & 6 & 6 & 7 & 7 & 7 & 7 & 8 & 8 & 8 & 8 & 8 \\
\hline $52 \rightarrow 57$ & 0 & 2 & 3 & 4 & 4 & 5 & 5 & 6 & & 6 & 6 & 7 & 7 & 7 & 7 & 8 & 8 & 8 & 8 & 9 & 9 \\
\hline $58 \rightarrow 63$ & 0 & 2 & 3 & 4 & 5 & 5 & 5 & 6 & & 6 & 7 & 7 & 7 & 8 & 8 & 8 & 8 & 9 & 9 & 9 & 9 \\
\hline--- & & & & & & & & & & & & & & & - & & & $\frac{1}{1}-$ & - & $=-$ & \\
\hline $64 \rightarrow 69$ & 0 & 3 & 3 & 4 & 5 & 5 & 6 & 6 & & 7 & 7 & 7 & 8 & 8 & 8 & 8 & 9 & 9 & 9 & 9 & 10 \\
\hline $70 \rightarrow 75$ & 0 & 3 & 4 & 4 & 5 & 5 & 6 & 6 & & 7 & 7 & 8 & 8 & 8 & 8 & 9 & 9 & 9 & 10 & 10 & 10 \\
\hline $76 \rightarrow 81$ & 0 & 3 & 4 & 4 & 5 & 6 & 6 & 7 & & 7 & 7 & 8 & 8 & 8 & 9 & 9 & 9 & 10 & 10 & 10 & 10 \\
\hline $82 \rightarrow 87$ & 0 & 3 & 4 & 5 & 5 & 6 & 6 & 7 & 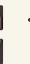 & 7 & 8 & 8 & 8 & 9 & 9 & 9 & 10 & 10 & 10 & 11 & 11 \\
\hline$-\pi-$ & & & & 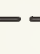 & & & & & & & & . & & & & & & & $=-$ & -- & \\
\hline $88 \rightarrow 92$ & 0 & 3 & 4 & 5 & 5 & 6 & 7 & 7 & 8 & 3 & 8 & 8 & 9 & 9 & 9 & 10 & 10 & 10 & 11 & 11 & 11 \\
\hline $93 \rightarrow 99$ & 0 & 3 & 4 & 5 & 6 & 6 & 7 & 7 & 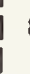 & 3 & 8 & 9 & 9 & 9 & 10 & 10 & 10 & 11 & 11 & 11 & 11 \\
\hline 100 & 0 & 3 & 4 & 5 & 6 & 6 & 7 & 7 & 8 & 3 & 8 & 9 & 9 & 10 & 10 & 10 & 11 & 11 & 11 & 12 & 12 \\
\hline
\end{tabular}

Purpose: To compute a number related to the amount of effort needed to contain a single fire burning in fuels represented by this fuel model.*

Procedure: Read the BI at the intersection of the row indexed by the SC (column 18) and the ERC (column 21); record in column 22.

* If it is raining (state of weather code 5, 6, or 7) or there is snow or ice on the ground fuels, record a zero (0) in column 22. 
FIRE LOAD INDEX - FUEL MODEL A

Col. 23

\begin{tabular}{|c|c|c|c|c|c|c|c|c|c|c|c|c|c|c|}
\hline \multirow{2}{*}{$\begin{array}{c}\text { Occurrence } \\
\text { Index } \\
\text { Col. } 14\end{array}$} & \multicolumn{14}{|c|}{$\begin{array}{l}\text { Burning Index } \\
\text { Col. } 22\end{array}$} \\
\hline & 0 & 1 & 2 & 3 & 4 & 5 & & 6 & 7 & 8 & 9 & 10 & 11 & 12 \\
\hline 0 & 0 & 0 & 0 & 0 & 0 & 0 & & 0 & 0 & 0 & 0 & 0 & 0 & 0 \\
\hline $1 \rightarrow 5$ & 0 & 0 & 0 & 0 & 0 & 0 & & 0 & 0 & 0 & 0 & 0 & 0 & 0 \\
\hline $6 \rightarrow 10$ & 0 & 0 & 0 & 0 & 0 & 0 & & 0 & 1 & 1 & 1 & 1 & 1 & 1 \\
\hline $11 \rightarrow 15$ & 0 & 0 & 0 & 0 & 1 & 1 & & 1 & 1 & 1 & 1 & 1 & 1 & 2 \\
\hline $16 \rightarrow 20$ & 0 & 0 & 0 & 1 & 1 & 1 & & 1 & 1 & 1 & 2 & 2 & 2 & 2 \\
\hline $21 \rightarrow 25$ & 0 & 0 & 0 & 1 & 1 & 1 & & 1 & 2 & 2 & 2 & 2 & 3 & 3 \\
\hline--- & & & & & & & & & & & & - & - & -- \\
\hline $26 \rightarrow 30$ & 0 & 0 & 1 & 1 & 1 & 1 & & 2 & 2 & 2 & 3 & 3 & 3 & 3 \\
\hline $31 \rightarrow 35$ & 0 & 0 & 1 & 1 & 1 & 2 & & 2 & 2 & 3 & 3 & 3 & 4 & 4 \\
\hline $36 \rightarrow 40$ & 0 & 0 & 1 & 1 & 2 & 2 & & 2 & 3 & 3 & 3 & 4 & 4 & 5 \\
\hline $41 \rightarrow 45$ & 0 & 0 & 1 & 1 & 2 & 2 & & 3 & 3 & 4 & 4 & 4 & 5 & 5 \\
\hline $46 \rightarrow 50$ & 0 & 0 & 1 & 1 & 2 & 2 & & 3 & 3 & 4 & 4 & 5 & 5 & 6 \\
\hline $51 \rightarrow 55$ & 0 & 1 & 1 & 2 & 2 & 3 & & 3 & 4 & 4 & 5 & 5 & 6 & 6 \\
\hline $56 \rightarrow 60$ & 0 & 1 & 1 & 2 & 2 & 3 & & 4 & 4 & 5 & 5 & 6 & 7 & 7 \\
\hline $61 \rightarrow 65$ & 0 & 1 & 1 & 2 & 3 & 3 & & 4 & 5 & 5 & $\epsilon$ & 6 & 7 & 8 \\
\hline $66 \rightarrow 70$ & 0 & 1 & 1 & 2 & 3 & 3 & & 4 & 5 & 6 & 6 & 7 & 8 & 8 \\
\hline--- & & & & & & & & & & & & - & - & - \\
\hline $71 \rightarrow 75$ & 0 & 1 & 1 & 2 & 3 & 4 & & 4 & 5 & 6 & 7 & 7 & 8 & 9 \\
\hline $76 \rightarrow 80$ & 0 & 1 & 2 & 2 & 3 & 4 & & ; & 6 & 6 & 7 & 8 & 9 & 10 \\
\hline $81 \rightarrow 85$ & 0 & 1 & 2 & 3 & 3 & 4 & & ; & 6 & 7 & 8 & 8 & 9 & 10 \\
\hline & & & & & & & & & & & & & & \\
\hline $86 \rightarrow 90$ & 0 & 1 & 2 & 3 & 4 & 4 & & ; & 6 & 7 & 8 & 9 & 10 & 11 \\
\hline $91 \rightarrow 95$ & 0 & 1 & 2 & 3 & 4 & 5 & & ; & 7 & 8 & 9 & 9 & 10 & 11 \\
\hline $96 \rightarrow 100$ & 0 & 1 & 2 & 3 & 4 & 5 & & 5 & 7 & 8 & 9 & 10 & 11 & 12 \\
\hline
\end{tabular}

Purpose: To compute a number related to the total effort needed to contain all probable fires on a rating area.*

Procedure: Read the FLI at the intersection of the row indexed by the OI (column 14) and the column indexed by the BI (column 22); record in column 23.

* If it is raining (state of weather code 5, 6, or 7) or there is snow or ice on the ground fuels, record a zero $(0)$ in column 23. 


\section{Fuel Model B}




\section{COMPUTATIONAL FLOW CHART FUEL MODEL B}

(1)

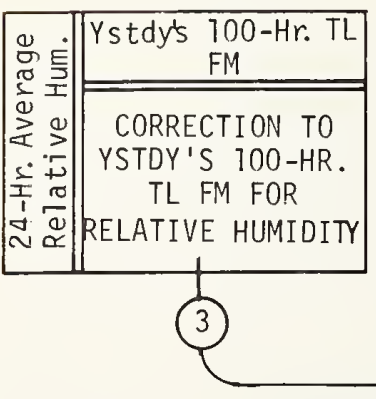

(2)

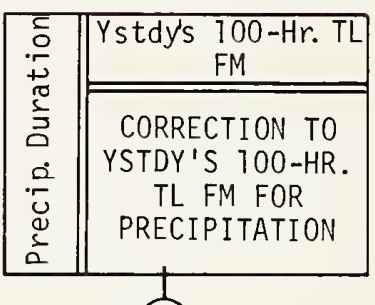

(3)

(4)

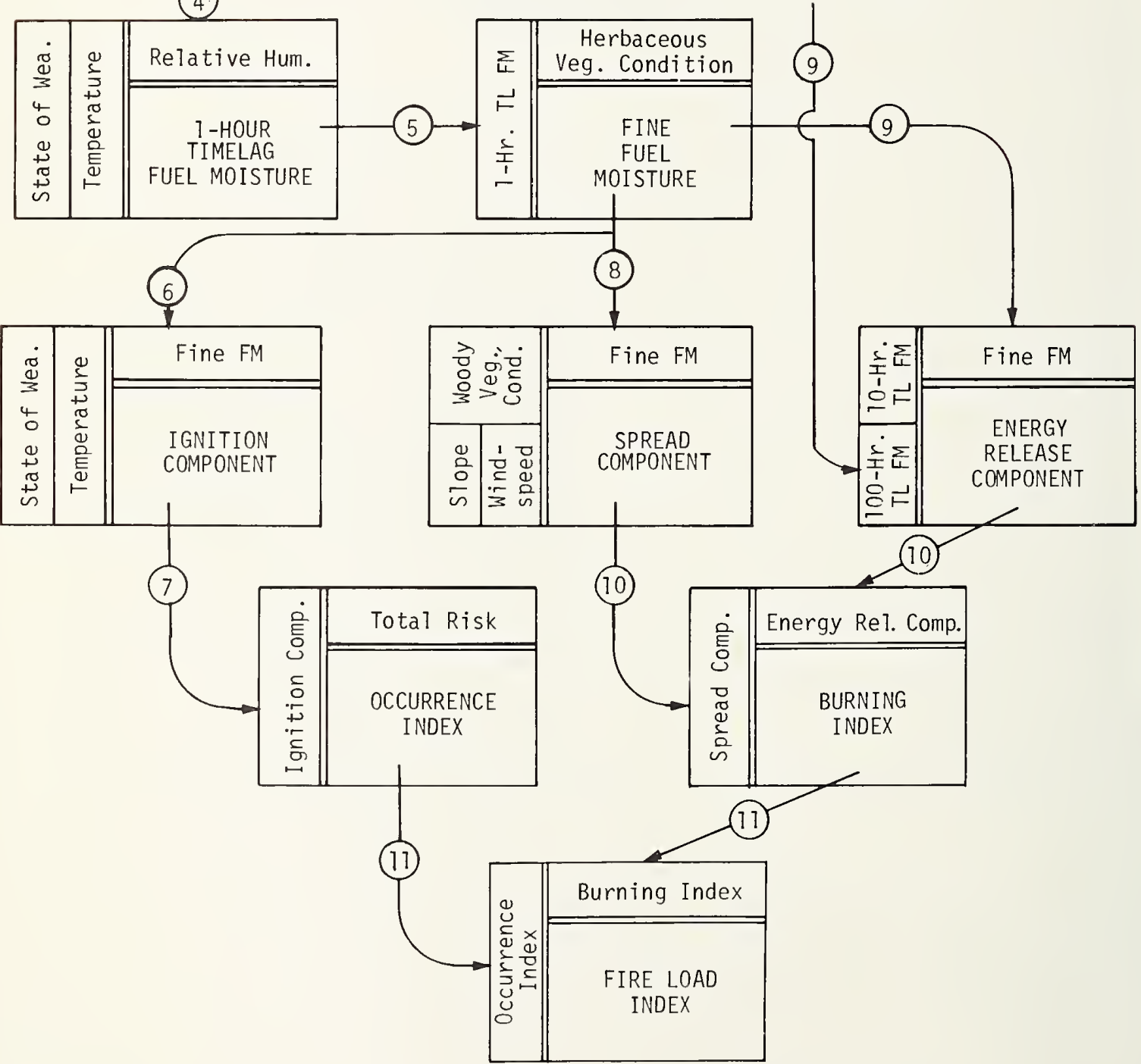




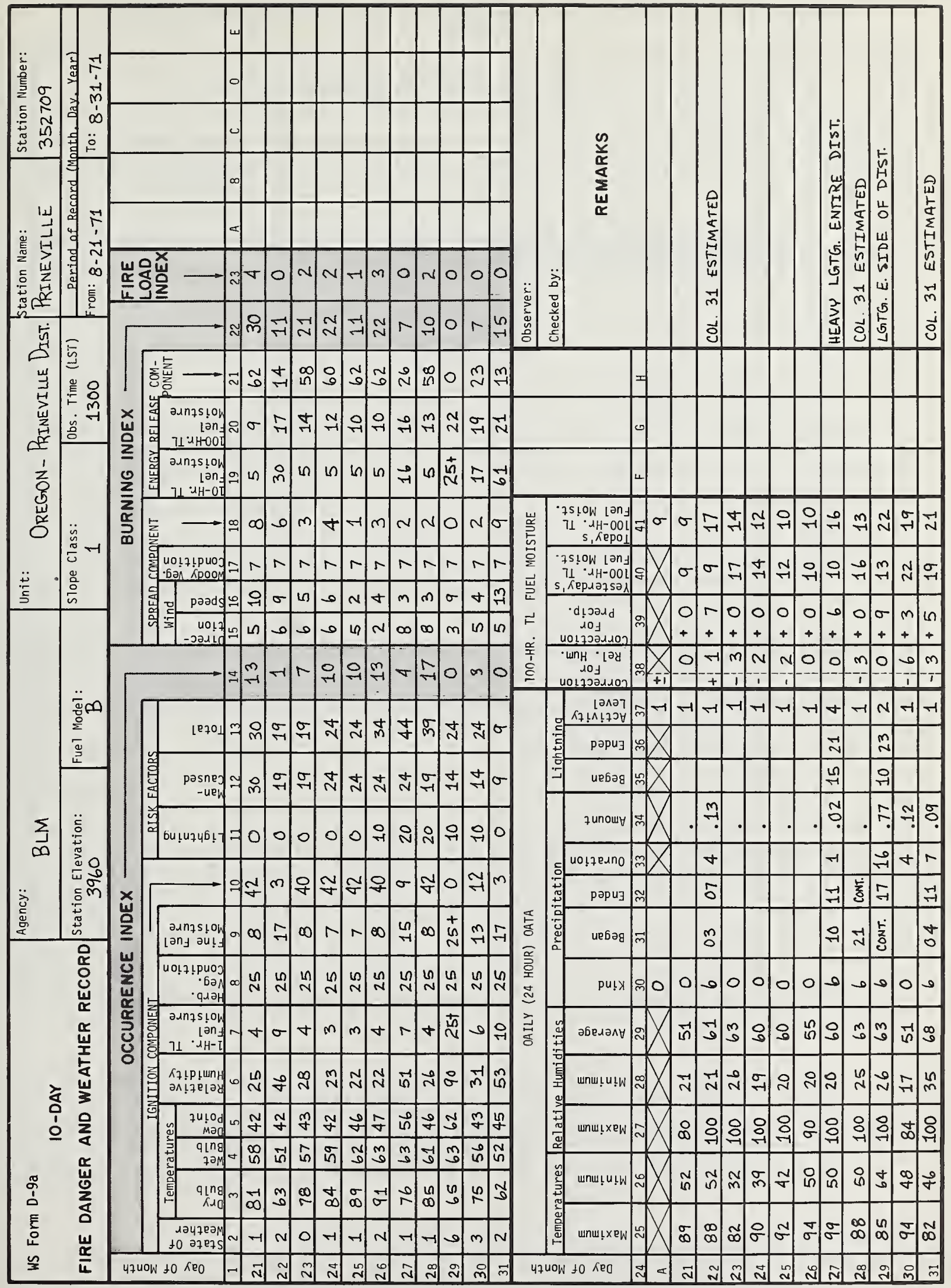




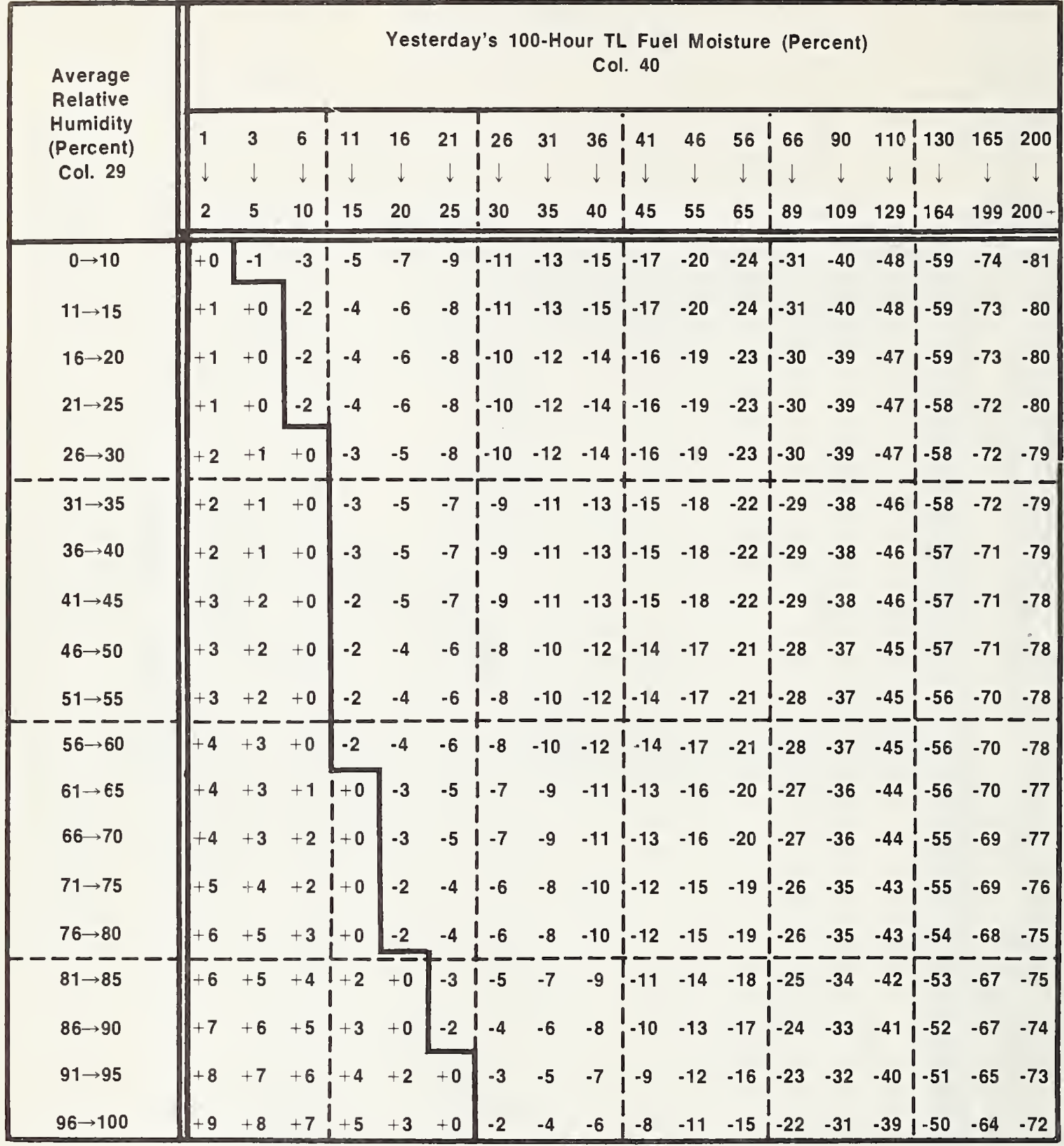

Purpose: To compute the effect of atmospheric humidity (water vapor) since Basic Observation Time yesterday, on the moisture content of the 100-Hr. TL fuels.*, **

Procedures: At the intersection of the column indexed by yesterday's 100-Hr. TL FM (column $40)^{* * *}$ and the row indexed by the 24 -hour average relative humidity (column 29) is the correction to the $100-\mathrm{Hr}$. TL FM for relative humidity; record in column 38.

* Values can be positive (+) or negative (-), record the proper sign.

** If it has rained continuously for the past 24 hours, record a zero (0) in column 38.

*** At the beginning of the fire season, an initial value of 35 percent should be assumed. 


\begin{tabular}{|c|c|c|c|c|c|c|c|c|c|c|c|}
\hline \multirow[b]{2}{*}{$\begin{array}{l}\text { Precipitation } \\
\text { Duration } \\
\text { (Hours) } \\
\text { Col. } 33\end{array}$} & \multicolumn{11}{|c|}{$\begin{array}{c}\text { Yesterday's } 100 \text {-Hour TL Fuel Moisture (Percent) } \\
\text { Col. } 40\end{array}$} \\
\hline & 2 & $\begin{array}{l}3 \\
\downarrow \\
5\end{array}$ & $\downarrow$ & 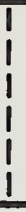 & $\begin{array}{c}11 \\
\downarrow \\
15\end{array}$ & $\downarrow$ & $\begin{array}{l}21 \\
\downarrow \\
25\end{array}$ & $\begin{array}{l}1 \\
1 \\
1 \\
1\end{array}$ & $\begin{array}{c}26 \\
\downarrow \\
30\end{array}$ & $\begin{array}{c}31 \\
\downarrow \\
35\end{array}$ & $\begin{array}{c}36 \\
\downarrow \\
36+\end{array}$ \\
\hline $1 \rightarrow 3$ & 8 & 7 & 6 & i & 4 & 3 & 2 & & 1 & 0 & 0 \\
\hline $4 \rightarrow 6$ & 9 & 8 & 7 & | & 5 & 4 & 3 & & 1 & 1 & 1 \\
\hline $7 \rightarrow 9$ & 10 & 9 & 8 & & 6 & 5 & 3 & i & 2 & 1 & 1 \\
\hline $10 \rightarrow 12$ & 11 & 10 & 9 & I & 7 & 6 & 4 & $i$ & 2 & 2 & 2 \\
\hline $13 \rightarrow 15$ & 12 & 11 & 10 & 1 & 7 & 6 & 5 & 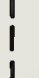 & 3 & 2 & 2 \\
\hline $16 \rightarrow 18$ & 13 & 13 & 11 & I & 9 & 7 & 6 & i & 4 & 3 & 3 \\
\hline $19 \rightarrow 21$ & 15 & 14 & 12 & | & 10 & 8 & 6 & $i$ & 5 & 4 & 4 \\
\hline $22 \rightarrow 24$ & 16 & 15 & 14 & 1 & 11 & 9 & 7 & i & 5 & 5 & 4 \\
\hline
\end{tabular}

Purpose: To compute the effect of precipitation occurring since Basic Observation Time yesterday on the moisture content of the 100 -Hr. TL fuels.*

Procedure: At the intersection of the column indexed by yesterday's 100-Hr. TL FM (column 40) and the row indexed by the precipitation duration (column 33) is the correction to the 100-Hr. TL FM for precipitation; record in column 39.

\section{Computation of Today's 100-Hour Timelag Fuel Moisture}

Being careful of the arithmetic signs, add the entries in columns 38, 39, and 40 . Enter the results in columns 41 and 20; this is today's 100-Hr. TL FM.

* If no precipitation has occurred in the past 24 hours, record a zero (0) in column 39. 


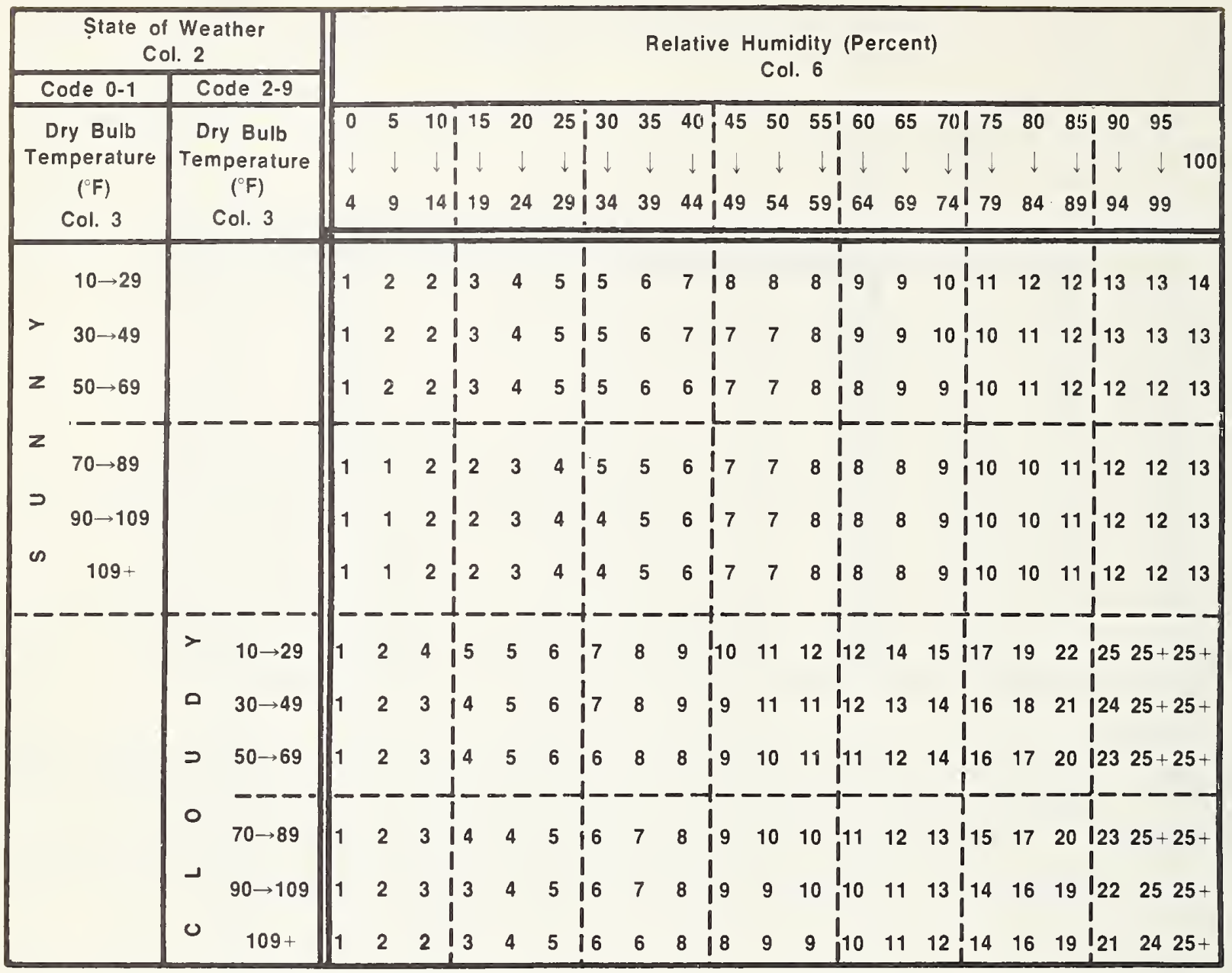

Purpose: To compute the moisture content of dead fuels one-quarter inch and less in diameter.* Procedure: If the state of the weather is coded 2, 3, 4, 8, or 9 (column 2), or if the observation is being taken before 1000 or after $1500 \mathrm{~L} . \mathrm{ST}$, the dry-bulb temperature is entered to the left in that section of the table labeled "cloudy." Otherwise enter the temperature in the section labeled "sunny." Read the 1-Hr. TL FM at the intersection of this row and the column indexed by the appropriate value for relative humidity (column 6); record in column 7.

* If it is raining (state of weather codes 5,6, or 7) or there is snow or ice on the ground fuels, record $25+$ in column 7 . 
FINE FUEL MOISTURE (PERCENT)

Col. 9

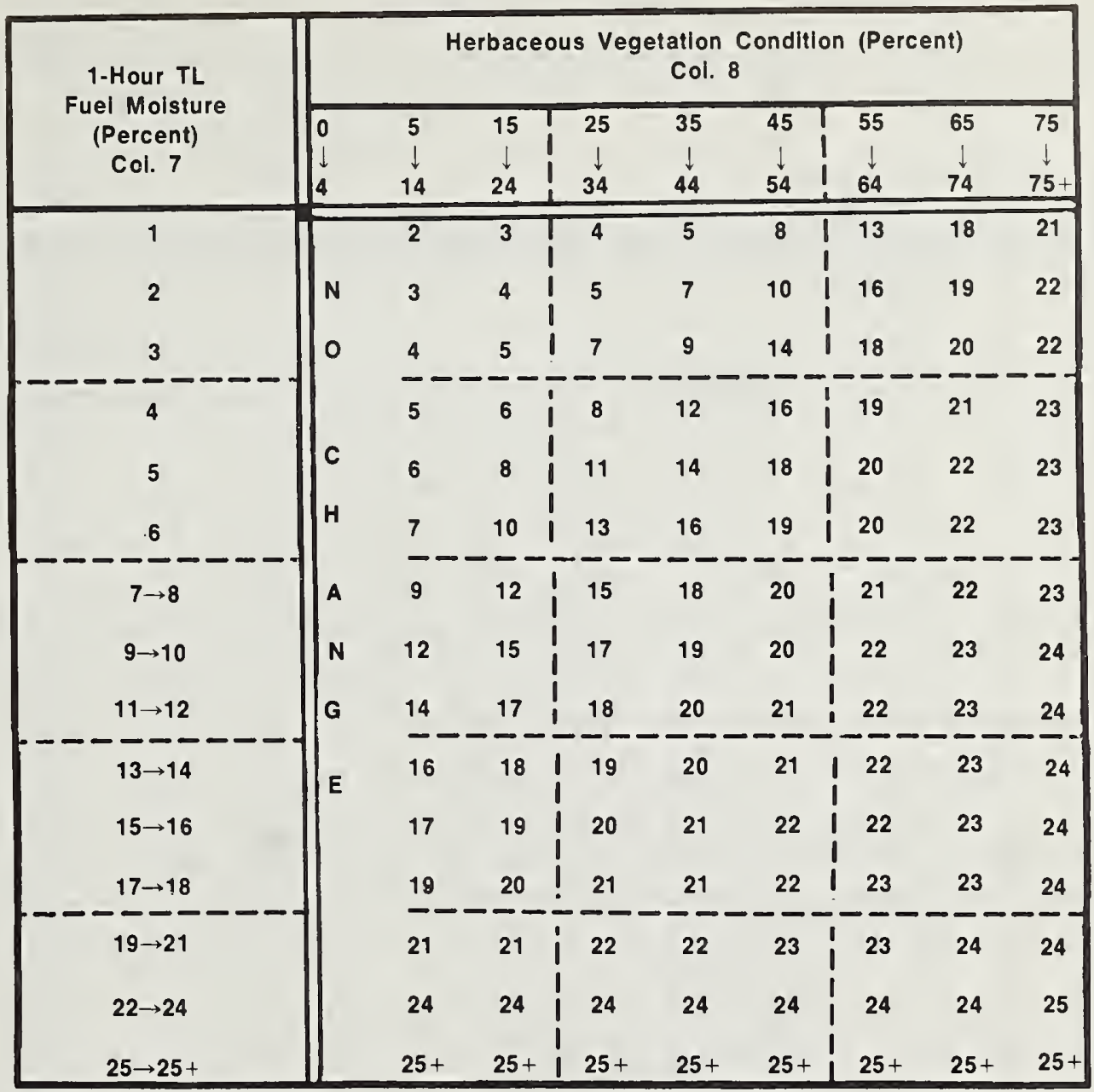

Purpose: To adjust the 1-Hr. TL, FM to account for the reduced flammability of the lesser fuels due to the presence of living herbaceous plant material.*

Procedure: Read the FFM at the intersection of the row indexed by the 1-Hr. TL FM (column 7) and the column indexed by herbaceous vegetation condition (column 8); record in column 9.

* If the herbaceous vegetation condition is 4 or less, enter the value of the 1-Hr. TL FM directly into column 9. 
Col. 10

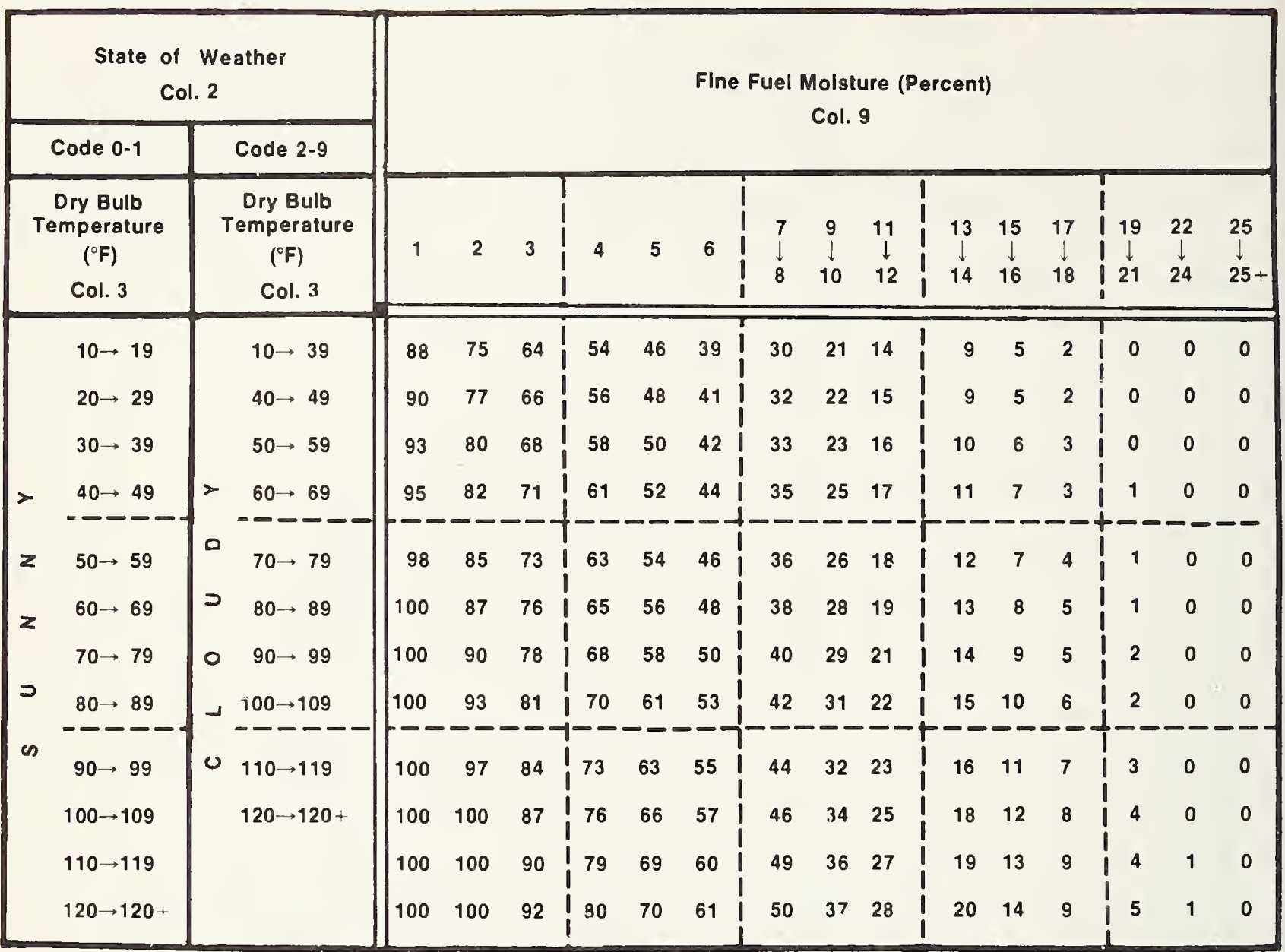

Purpose: To compute a number related to the probability that a fire will result if a firebrand is introduced into the fine fuel complex.*

Procedure: If the state of the weather is coded $2,3,4,8$, or 9 (column 2 ), or if the observation is being taken before 1000 or after 1500 LST, the dry-bulb temperature (column 3) is entered to the left in that section of the table labeled "cloudy." Otherwise, enter the temperature in the section labeled "sunny." Read the IC at the intersection of the column indexed by the FFM (column 9) and the row indexed by the dry-bulb temperature (column 3 ); record in column 10 .

* If it is raining (state of weather code 5, 6, or 7) or there is snow or ice on the ground fuels, record a zero (0) in column 10. 


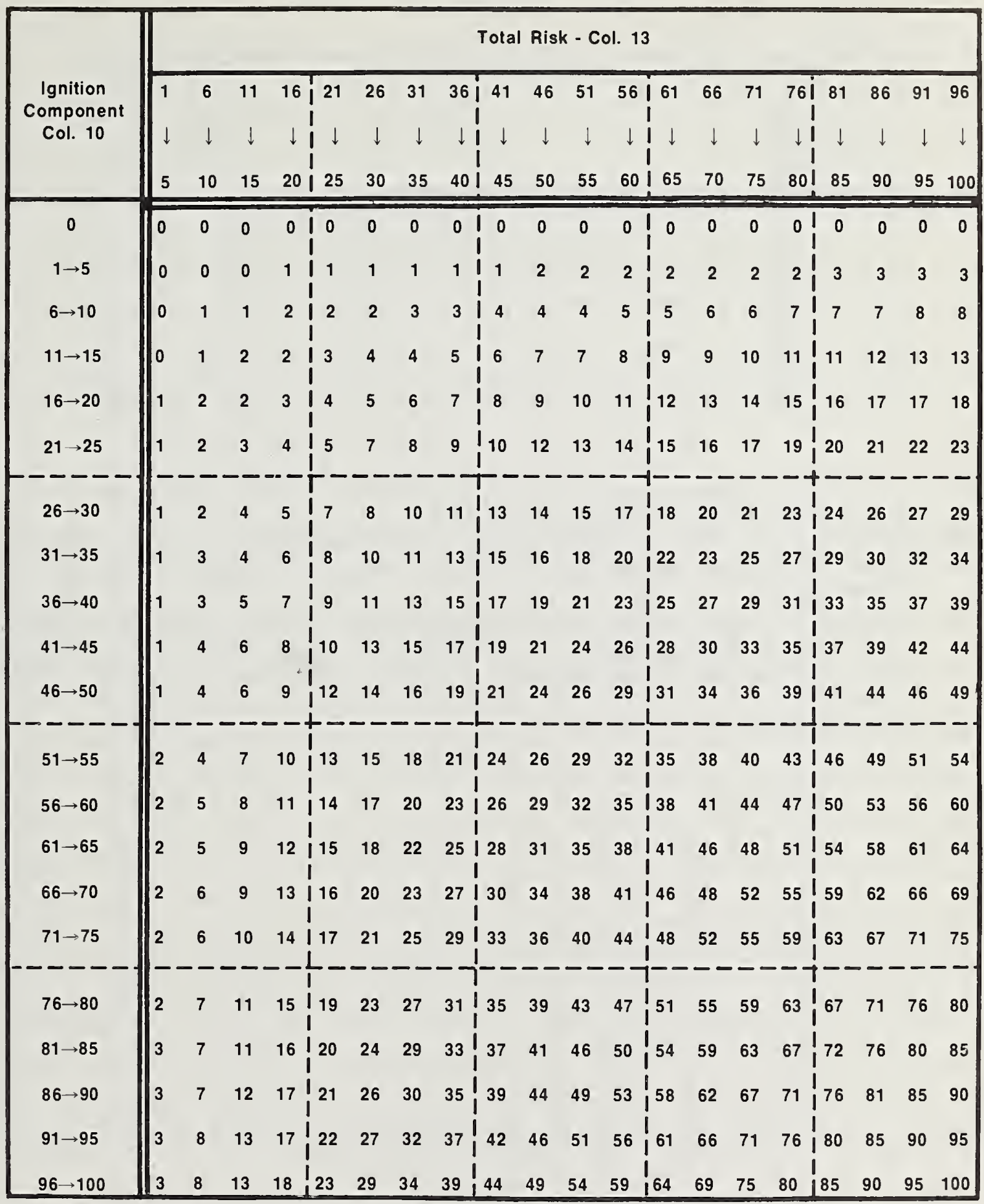

Purpose: To compute a number related to the probable level of fire incidence on the rating area.*

Procedure: At the intersection of the row indexed by the IC (column 10) and the column indexed by total Risk (column 13) is the OI; record in column 14.

* If it is raining (state of the weather code 5,6 , or 7 ) or there is snow or ice on the ground fuels, record a zero (0) in column 14. 
Col. 18

PART A

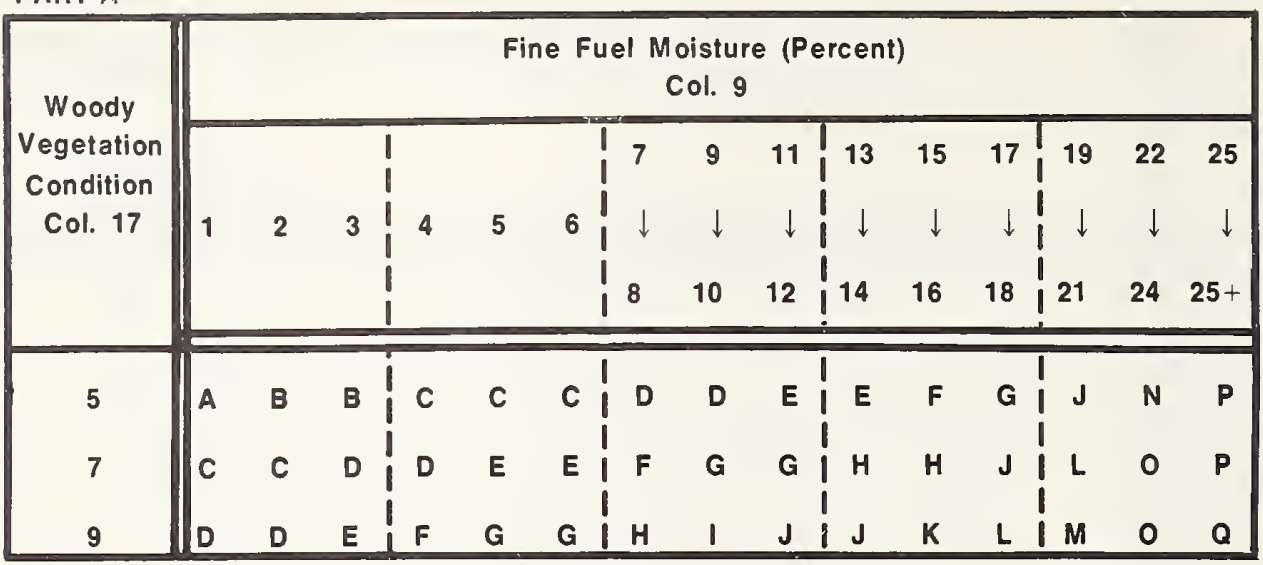

Purpose: To compute a number related to the forward rate of spread of the head of a fire burning in fuels represented by this fuel model.*

Procedure: In Part A-Read the transfer letter at the intersection of the row indexed by the woody vegetation condition (column 17) and the column indexed by the FFM (column 9).

In Part B-Enter the windspeed (column 16) into the table from the column headed by the slope class assigned to the rating area. Read the SC at the intersection of this row and the column indexed by the transfer letter from Part $\mathrm{A}$; record in column 18 .

* If it is raining (state of weather code 5, 6, or 7) or there is snow or ice on the ground fuels, record a zero $(0)$ in column 18. 
PART B

\begin{tabular}{|c|c|c|c|c|c|c|c|c|c|c|c|c|c|c|c|c|c|c|c|}
\hline \multicolumn{3}{|c|}{ Slope Class } & \multirow{2}{*}{\multicolumn{17}{|c|}{ Transfer Letter From Part A }} \\
\hline 1 & 2 & 3 & & & & & & & & & & & & & & & & & \\
\hline $\begin{array}{l}\text { Wind- } \\
\text { speed } \\
\text { (MPH) } \\
\text { Col. } 16\end{array}$ & $\begin{array}{l}\text { Wind- } \\
\text { speed } \\
\text { (MPH) } \\
\text { Col. } 16\end{array}$ & $\begin{array}{l}\text { Wind- } \\
\text { speed } \\
\text { (MPH) } \\
\text { Col. } 16\end{array}$ & $\mathbf{A}$ & B & C & & $\mathbf{E}$ & $\mathbf{F}$ & G & H & 1 & $J$ & K & L & $M$ & $\mathbf{N}$ & 0 & $\mathbf{P}$ & Q \\
\hline $0-1$ & & & 1 & 1 & 1 & & 1 & 1 & 1 & & 1 & 1 & 1 & 1 & 1 & 1 & 0 & 0 & 0 \\
\hline 2 & & & 3 & 2 & 2 & 2 & 1 & 1 & 1 & 1 & 1 & 1 & 1 & 1 & 1 & 1 & 1 & 0 & 0 \\
\hline 3 & $0-1$ & & 4 & 4 & 3 & 2 & 2 & 2 & 2 & 2 & 2 & 1 & 1 & 1 & 1 & 1 & 1 & 0 & 0 \\
\hline 4 & $2-3$ & & 6 & 5 & 4 & 3 & 3 & 3 & 2 & 2 & 2 & 2 & 2 & 2 & 1 & 1 & 1 & 0 & 0 \\
\hline 5 & 4 & $0-1$ & 8 & 6 & 5 & 4 & 4 & 3 & 3 & 3 & 3 & 2 & 2 & 2 & 2 & 2 & 1 & 1 & 0 \\
\hline 6 & 5 & 2 & 10 & 8 & 6 & 5 & 5 & 4 & 4 & 4 & 3 & 3 & 3 & 2 & 2 & 2 & 1 & 1 & 0 \\
\hline 7 & 6 & $3-4$ & 12 & 10 & 8 & 7 & 6 & 5 & 5 & 4 & 4 & 4 & 3 & 3 & 3 & 2 & 2 & 1 & 0 \\
\hline 8 & 7 & 5 & 14 & 12 & 9 & 8 & 7 & 6 & 6 & 5 & 5 & 4 & 4 & 4 & 3 & 3 & 2 & 1 & 0 \\
\hline $9-10$ & $8-9$ & $6-7$ & 17 & 14 & 12 & 10 & 9 & 8 & 7 & 7 & 6 & 6 & 5 & 4 & 4 & 3 & 2 & 1 & 0 \\
\hline $11-12$ & $10-11$ & $8-9$ & 23 & 19 & 15 & 13 & 11 & 10 & 9 & 9 & 8 & 7 & 6 & 6 & 5 & 4 & 3 & 1 & 0 \\
\hline $13-14$ & $12-13$ & $10-12$ & 28 & 23 & 19 & 16 & 14 & 12 & 12 & 11 & 10 & 9 & 8 & 7 & 6 & 5 & 4 & 1 & 0 \\
\hline $15-16$ & $14-15$ & $13-14$ & 34 & 28 & 23 & 19 & 17 & 15 & 14 & 13 & 12 & 11 & 10 & 9 & 8 & 7 & 5 & 1 & 0 \\
\hline & & & & & & & - & & & & & & & - & & & . & & - \\
\hline $17-18$ & $16-17$ & $15-16$ & 41 & 34 & 27 & 23 & 20 & 18 & 17 & 15 & 14 & 13 & 12 & 10 & 9 & 8 & 5 & 2 & 0 \\
\hline $19-20$ & $18-19$ & $17-18$ & 47 & 39 & 32 & 27 & 23 & 21 & 19 & 18 & 16 & 15 & 13 & 12 & 11 & 9 & 6 & 2 & 0 \\
\hline $21-22$ & $20-21$ & $19-20$ & 54 & 45 & 37 & 31 & 27 & 24 & 22 & 20 & 19 & 17 & 15 & 14 & 12 & 10 & 7 & 2 & 0 \\
\hline $23-24$ & $22-23$ & $21-22$ & 62 & 51 & 42 & $35 !$ & 30 & 27 & 25 & 23 & 21 & 19 & 18 & 16 & 14 & 12 & 8 & 2 & 0 \\
\hline $25-26$ & 24-25 & $23-24$ & 69 & 58 & 47 & 39 & 34 & 30 & 28 & 26 & 24 & 22 & 20 & 18 & 15 & 13 & 9 & 3 & 0 \\
\hline $27-28$ & $26-27$ & $25-26$ & 77 & 64 & 52 & 44 & 38 & 34 & 31 & $29 i$ & 27 & 24 & 22 & 20 & 17 & 15 & 10 & 3 & 0 \\
\hline $29-30$ & $28-29$ & $27-28$ & 85 & 71 & 58 & $49 I$ & 42 & 37 & 35 & 32 I & 30 & 27 & 24 & 22 & 19 & 16 & 11 & 3 & 0 \\
\hline $31-31+$ & $30-30+$ & $29-29+$ & 87 & 73 & 59 & 50 & 43 & 38 & 36 & 33 & 30 & 28 & 25 & 22 & 20 & 17 & 11 & 3 & 0 \\
\hline
\end{tabular}




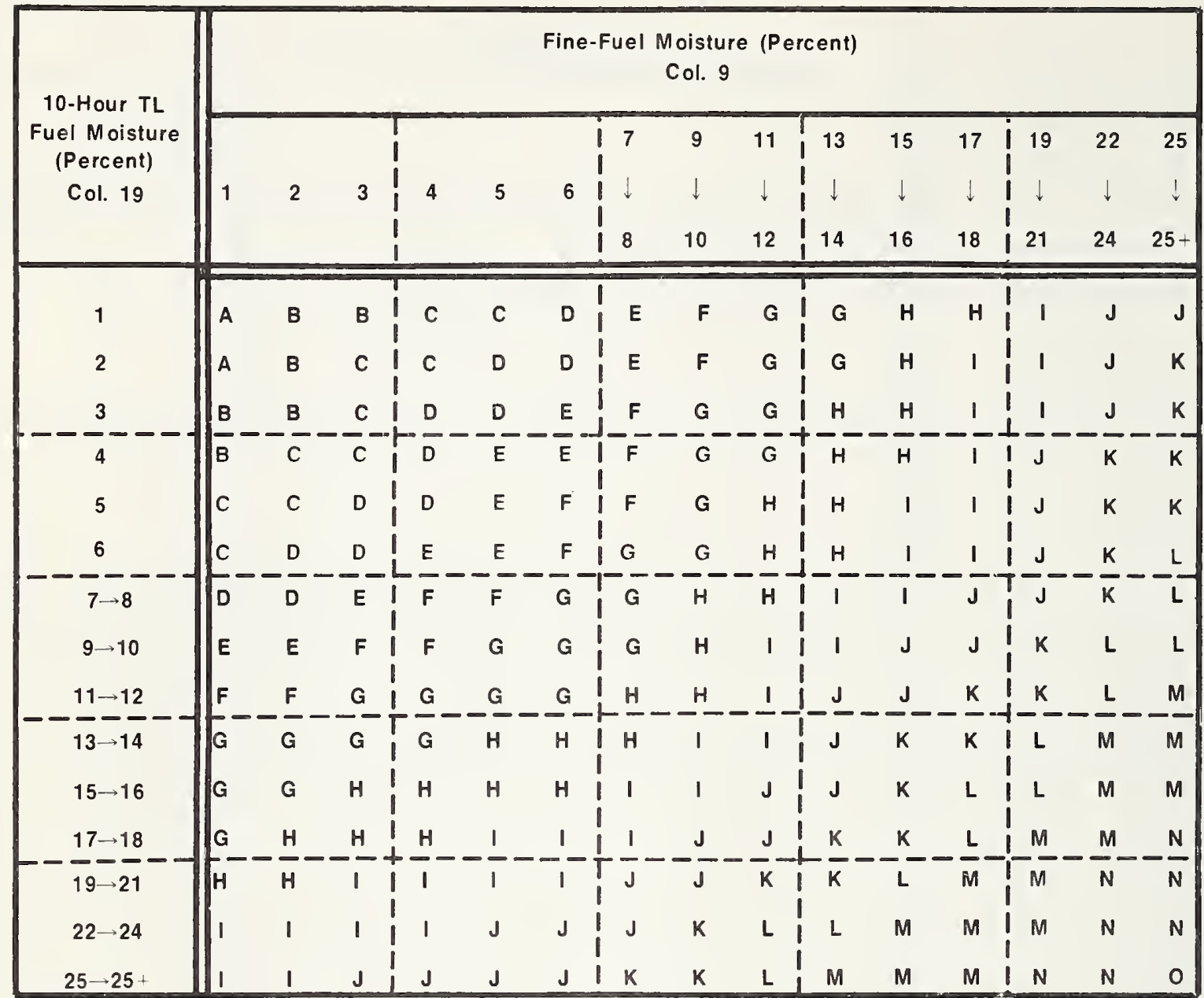

Procedure: To compute a number related to the rate of combustion at the head of a fire burning in fuels represented by this fuel model.*

Procedure: In Part A-Read the transfer letter at the intersection of the row indexed by the 10-Hr. TL, FM (column 19) and the column indexed by the FFM (column 9).

In Part B-Read the ERC at the intersection of the row indexed by the 100-Hr. TL FM (column 20) and the column indexed by the transfer letter from Part A; record in column 21 .

\footnotetext{
* If it is raining (state of weather code 5,6, or 7) or there is snow or ice on the ground
} fuels, record a zero (0) in column 21. 
ENERGY RELEASE COMPONENT - FUEL MODEL B

Col. 21

PART B

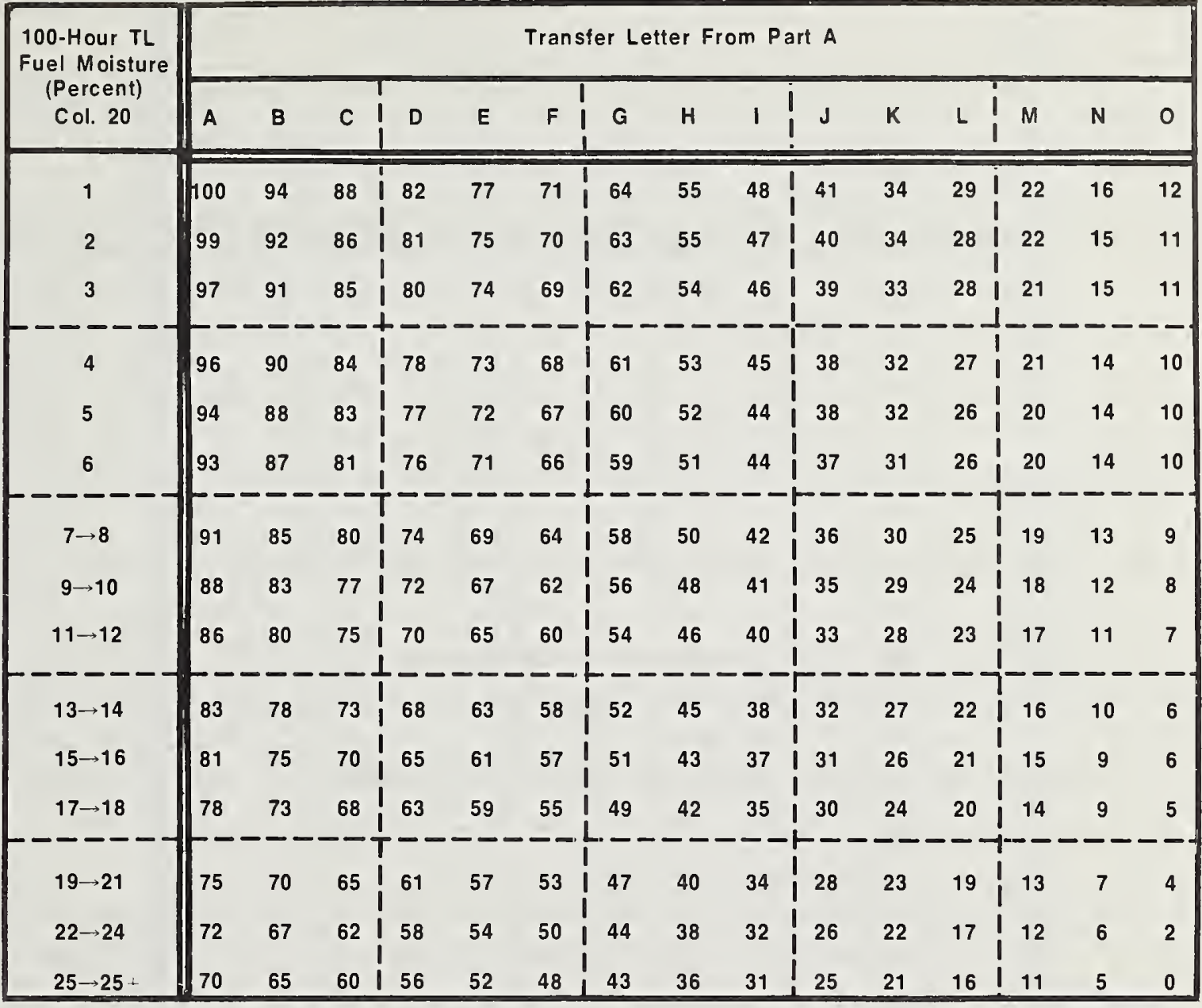




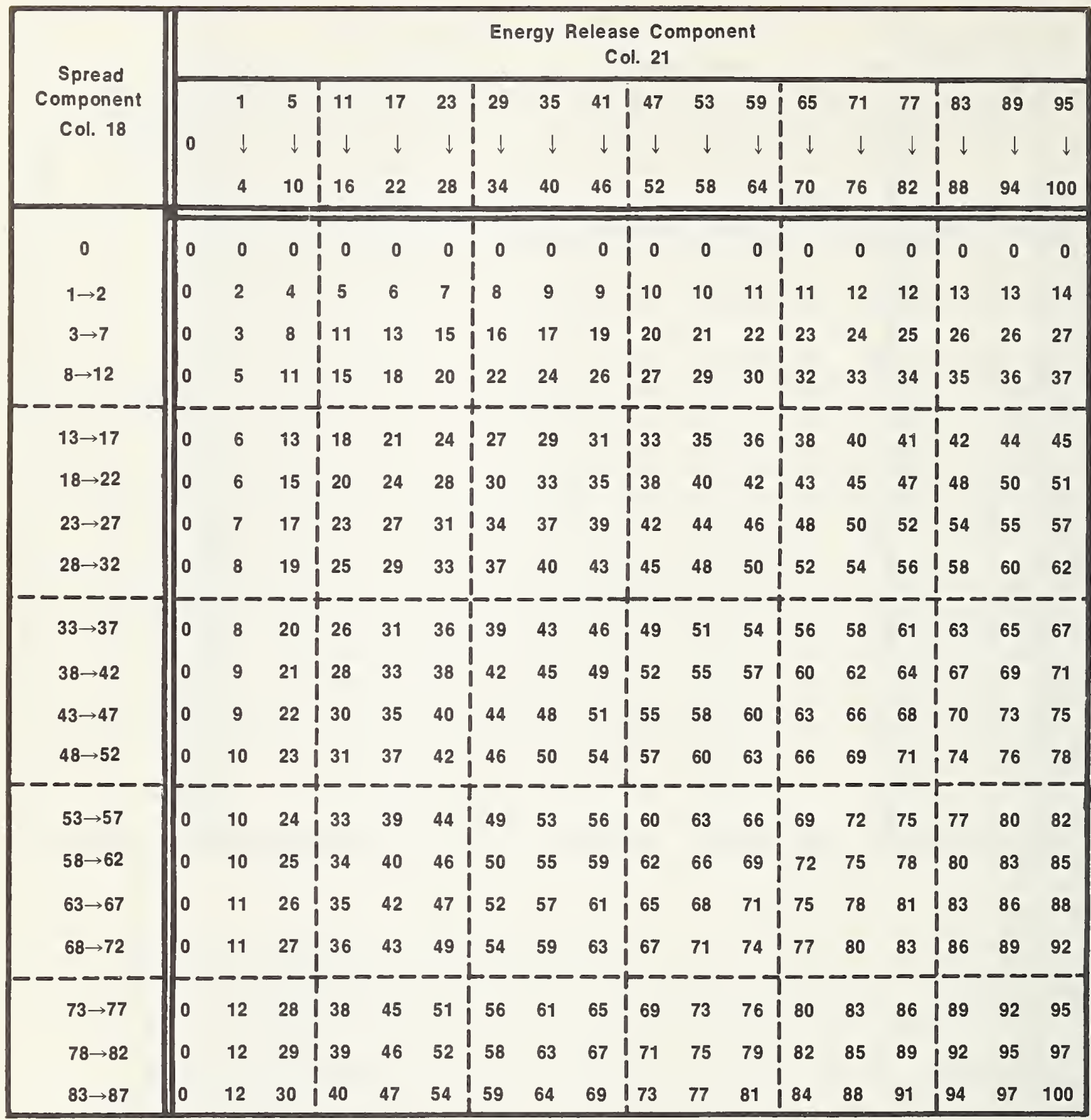

Purpose: To compute a number related to the amount of effort needed to contain a single fire burning in fuels represented by this fuel model.*

Procedure: Read the BI at the intersection of the row indexed by the SC (column 18) and the ERC (column 21); record in column 22.

\footnotetext{
* If it is raining (state of weather code 5, 6, or 7) or there is snow or ice on the ground fuels, record a zero (0) in column 22.
} 


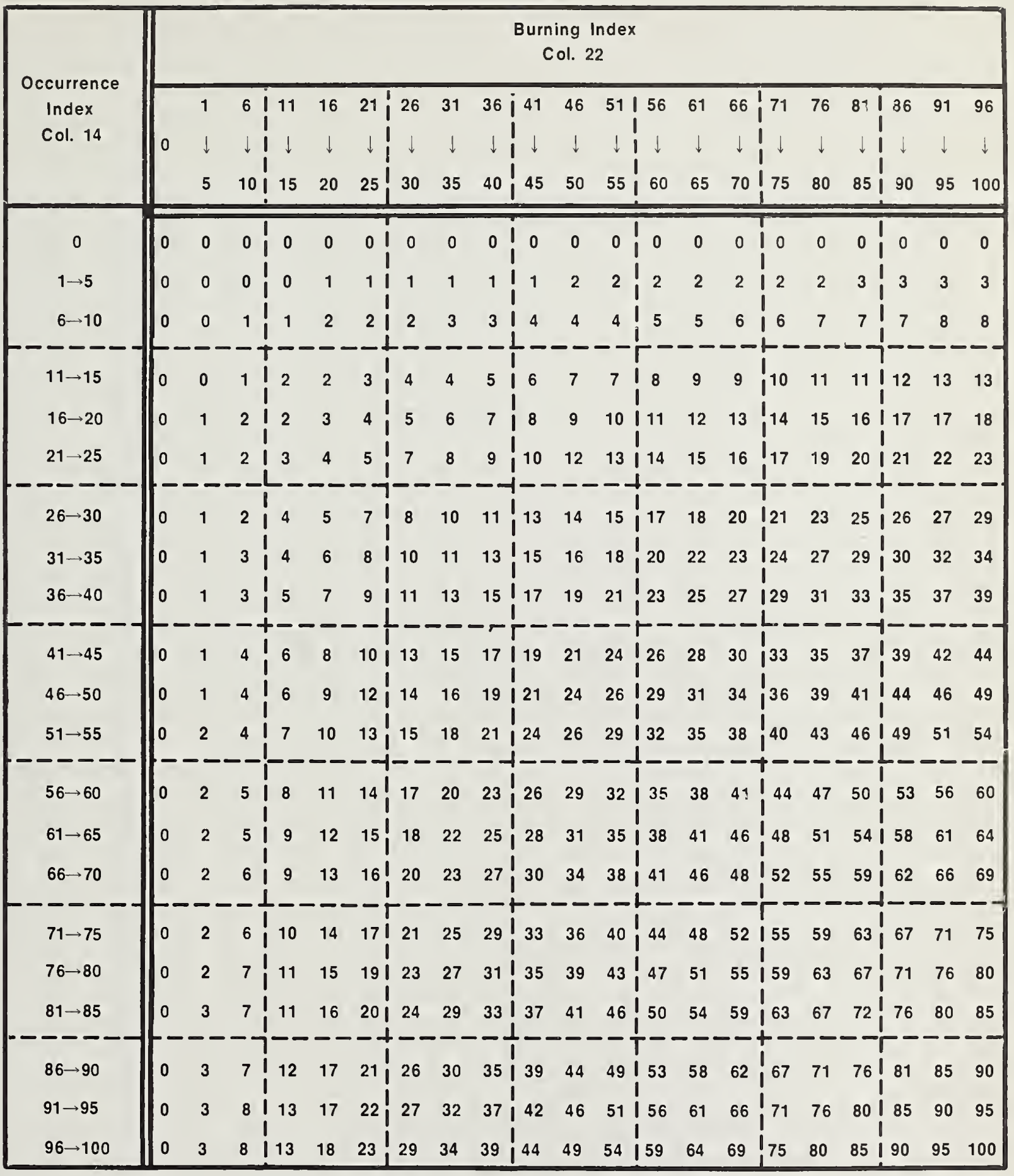

Purpose: To compute a number related to the total effort needed to contain all probable fires on a rating area.*

Procedure: Read the FLI at the intersection of the row indexed by the OI (column 14) and the column indexed by the BI (column 22 ); record in column 23 .

* If it is raining (state of weather code 5, 6, or 7) or there is snow or ice on the ground fuels, record a zero (0) in column 23. 
66 
Fuel Model C 


\section{COMPUTATIONAL FLOW CHART \\ FUEL MODEL C}

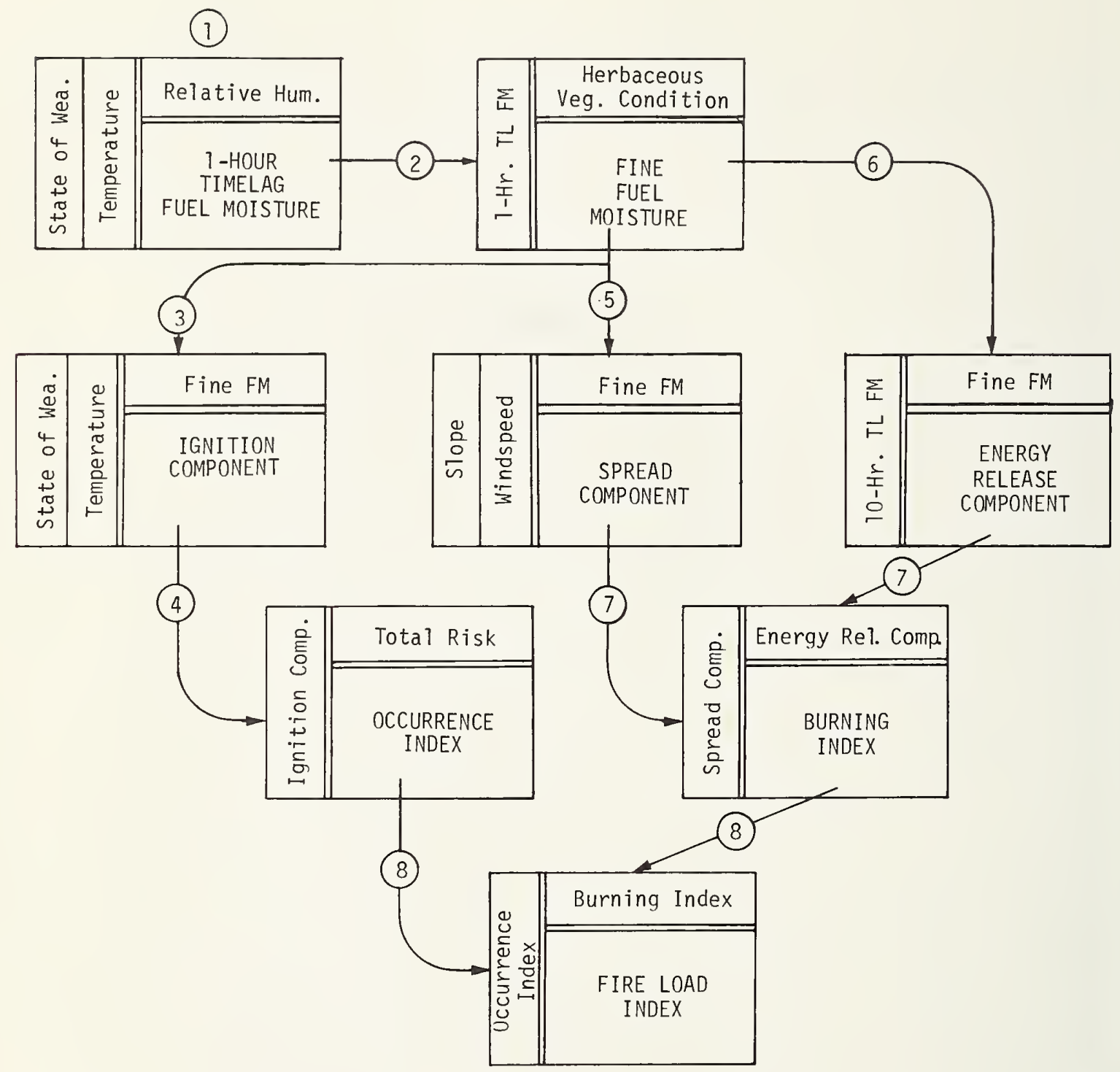




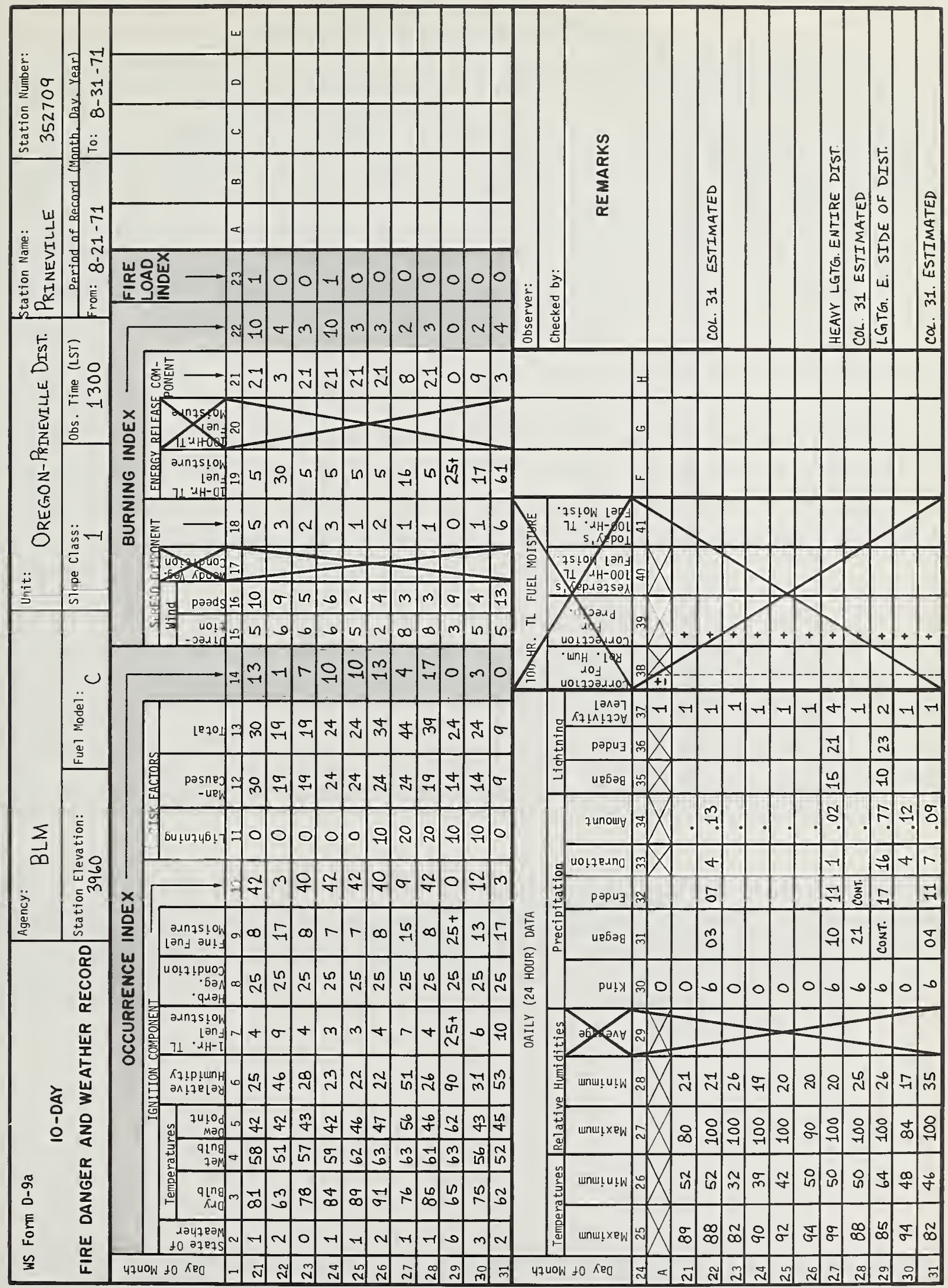




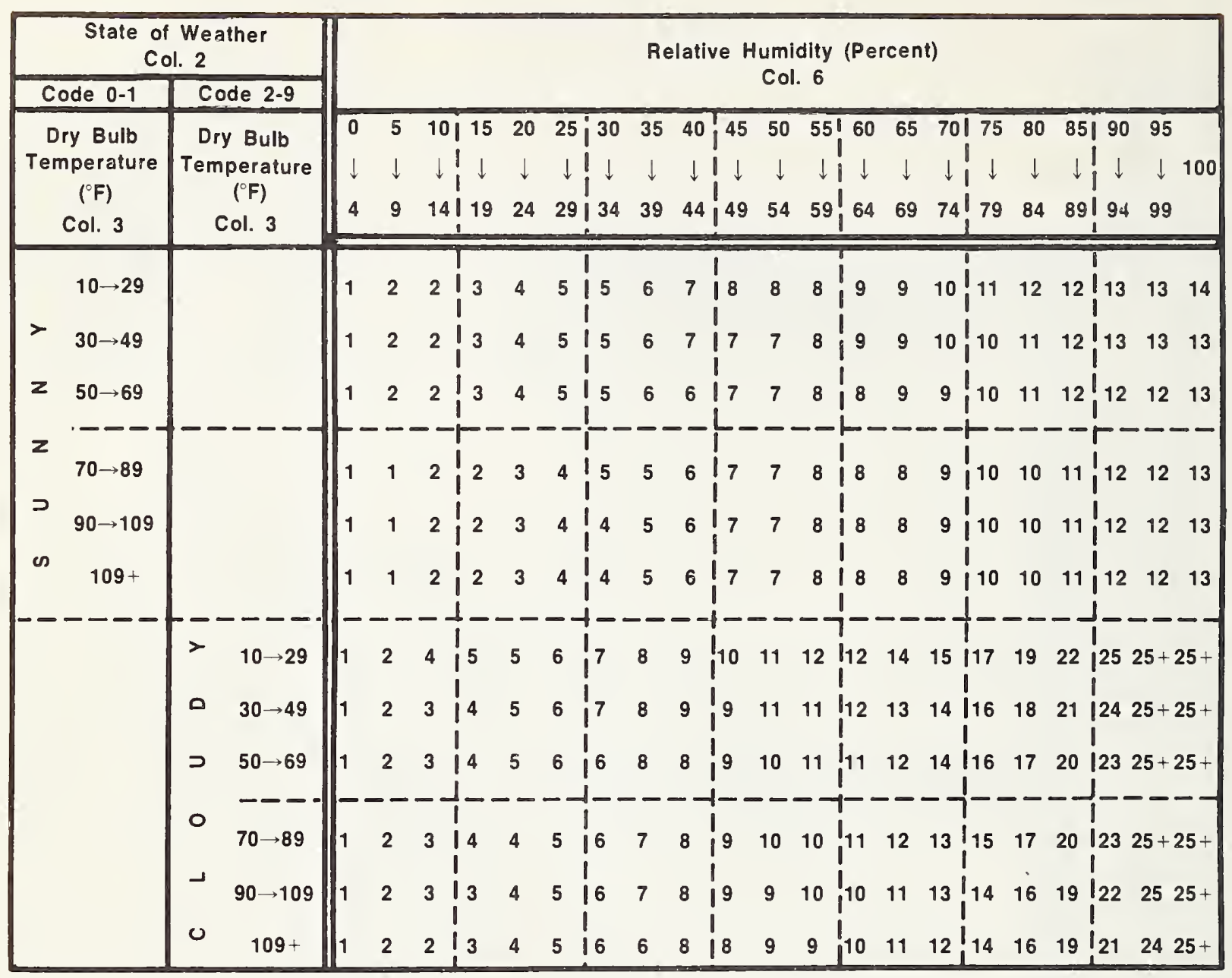

Purpose: To compute the moisture content of dead fuels one-quarter inch and less in diameter.* Procedure: If the state of the weather is coded $2,3,4,8$, or 9 (column 2), or if the observation is being taken before 1000 or after $1500 \mathrm{LST}$, the dry-bulb temperature is entered to the left in that section of the table labeled "cloudy." Otherwise enter the temperature in the section labeled "sunny." Read the 1-Hr. TL, FM at the intersection of this row and the column indexed by the appropriate value for relative humidity (column 6); record in column 7.

* If it is raining (state of weather codes 5, 6, or 7) or there is snow or ice on the ground fuels, record $25+$ in column 7 . 
FINE FUEL MOISTURE (PERCENT)

Col. 9

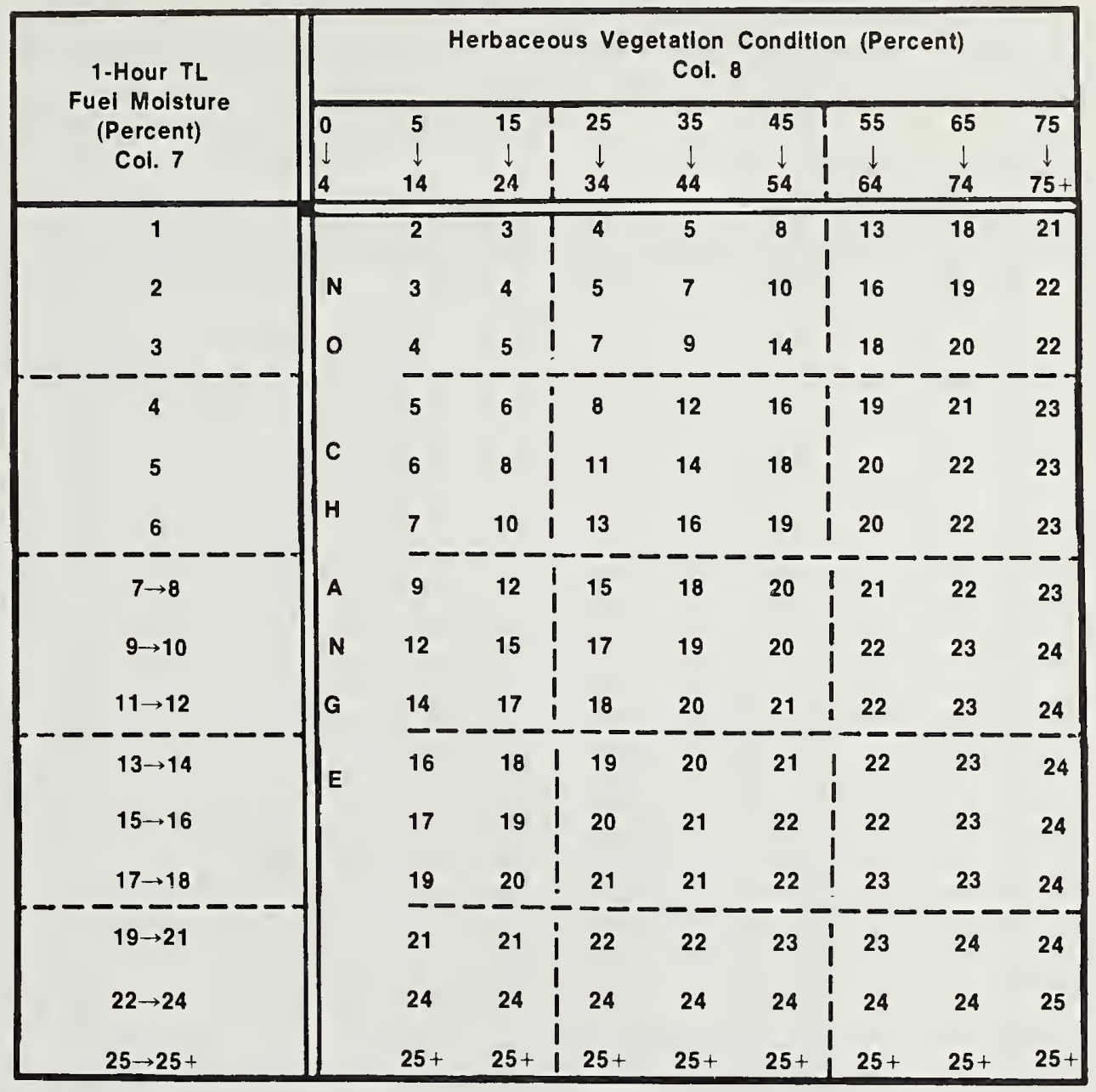

Purpose: To adjust the 1-Hr. TL FM to account for the reduced flammability of the lesser fuels due to the presence of living herbaceous plant material.*

Procedure: Read the FFM at the intersection of the row indexed by the 1-Hr. TL, FM (column 7) and the column indexed by herbaceous vegetation condition (column 8); record in column 9.

* If the herbaceous vegetation condition is 4 or less, enter the value of the 1-Hr. TL FM directly into column 9. 


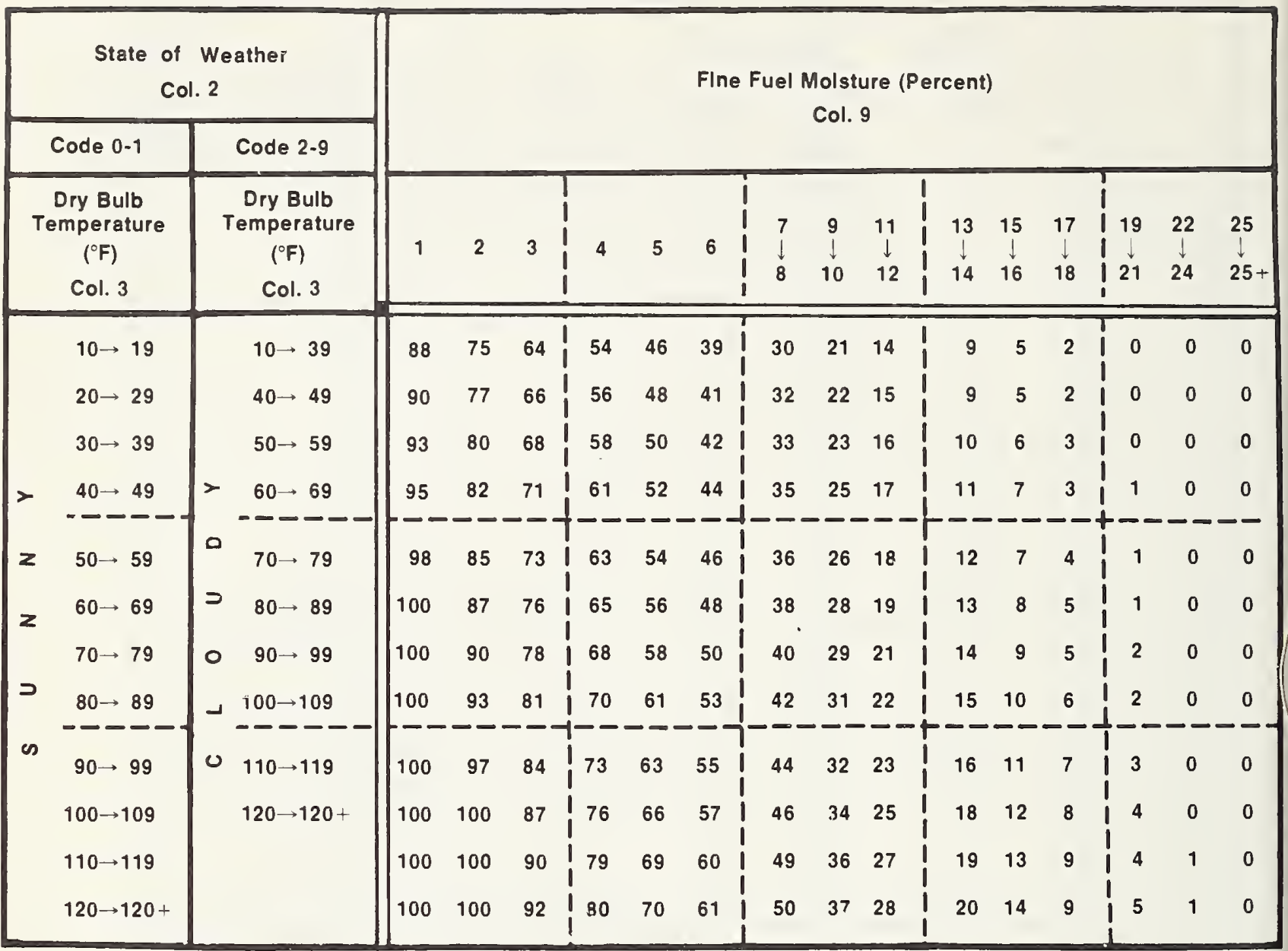

Purpose: To compute a number related to the probability that a fire will result if a firebrand is introduced into the fine fuel complex.*

Procedure: If the state of the weather is coded 2,3,4,8, or 9 (column 2), or if the observation is being taken before 1000 or after 1500 LST, the dry-bulb temperature (column 3) is entered to the left in that section of the table labeled "cloudy." Otherwise, enter the temperature in the section labeled "sunny." Read the IC at the intersection of the column indexed by the FFM (column 9) and the row indexed by the dry-bulb temperature (column 3 ); record in column 10 .

* If it is raining (state of the weather code 5,6, or 7) or there is snow or ice on the ground fuels, record a zero (0) in column 10. 


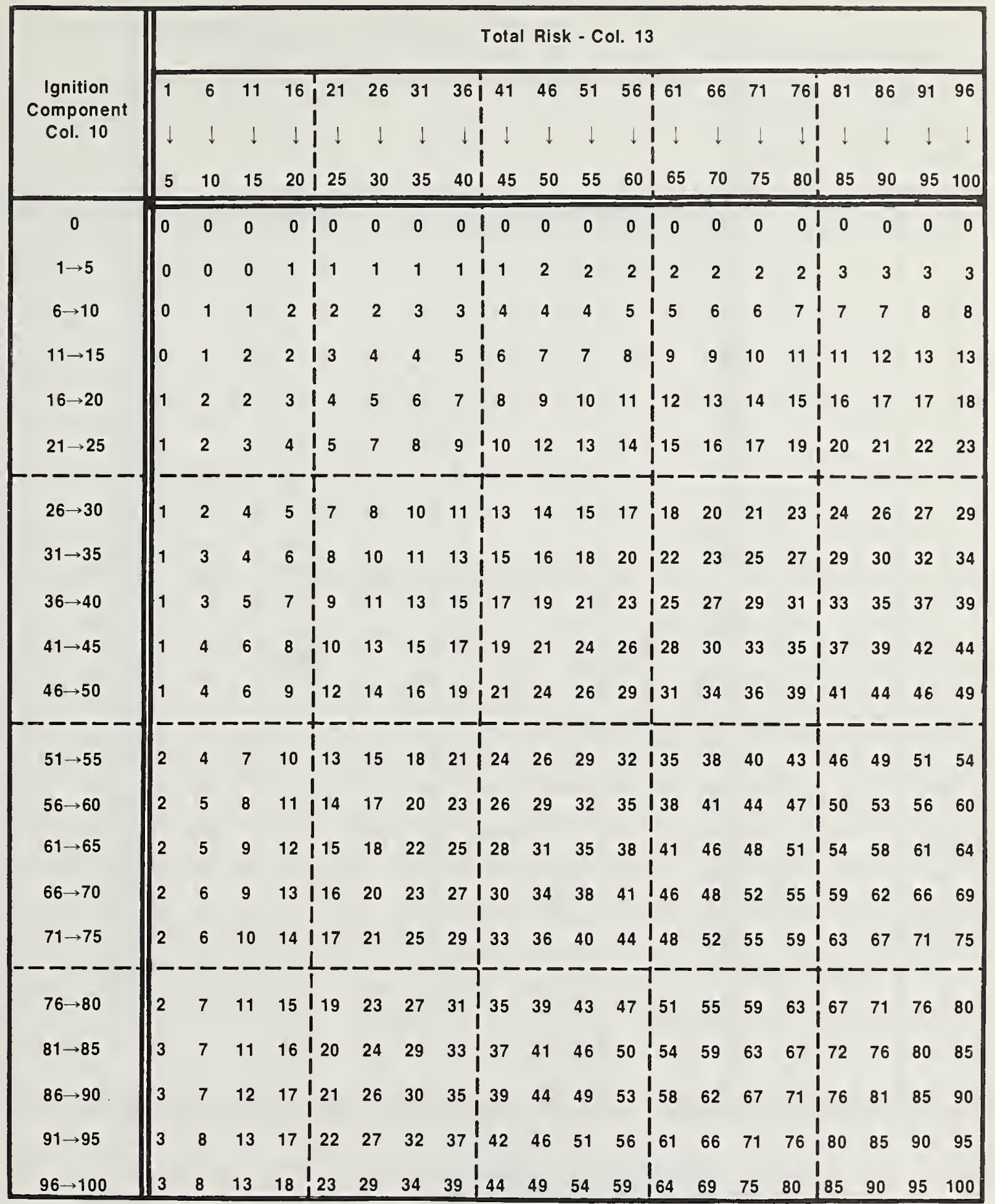

Purpose: To compute a number related to the probable level of fire incidence on the rating area.*

Procedure: At the intersection of the row indexed by the IC (column 10) and the column indexed by total Risk (column 13) is the OI; record in column 14.

* If it is raining (state of weather code 5, 6, or 7) or there is snow or ice on the ground fuels, record a zero (0) in column 14. 


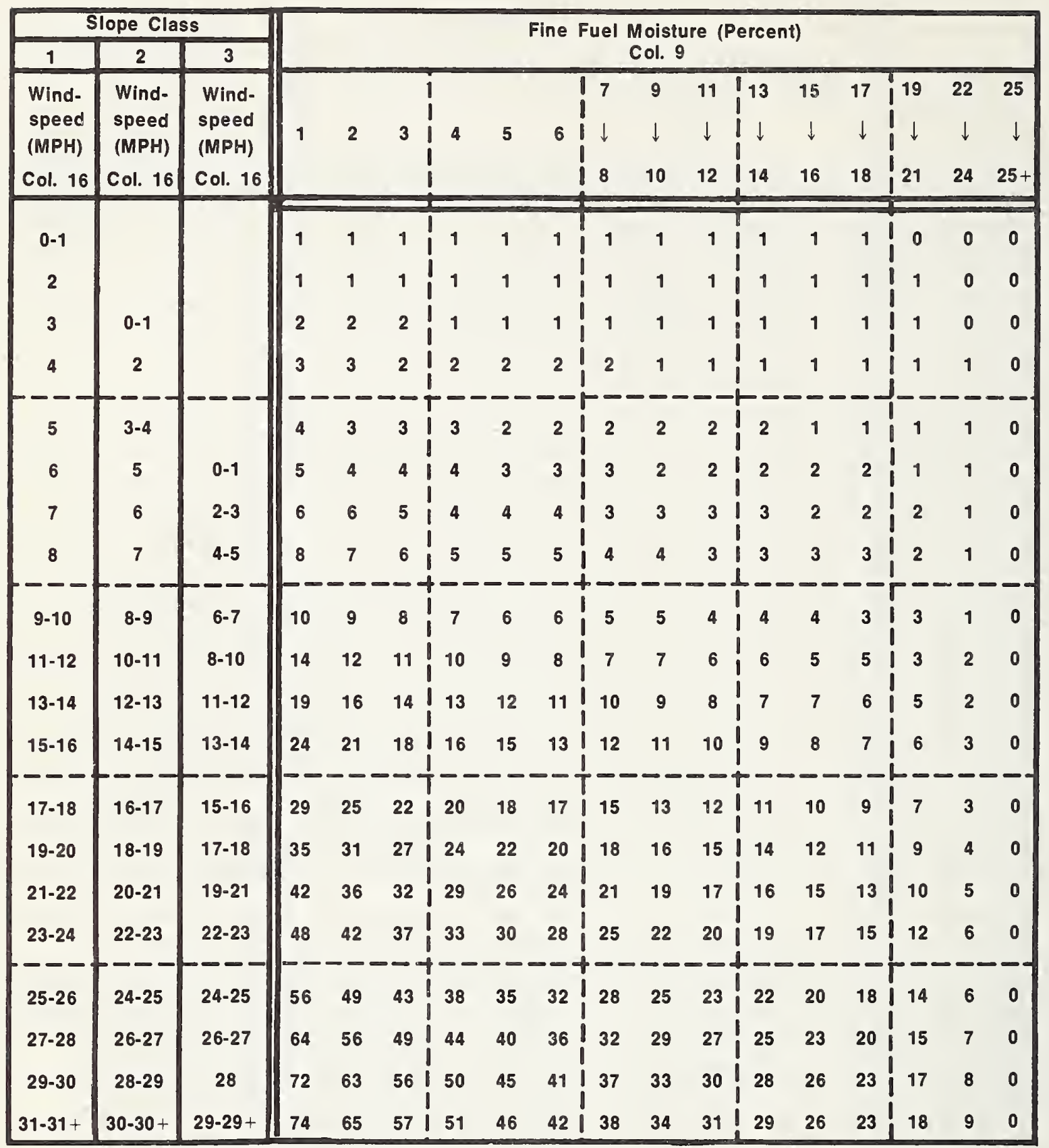

Purpose: To compute a number related to the forward rate of spread of the head of a fire burning in fuels represented by this fuel model.*

Procedure: The windspeed (column 16) is entered into the table from the column headed by the slope class assigned to the rating area. At the intersection of this row and the column indexed by the FFM (column 9) is the SC; record in column 18.

* If it is raining (state of weather code 5, 6, or 7) or there is snow or ice on the ground fuels, record a zero (0) in column 18. 
ENERGY RELEASE COMPONENT - FUEL MODEL C

Col. 21

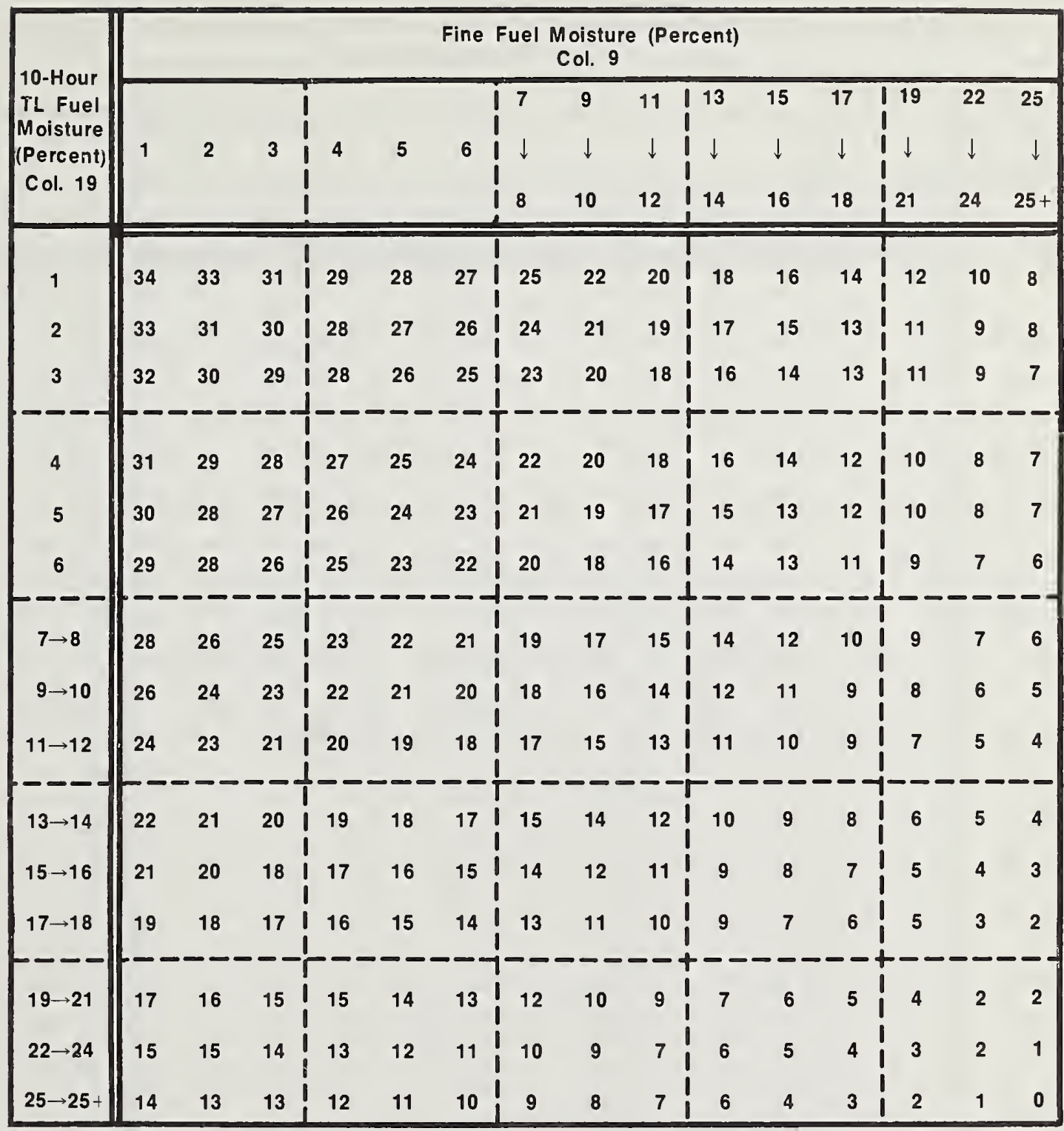

Purpose: To compute a number related to the rate of combustion at the head of a fire burning in fuels represented by this fuel model.*

Procedure: Read the ERC at the intersection of the row indexed by the 10-Hr. TL FM (column 19) and the column indexed by the FFM (column 9); record in column 21.

* If it is raining (state of weather code 5, 6, or 7) or there is snow or ice on the ground fuels, record a zero (0) in column 21. 
BURNING INDEX - FUEL MODEL C

Col. 22

\begin{tabular}{|c|c|c|c|c|c|c|c|c|c|c|c|c|c|c|c|c|c|c|}
\hline \multirow{2}{*}{$\begin{array}{c}\text { Spread } \\
\text { Component } \\
\text { Col. } 18\end{array}$} & \multicolumn{18}{|c|}{$\begin{array}{l}\text { Energy Release Component } \\
\text { Col. } 21\end{array}$} \\
\hline & 0 & $\begin{array}{l}1 \\
\downarrow \\
2\end{array}$ & $\begin{array}{l}3 \\
\downarrow \\
4\end{array}$ & $\begin{array}{ll} & 5 \\
1 & \\
1 & \downarrow \\
1 & \\
1 & 6\end{array}$ & $\begin{array}{l}7 \\
\downarrow \\
8\end{array}$ & $\begin{array}{r}9 \\
\downarrow \\
10\end{array}$ & $\begin{array}{c}11 \\
11 \\
\downarrow \\
\downarrow \\
12\end{array}$ & $\begin{array}{r}13 \\
\downarrow \\
14\end{array}$ & $\begin{array}{c}15 \\
\downarrow \\
16\end{array}$ & $\begin{array}{ll}1 & 17 \\
1 & \downarrow \\
1 & 18\end{array}$ & $\begin{array}{r}19 \\
\downarrow \\
20\end{array}$ & $\begin{array}{c}21 \\
\downarrow \\
22\end{array}$ & {$\left[\begin{array}{l}23 \\
\downarrow \\
24\end{array}\right.$} & $\begin{array}{c}25 \\
\downarrow \\
26\end{array}$ & $\begin{array}{r}27 \\
\downarrow \\
28\end{array}$ & $\left\{\begin{array}{l}29 \\
\downarrow \\
30\end{array}\right.$ & $\begin{array}{r}31 \\
\downarrow \\
32\end{array}$ & $\begin{array}{c}33 \\
\downarrow \\
34\end{array}$ \\
\hline 0 & 0 & 0 & 0 & 0 & 0 & 0 & 0 & 0 & 0 & 10 & 0 & 0 & 0 & 0 & & i 0 & 0 & 0 \\
\hline $1 \rightarrow 2$ & 0 & 1 & 2 & 12 & 2 & 2 & 2 & 3 & 3 & 3 & 3 & 3 & 3 & 4 & 4 & 4 & 4 & 4 \\
\hline $3 \rightarrow 7$ & 0 & 3 & 4 & 5 & 6 & 7 & 7 & 8 & 8 & 9 & 9 & 10 & 10 & 11 & 11 & 11 & 12 & 12 \\
\hline $8 \rightarrow 12$ & 0 & 4 & 6 & 7 & 8 & 9 & 0 & 11 & 12 & 12 & 13 & 13 & 14 & 14 & 15 & 15 & 16 & 16 \\
\hline $13 \rightarrow 17$ & 0 & 5 & 7 & 9 & 10 & 11 & 12 & 13 & 14 & 15 & 15 & 16 & 17 & 17 & 18 & 19 & 19 & 20 \\
\hline $18 \rightarrow 22$ & 0 & 6 & 8 & 10 & 12 & 13 & 14 & 15 & 16 & 17 & 18 & 18 & 19 & 20 & 21 & 21 & 22 & 23 \\
\hline $23 \rightarrow 27$ & 0 & 7 & 9 & & 13 & 14 & 15 & 17 & 18 & 19 & 20 & 20 & 21 & 22 & 23 & & 24 & 25 \\
\hline $28 \rightarrow 32$ & 0 & 7 & 10 & $j^{12}$ & 14 & 15 & 17 & 18 & 19 & i 20 & 21 & 22 & 23 & 24 & & 26 & 26 & 27 \\
\hline $33 \rightarrow 37$ & 0 & 8 & 11 & 13 & 15 & 17 & 18 & 19 & 21 & 22 & 23 & 24 & 25 & 26 & 27 & 27 & 28 & 29 \\
\hline $38 \rightarrow 42$ & 0 & 8 & 12 & I 14 & 16 & 18 & 19 & 21 & 22 & | 23 & 24 & 25 & 26 & 27 & & 29 & 30 & 31 \\
\hline $43 \rightarrow 47$ & 0 & 9 & 12 & i 15 & 17 & 19 & 20 & 22 & 23 & j 24 & 26 & 27 & 28 & 29 & 30 & | 31 & 32 & 33 \\
\hline $48 \rightarrow 52$ & 0 & 9 & 13 & 15 & 18 & 20 & 21 & 23 & 24 & 26 & 27 & 28 & 29 & 30 & & & 33 & 34 \\
\hline & & & & & & & & & & \pm & & - & 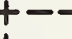 & & -- & & & - \\
\hline $53 \rightarrow 57$ & 0 & 10 & 13 & 16 & 18 & 20 & 22 & 24 & 25 & 27 & 28 & 29 & 31 & 32 & & 34 & 35 & 36 \\
\hline $58 \rightarrow 62$ & 0 & 10 & 14 & 17 & 19 & 21 & 23 & 25 & 26 & 28 & 29 & 31 & 32 & 33 & & 35 & 36 & 37 \\
\hline $63 \rightarrow 67$ & 0 & 11 & 14 & 17 & 20 & 22 & 24 & 26 & 27 & 29 & 30 & 32 & 33 & 34 & 35 & 37 & 38 & 39 \\
\hline & & & & & & & & & & & & & & & & & & \\
\hline $68 \rightarrow 72$ & 0 & 11 & 15 & 18 & 21 & 23 & 25 & 27 & 28 & 30 & 31 & 33 & 34 & 35 & & & 39 & 40 \\
\hline $73 \rightarrow 77$ & 0 & 11 & 15 & 19 & 21 & 24 & 26 & 27 & 29 & 31 & 32 & $34 !$ & 35 & 37 & 38 & 39 & 40 & 41 \\
\hline
\end{tabular}

Purpose: To compute a number related to the amount of effort needed to contain a single fire burning in fuels represented by this fuel model.*

Procedure: Read the BI at the intersection of the row indexed by the SC (column 18) and the ERC (column 21); record in column 22.

* If it is raining (state of weather code 5, 6, or 7) or there is snow or ice on the ground fuels, record a zero (0) in column 22 . 
FIRE LOAD INDEX - FUEL MODEL C

Col. 23

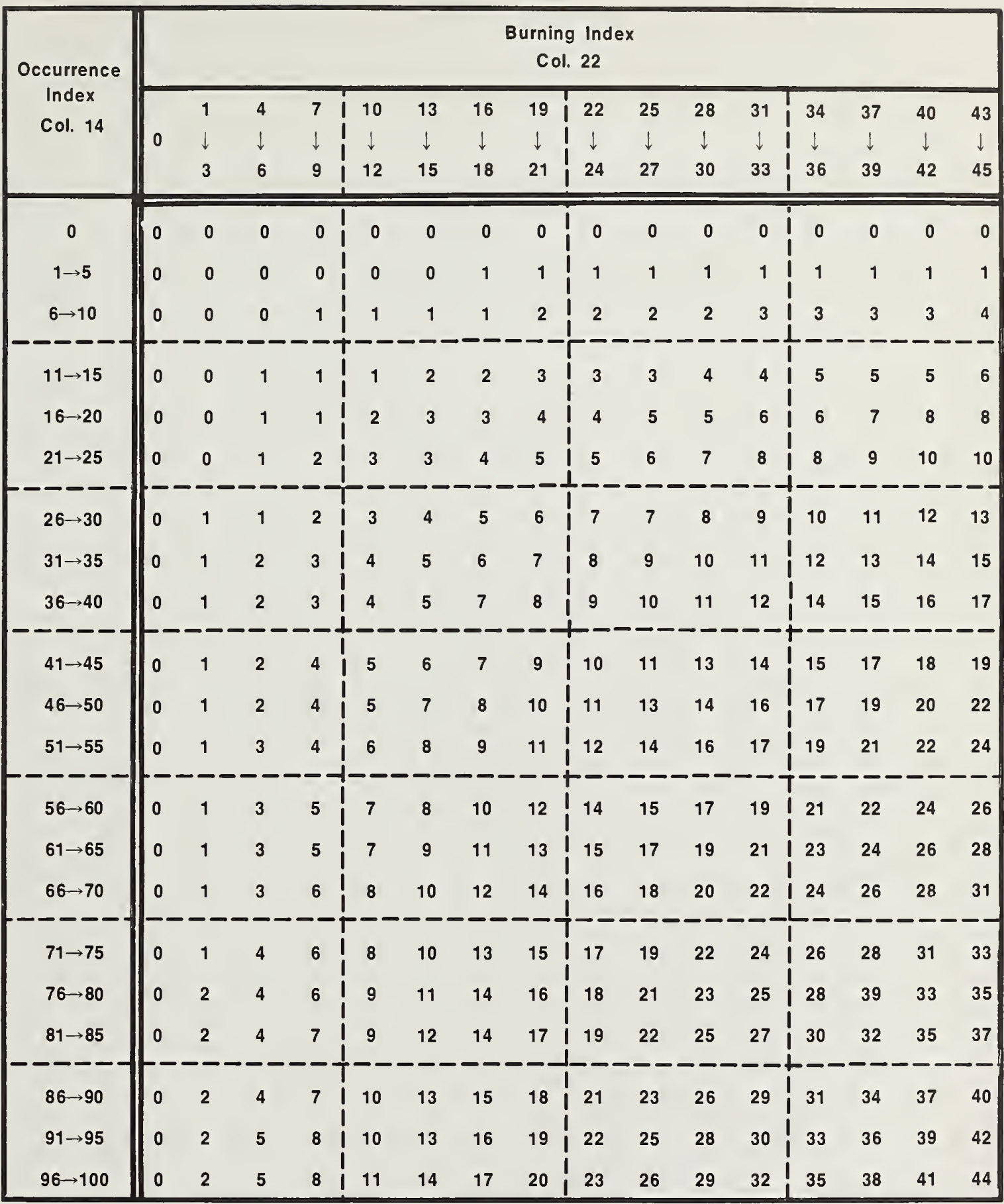

Purpose: To compute a number related to the total effort needed to contain all probable fires on a rating area.*

Procedure: Read the FLI at the intersection of the row indexed by the OI (column 14) and the column indexed by the BI (column 22 ); record in column 23 .

* If it is raining (state of weather code 5, 6, or 7) or there is snow or ice on the ground fuels, record a zero (0) in column 23. 
78 
Fuel Model D

79 


\section{COMPUTATIONAL FLOW CHART FUEL MODEL D}

(1)

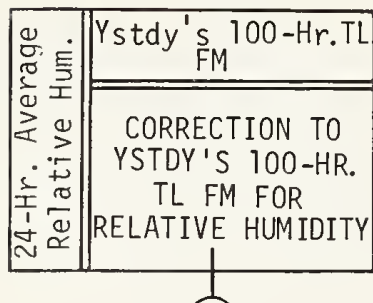

(3)
(2)

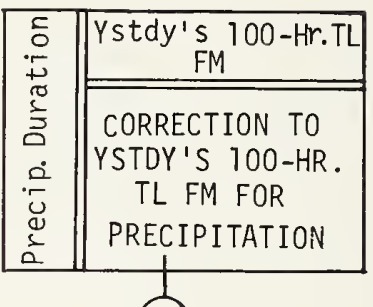

(3)

(4)

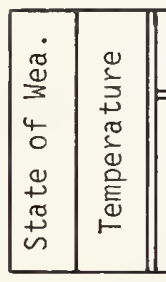

Relative Hum.

1 -HOUR

TIMELAG

FUEL MOISTURE

(6)

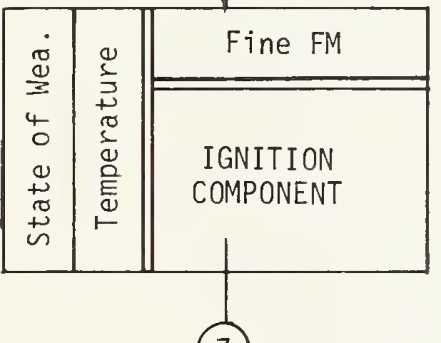

(7)
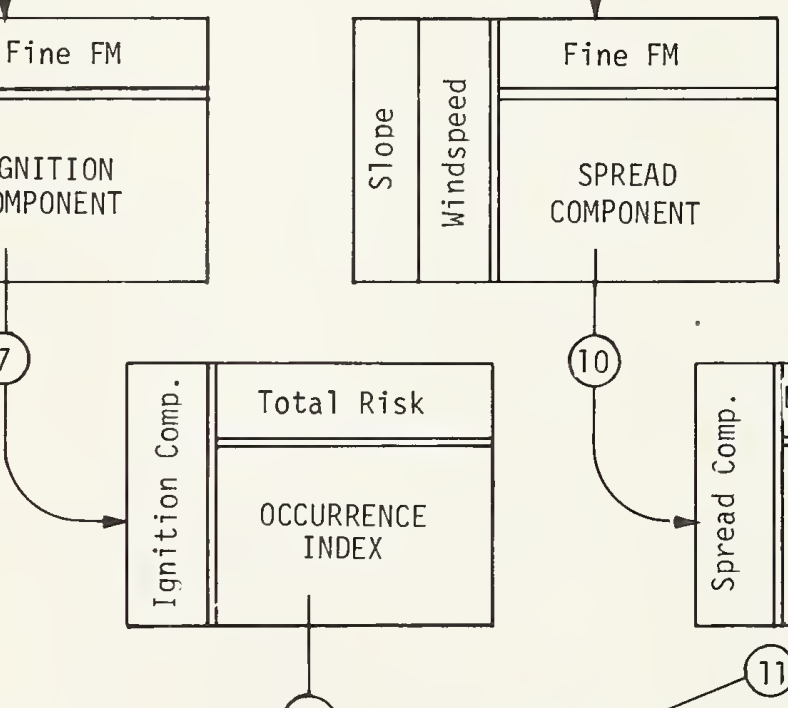

FINE

FUEL

MOISTURE oday's $100-\mathrm{Hr}$. TL FM
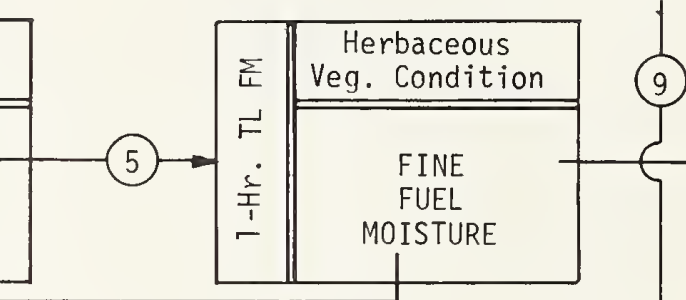

(9)

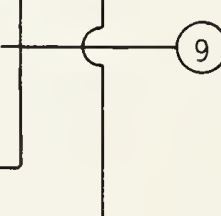

(8)

(11)

(10)
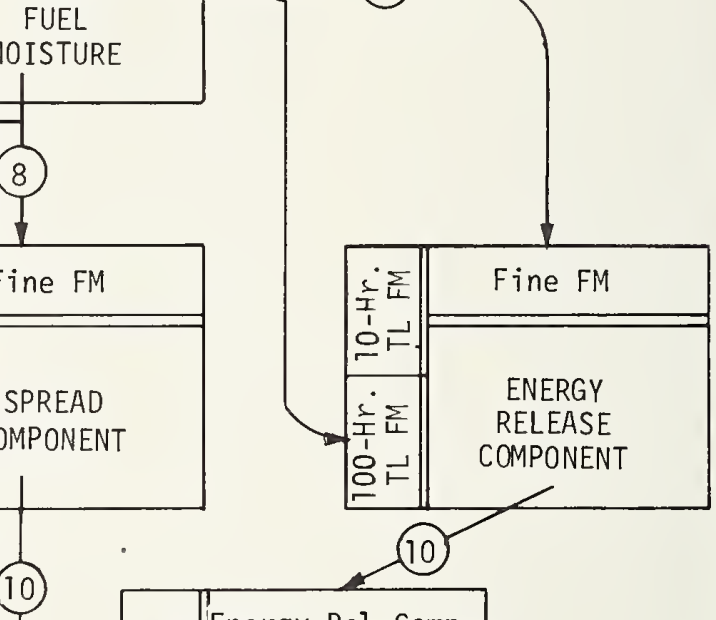


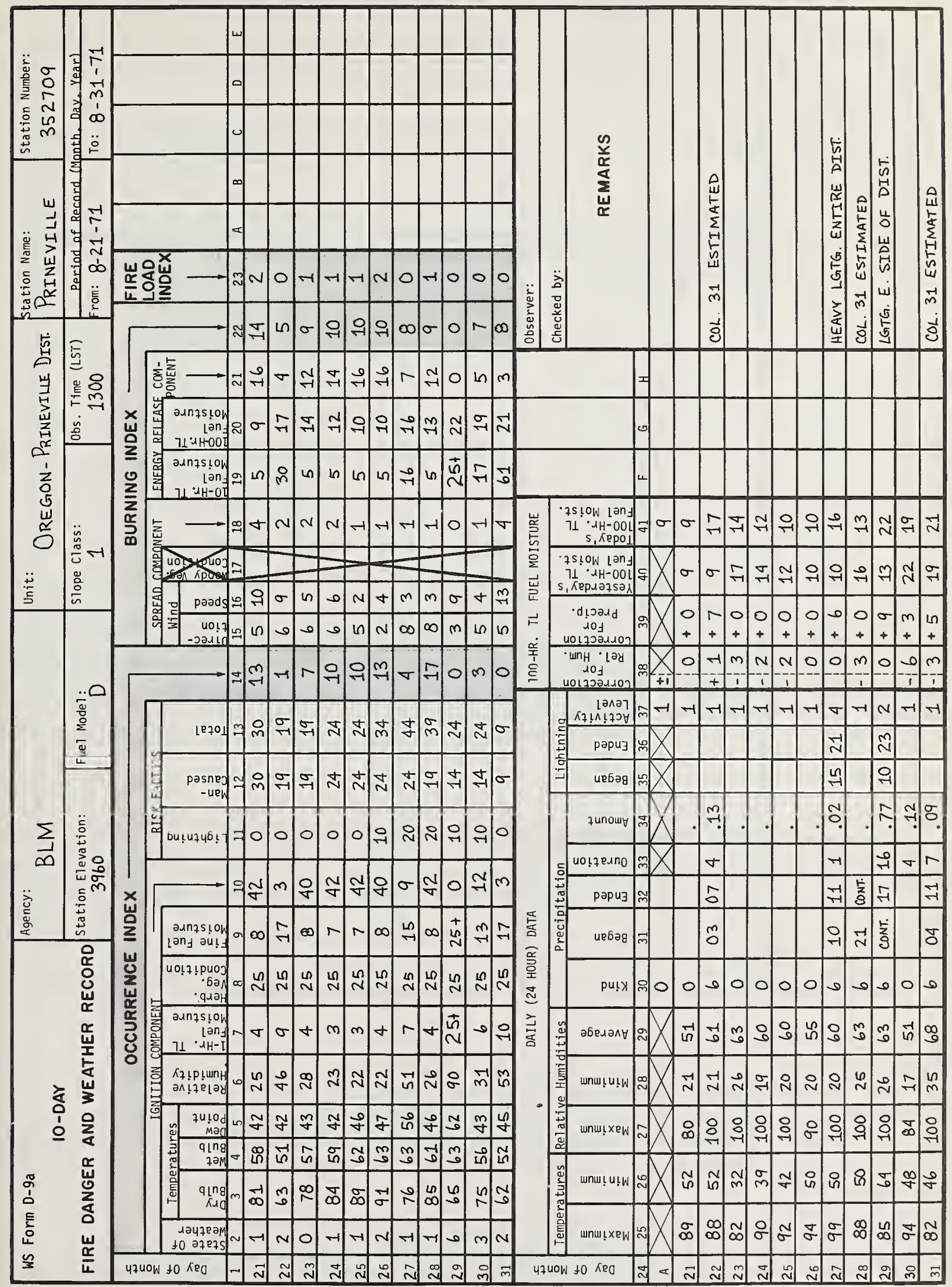


CORRECTION TO 100 - HOUR TIMELAG FUEL MOISTURE FOR RELATIVE HUMIDITY (PERCENT) Col. 38

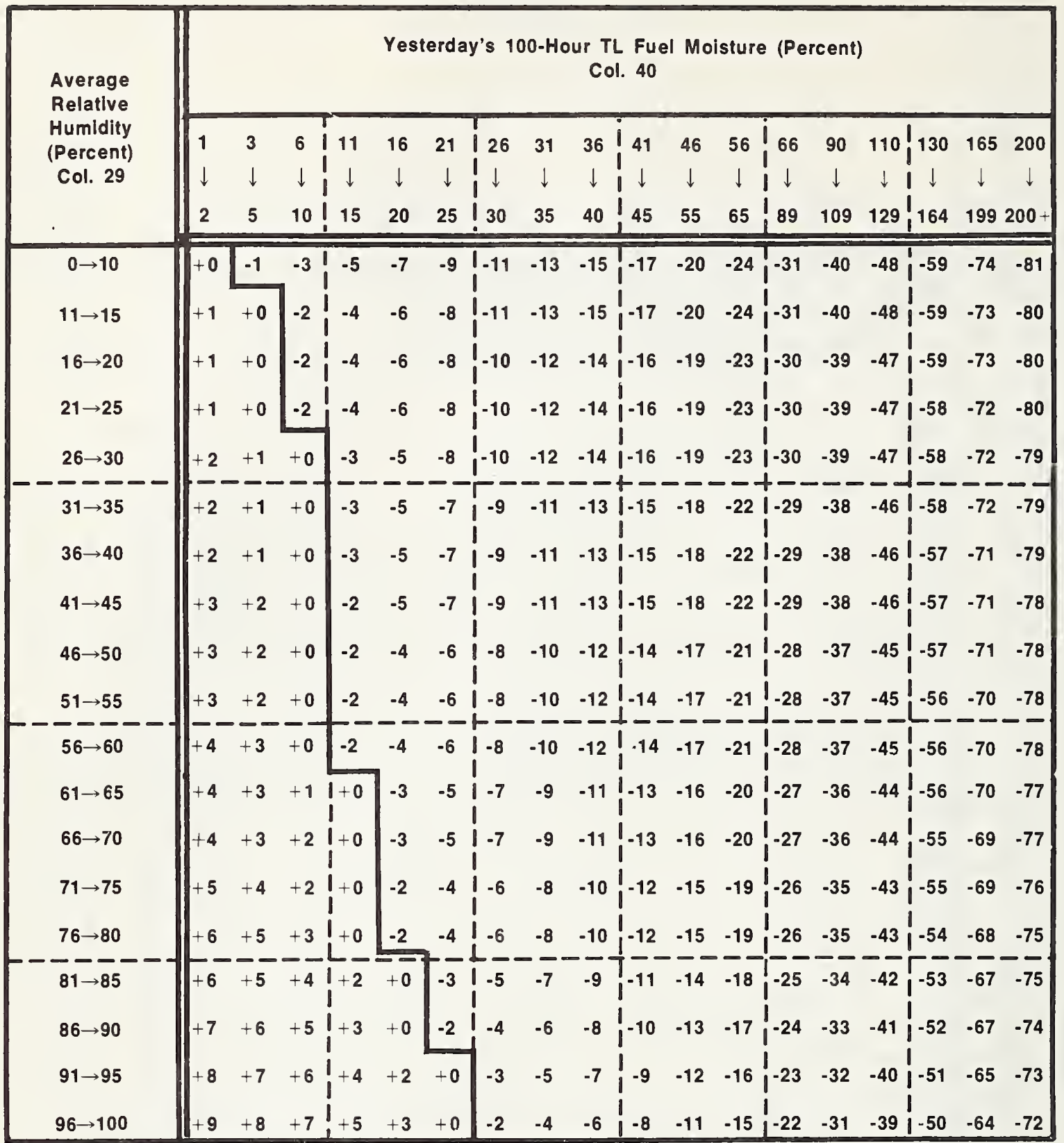

Purpose: To compute the effect of atmospheric humidity (water vapor) since Basic Observation Time yesterday, on the moisture content of the $100-\mathrm{Hr}$. TL, fuels.*, **

Procedures: At the intersection of the column indexed by yesterday's 100-Hr. TL, FM (column 40 )*** and the row indexed by the 24-hour average relative humidity (column 29) is the correction to the $100-\mathrm{Hr}$. TL FM for relative humidity; record in column 38.

* Values can be positive (+) or negative (-), record the proper sign.

** If it has rained continuously for the past 24 hours, record a zero $(0)$ in column 38 .

*** At the beginning of the fire season, an initial value of 35 percent should be assumed. 


\begin{tabular}{|c|c|c|c|c|c|c|c|c|c|}
\hline \multirow[b]{2}{*}{$\begin{array}{l}\text { Precipitation } \\
\text { Duration } \\
\text { (Hours) } \\
\text { Col. } 33\end{array}$} & \multicolumn{9}{|c|}{$\begin{array}{c}\text { Yesterday's 100-Hour TL Fuel Moisture (Percent) } \\
\text { Col. } 40\end{array}$} \\
\hline & 2 & $\begin{array}{l}3 \\
\downarrow \\
5\end{array}$ & $\begin{array}{c}6 \\
\downarrow \\
10\end{array}$ & $\begin{array}{c}11 \\
\downarrow \\
15\end{array}$ & $\begin{array}{c}16 \\
\downarrow \\
20\end{array}$ & $\begin{array}{c}21 \\
\downarrow \\
25\end{array}$ & $\begin{array}{c}26 \\
\downarrow \\
30\end{array}$ & $\begin{array}{c}31 \\
\downarrow \\
35\end{array}$ & $\begin{array}{c}36 \\
\downarrow \\
36+\end{array}$ \\
\hline $1 \rightarrow 3$ & 8 & 7 & 6 & 4 & 3 & 2 & 1 & 0 & 0 \\
\hline $4 \rightarrow 6$ & 9 & 8 & 7 & 5 & 4 & 3 & 1 & 1 & 1 \\
\hline $7 \rightarrow 9$ & 10 & 9 & 8 & 6 & 5 & 3 & 2 & 1 & 1 \\
\hline $10 \rightarrow 12$ & 11 & 10 & 9 & 7 & 6 & 4 & 2 & 2 & 2 \\
\hline $13 \rightarrow 15$ & 12 & 11 & 10 & 7 & 6 & 5 & 3 & 2 & 2 \\
\hline $16 \rightarrow 18$ & 13 & 13 & 11 & 9 & 7 & 6 & 4 & 3 & 3 \\
\hline $19 \rightarrow 21$ & 15 & 14 & 12 & 10 & 8 & 6 & 5 & 4 & 4 \\
\hline $22 \rightarrow 24$ & 16 & 15 & 14 & 11 & 9 & 7 & 5 & 5 & 4 \\
\hline
\end{tabular}

Purpose: To compute the effect of precipitation occurring since Basic Observation Time yesterday on the moisture content of the $100-\mathrm{Hr}$. TL fuels.*

Procedure: At the intersection of the column indexed by yesterday's 100-Hr. TL FM (column 40) and the row indexed by the precipitation duration (column 33) is the correction to the 100-Hr. TL, FM for precipitation; record in column 39.

\section{Computation Of Today's 100-Hour Timelag Fuel Moisture}

Being careful of the arithmetic signs, add the entries in columns 38,39 , and 40 . Enter the results in columns 41 and 20; this is today's $100-\mathrm{Hr}$. TL FM.

* If no precipitation has occurred in the past 24 hours, record a zero (0) in column 39. 


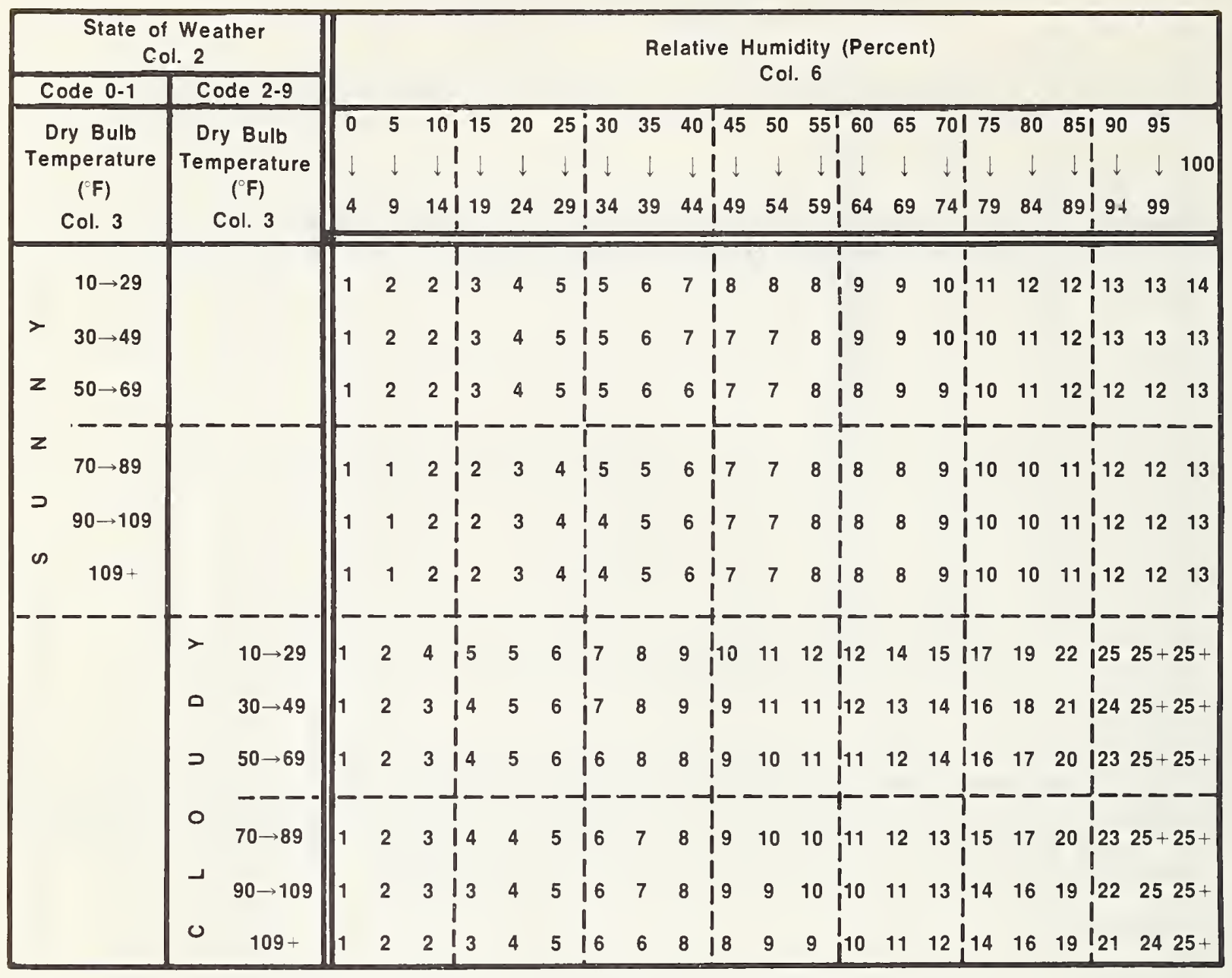

Purpose: To compute the moisture content of dead fuels one-quarter inch and less in diameter.* Procedure: If the state of the weather is coded 2, 3, 4, 8, or 9 (column 2), or if the observation is being taken before 1000 or after 1500 LST, the dry-bulb temperature is entered to the left in that section of the table labeled "cloudy." Otherwise enter the temperature in the section labeled "sunny." Read the 1-Hr. TL FM at the intersection of this row and the column indexed by the appropriate value for relative humidity (column 6); record in column 7 .

* If it is raining (state of weather codes 5, 6, or 7) or there is snow or ice on the ground fuels, record $25+$ in column 7 . 
FINE FUEL MOISTURE (PERCENT)

Col. 9

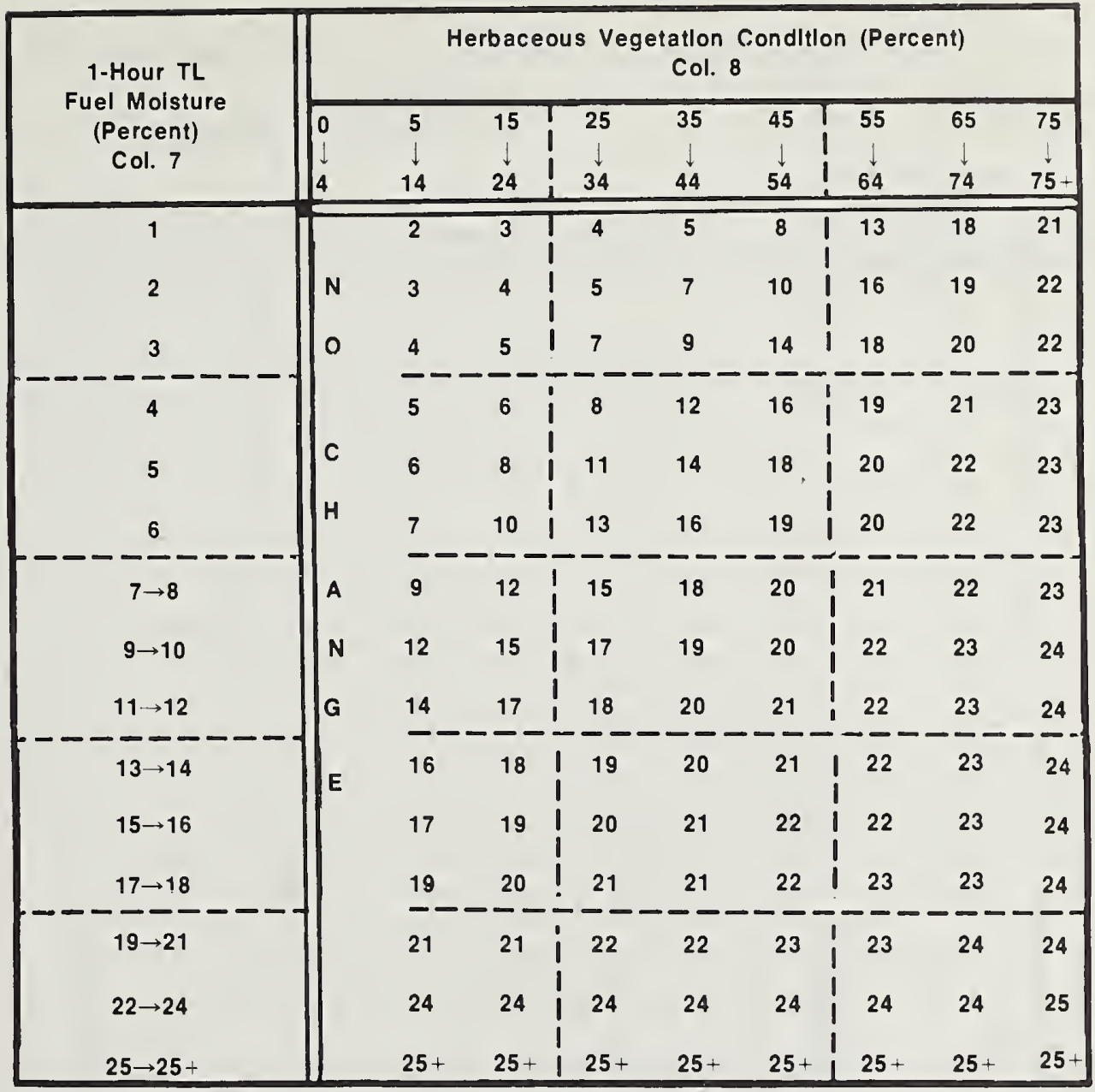

Purpose: To adjust the 1-Hr. TL FM to account for the reduced flammability of the lesser fuels due to the presence of living herbaceous plant material.*

Procedure: Read the FFM at the intersection of the row indexed by the 1-Hr. TL FM (column 7) and the column indexed by herbaceous vegetation condition (column 8); record in column 9 .

* If the herbaceous vegetation condition is 4 or less, enter the value of the 1-Hr. TL FM directly into column 9. 


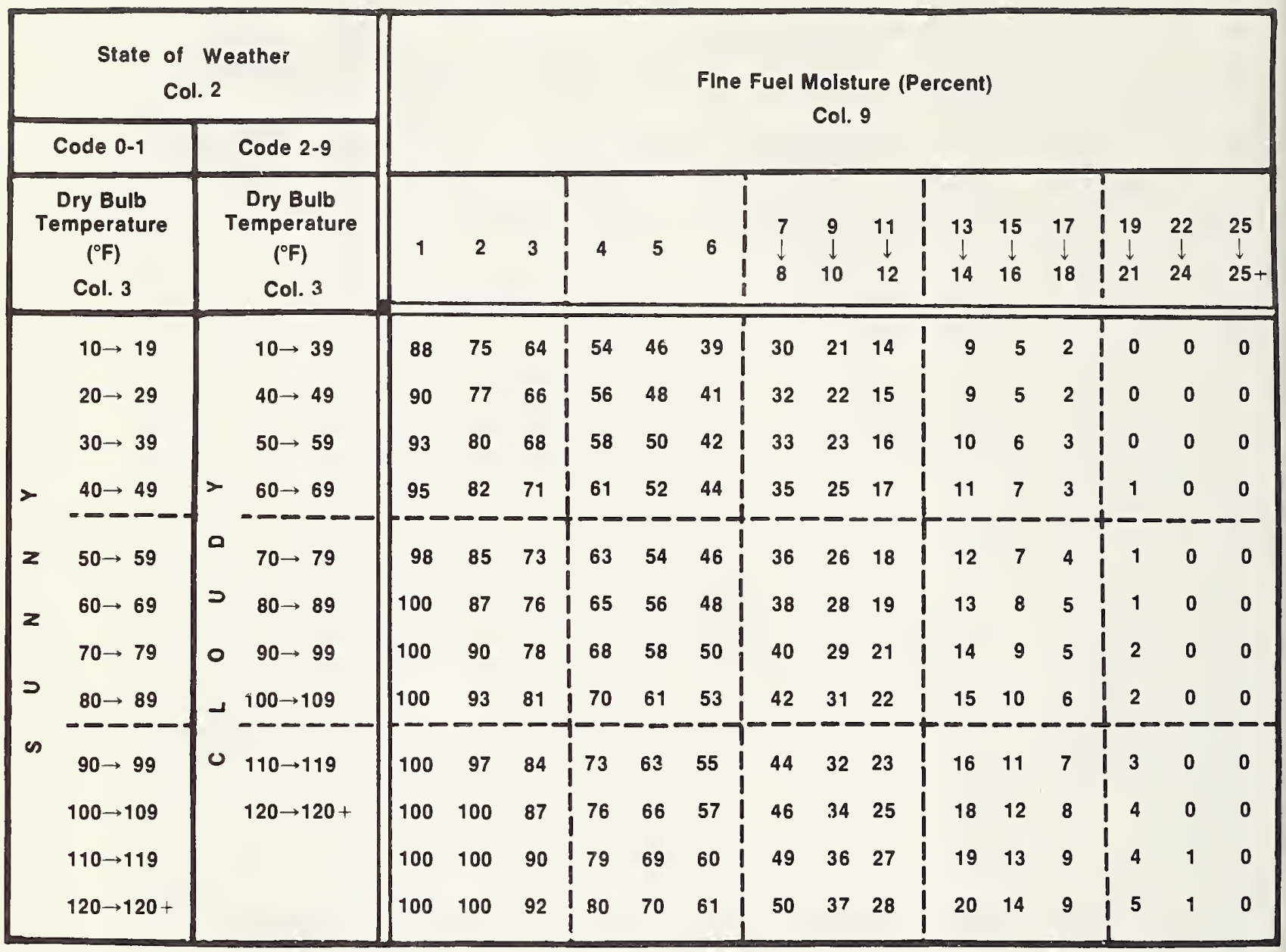

Purpose: To compute a number related to the probability that a fire will result if a firebrand is introduced into the fine fuel complex.*

Procedure: If the state of the weather is coded 2,3,4,8, or 9 (column 2), or if the observation is being taken before 1000 or after 1500 LST, the dry-bulb temperature (column 3) is entered to the left in that section of the table labeled "cloudy." Otherwise, enter the temperature in the section labeled "sunny." Read the IC at the intersection of the column indexed by the FFM (column 9) and the row indexed by the dry-bulb temperature (column 3); record in column 10.

* If it is raining (state of weather code 5,6, or 7) or there is snow or ice on the ground fuels, record a zero (0) in column 10. 


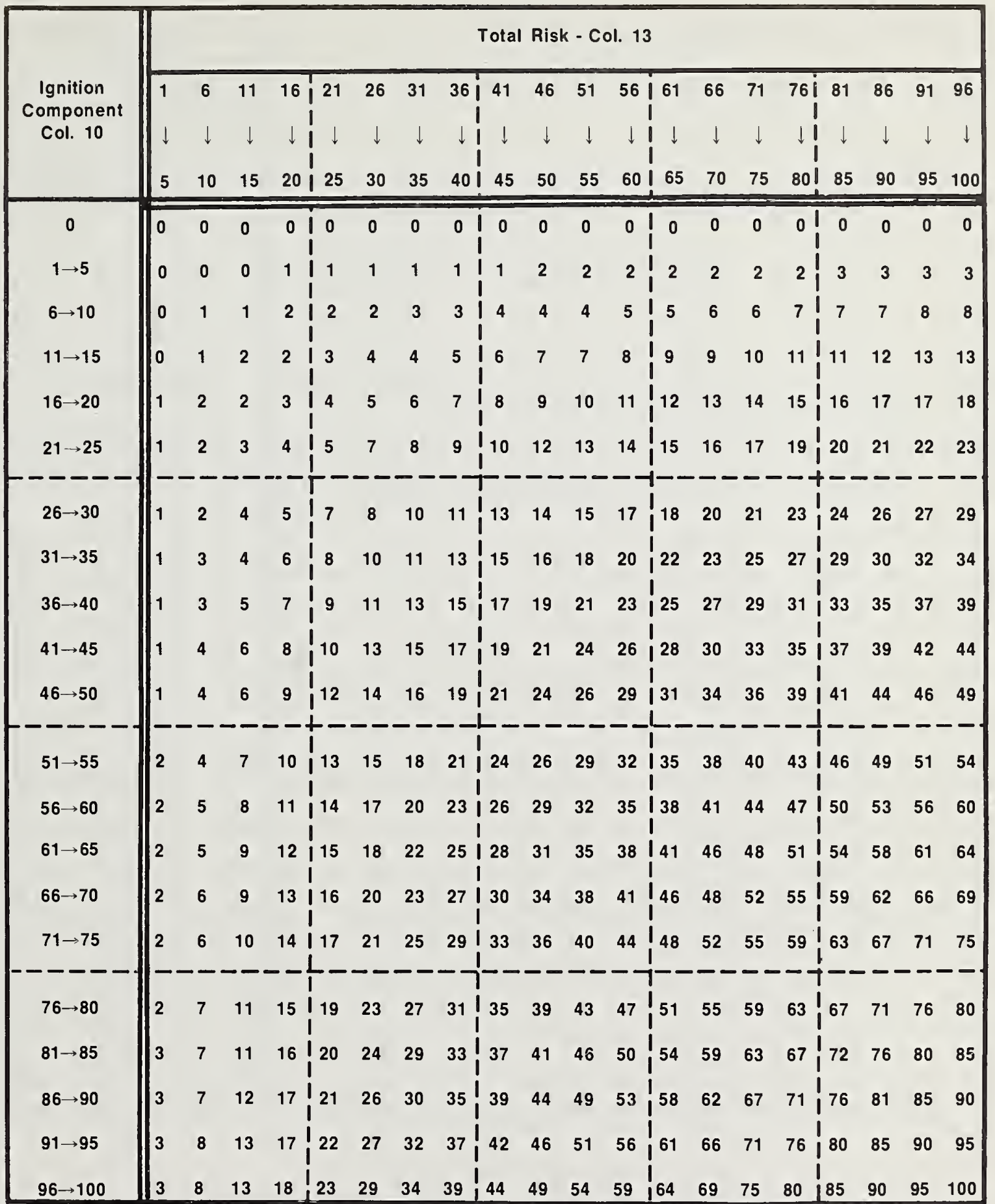

Purpose: To compute a number related to the probable level of fire incidence on the rating area.*

Procedure: At the intersection of the row indexed by the IC (column 10) and the column indexed by total Risk (column 13) is the OI; record in column 14.

* If it is raining (state of weather code 5, 6, or 7) or there is snow or ice on the ground fuels, record a zero (0) in column 14. 


\section{Spread Component - Fuel Model D}

Purpose: To compute a number related to the forward rate of spread of the head of a fire burning in fuels represented by this fuel model.*

Procedure: The windspeed (column 16) is entered into the table from the column headed by the slope class assigned to the rating area. At the intersection of this row and the column indexed by the FFM (column 9) is the SC; record in column 18.

* If it is raining (state of weather code 5,6,7) or there is snow or ice on the ground fuels, record a zero (0) in column 18. 


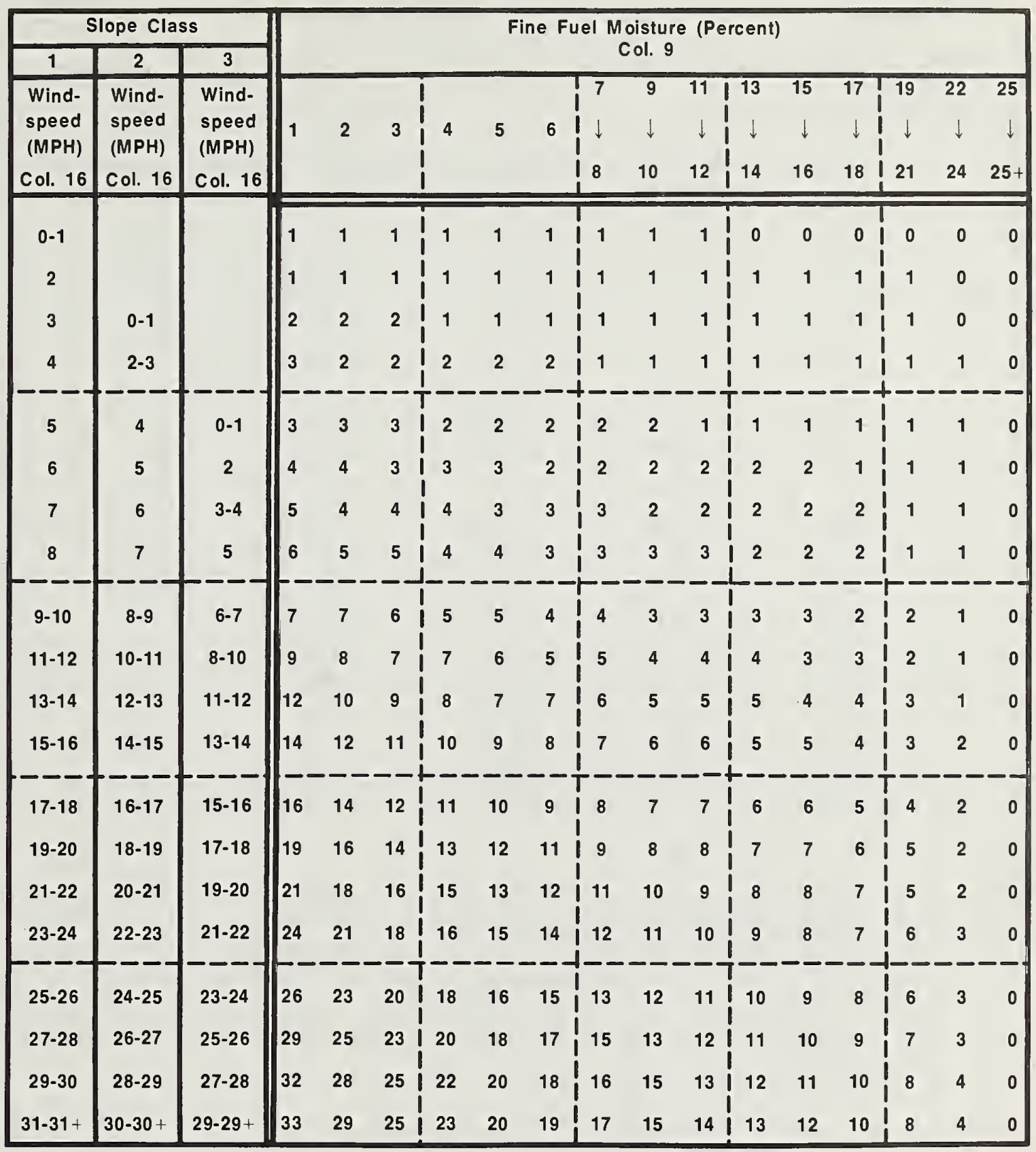




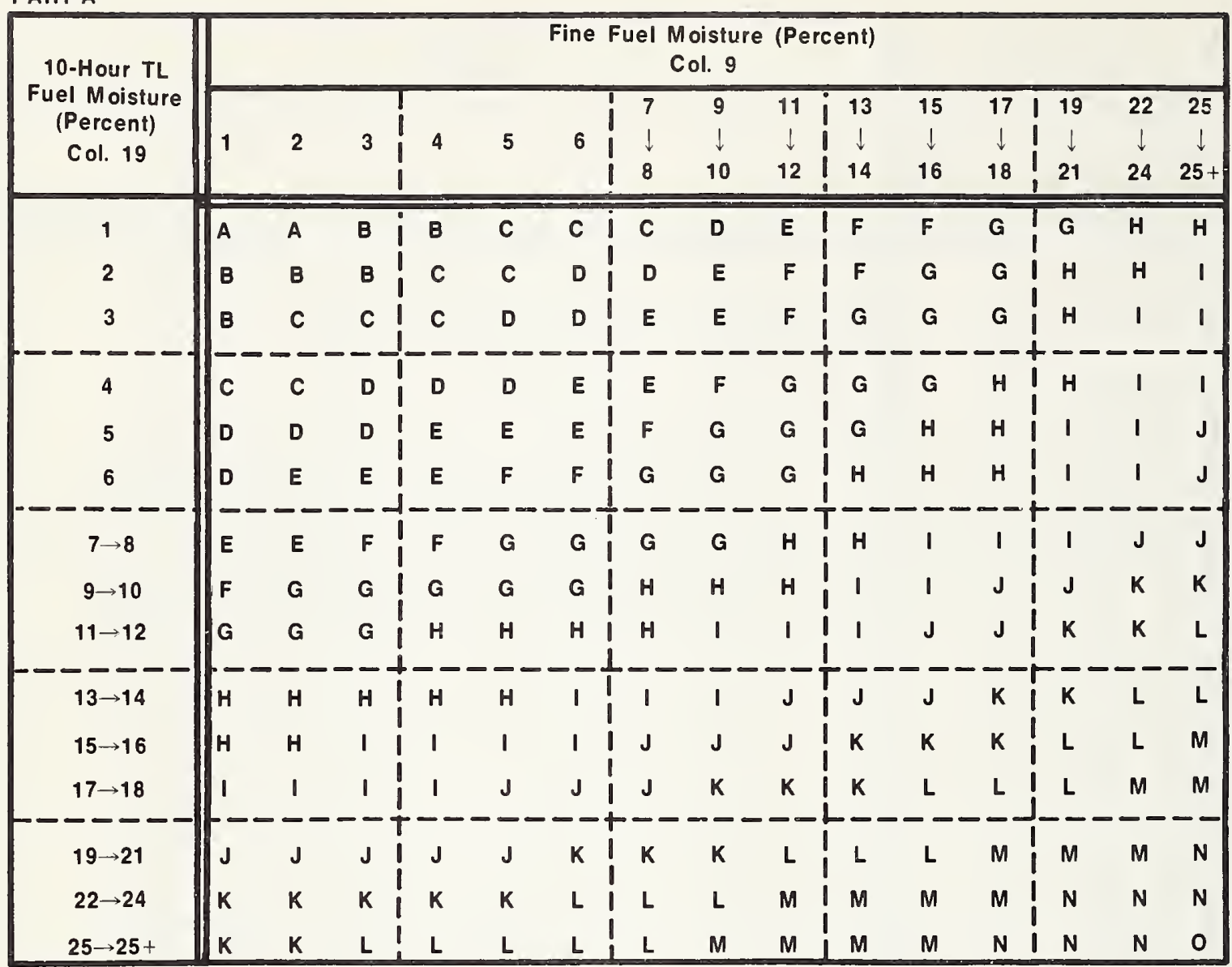

Procedure: To compute a number related to the rate of combustion at the head of a fire burning in fuels represented by this fuel model.*

Procedure: In Part A-Read the transfer letter at the intersection of the row indexed by the 10-Hr. TL FM (column 19) and the column indexed by the FFM (column 9).

In Part B-Read the ERC at the intersection of the row indexed by the $100-\mathrm{Hr}$. TL FM (column 20) and the column indexed by the transfer letter from Part A; record in column 21 .

* If it is raining (state of weather code 5, 6, or 7) or there is snow or ice on the ground fuels, record a zero (0) in column 21. 


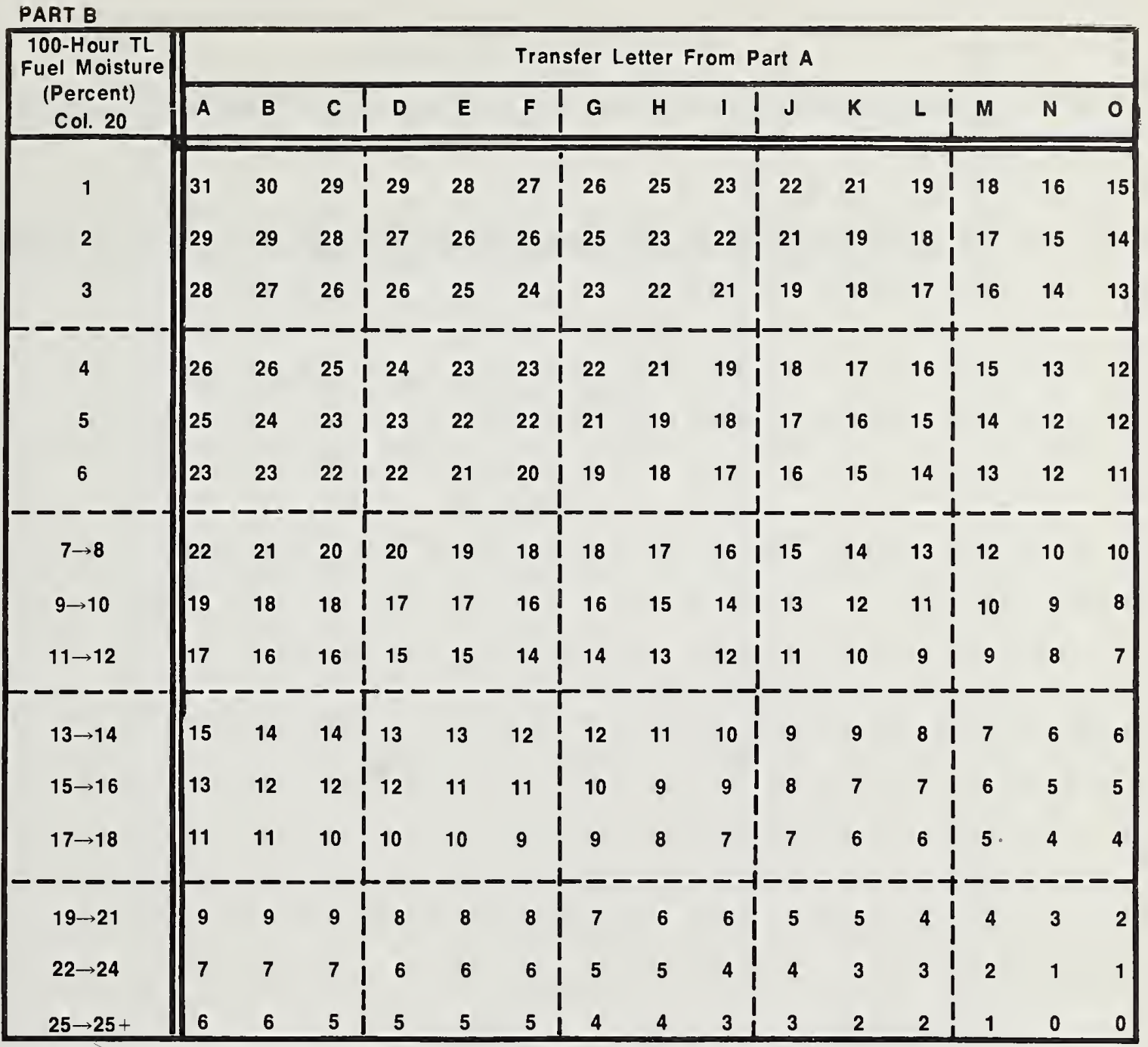




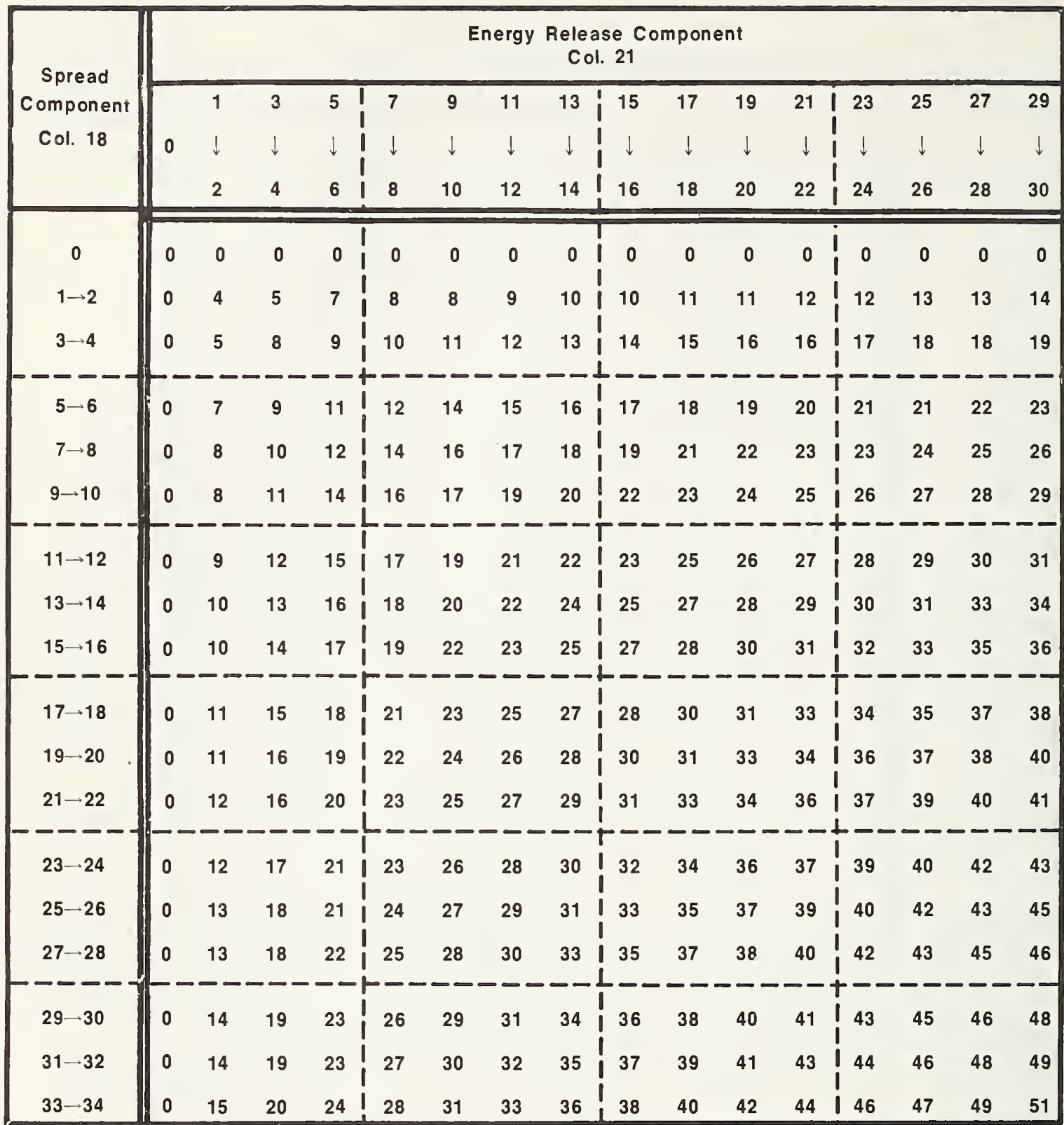

Purpose: To compute a number related to the amount of effort needed to contain a single fire burning in fuels represented by this fuel model.*

Procedure: Read the BI at the intersection of the row indexed by the SC (column 18) and the ERC (column 21); record in column 22.

* If it is raining (state of weather code 5,6, or 7) or there is snow or ice on the ground fuels, record a zero (0) in column 22. 


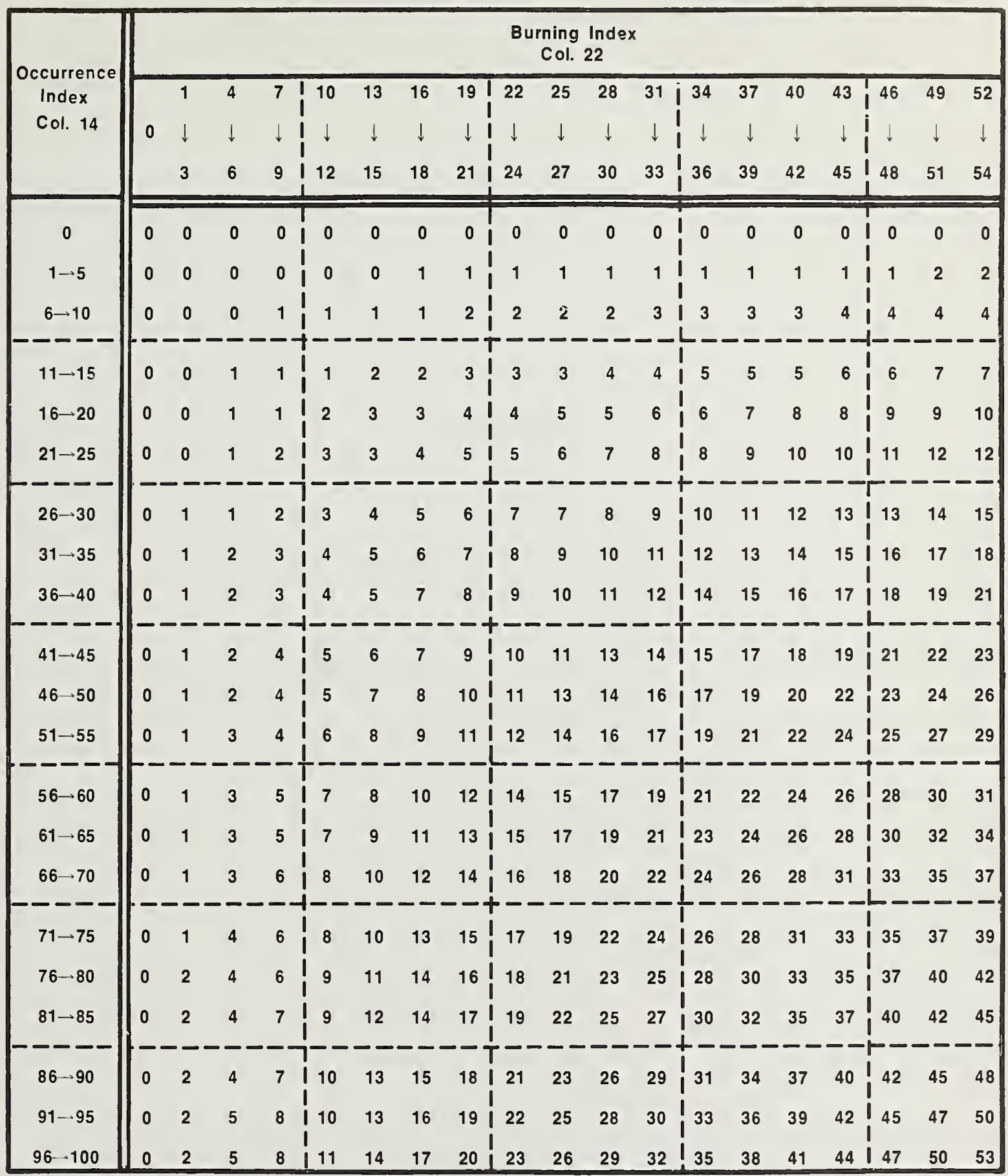

Purpose: To compute a number related to the total effort needed to contain all probable fires on a rating area.*

Procedure: Read the FLI at the intersection of the row indexed by the OI (column 14) and the column indexed by the BI (column 22 ); record in column 23.

* If it is raining (state of weather code 5, 6, or 7) or there is snow or ice on the ground fuels, record a zero (0) in column 23. 
94 
Fuel Model E

95 


\section{COMPUTATIONAL FLOW CHART \\ FUEL MODEL E}

(1)

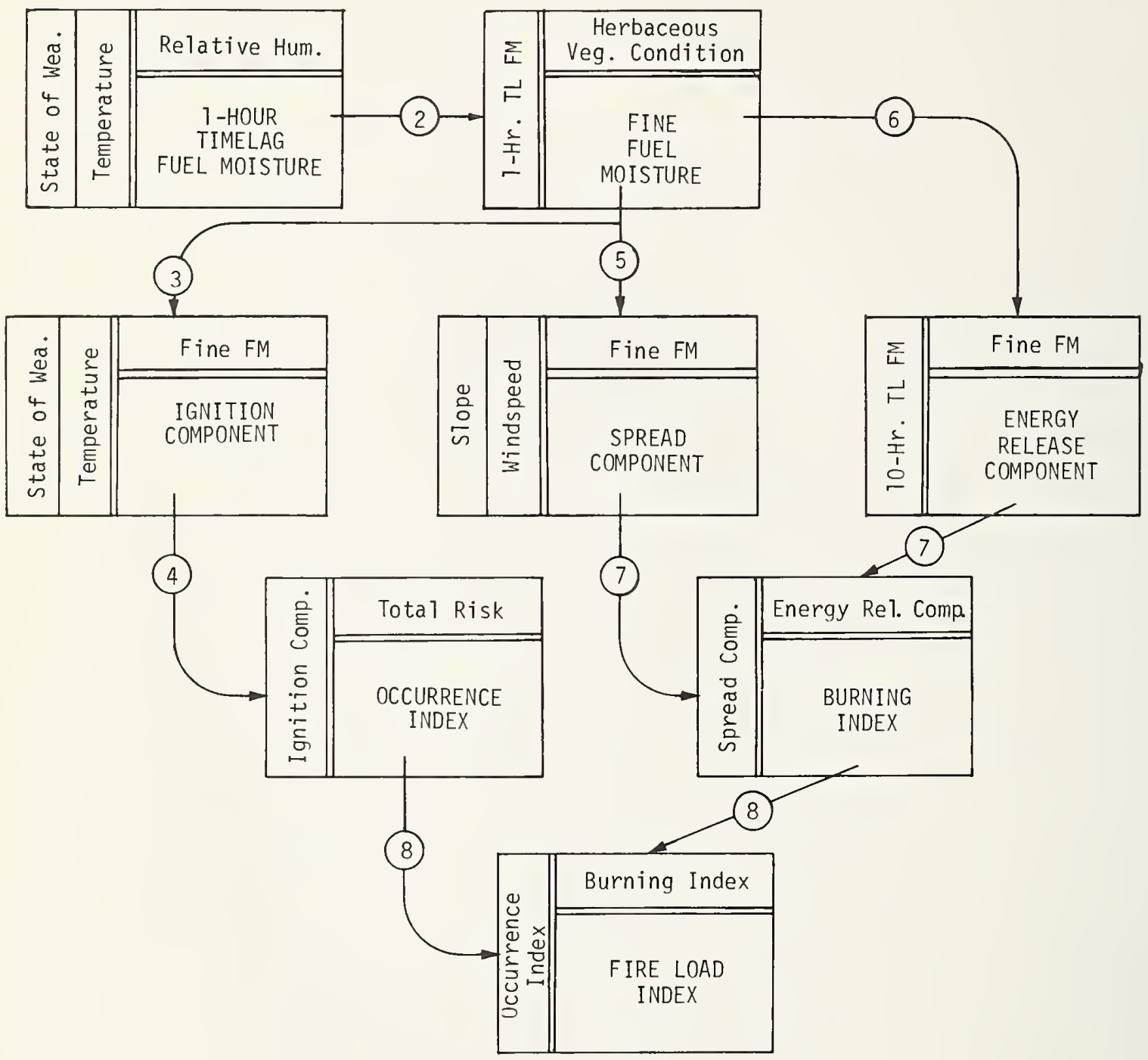




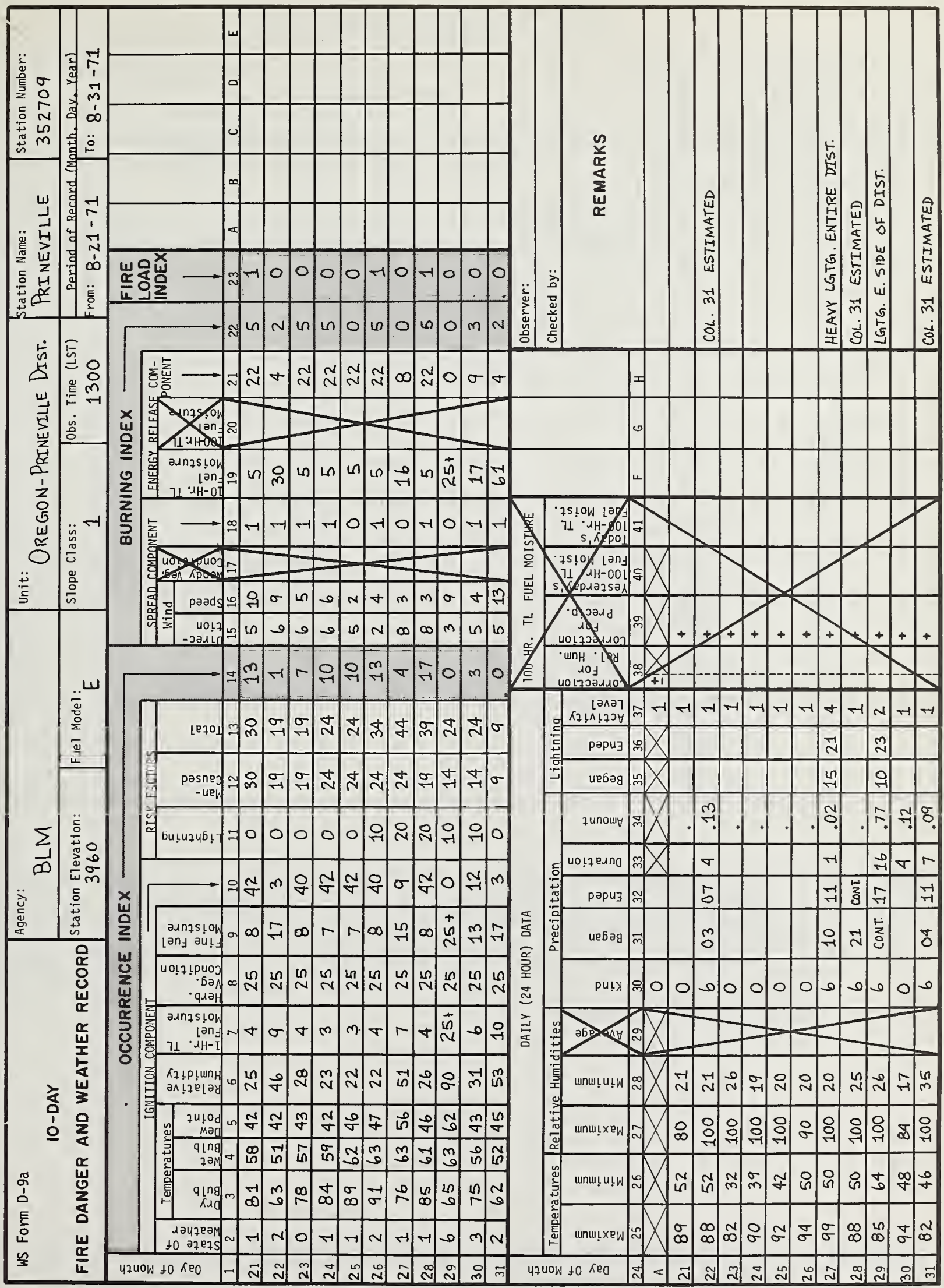




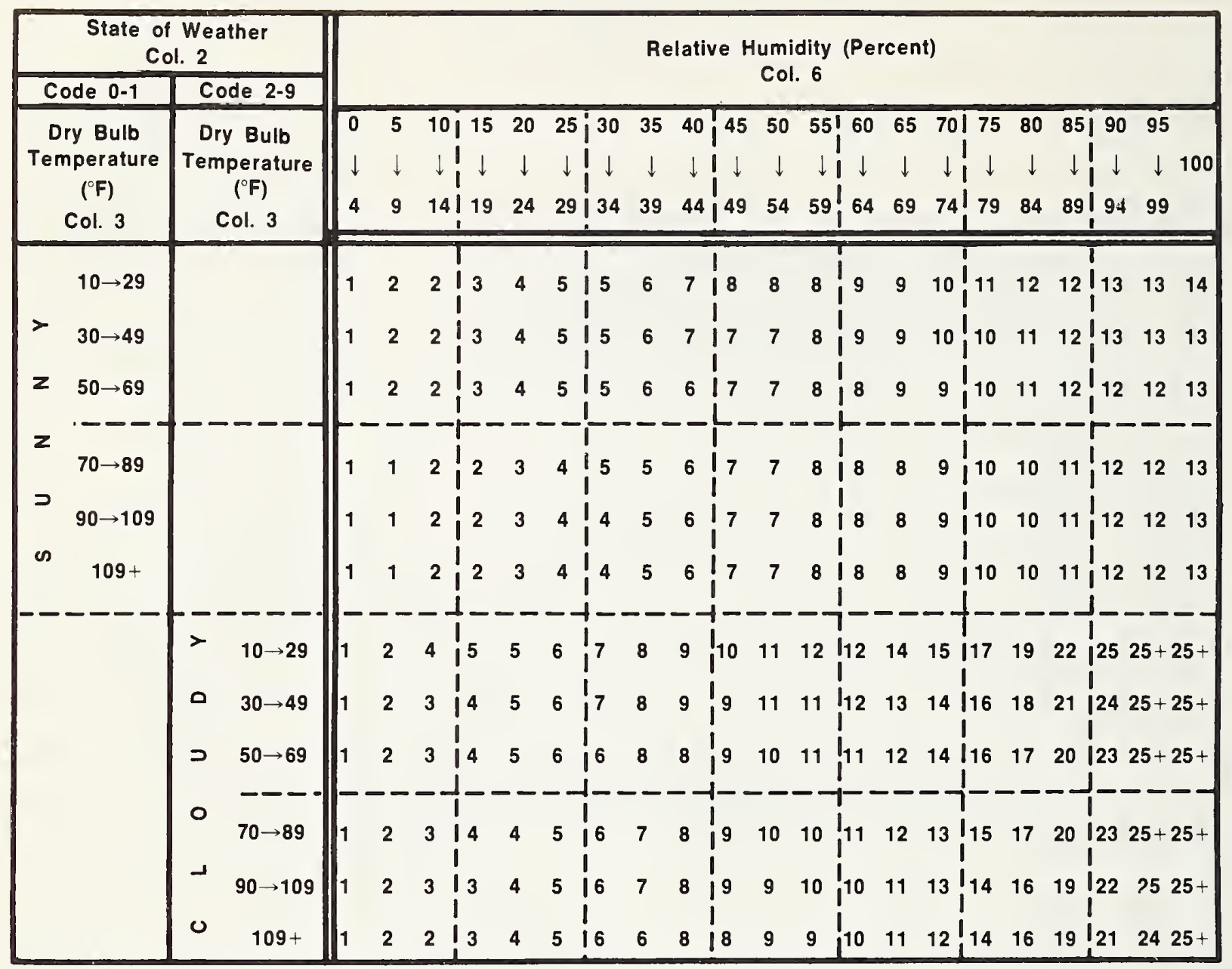

Purpose: To compute the moisture content of dead fuels one-quarter inch and less in diameter.* Procedure: If the state of the weather is coded $2,3,4,8$, or 9 (column 2), or if the observation is being taken before 1000 or after 1500 LST, the dry-bulb temperature is entered to the left in that section of the table labeled "cloudy." Otherwise enter the temperature in the section labeled "sunny." Read the 1-Hr. TL FM at the intersection of this row and the column indexed by the appropriate value for relative humidity (column 6); record in column 7 .

* If it is raining (state of weather codes 5,6, or 7) or there is snow or ice on the ground fuels, record $25+$ in column 7 . 
FINE FUEL MOISTURE (PERCENT)

Col. 9

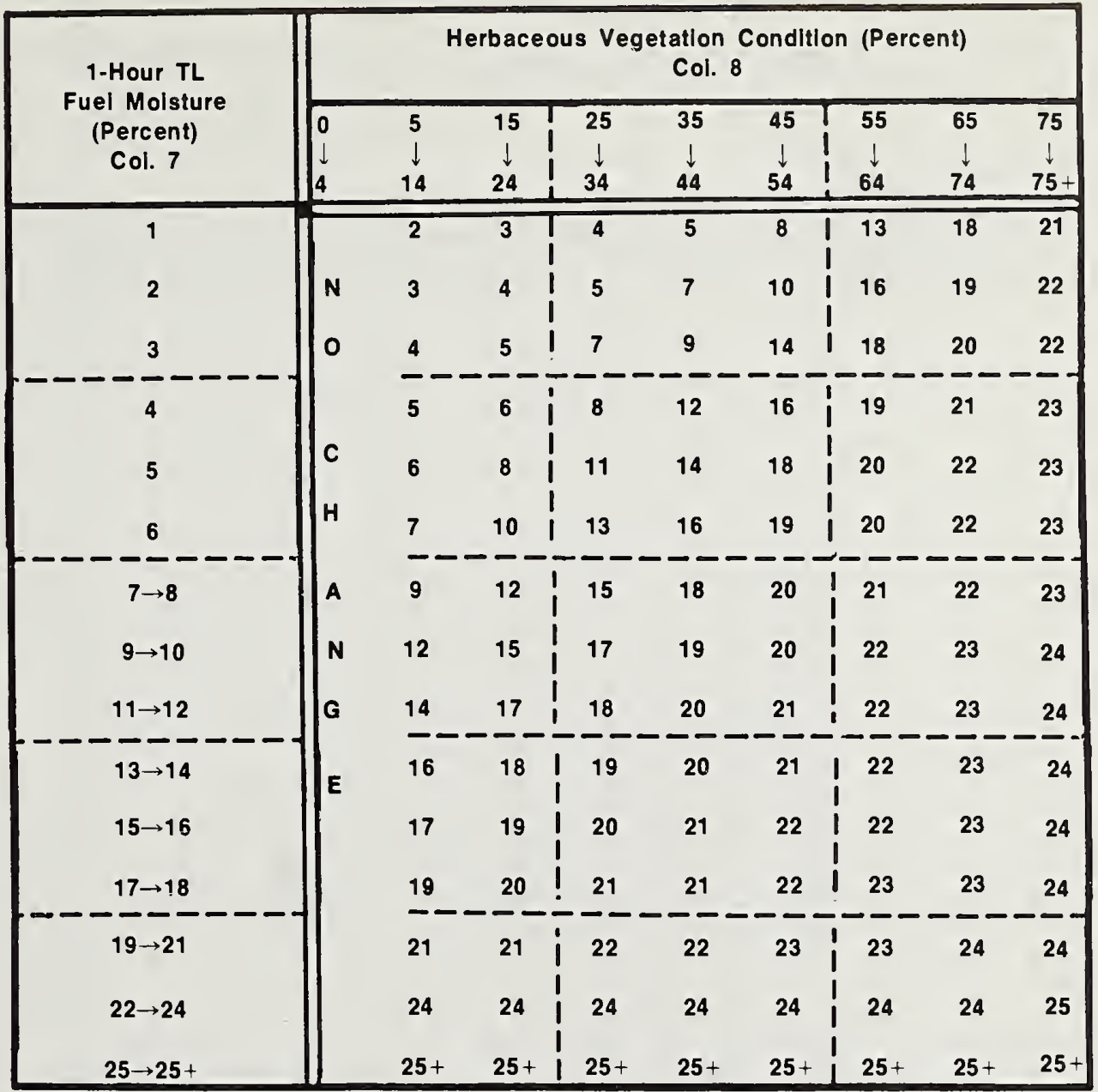

Purpose: To adjust the 1-Hr. TL FM to account for the reduced flammability of the lesser fuels due to the presence of living herbaceous plant material.*

Procedure: Read the FFM at the intersection of the row indexed by the 1-Hr. TL FM (column 7) and the column indexed by herbaceous vegetation condition (column 8); record in column 9 .

* If the herbaceous vegetation condition is 4 or less, enter the value of the 1-Hr. TL FM directly into column 9. 
I GNITION COMPONENT

Col. 10

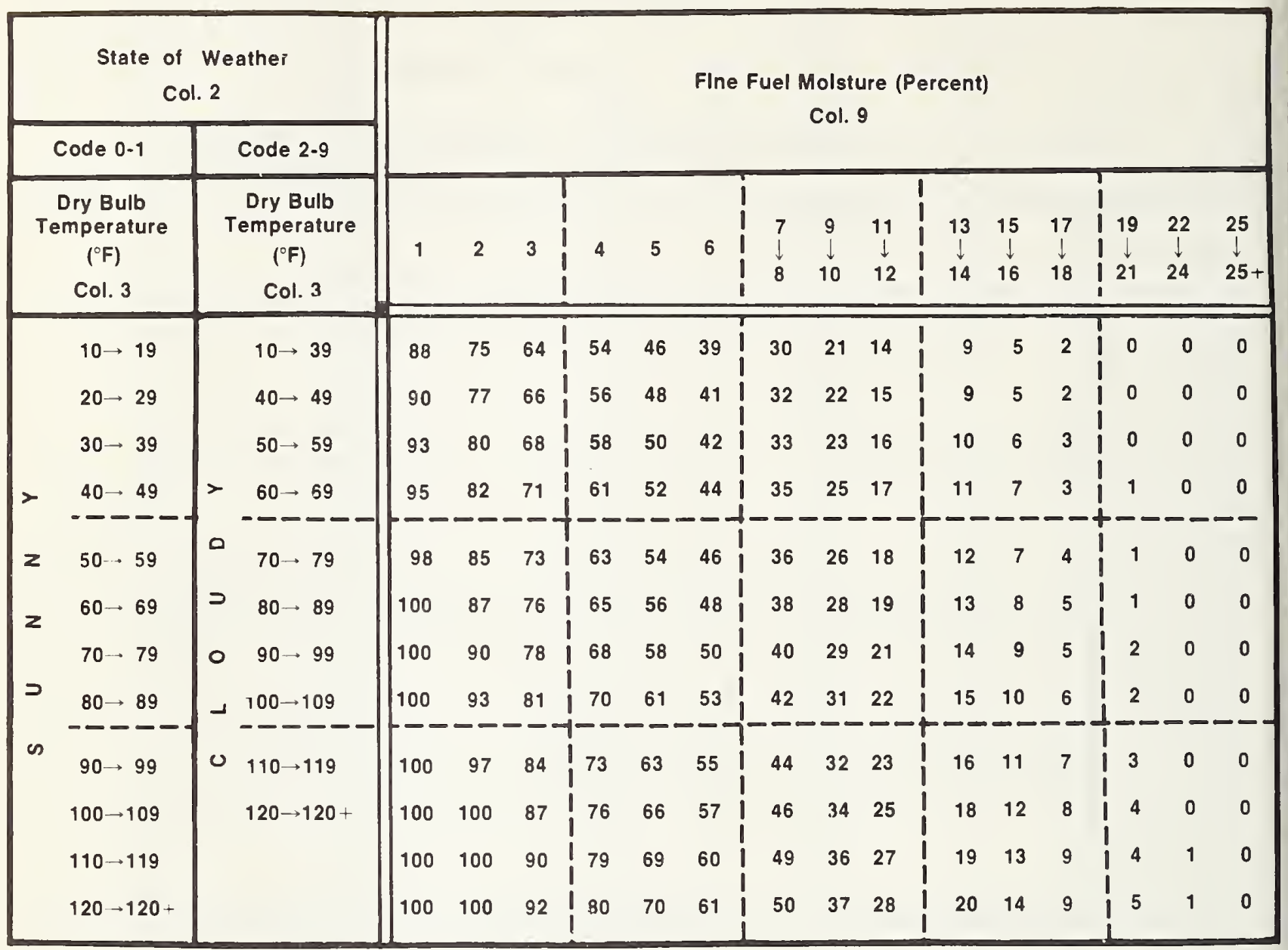

Purpose: To compute a number related to the probability that a fire will result if a firebrand is introduced into the fine fuel complex.*

Procedure: If the state of the weather is coded 2, 3, 4, 8, or 9 (column 2), or if the observation is being taken before 1000 or after 1500 LST, the dry-bulb temperature (column 3) is entered to the left in that section of the table labeled "cloudy." Otherwise, enter the temperature in the section labeled "sunny." Read the IC at the intersection of the column indexed by the FFM (column 9) and the row indexed by the dry-bulb temperature (column 3 ); record in column 10.

* If it is raining (state of the weather code 5,6, or 7) or there is snow or ice on the ground fuels, record a zero (0) in column 10. 


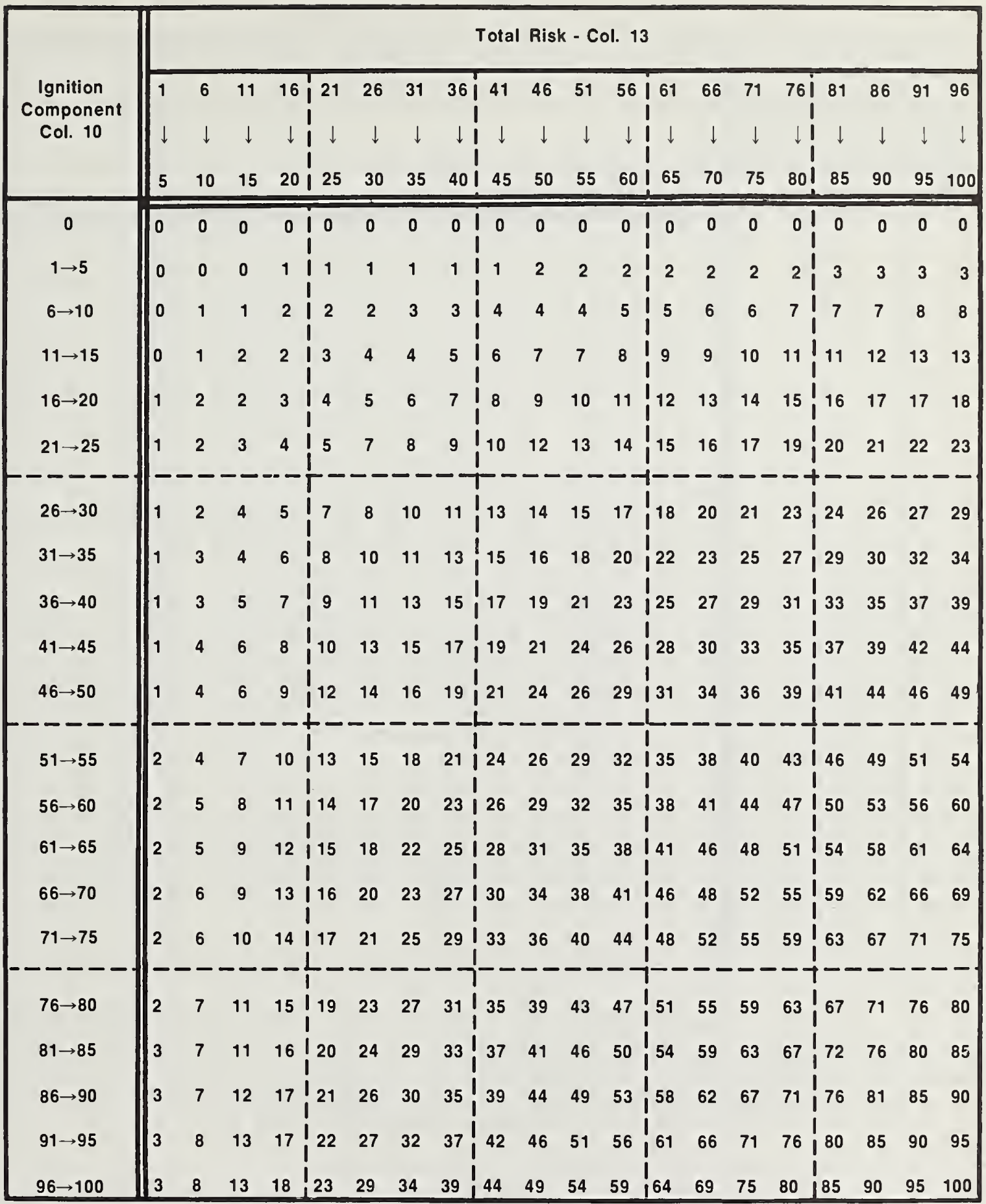

Purpose: To compute a number related to the probable level of fire incidence on the rating area.*

Procedure: At the intersection of the row indexed by the IC (column 10) and the column indexed by total Risk (column 13) is the OI; record in column 14.

* If it is raining (state of weather code 5, 6, or 7) or there is snow or ice on the ground fuels, record a zero (0) in column 14. 
Col. 18

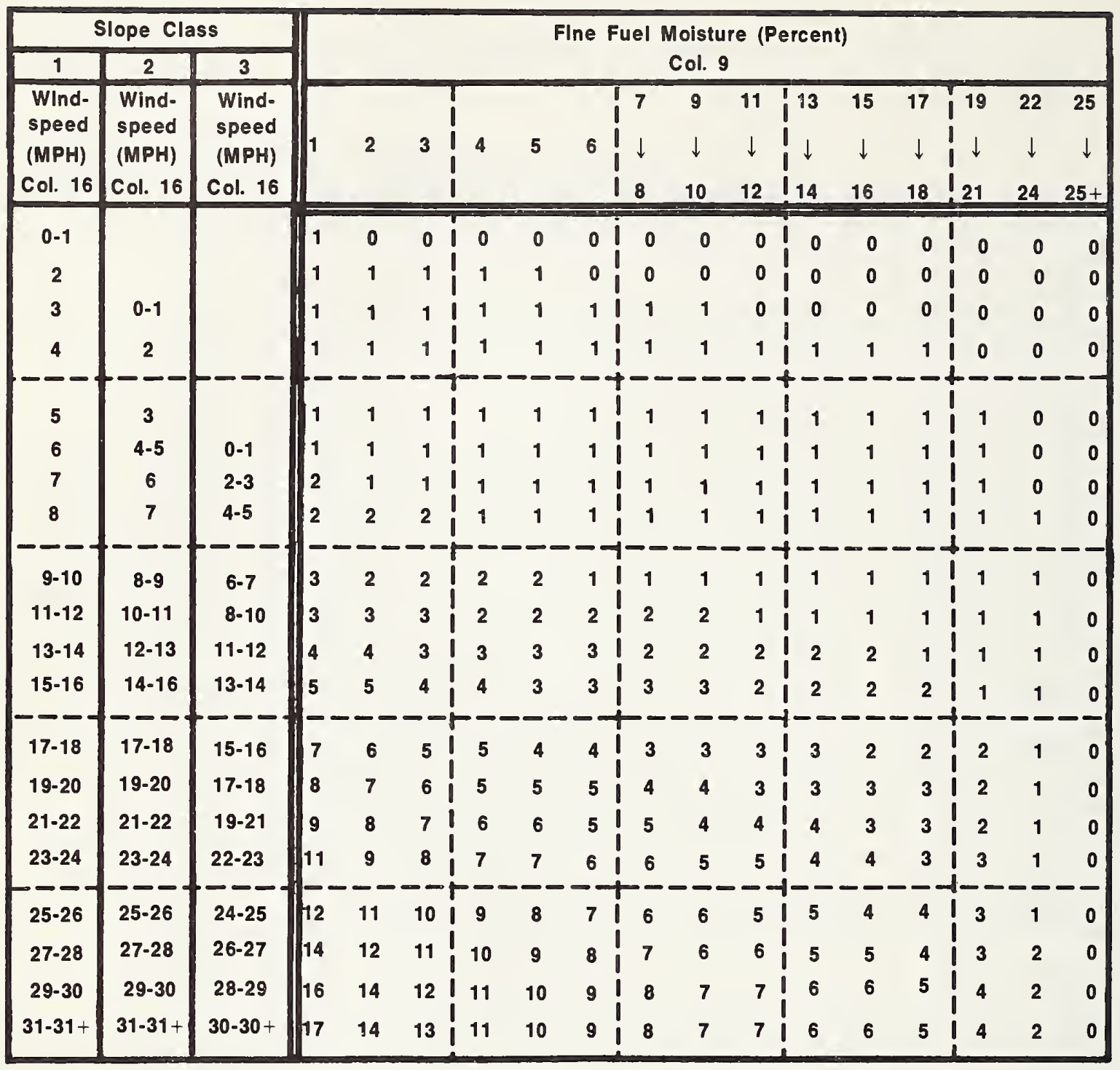

Purpose: To compute a number related to the forward rate of spread of the head of a fire burning in fuels represented by this fuel model.*

Procedure: The windspeed (column 16) is entered into the table from the column headed by the slope class assigned to the rating area. At the intersection of this row and the column indexed by the FFM (column 9) is the SC; record in column 18.

* If it is raining (state of weather code 5, 6, or 7) or there is snow or ice on the ground fuels, record a zero (0) in column 18. 
ENERGY RELEASE COMPONENT - FUEL MODEL E

Col. 21

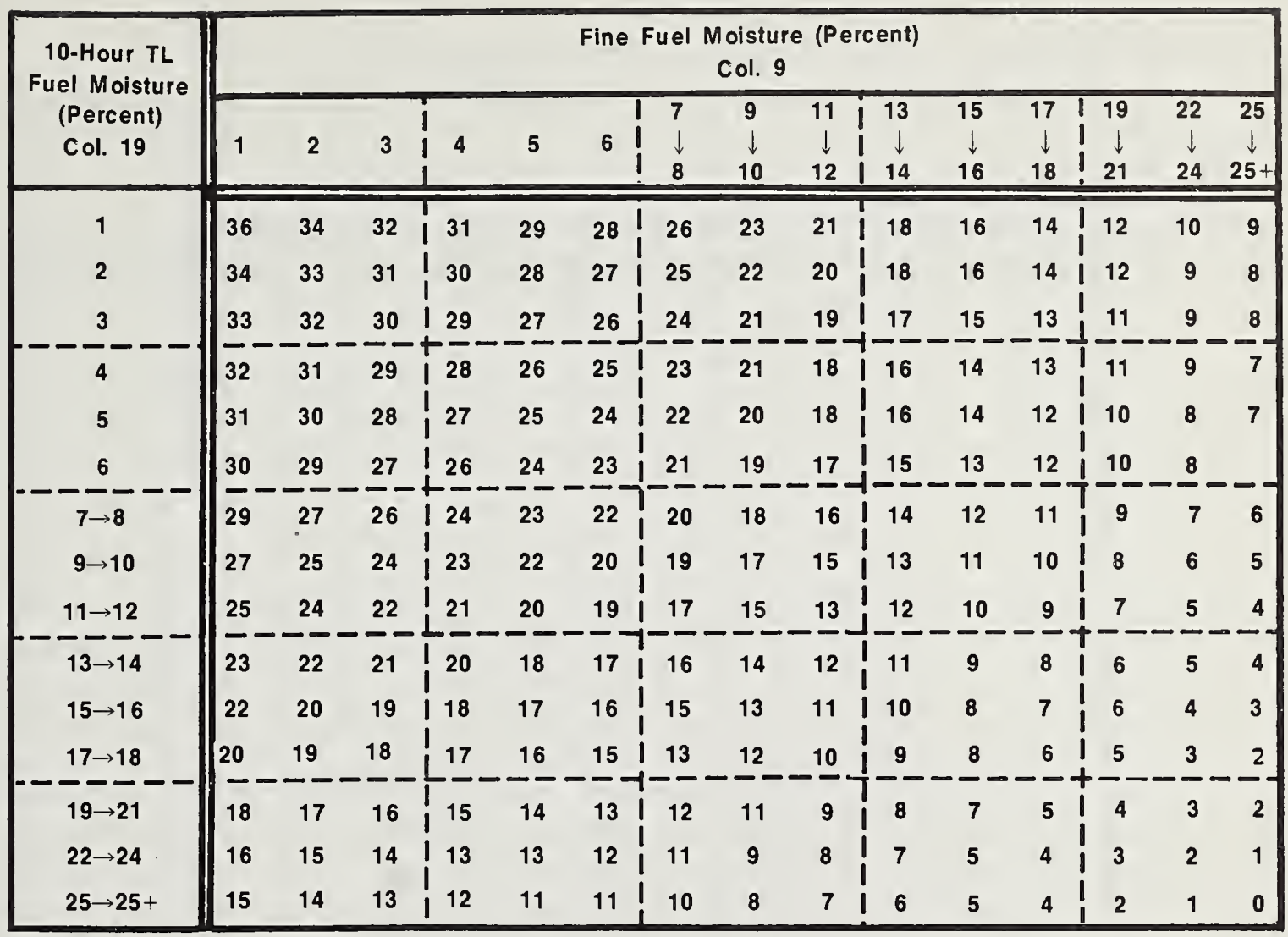

Purpose: To compute a number related to the rate of combustion at the head of a fire burning in fuels represented by this fuel model.*

Procedure: Read the ERC at the intersection of the row indexed by the 10-Hr. TL, FM (column 19) and the column indexed by the FFM (column 9); record in column 21 .

* If it is raining (state of weather code 5,6, or 7) or there is snow or ice on the ground fuels, record a zero (0) in column 21. 


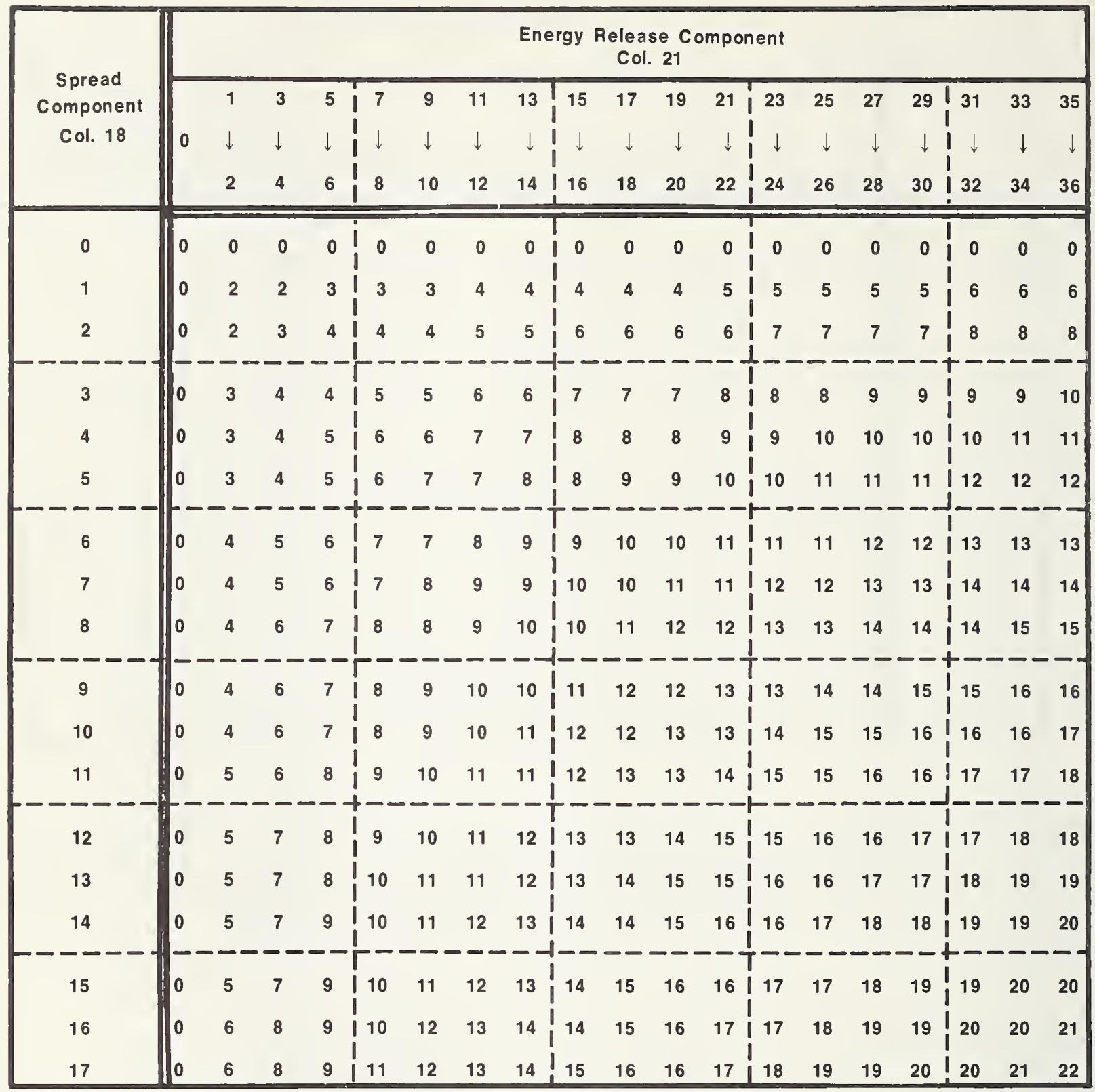

Purpose: To compute a number related to the amount of effort needed to contain a single fire burning in fuels represented by this fuel model.*

Procedure: Read the BI at the intersection of the row indexed by the SC (column 18) and the ERC (column 21); record in column 22.

* If it is raining (state of weather code 5,6, or 7) or there is snow or ice on the ground fuels, record a zero (0) in column 22. 
FIRE LOAD INDEX - FUEL MODEL E

Col. 23

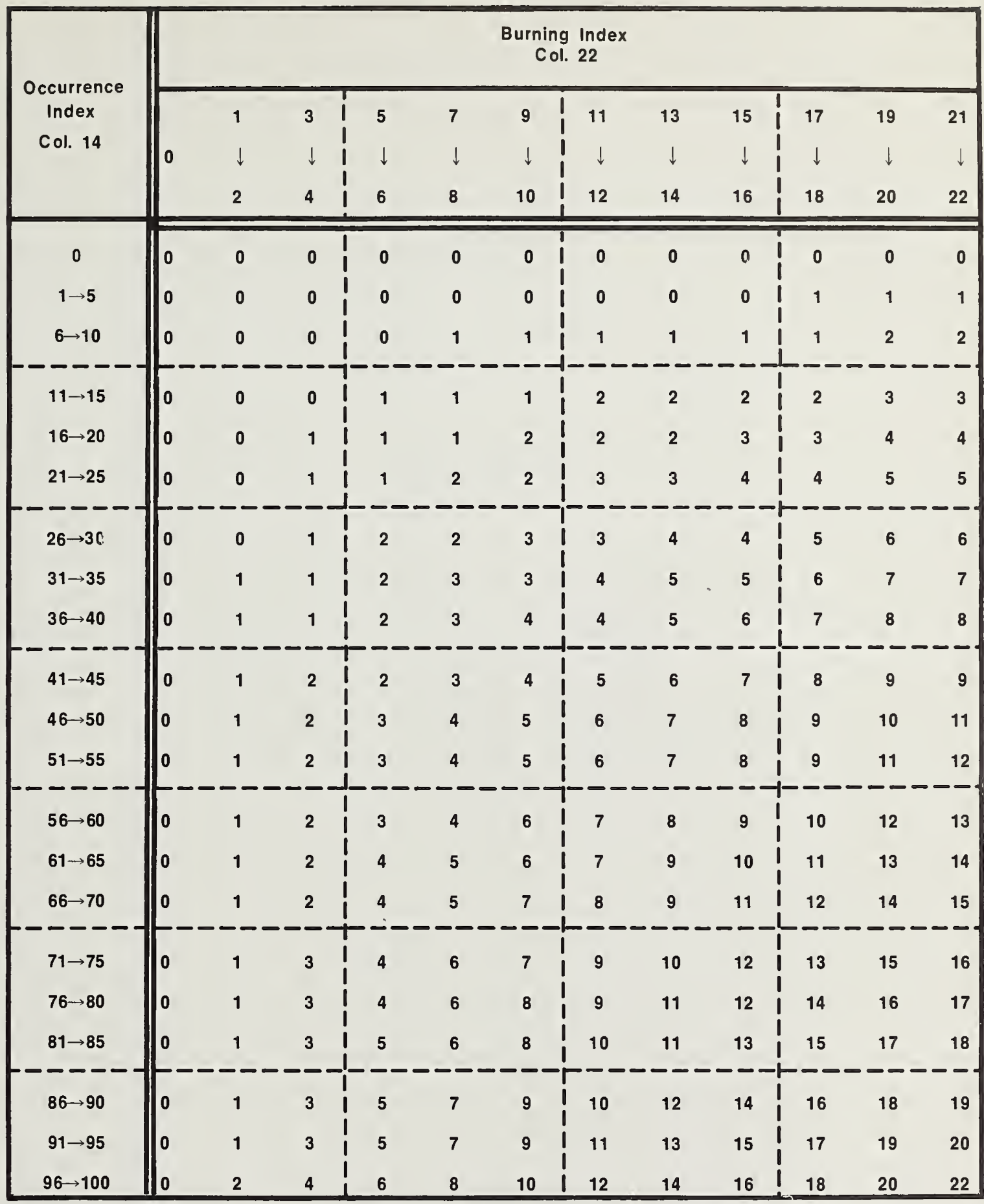

Purpose: To compute a number related to the total effort needed to contain all probable fires on a rating area.*

Procedure: Read the FLI at the intersection of the row indexed by the OI (column 14) and the column indexed by the BI (column 22); record in column 23.

* If it is raining (state of weather code 5, 6, or 7) or there is snow or ice on the ground fuels, record a zero (0) in column 23. 
Fuel Model F 


\section{COMPUTATIONAL FLOW CHART \\ FUEL MODEL F}

(1)

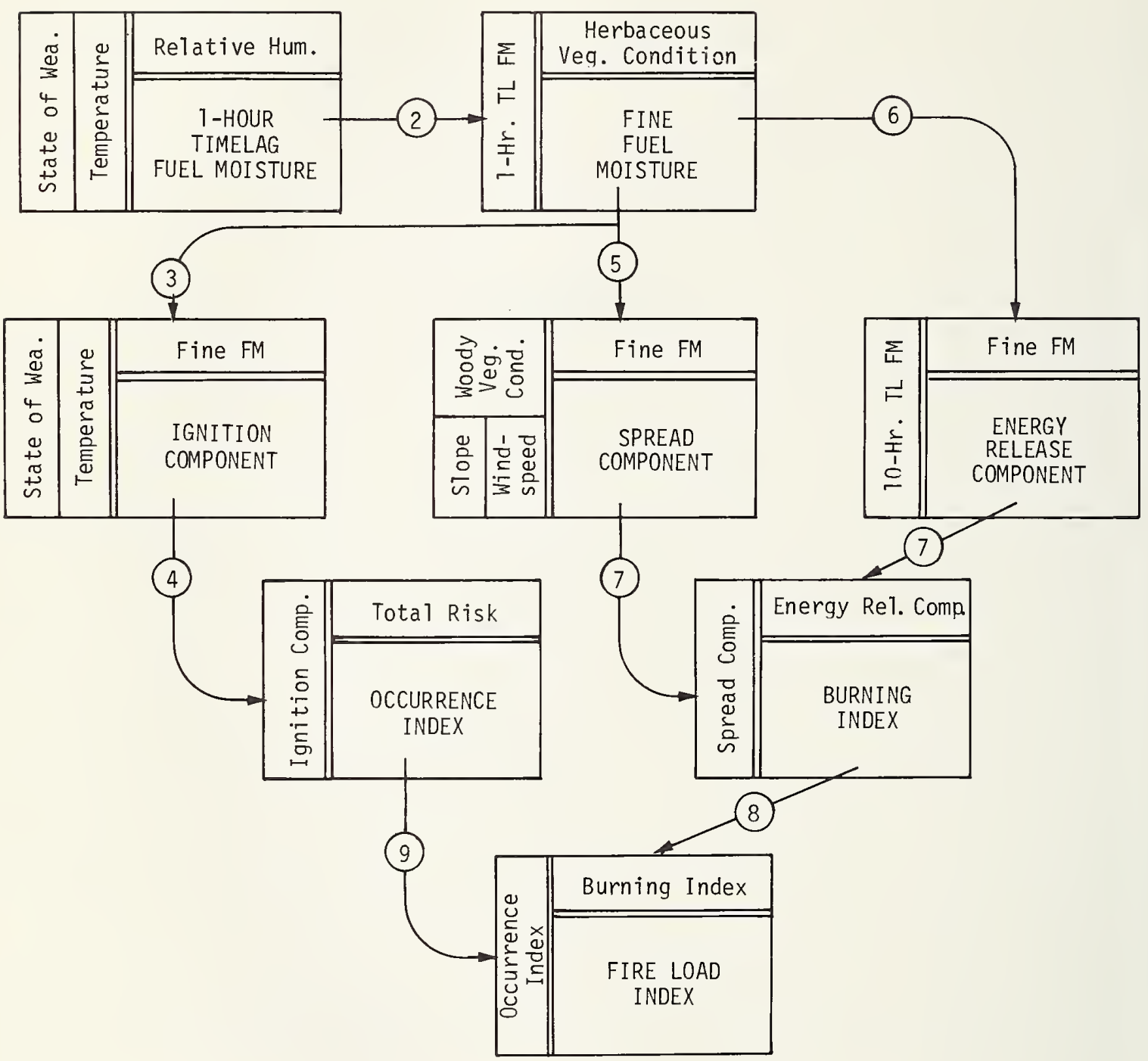




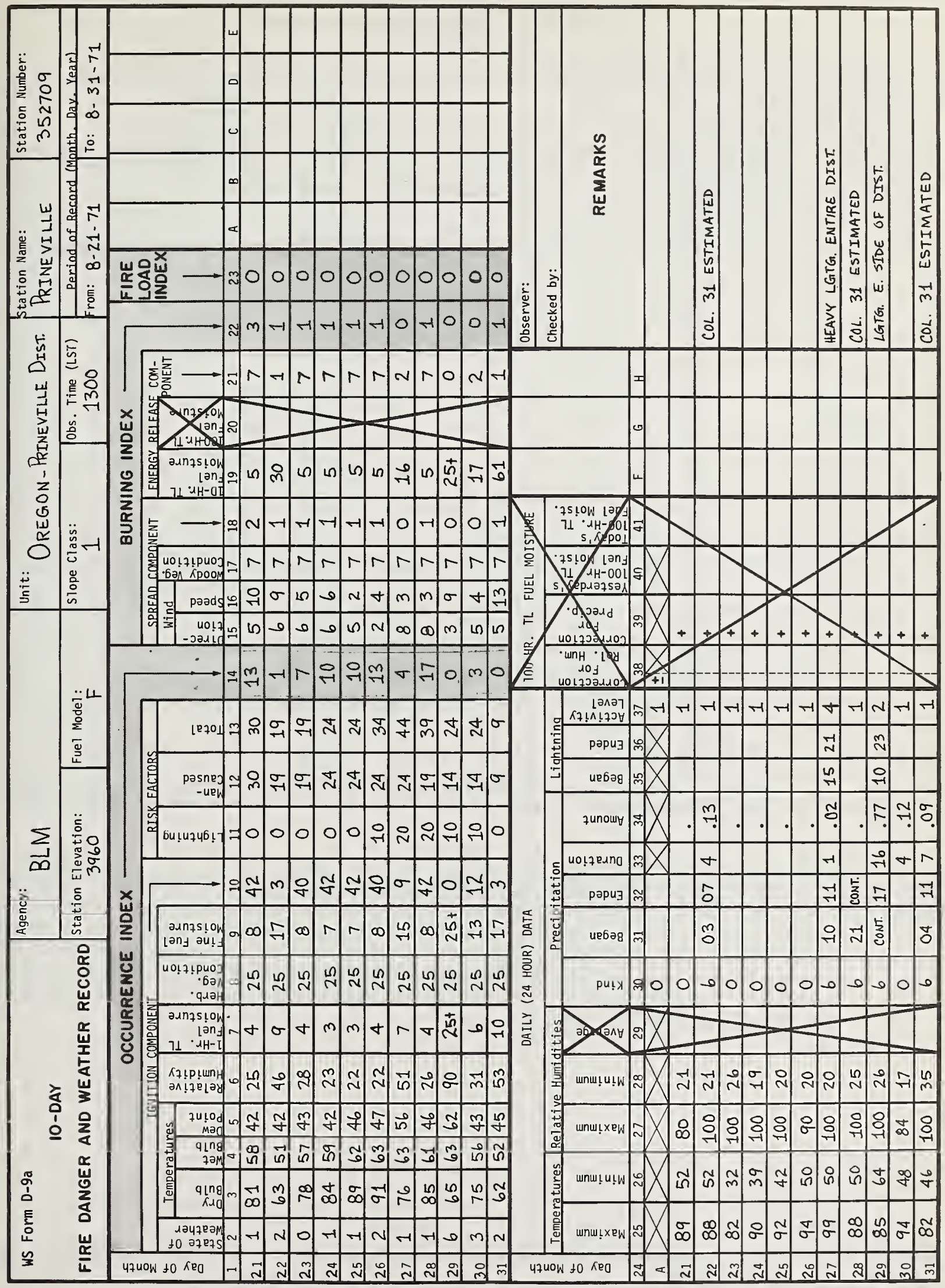


1 - HOUR TIMELAG FUEL MOISTURE (PERCENT)

Col. 7

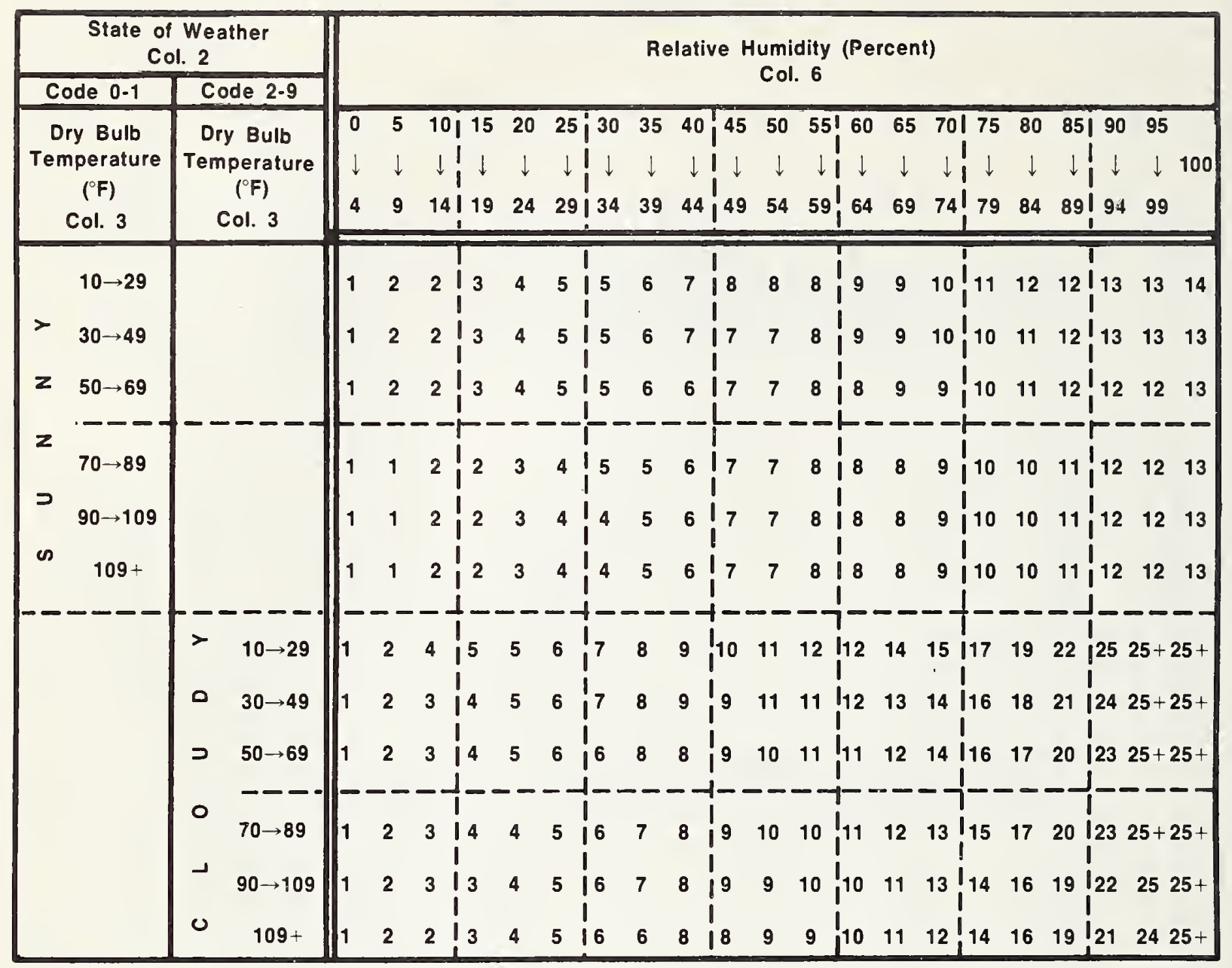

Purpose: To compute the moisture content of dead fuels one-quarter inch and less in diameter.* Procedure: If the state of the weather is coded 2,3,4,8, or 9 (column 2), or if the observation is being taken before 1000 or after $1500 \mathrm{LST}$, the dry-bulb temperature is entered to the left in that section of the table labeled "cloudy." Otherwise enter the temperature in the section labeled "sunny." Read the 1-Hr. TI, FM at the intersection of this row and the column indexed by the appropriate value for relative humidity (column 6); record in column 7 .

* If it is raining (state of weather codes 5,6, or 7) or there is snow or ice on the ground fuels, record $25+$ in column 7 . 
FINE FUEL MOISTURE (PERCENT)

Col. 9

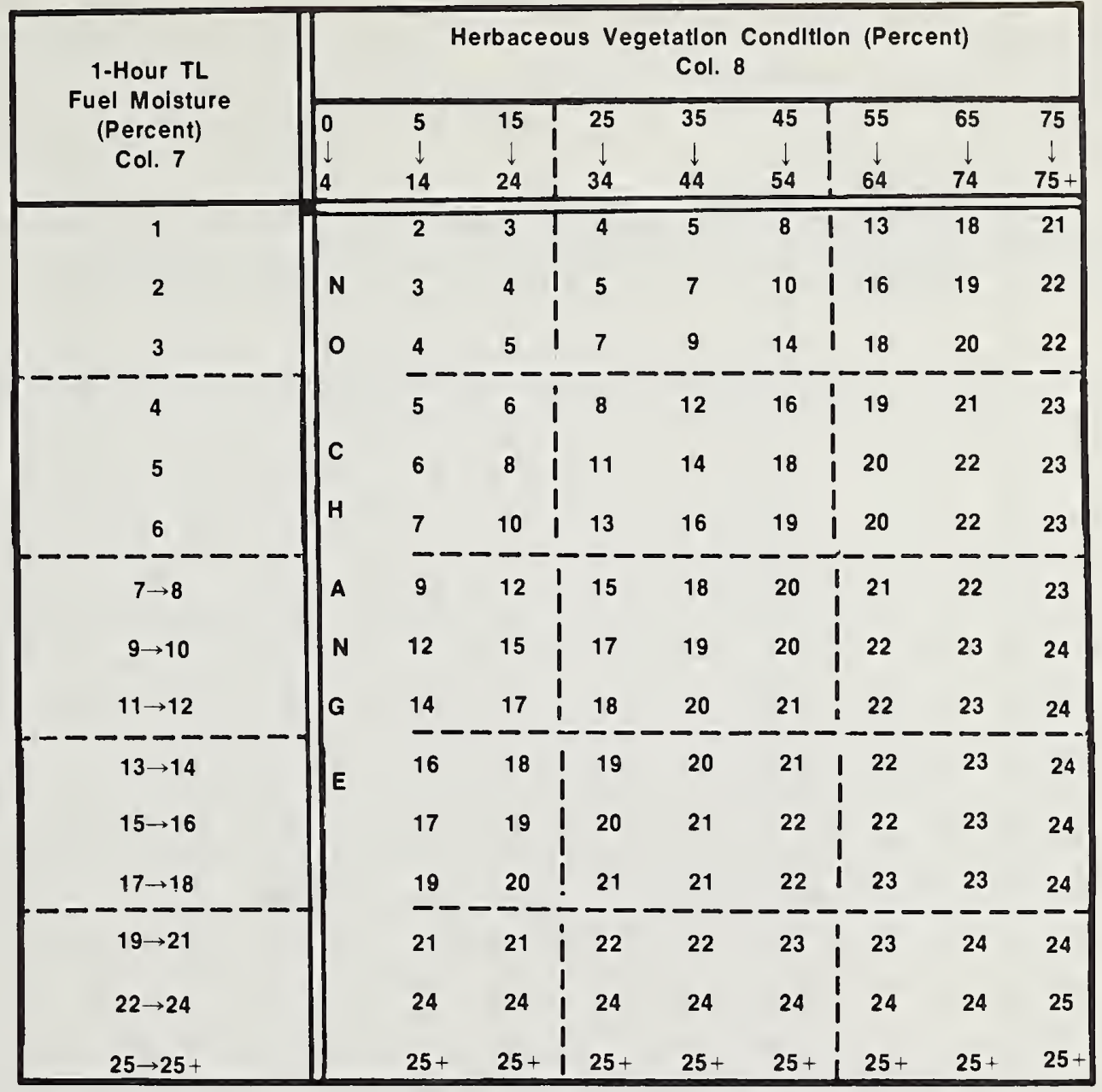

Purpose: To adjust the 1-Hr. TI, FM to account for the reduced flammability of the lesser fuels due to the presence of living herbaceous plant material.*

Procedure: Read the FFM at the intersection of the row indexed by the 1-Hr. TL FM (column 7 ) and the column indexed by herbaceous vegetation condition (column 8 ); record in column 9.

* If the herbaceous vegetation condition is 4 or less, enter the value of the 1-Hr. TL FM directly into column 9. 


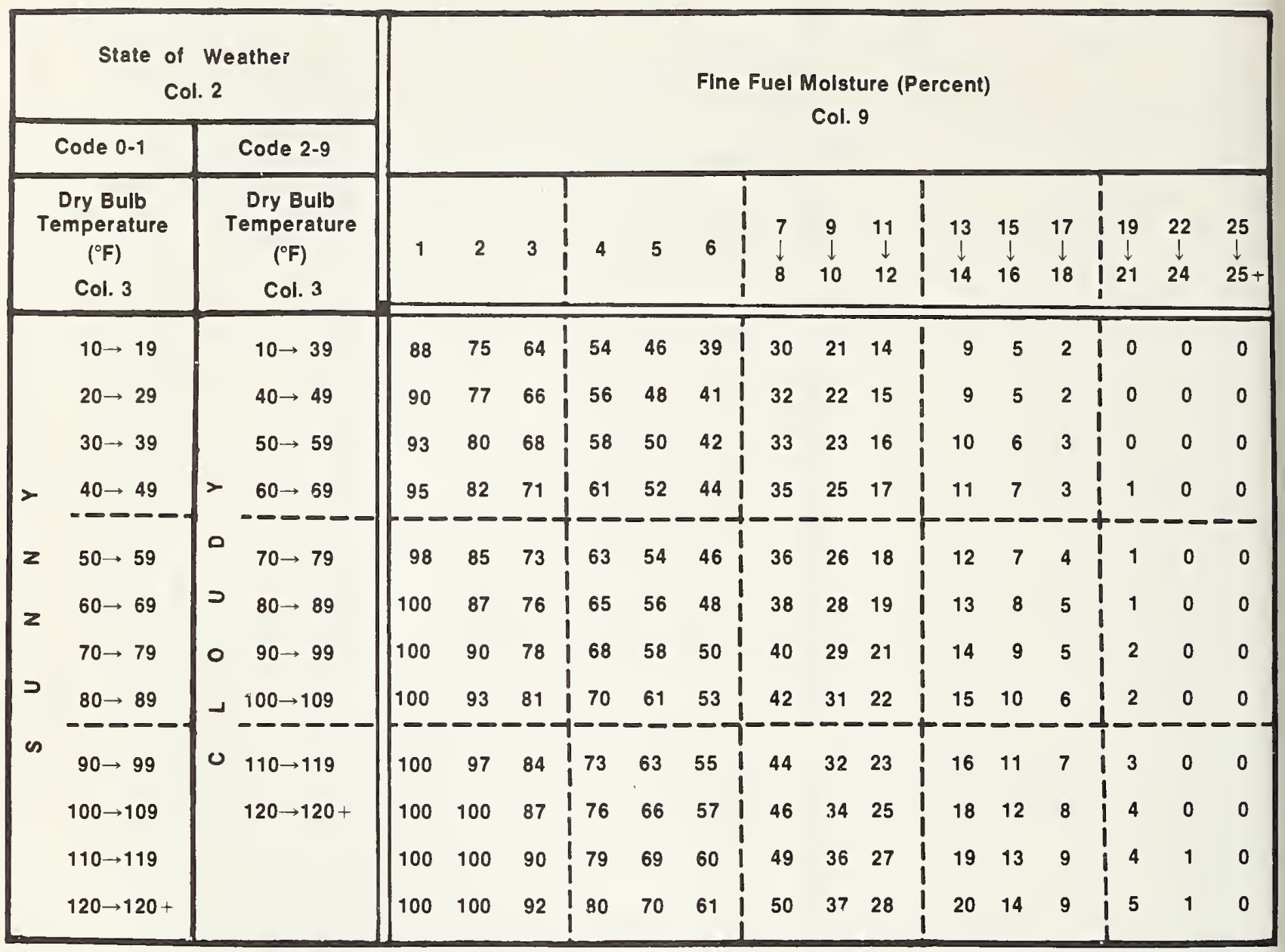

Purpose: To compute a number related to the probability that a fire will result if a firebrand is introduced into the fine fuel complex.*

Procedure: If the state of the weather is coded 2,3,4,8, or 9 (column 2), or if the observation is being taken before 1000 or after 1500 LST, the dry-bulb temperature (column 3) is entered to the left in that section of the table labeled "cloudy." Otherwise, enter the temperature in the section labeled "sunny." Read the IC at the intersection of the column indexed by the FFM (column 9) and the row indexed by the dry-bulb temperature (column 3); record in column 10.

* If it is raining (state of weather code 5,6, or 7) or there is snow or ice on the ground fuels, record a zero (0) in column 10. 


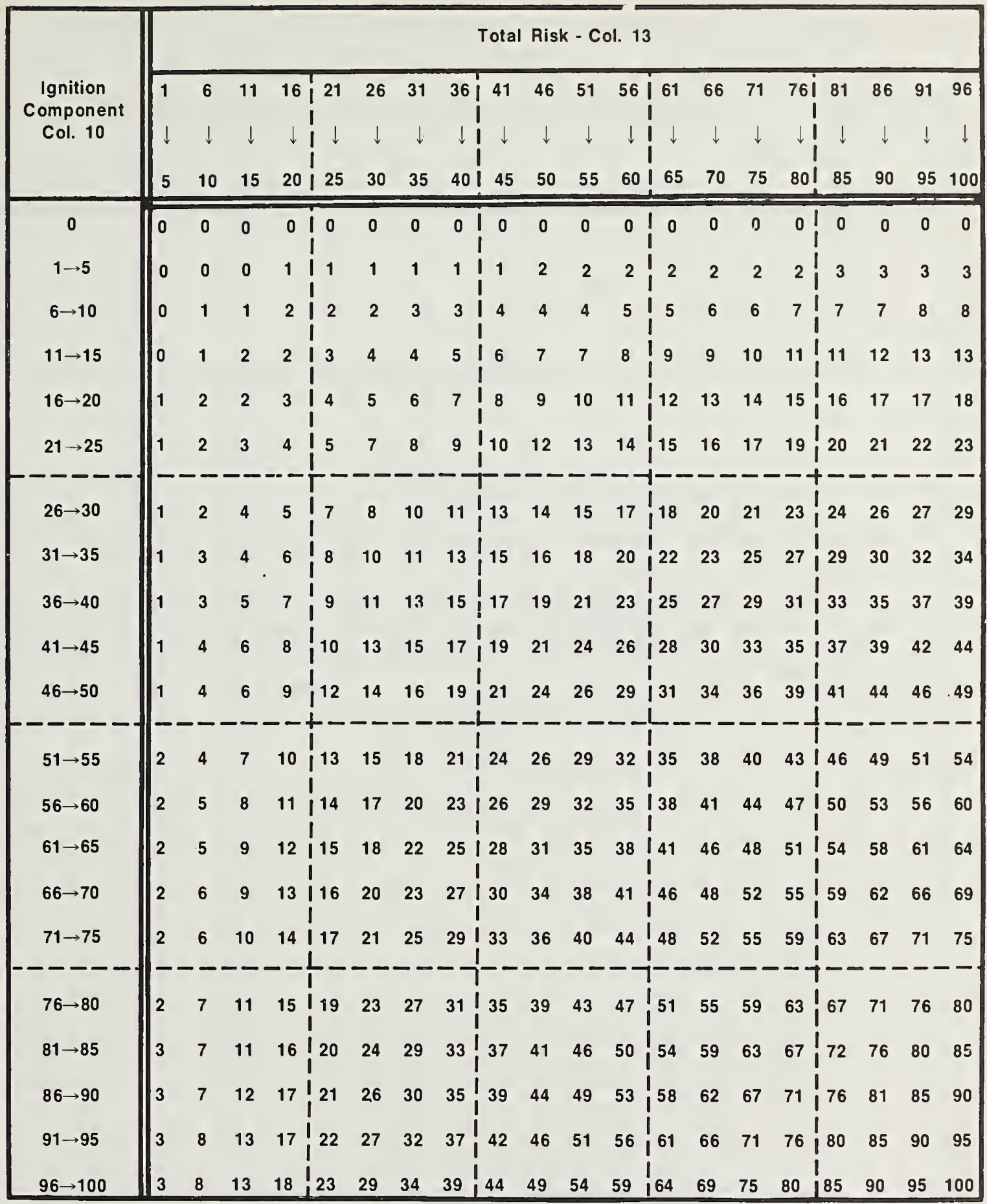

Purpose: To compute a number related to the probable level of fire incidence on the rating area.*

Procedure: At the intersection of the row indexed by the IC (column 10) and the column indexed by total Risk (column 13) is the OI; record in column 14.

* If it is raining (state of the weather code 5,6, or 7) or there is snow or ice on the ground fuels, record a zero (0) in column 14. 
Col. 18

PART A

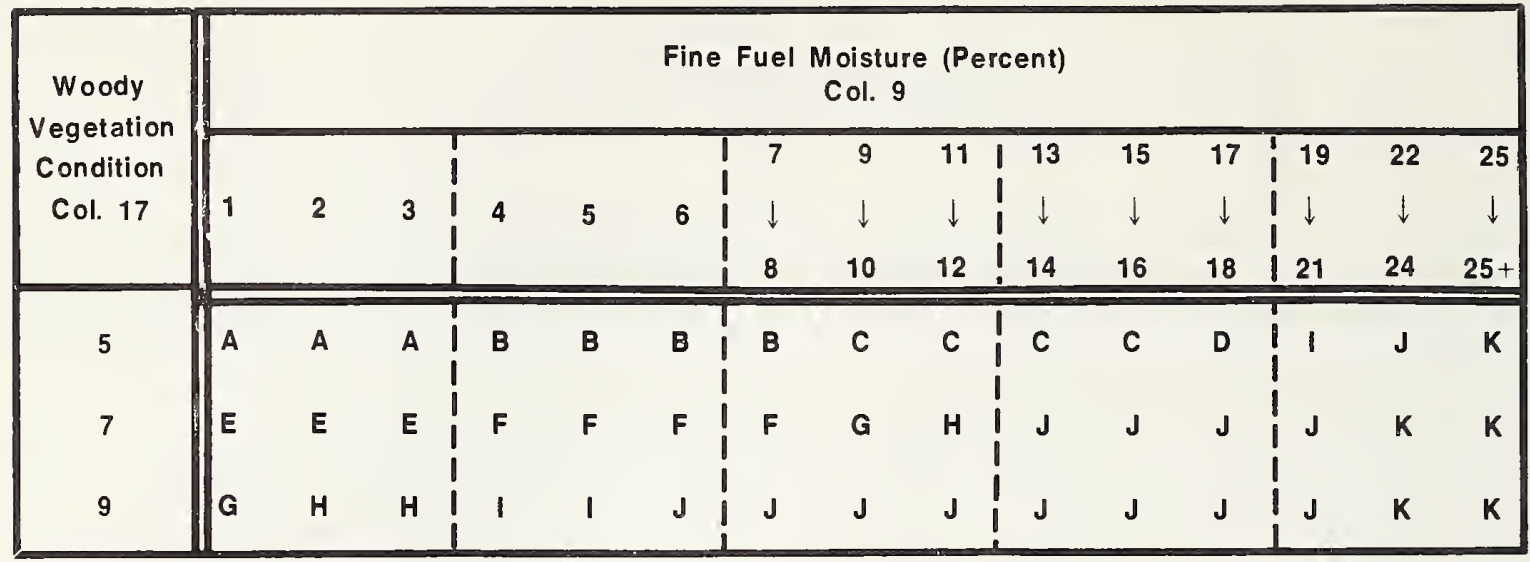

Purpose: To compute a number related to the forward rate of spread of the head of a fire burning in fuels represented by this fuel model.*

Procedure: In Part A-Read the transfer letter at the intersection of the row indexed by the woody vegetation condition (column 17) and the column indexed by the FFM (column 9).

In Part B-Enter the windspeed (column 16) into the table from the column headed by the slope class assigned to the rating area. Read the $\mathrm{SC}$ at the intersection of this row and the column indexed by the transfer letter from Part A; record in column 18 .

* If it is raining (state of weather code 5,6,7) or there is snow or ice on the ground fuels, record a zero $(0)$ in column 18. 
PART B

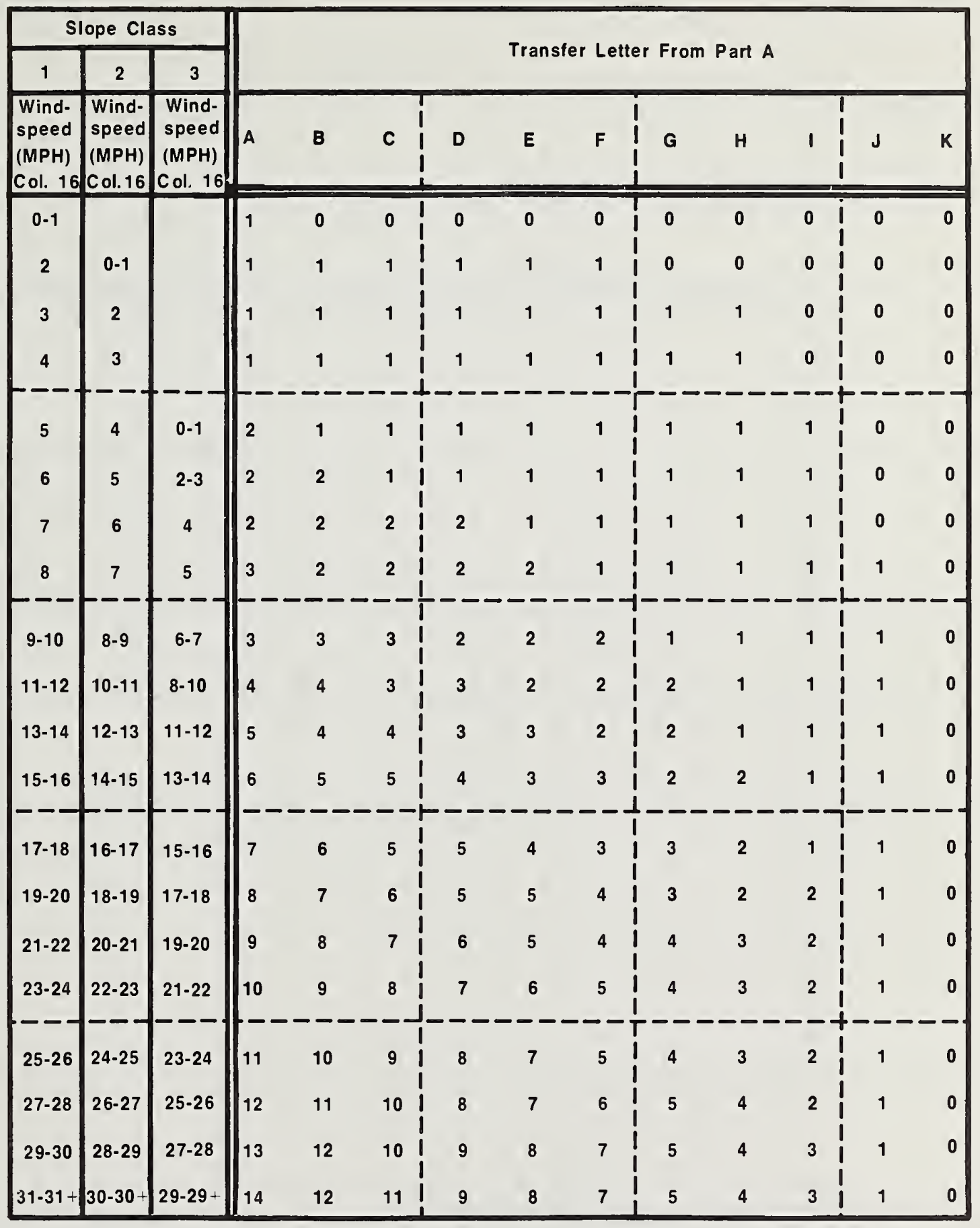


ENERGY RELEASE COMPONENT - FUEL MODEL F

Col. 21

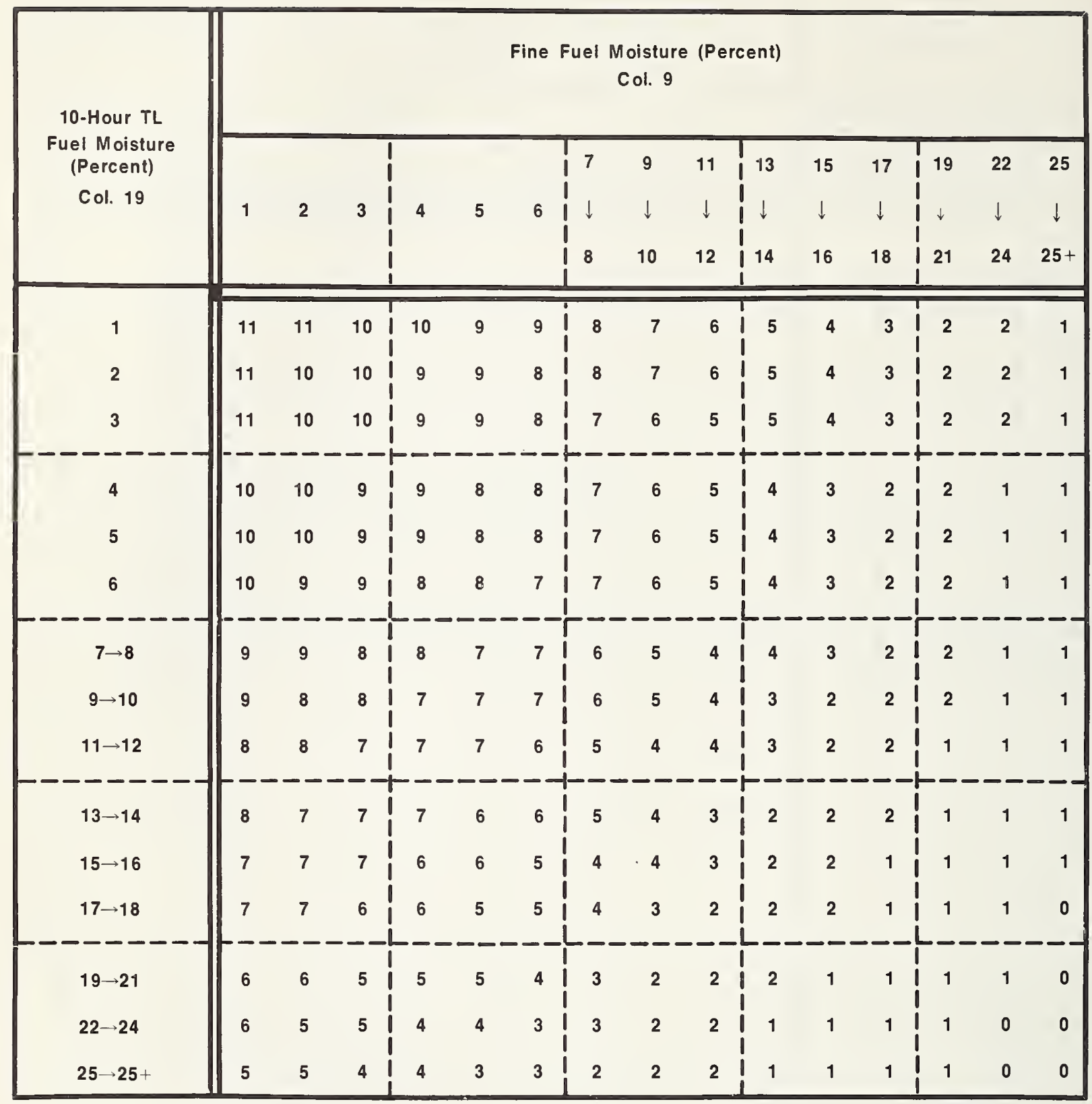

Purpose: To compute a number related to the rate of combustion at the head of a fire burning in fuels represented by this fuel model.*

Procedure: Read the ERC at the intersection of the row indexed by the 10-Hr. TL FM (column 19) and the column indexed by the FFM (column 9); record in column 21.

* If it is raining (state of weather code 5, 6, or 7) or there is snow or ice on the ground fuels, record a zero (0) in column 21. 


\begin{tabular}{|c|c|c|c|c|c|c|c|c|c|c|c|c|c|}
\hline \multirow{2}{*}{$\begin{array}{l}\text { Spread } \\
\text { Component } \\
\text { Col. } 18\end{array}$} & \multicolumn{13}{|c|}{$\begin{array}{c}\text { Energy Release Component } \\
\text { Col. } 21\end{array}$} \\
\hline & 0 & 1 & 2 & 3 & 4 & 5 & i & 6 & 7 & 8 & 9 & 10 & 11 \\
\hline 0 & 0 & 0 & 0 & 0 & 0 & 0 & 1 & 0 & 0 & 0 & 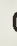 & 0 & 0 \\
\hline 1 & 0 & 1 & 1 & 1 & 1 & 1 & i & 1 & 1 & 1 & & 2 & 2 \\
\hline 2 & 0 & 1 & 2 & 2 & 2 & 2 & I & 3 & 3 & 3 & & 3 & 3 \\
\hline 3 & 0 & 1 & 2 & 2 & 3 & 3 & 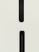 & 3 & 3 & 3 & & 4 & 4 \\
\hline 4 & 0 & 2 & 2 & 3 & 3 & 3 & I & 4 & 4 & 4 & & 4 & 5 \\
\hline 5 & 0 & 2 & 2 & 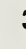 & 3 & 4 & i & 4 & 4 & 4 & & 5 & 5 \\
\hline 6 & 0 & 2 & 3 & 3 & 4 & 4 & i & 4 & 5 & 5 & & 5 & 6 \\
\hline 7 & 0 & 2 & 3 & 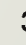 & 4 & 4 & 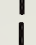 & 5 & 5 & 5 & & 6 & 6 \\
\hline 8 & 0 & 2 & 3 & 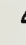 & 4 & 4 & ! & 5 & 5 & 5 & & 6 & 6 \\
\hline 9 & 0 & 2 & 3 & 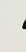 & 4 & 5 & 1 & 5 & 5 & 6 & & 6 & 7 \\
\hline 10 & 0 & 2 & 3 & 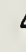 & 4 & 5 & I & 5 & 6 & 6 & & 7 & 7 \\
\hline 11 & 0 & 2 & 3 & 4 & 5 & 5 & 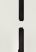 & 6 & 6 & 6 & & 7 & 7 \\
\hline 12 & 0 & 3 & 4 & 4 & 5 & 5 & 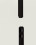 & 6 & 6 & 7 & & 7 & 8 \\
\hline 13 & 0 & 3 & 4 & 4 & 5 & 6 & 1 & 6 & 6 & 7 & & 8 & 8 \\
\hline 14 & 0 & 3 & 4 & 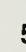 & 5 & 6 & I & 6 & 7 & 7 & & 8 & 8 \\
\hline
\end{tabular}

Purpose: To compute a number related to the amount of effort needed to contain a single fire burning in fuels represented by this fuel model.*

Procedure: Read the BI at the intersection of the row indexed by the SC (column 18) and the ERC (column 21); record in column 22.

* If it is raining (state of weather code 5, 6, or 7) or there is snow or ice on the ground fuels, record a zero (0) in column 22. 
FIRE LOAD INDEX - FUEL MODEL F

Col. 23

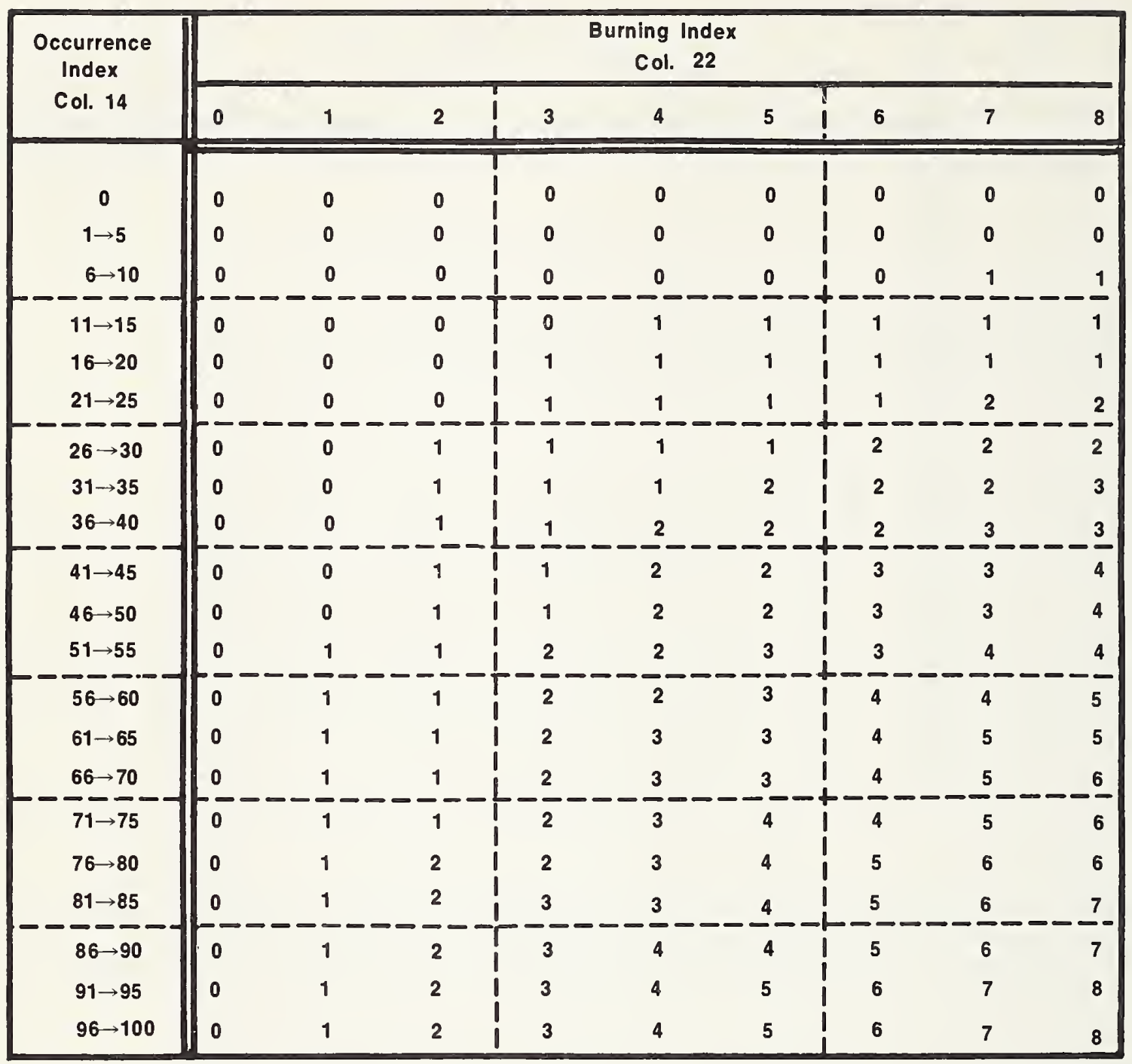

Purpose: To compute a number related to the total effort needed to contain all probable fires on a rating area.*

Procedure: Read the FLI at the intersection of the row indexed by the OI (column 14) and the column indexed by the BI (column 22); record in column 23 .

* If it is raining (state of weather code 5, 6, or 7) or there is snow or ice on the ground fuels, record a zero (0) in column 23. 
Fuel Model G

119 


\section{COMPUTATIONAL FLOW CHART FUEL MODEL G}

(1)

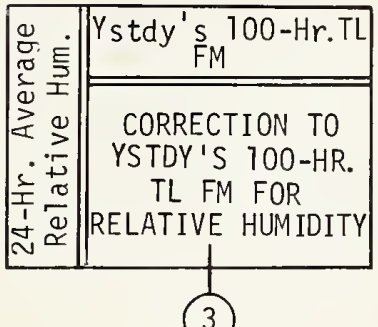

(2)

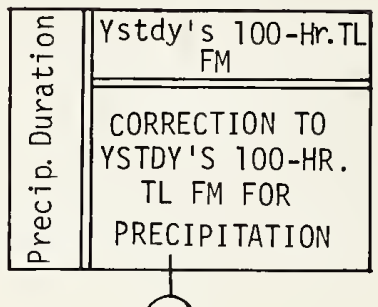

(3)

(4)

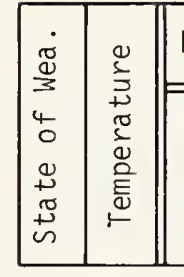
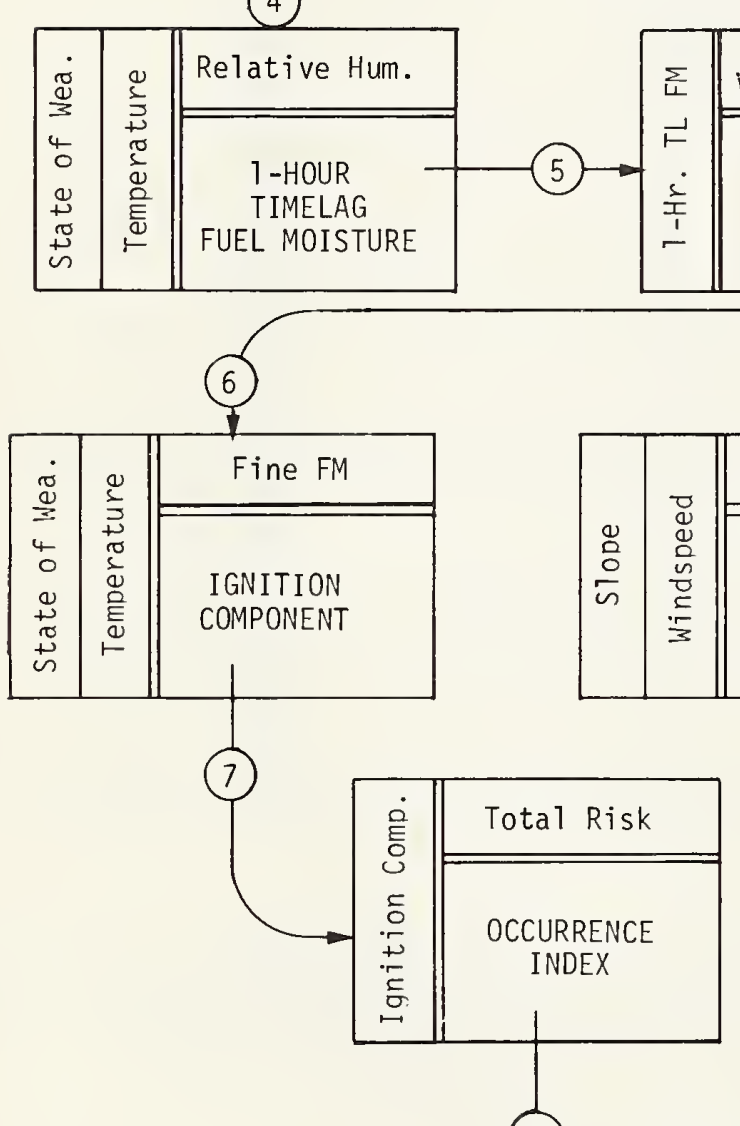

11

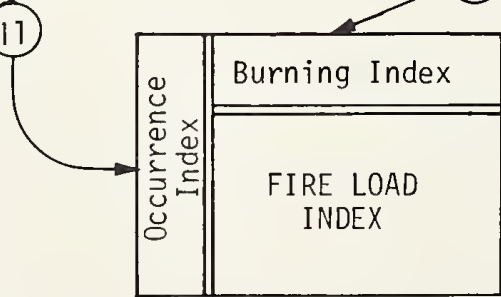




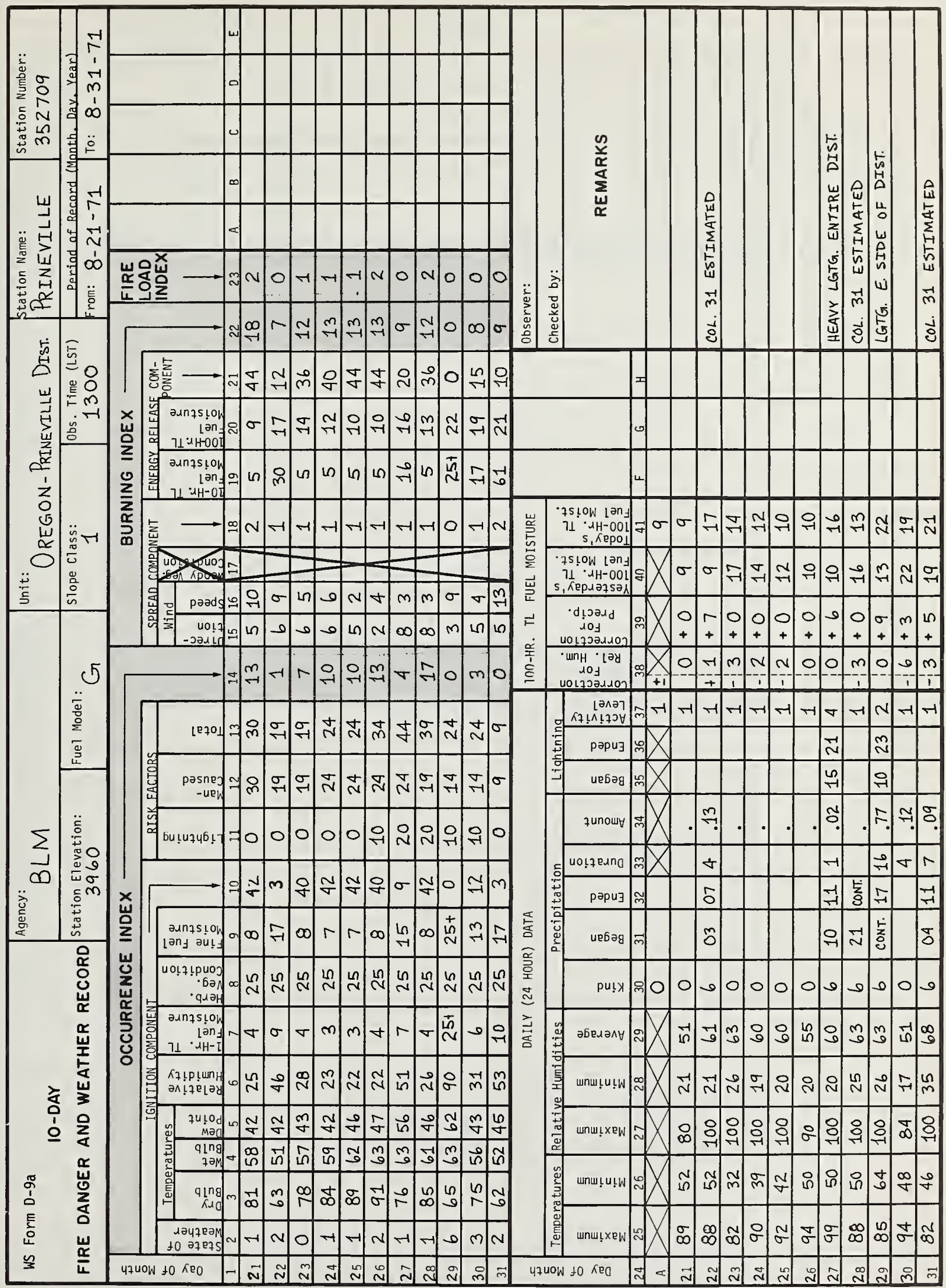




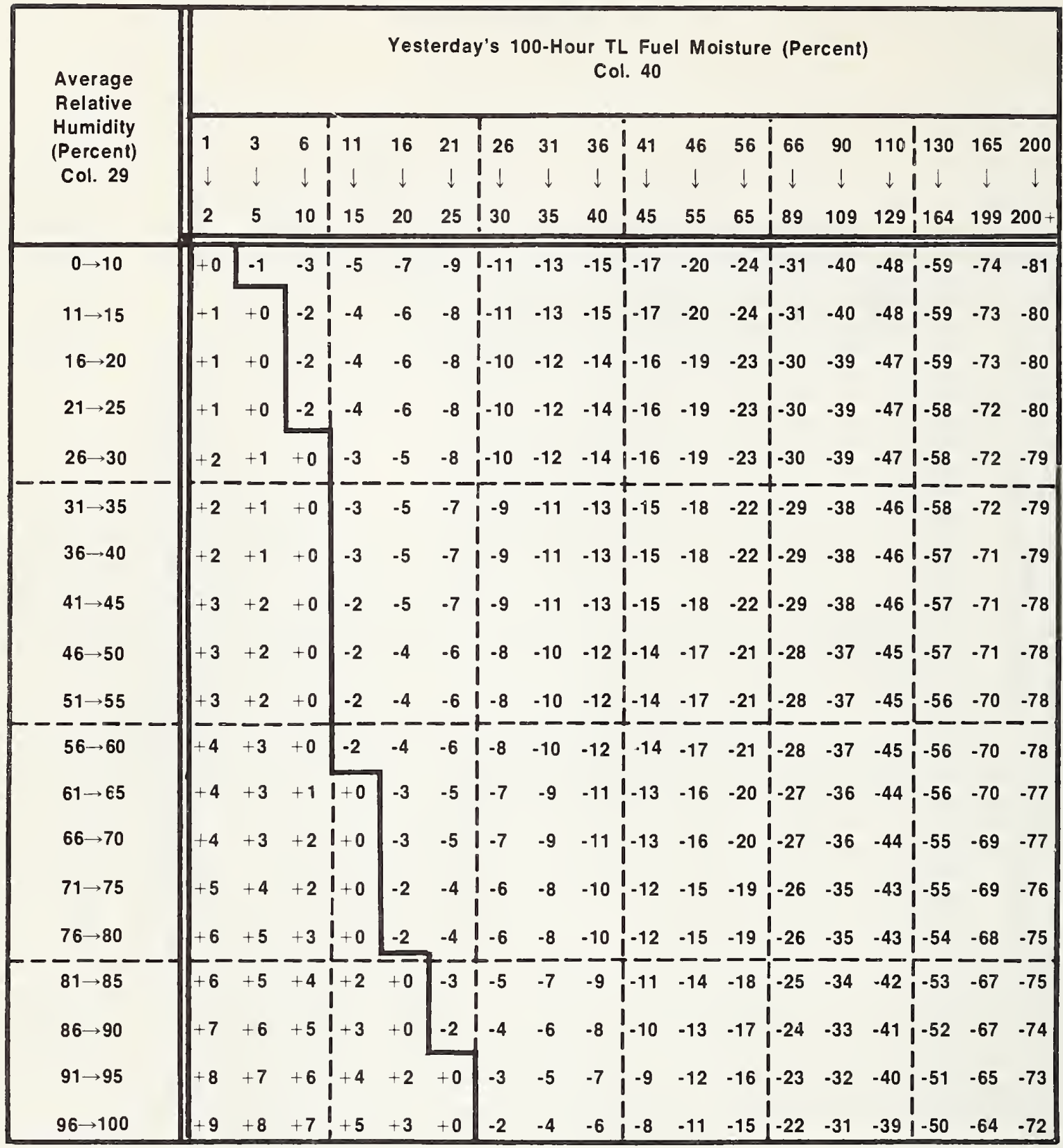

Purpose: To compute the effect of atmospheric humidity (water vapor) since Basic Observation Time yesterday, on the moisture content of the 100-Hr. TL fuels.*, **

Procedures: At the intersection of the column indexed by yesterday's 100-Hr. TL FM (column 40 )*** and the row indexed by the 24-hour average relative humidity (column 29) is the correction to the $100-\mathrm{Hr}$. TL FM for relative humidity; record in column 38 .

* Values can be positive (+) or negative (-), record the proper sign.

** If it has rained continuously for the past 24 hours, record a zero (0) in column 38.

*** At the beginning of the fire season, an initial value of 35 percent should be assumed. 


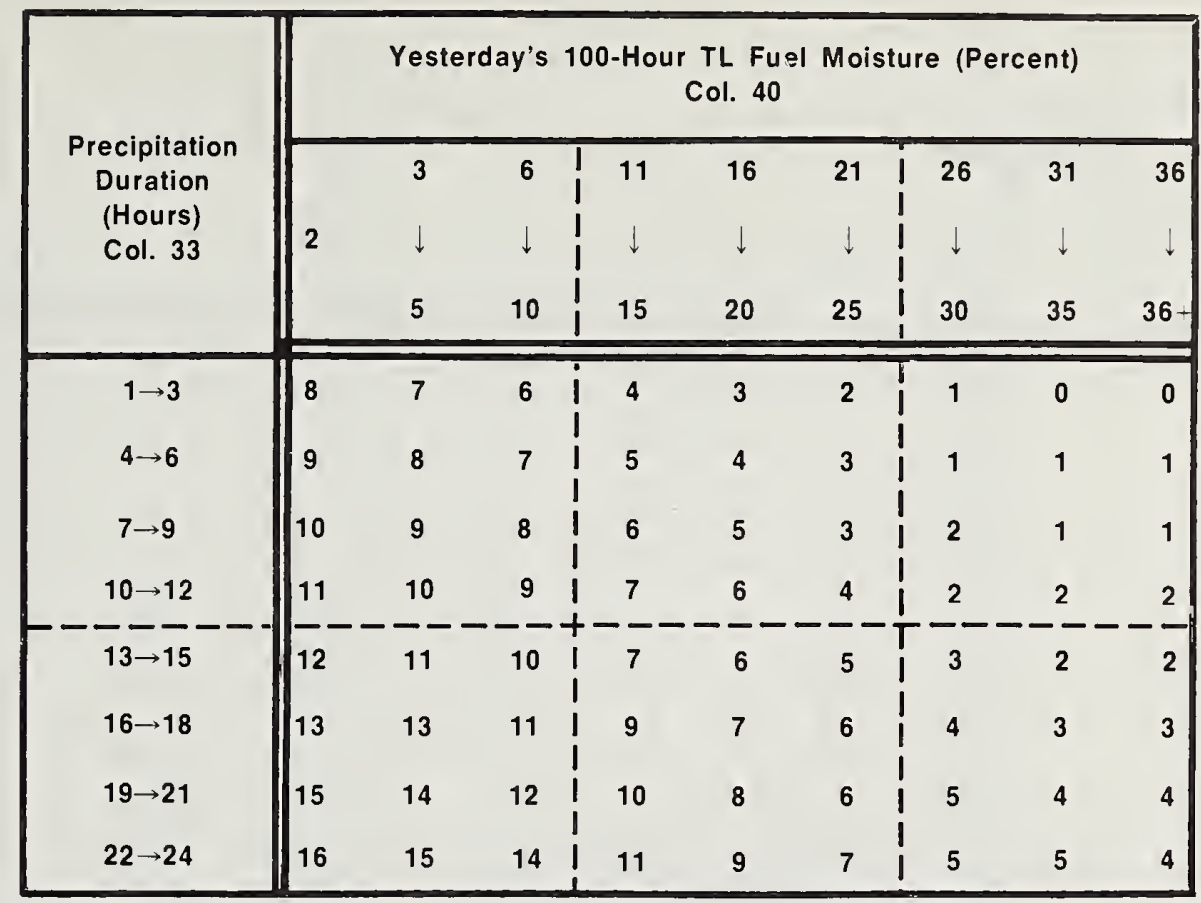

Purpose: To compute the effect of precipitation occurring since Basic Observation Time yesterday on the moisture content of the $100-\mathrm{Hr}$. TL، fuels.*

Procedure: At the intersection of the column indexed by yesterday's 100-Hr. TI، FM (column 40) and the row indexed by the precipitation duration (column 33) is the correction to the 100-Hr. TL FM for precipitation; record in column 39.

\section{Computation Of Today's 100-Hour Timelag Fuel Moisture}

Being careful of the arithmetic signs, add the entries in columns 38, 39, and 40. Enter the results in columns 41 and 20; this is today's 100-Hr. TL FM.

* If no precipitation has occurred in the past 24 hours, record a zero (0) in column 39. 


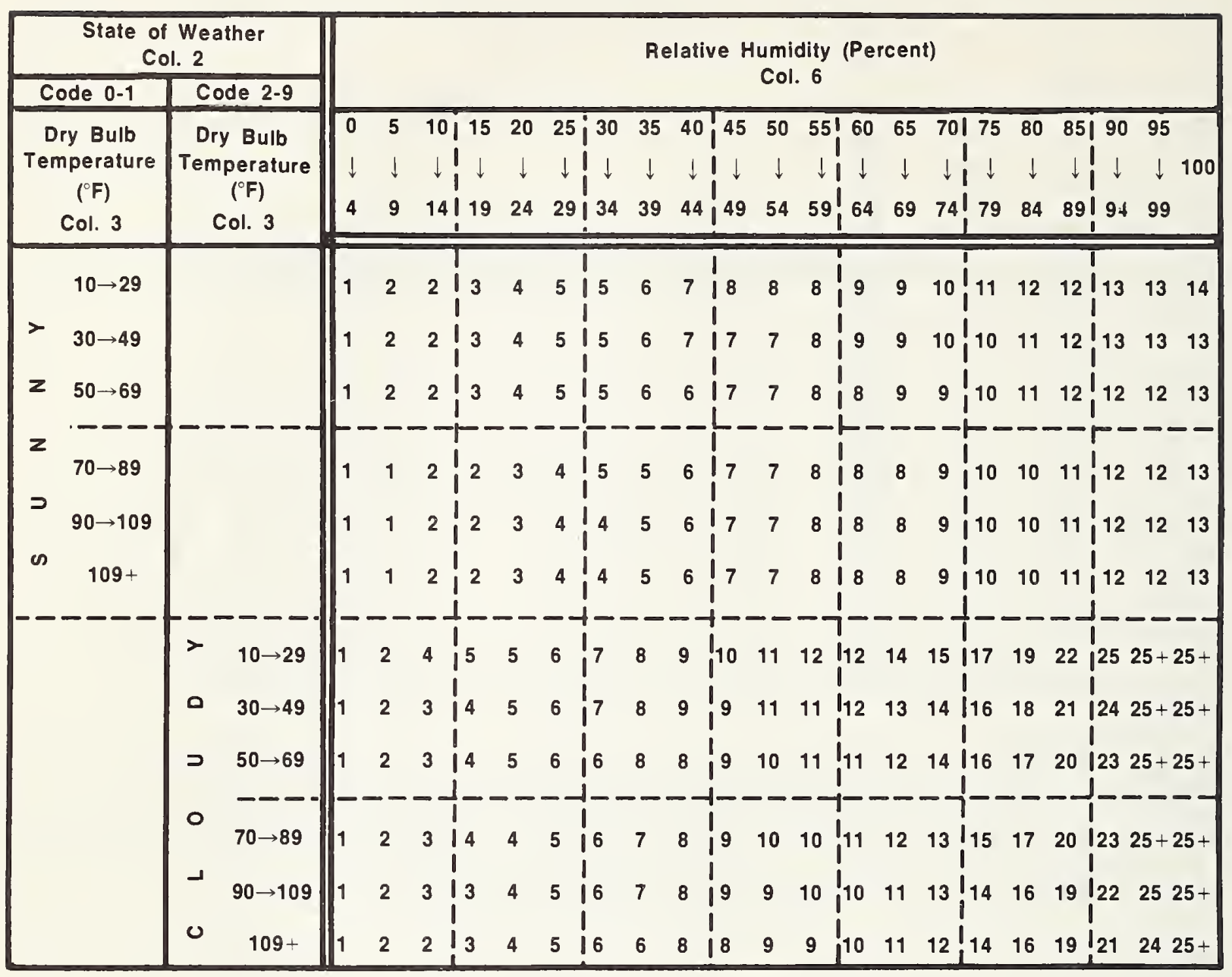

Purpose: To compute the moisture content of dead fuels one-quarter inch and less in diameter.* Procedure: If the state of the weather is coded $2,3,4,8$, or 9 (column 2), or if the observation is being taken before 1000 or after $1500 \mathrm{LST}$, the dry-bulb temperature is entered to the left in that section of the table labeled "cloudy." Otherwise enter the temperature in the section labeled "sunny." Read the 1-Hr. TL FM at the intersection of this row and the column indexed by the appropriate value for relative humidity (column 6); record in column 7.

* If it is raining (state of weather codes 5,6, or 7) or there is snow or ice on the ground fuels, record $25+$ in column 7 . 
FINE FUEL MOISTURE (PERCENT)

Col. 9

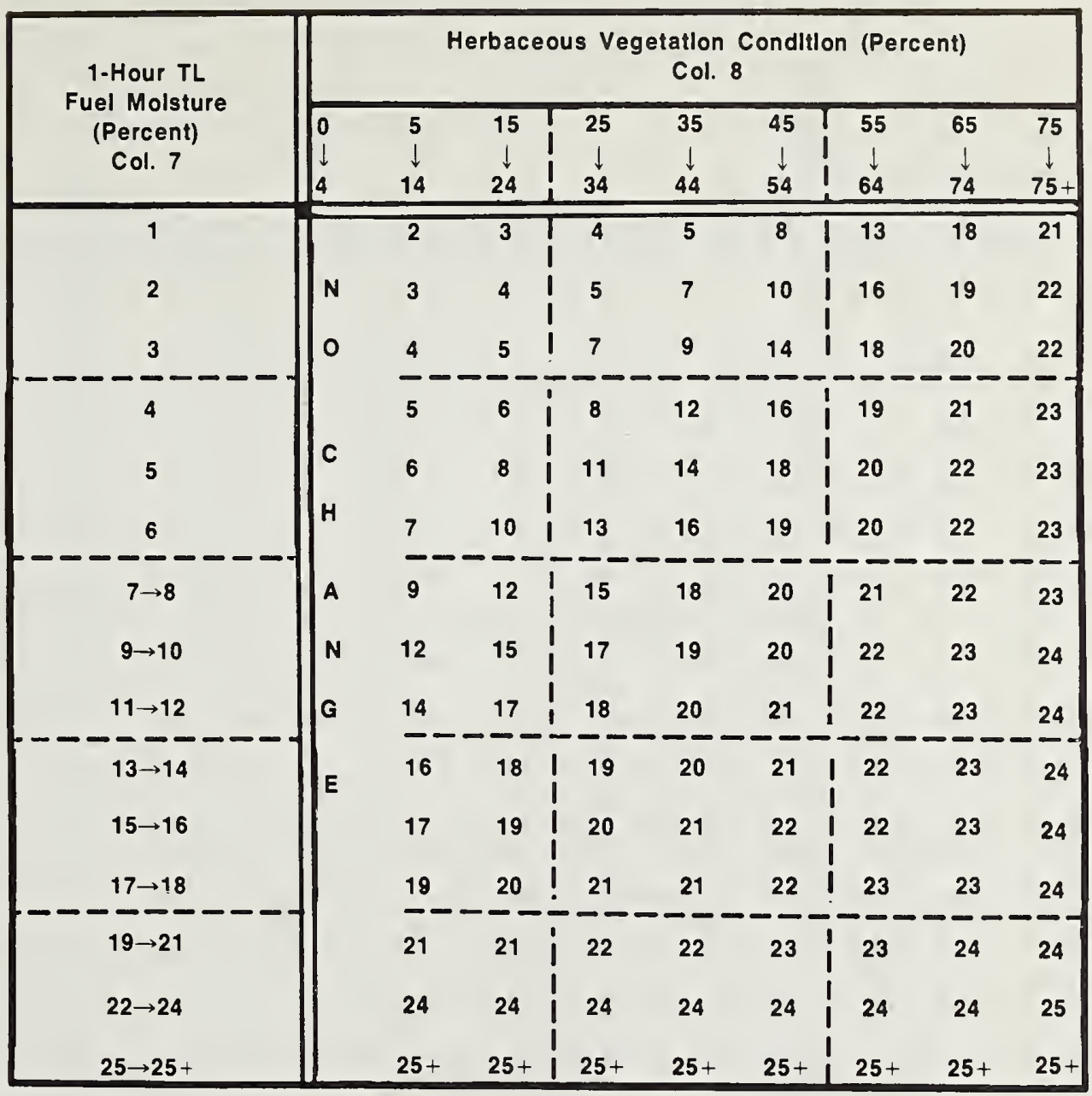

Purpose: To adjust the 1-Hr. TL FM to account for the reduced flammability of the lesser fuels due to the presence of living herbaceous plant material.*

Procedure: Read the FFM at the intersection of the row indexed by the 1-Hr. TL, FM (column 7) and the column indexed by herbaceous vegetation condition (column 8); record in column 9 .

* If the herbaceous vegetation condition is 4 or less, enter the value of the 1-Hr. TL FM directly into column 9. 


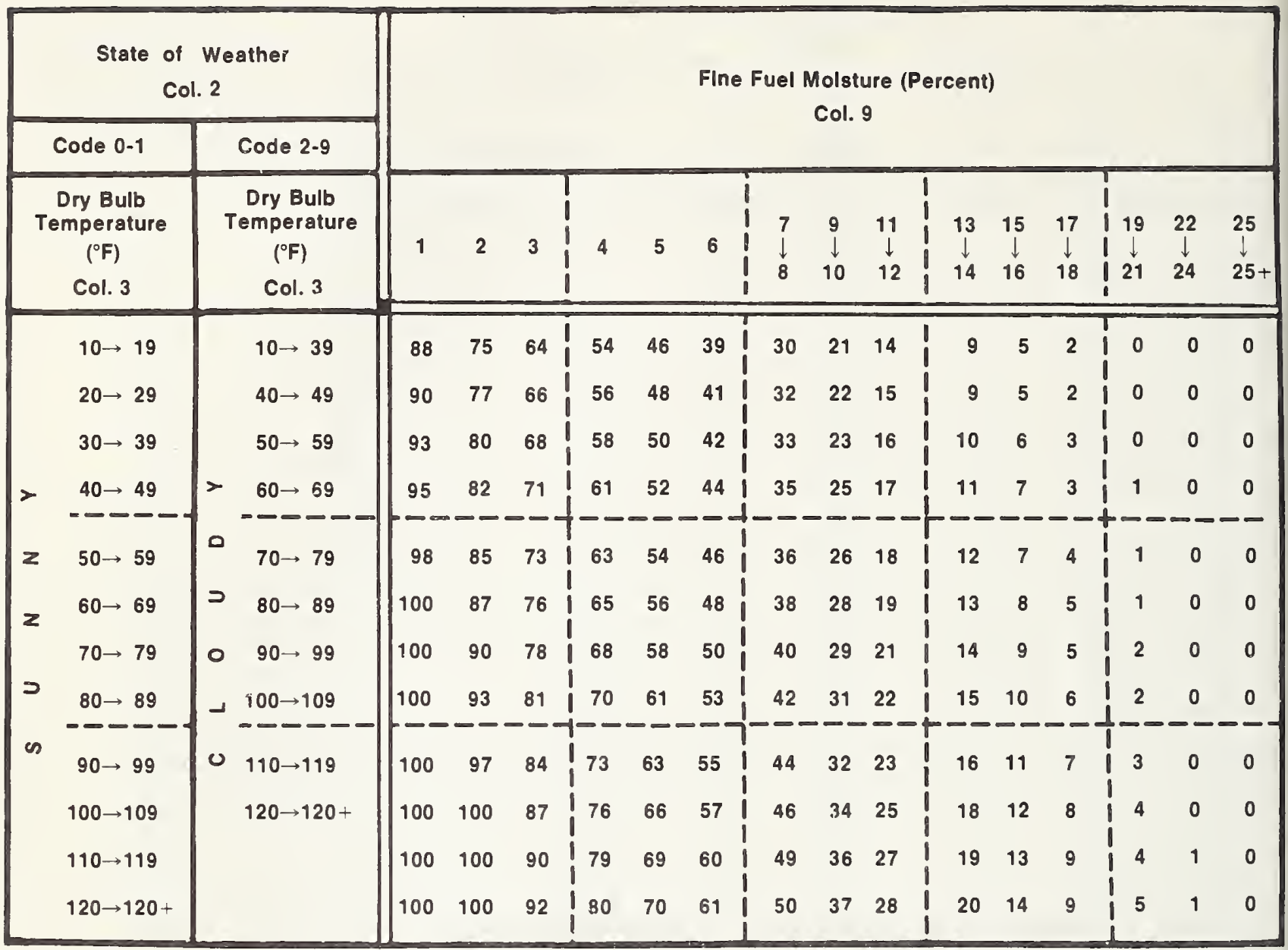

Purpose: To compute a number related to the probability that a fire will result if a firebrand is introduced into the fine fuel complex.*

Procedure: If the state of the weather is coded 2, 3, 4, 8, or 9 (column 2), or if the observation is being taken before 1000 or after 1500 LST, the dry-bulb temperature (column 3) is entered to the left in that section of the table labeled "cloudy." Otherwise, enter the temperature in the section labeled "sunny." Read the IC at the intersection of the column indexed by the FFM (column 9) and the row indexed by the dry-bulb temperature (column 3); record in column 10.

* If it is raining (state of weather code 5, 6, or 7) or there is snow or ice on the ground fuels, record a zero (0) in column 10. 


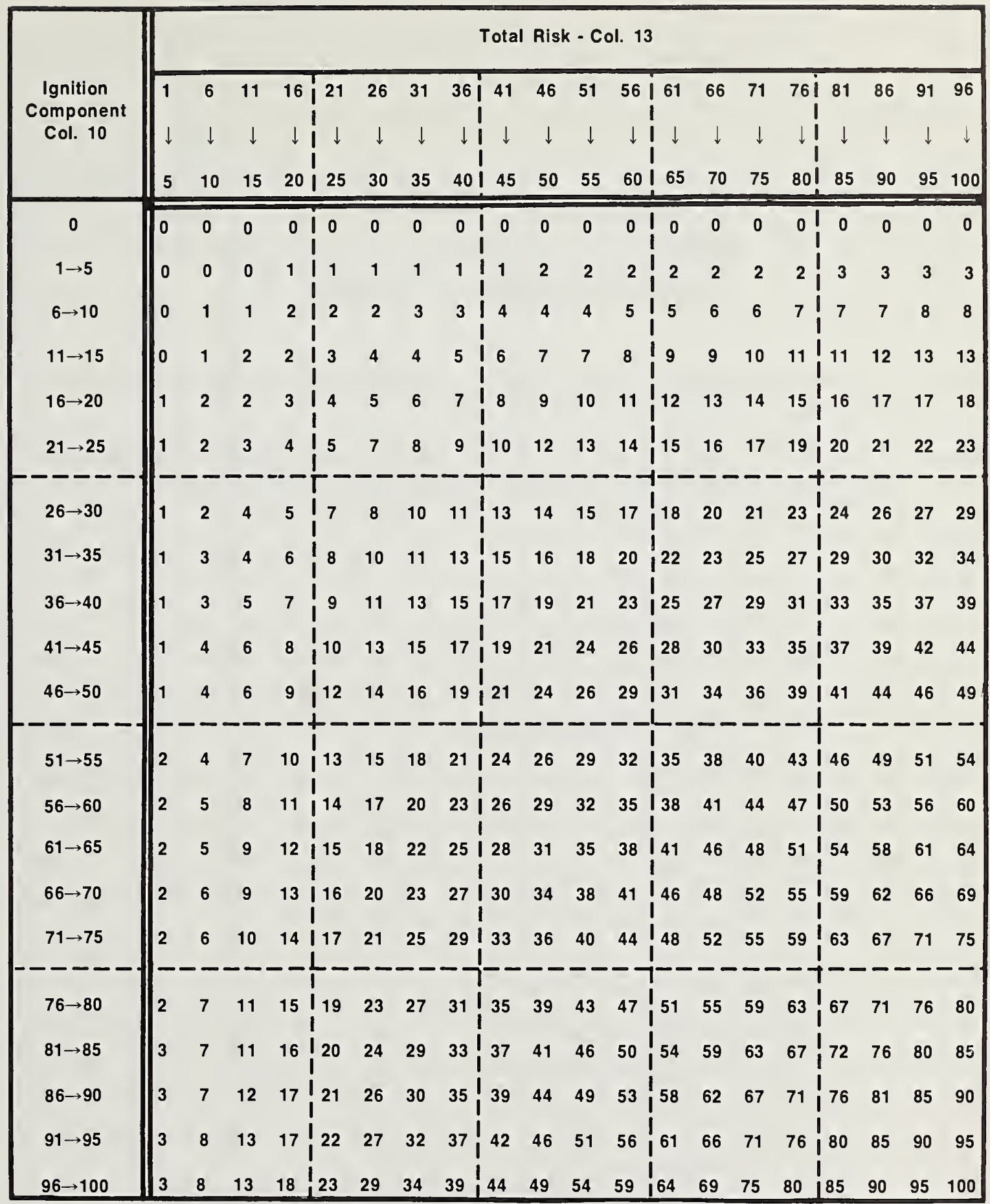

Purpose: To compute a number related to the probable level of fire incidence on the rating area.*

Procedure: At the intersection of the row indexed by the IC (column 10) and the column indexed by total Risk (column 13) is the OI; record in column 14.

* If it is raining (state of the weather code 5,6, or 7 ) or there is snow or ice on the ground fuels, record a zero (0) in column 14. 


\section{Spread Component - Fuel Model G}

Purpose: To compute a number related to the forward rate of spread of the head of a fire burning in fuels represented by this fuel model.*

Procedure: The windspeed (column 16) is entered into the table from the column headed by the slope class assigned to the rating area. At the intersection of this row and the column indexed by the FFM (column 9) is the SC; record in column 18.

* If it is raining (state of weather code 5, 6, or 7) or there is snow or ice on the ground fuels, record a zero (0) in column 18. 
SPREAD COMPONENT - FUEL MODEL G

Col. 18

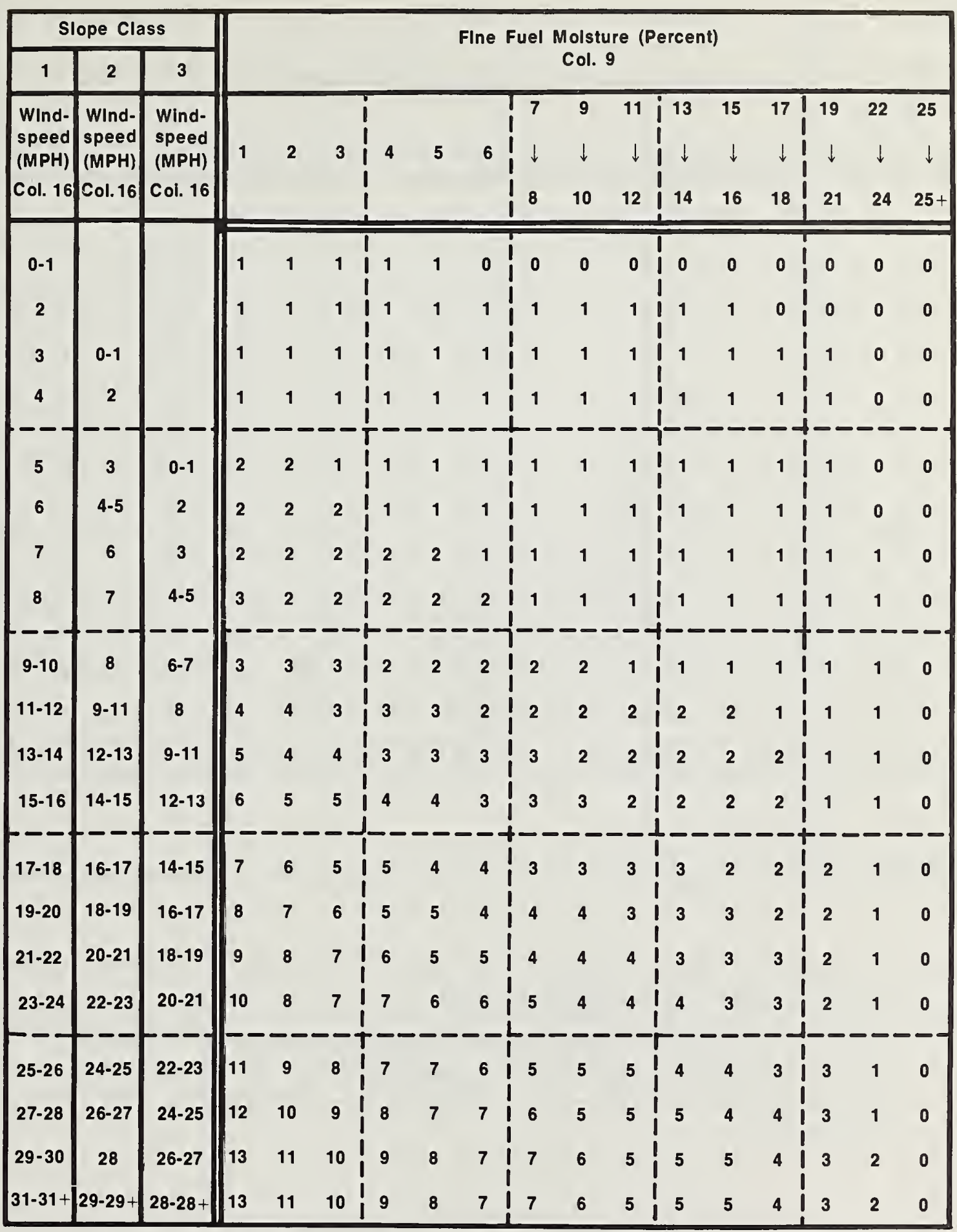




\begin{tabular}{|c|c|c|c|c|c|c|c|c|c|c|c|c|c|c|c|c|}
\hline \multirow{2}{*}{$\begin{array}{l}\text { 10-Hour TL } \\
\text { Fuel Molsture } \\
\text { (Percent) } \\
\text { Col. } 19\end{array}$} & \multicolumn{16}{|c|}{$\begin{array}{l}\text { Flne Fuel Molsture (Percent) } \\
\text { Col. } 9\end{array}$} \\
\hline & 1 & 2 & 3 & 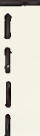 & 4 & 5 & 6 & $\begin{array}{l}7 \\
\downarrow \\
8\end{array}$ & $\begin{array}{c}9 \\
\downarrow \\
10\end{array}$ & $\begin{array}{c}11 \\
\downarrow \\
12\end{array}$ & $\begin{array}{c}13 \\
\downarrow \\
14\end{array}$ & $\begin{array}{c}15 \\
\downarrow \\
16\end{array}$ & $\begin{array}{c}17 \\
\downarrow \\
18\end{array}$ & $\begin{array}{c}19 \\
\downarrow \\
21\end{array}$ & $\begin{array}{c}22 \\
\downarrow \\
24\end{array}$ & $\begin{array}{c}25 \\
\downarrow \\
25+\end{array}$ \\
\hline 1 & A & B & B & i & c & C & D & E & $F$ & G & $\mathrm{H}$ & H & 1 & 1 & $J$ & K \\
\hline 2 & A & B & C & 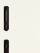 & C & D & D i & E & G & G & $H$ & H & I & J & K & K \\
\hline 3 & B & B & c & 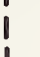 & D & D & E I & $F$ & G & G & $H$ & I & 1 & J & K & K \\
\hline 4 & B & C & C & i & D & E & E & $\mathbf{F}$ & G & H & H & I & I & J & K & L \\
\hline 5 & C & C & D & 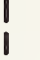 & D & E & $\mathbf{F}$ & G & G & H & H & 1 & $\mathrm{~J}$ & J & K & L \\
\hline 6 & c & D & D & 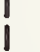 & $E$ & E & $\mathbf{F}$ & G & G & H & 1 & I & $\mathrm{J}$ & J & K & $\mathbf{L}$ \\
\hline $7 \rightarrow 8$ & D & $D$ & E & & $E$ & $\mathbf{F}$ & G I & G & H & H & I & 1 & $\mathbf{J}$ & $\mathrm{K}$ & $\mathbf{L}$ & $\mathbf{L}$ \\
\hline $9 \rightarrow 10$ & D & $E$ & $F$ & 1 & $F$ & G & G I & G & H & 1 & 1 & J & $\mathbf{J}$ & $K$ & $\mathbf{L}$ & $M$ \\
\hline $11 \rightarrow 12$ & E & $\mathbf{F}$ & $\mathbf{F}$ & i & G & G & G I & H & H & 1 & J & $\mathbf{J}$ & $\mathbf{K}$ & L & $\mathbf{L}$ & M \\
\hline $13 \rightarrow 14$ & $F$ & G & G & 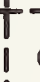 & G & G & H & H & 1 & & $\mathbf{J}$ & K & K & L & M & $M$ \\
\hline $15 \rightarrow 16$ & $G$ & G & G & $i$ & H & H & H & 1 & I & $J$ & J & $\mathbf{K}$ & $\mathbf{L}$ & L & M & M \\
\hline $17 \rightarrow 18$ & G & G & H & i & $\mathrm{H}$ & H & 11 & I & $\mathrm{J}$ & $\mathrm{J}$ & K & $\mathbf{K}$ & $\mathbf{L}$ & i & M & $\mathbf{N}$ \\
\hline--1 & & & & & & & & & & & & & & & & \\
\hline $19 \rightarrow 21$ & H & H & H & 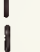 & H & 1 & 11 & J & J & $\mathbf{K}$ & K & $\mathbf{L}$ & M & $M$ & $\mathbf{N}$ & $\mathbf{N}$ \\
\hline $22 \rightarrow 24$ & H & H & I & ! & 1 & 1 & J ! & J & K & K & $\mathbf{L}$ & M & $M$ & $M$ & $\mathbf{N}$ & $\mathbf{N}$ \\
\hline $25 \rightarrow 25+$ & 1 & 1 & 1 & ! & I & $\mathrm{J}$ & Ji & K & K & $\mathbf{L}$ & $L$ & $\mathbf{M}$ & $\mathbf{M}$ & $N$ & $\mathbf{N}$ & 0 \\
\hline
\end{tabular}

Procedure: To compute a number related to the rate of combustion at the head of a fire burning in fuels represented by this fuel model.*

Procedure: In Part A-Read the transfer letter at the intersection of the row indexed by the 10-Hr. TL، FM (column 19) and the column indexed by the FFM (column 9).

In Part B-Read the ERC at the intersection of the row indexed by the 100-Hr. TL FM (column 20) and the column indexed by the transfer letter from Part A; record in column 21 .

* If it is raining (state of weather code 5, 6, or 7) or there is snow or ice on the ground fuels, record a zero (0) in column 21 . 


\begin{tabular}{|c|c|c|c|c|c|c|c|c|c|c|c|c|c|c|c|}
\hline \multirow{2}{*}{$\begin{array}{l}\text { 100-Hour TL } \\
\text { Fuel Moisture } \\
\text { (Percent) } \\
\text { Col. } 20\end{array}$} & \multicolumn{15}{|c|}{ Transfer Letter From Part A } \\
\hline & A & $\mathbf{B}$ & C & D & $\mathbf{E}$ & $\mathbf{F}$ & $\mathbf{G}$ & $H$ & 1 & $J$ & $\mathbf{K}$ & $\mathbf{L}$ & $\mathbf{M}$ & $\mathbf{N}$ & 0 \\
\hline 1 & 85 & 82 & 79 & 75 & 72 & 69 & 65 & 59 & 54 & 49 & 45 & 41 & 36 & 31 & 27 \\
\hline 2 & 82 & 79 & 75 & 72 & 69 & 66 & 62 & 57 & 52 & 47 & 43 & 39 & 34 & 29 & 26 \\
\hline 3 & 79 & 75 & 72 & 69 & 66 & 63 & 59 & 54 & 49 & 45 & 41 & 37 & 32 & 27 & 24 \\
\hline 4 & 75 & 72 & 69 & 66 & 63 & 61 & 57 & 52 & 47 & 43 & 39 & 35 & 31 & 26 & 23 \\
\hline 5 & 72 & 69 & 66 & 63 & 61 & 58 & 54 & 49 & 45 & 41 & 37 & 33 & 29 & 24 & 22 \\
\hline 6 & 69 & 66 & 63 & 61 & 58 & 55 & 52 & 47 & 43 & 39 & 35 & 31 & 27 & 23 & 20 \\
\hline $7 \rightarrow 8$ & 65 & 62 & 59 & 57 & 54 & 52 & 48 & 44 & 40 & 36 & 32 & 29 & 25 & 21 & 18 \\
\hline $9 \rightarrow 10$ & 59 & 57 & 54 & 52 & 49 & 47 & 44 & 40 & 36 & 32 & 29 & 26 & 22 & 18 & 16 \\
\hline $11 \rightarrow 12$ & 54 & 52 & 49 & 47 & 45 & 43 & 40 & 36 & 32 & 29 & 26 & 23 & 20 & 16 & 13 \\
\hline $13 \rightarrow 14$ & 49 & 47 & 45 & 43 & 41 & 39 & 36 & 32 & 29 & 26 & 23 & 20 & 17 & 13 & 11 \\
\hline $15 \rightarrow 16$ & 45 & 43 & 41 & 39 & 37 & 35 & 32 & 29 & 26 & 23 & 20 & 18 & 15 & 11 & 9 \\
\hline $17 \rightarrow 18$ & 41 & 39 & 37 & 35 & 33 & 31 & 29 & 26 & 23 & 20 & 18 & 15 & 12 & 9 & 7 \\
\hline $19 \rightarrow 21$ & 36 & 34 & 32 & 31 & 29 & 27 & 25 & 22 & 20 & 17 & 15 & 12 & 10 & 7 & 5 \\
\hline $22 \rightarrow 24$ & 31 & 29 & 27 & 26 & 24 & 23 & 21 & 18 & 16 & 13 & 11 & 9 & 7 & 4 & 2 \\
\hline $25 \rightarrow 25+$ & 27 & 26 & 24 & 23 & 22 & 20 & 18 & 16 & 13 & 11 & 9 & 7 & 5 & 2 & 0 \\
\hline
\end{tabular}


BURNING INDEX - FUEL MODEL G

Col. 22

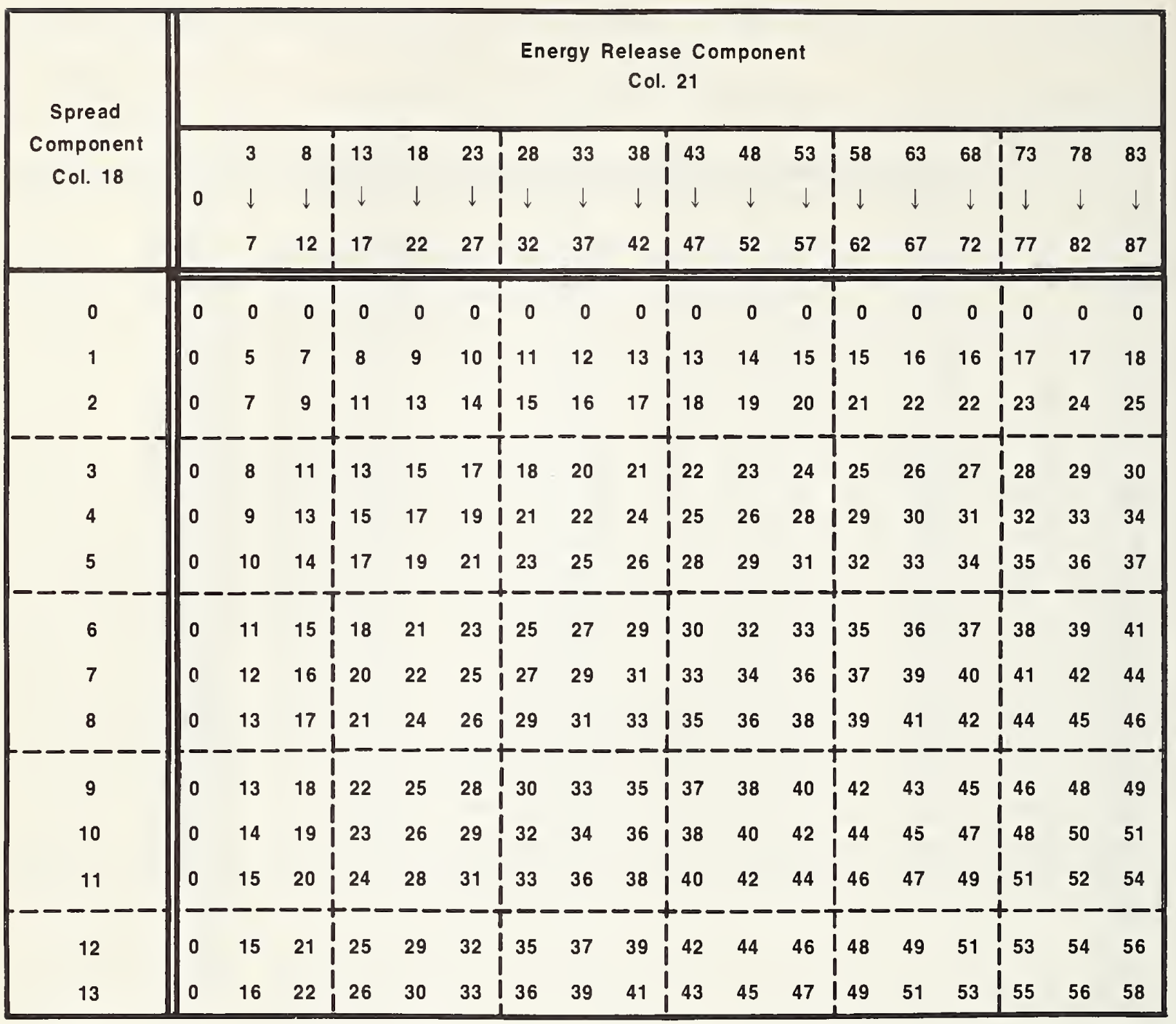

Purpose: To compute a number related to the amount of effort needed to contain a single fire burning in fuels represented by this fuel model.*

Procedure: Read the BI at the intersection of the row indexed by the SC (column 18) and the ERC (column 21); record in column 22.

* If it is raining (state of weather code 5,6, or 7) or there is snow or ice on the ground fuels, record a zero (0) in column 22. 


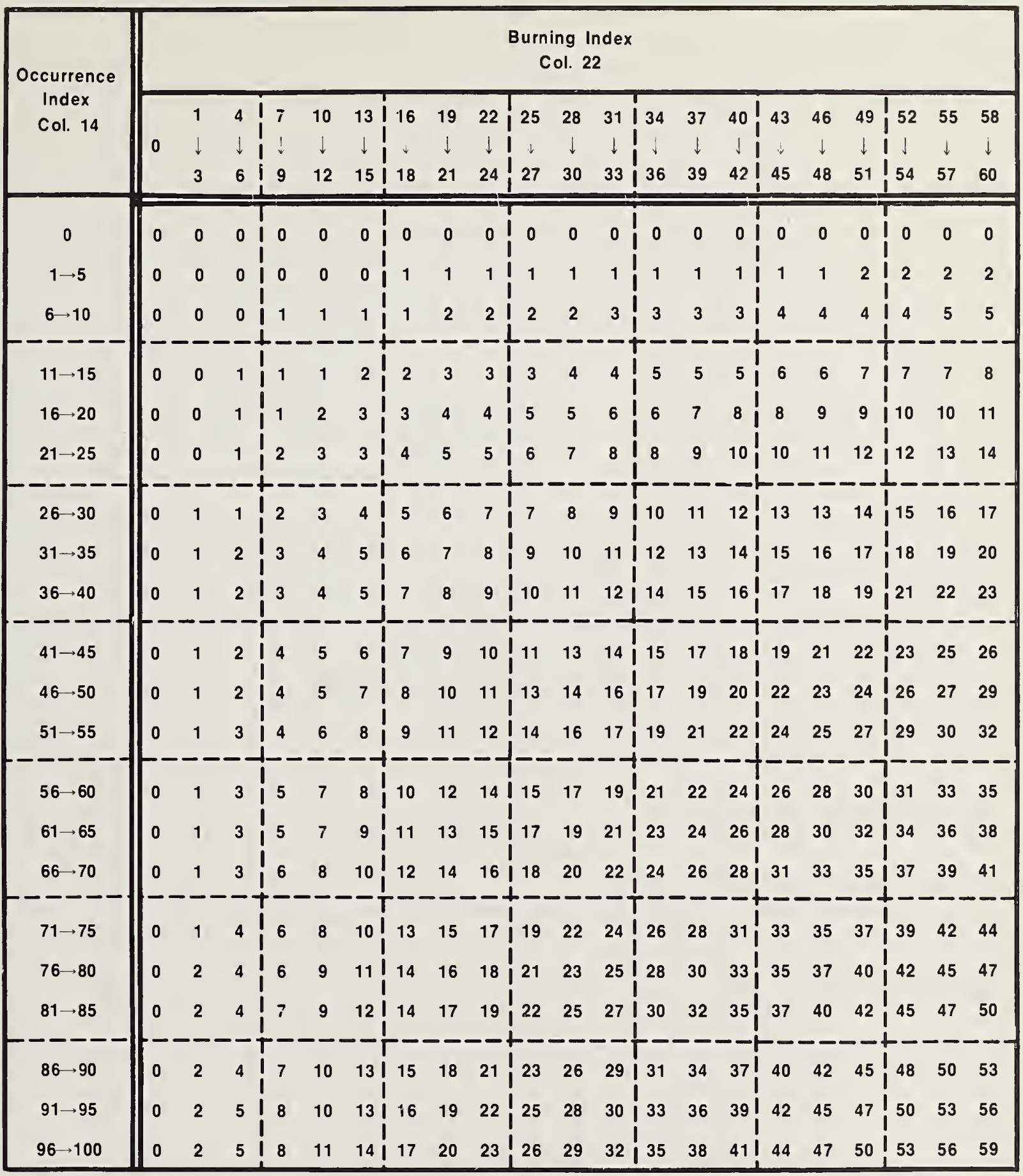

Purpose: To compute a number related to the total effort needed to contain all probable fires on a rating area.*

Procedure: Read the FLI at the intersection of the row indexed by the OI (column 14) and the column indexed by the BI (column 22); record in column 23 .

* If it is raining (state of weather code 5, 6, or 7) or there is snow or ice on the ground fuels, record a zero (0) in column 23. 


\section{Fuel Model H}




\section{COMPUTATIONAL FLOW CHART FUEL MODEL H}

(1)

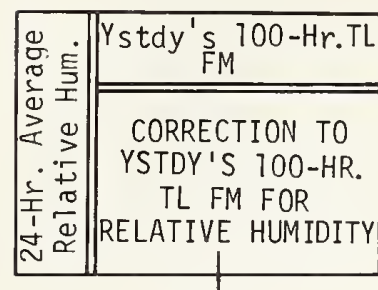

(3)

(4)

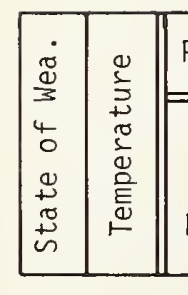
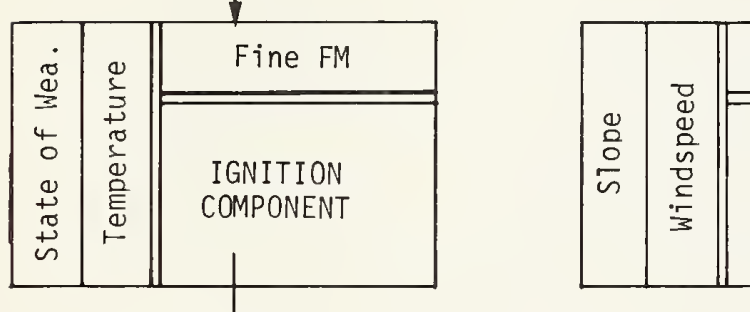

(6)

Fine FM

TITION

COMPONENT

1

1-HOUR

TIMELAG

FUEL MOISTURE
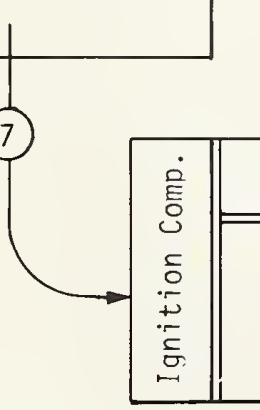

Total Risk

OCCURRENCE

INDEX

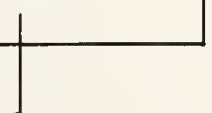

(11)

ine FM

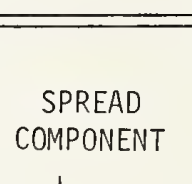

FUEL MOISTURE

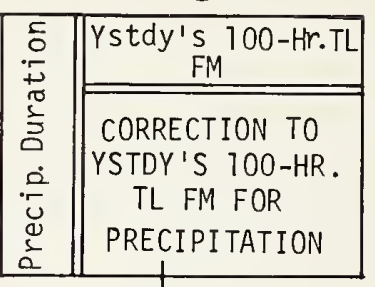

(3)

Today's 100-Hr. TL FM 


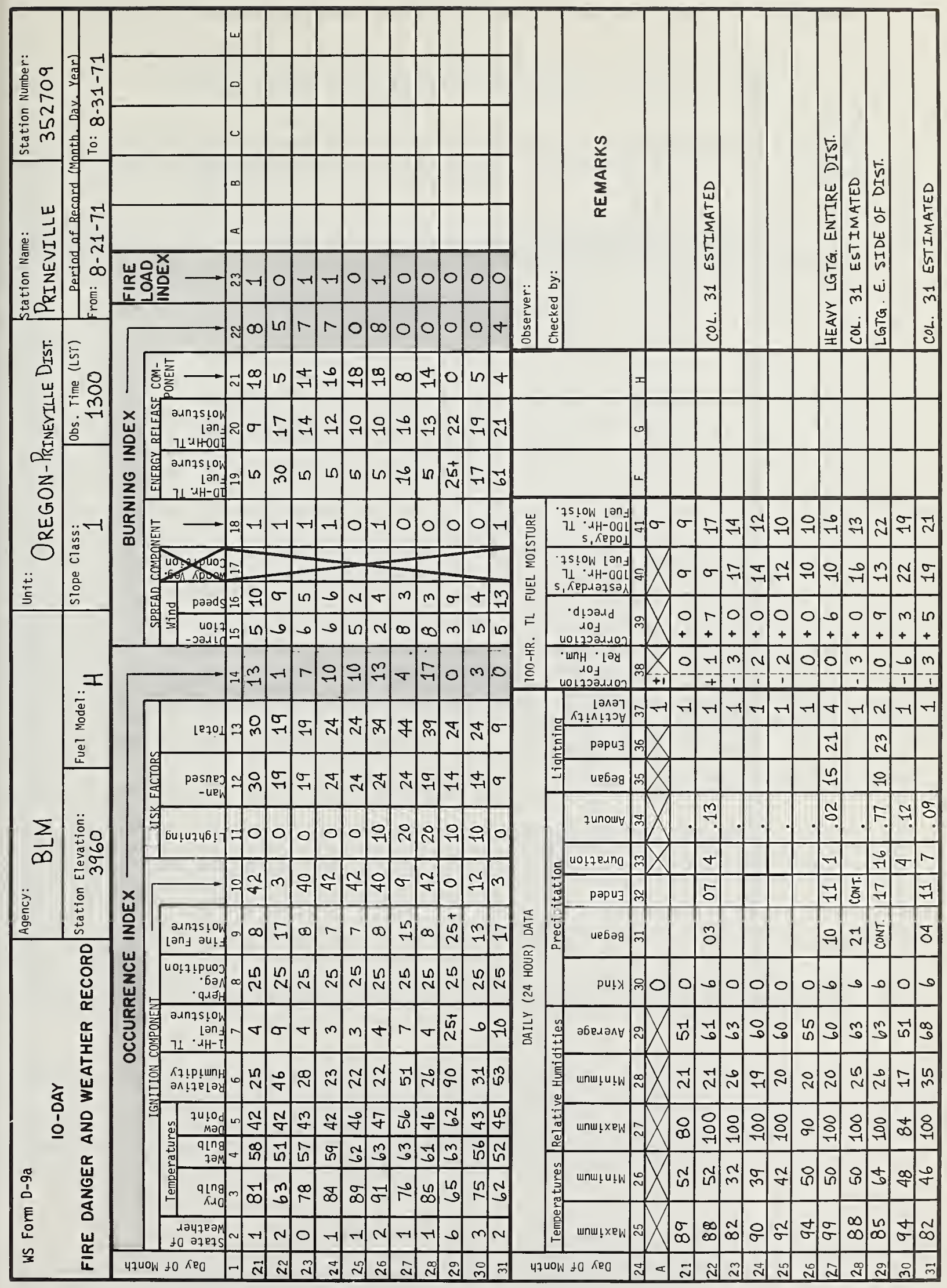




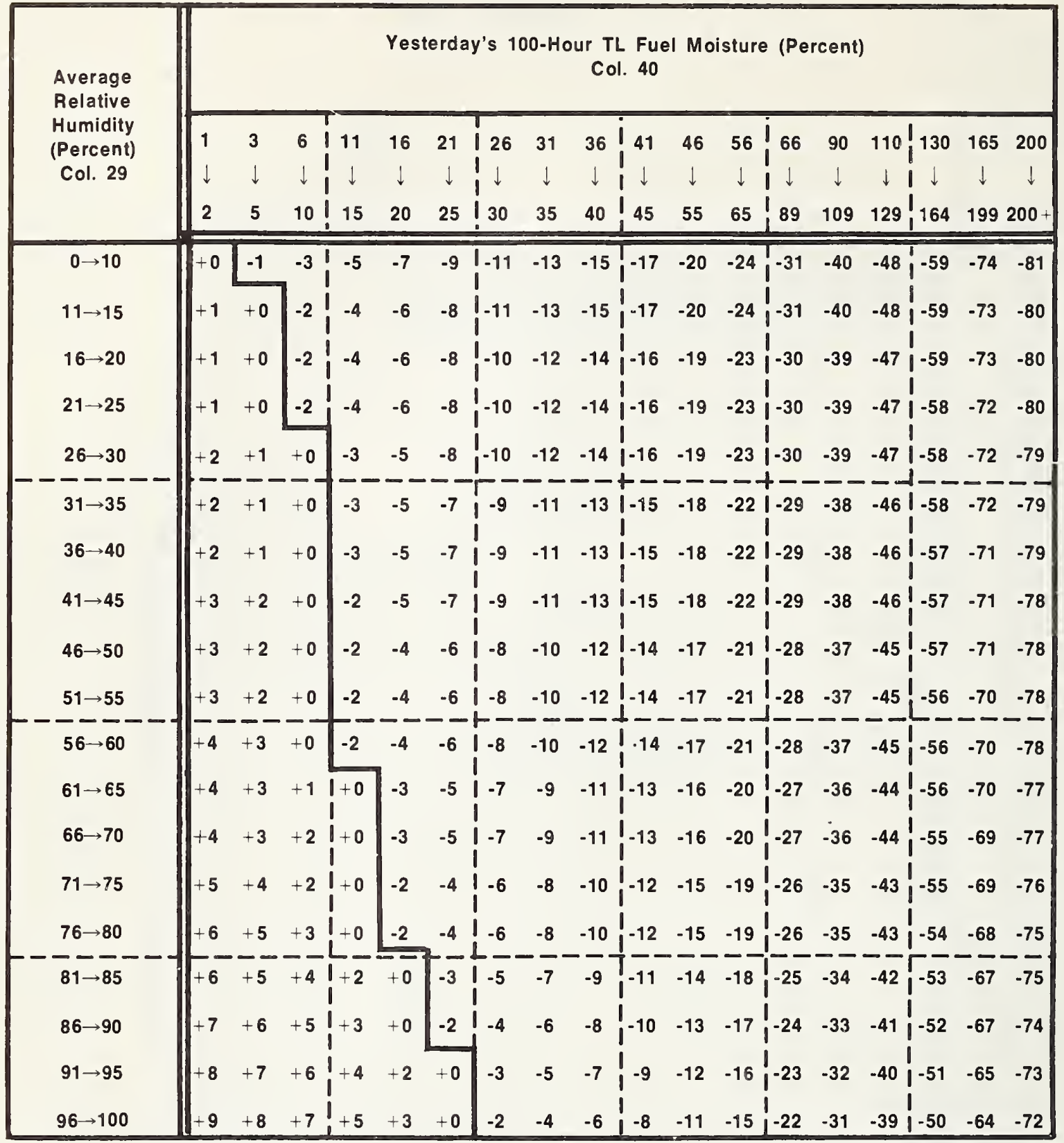

Purpose: To compute the effect of atmospheric humidity (water vapor) since Basic Observation Time yesterday, on the moisture content of the 100-Hr. TL fuels.*,**

Procedures: At the intersection of the column indexed by yesterday's 100-Hr. TL FM (column $40)^{* * *}$ and the row indexed by the 24 -hour average relative humidity (column 29) is the correction to the $100-\mathrm{Hr}$. TL FM for relative humidity; record in column 38.

* Values can be positive (+) or negative (-), record the proper sign.

** If it has rained continuously for the past 24 hours, record a zero $(0)$ in column 38 .

*** At the beginning of the fire season, an initial value of 35 percent should be assumed. 
CORRECTION TO 100 - HOUR TIMELAG FUEL MOISTURE FOR PRECIPITATION (PERCENT)

Col. 39

\begin{tabular}{|c|c|c|c|c|c|c|c|c|c|}
\hline \multirow[b]{2}{*}{$\begin{array}{l}\text { Precipitation } \\
\text { Duration } \\
\text { (Hours) } \\
\text { Col. } 33\end{array}$} & \multicolumn{9}{|c|}{$\begin{array}{l}\text { Yesterday's 100-Hour TL Fuel Moisture (Percent) } \\
\text { Col. } 40\end{array}$} \\
\hline & 2 & $\begin{array}{l}3 \\
\downarrow \\
5\end{array}$ & $\begin{array}{c}6 \\
\downarrow \\
10\end{array}$ & $\begin{array}{c}11 \\
\downarrow \\
15\end{array}$ & $\begin{array}{c}16 \\
\downarrow \\
20\end{array}$ & $\begin{array}{c}21 \\
\downarrow \\
25\end{array}$ & $\begin{array}{c}26 \\
\downarrow \\
30\end{array}$ & $\begin{array}{c}31 \\
\downarrow \\
35\end{array}$ & $\begin{array}{c}36 \\
\downarrow \\
36+\end{array}$ \\
\hline $1 \rightarrow 3$ & 8 & 7 & 6 & 4 & 3 & 2 & 1 & 0 & 0 \\
\hline $4 \rightarrow 6$ & 9 & 8 & 7 & 5 & 4 & 3 & 1 & 1 & 1 \\
\hline $7 \rightarrow 9$ & 10 & 9 & 8 & 6 & 5 & 3 & 2 & 1 & 1 \\
\hline $10 \rightarrow 12$ & 11 & 10 & 9 & 7 & 6 & 4 & 2 & 2 & 2 \\
\hline $13 \rightarrow 15$ & 12 & 11 & 10 & 7 & 6 & 5 & 3 & 2 & 2 \\
\hline $16 \rightarrow 18$ & 13 & 13 & 11 & 9 & 7 & 6 & 4 & 3 & 3 \\
\hline $19 \rightarrow 21$ & 15 & 14 & 12 & 10 & 8 & 6 & 5 & 4 & 4 \\
\hline $22 \rightarrow 24$ & 16 & 15 & 14 & 11 & 9 & 7 & 5 & 5 & 4 \\
\hline
\end{tabular}

Purpose: To compute the effect of precipitation occurring since Basic Observation Time yesterday on the moisture content of the 100-Hr. TL, fuels.*

Procedure: At the intersection of the column indexed by yesterday's 100-Hr. TL, FM (column 40) and the row indexed by the precipitation duration (column 33) is the correction to the $100-\mathrm{Hr}$. TL FM for precipitation; record in column 39.

\section{Computation Of Today's 100-Hour Timelag Fuel Moisture}

Being careful of the arithmetic signs, add the entries in columns 38,39 , and 40 . Enter the results in columns 41 and 20; this is today's 100-Hr. TL FM.

* If no precipitation has occurred in the past 24 hours, record a zero (0) in column 39. 


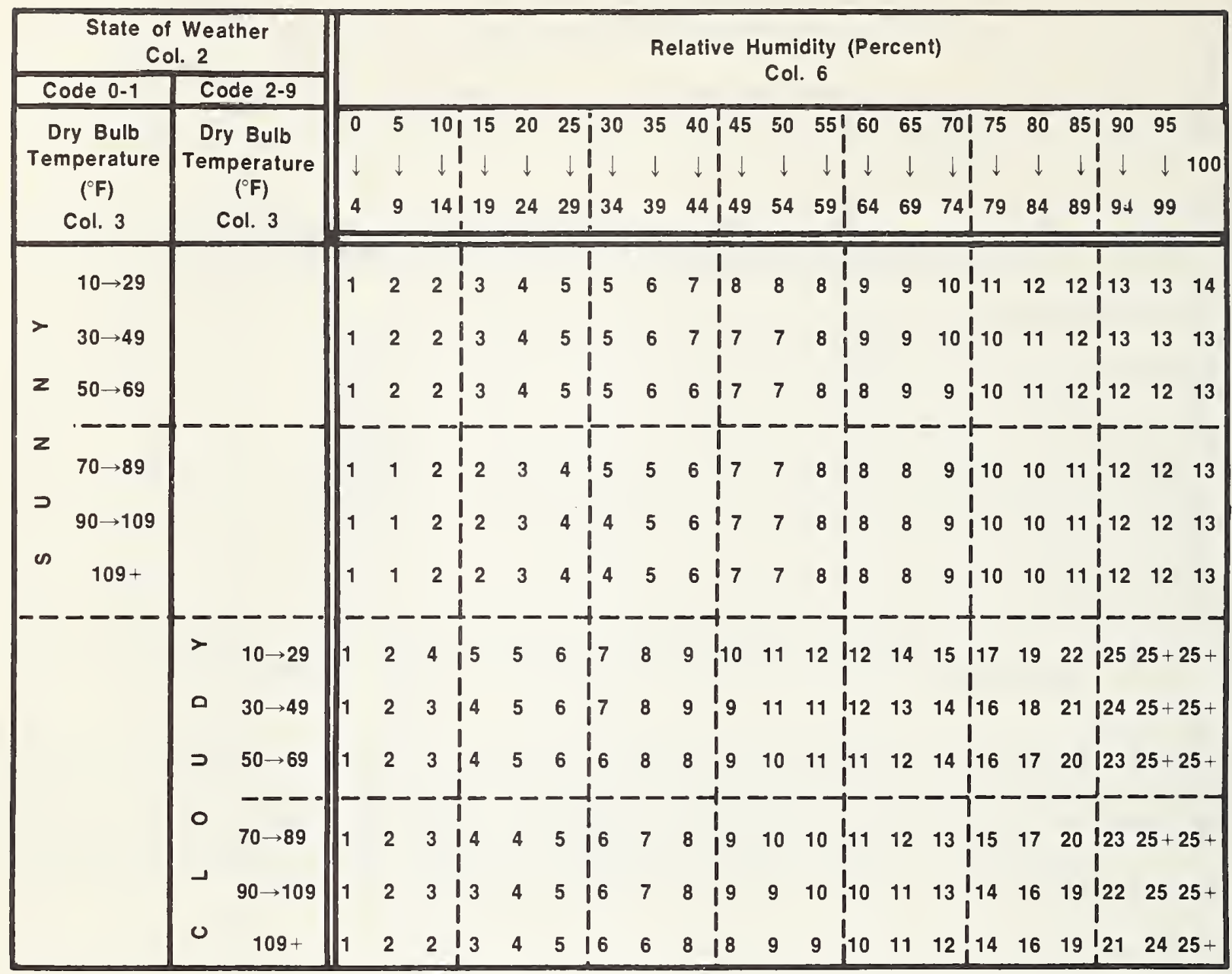

Purpose: To compute the moisture content of dead fuels one-quarter inch and less in diameter.* Procedure: If the state of the weather is coded $2,3,4,8$, or 9 (column 2), or if the observation is being taken before 1000 or after 1500 LST, the dry-bulb temperature is entered to the left in that section of the table labeled "cloudy." Otherwise enter the temperature in the section labeled "sunny." Read the 1-Hr. TL, FM at the intersection of this row and the column indexed by the appropriate value for relative humidity (column 6); record in column 7 .

* If it is raining (state of weather codes 5, 6, or 7) or there is snow or ice on the ground fuels, record $25+$ in column 7 . 


\section{Col. 9}

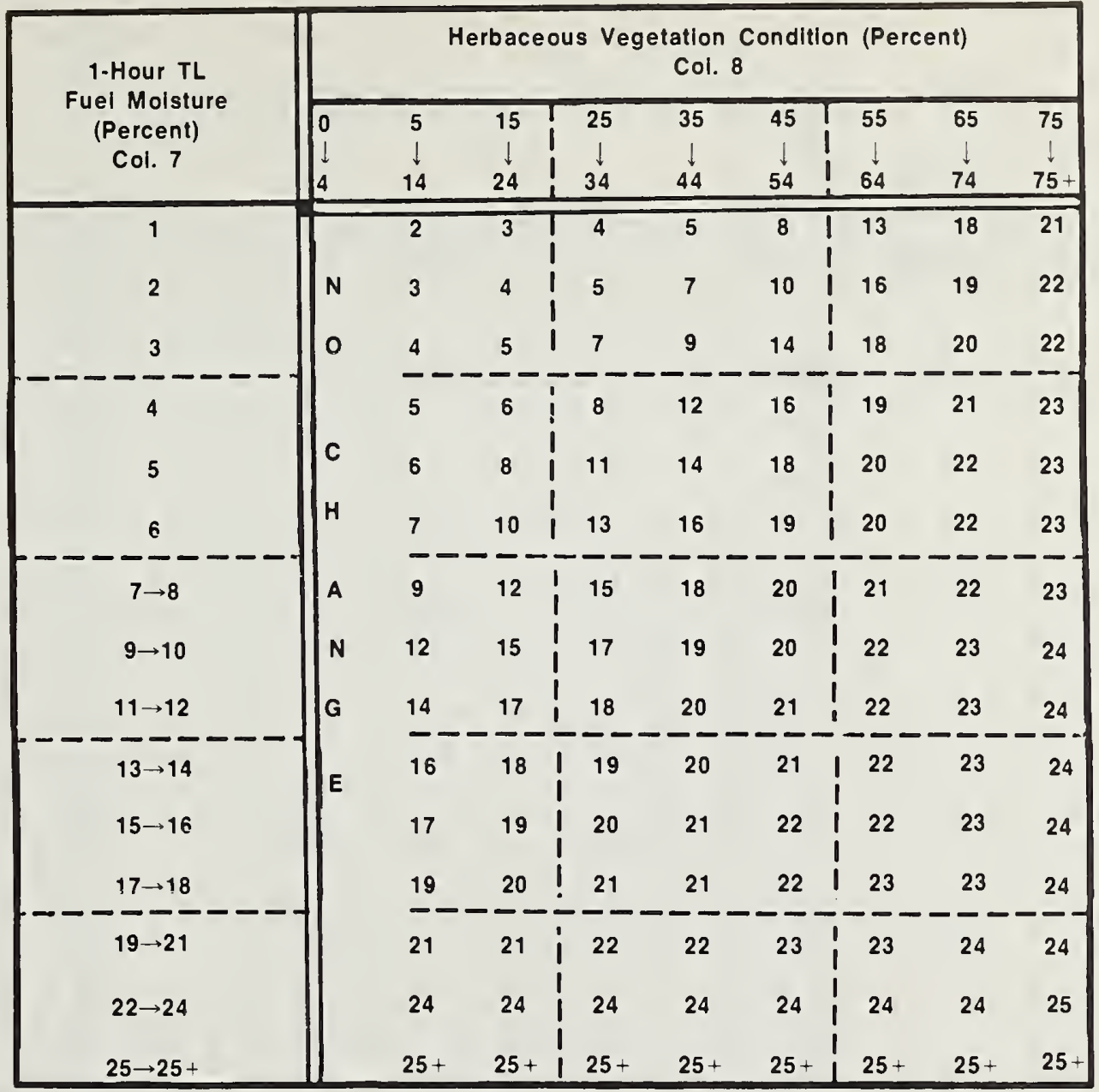

Purpose: To adjust the 1-Hr. TL FM to account for the reduced flammability of the lesser fuels due to the presence of living herbaceous plant material.*

Procedure: Read the FFM at the intersection of the row indexed by the 1-Hr. TL FM (column 7) and the column indexed by herbaceous vegetation condition (column 8); record in column 9 .

* If the herbaceous vegetation condition is 4 or less, enter the value of the 1-Hr. TL FM directly into column 9 . 


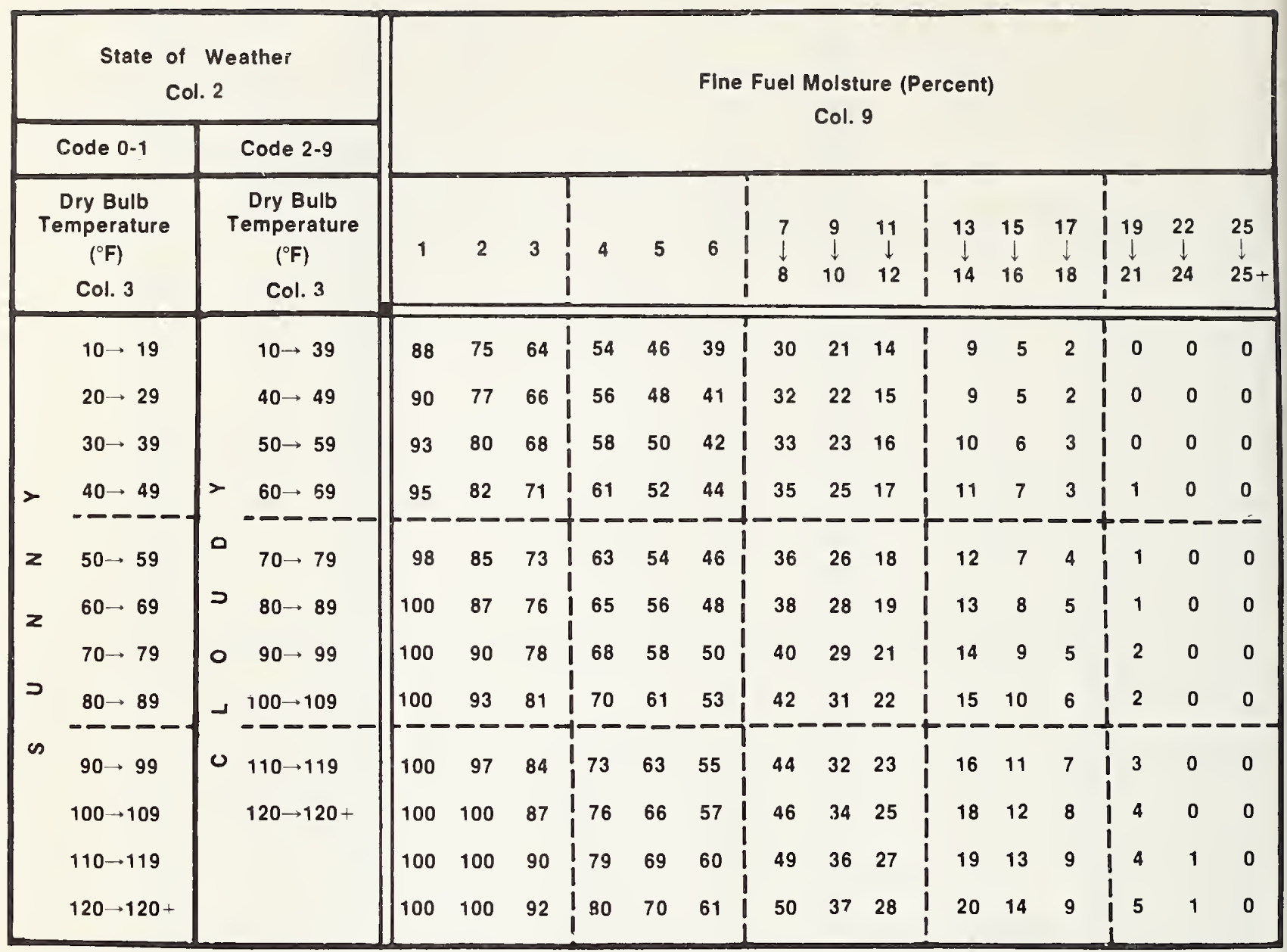

Purpose: To compute a number related to the probability that a fire will result if a firebrand is introduced into the fine fuel complex.*

Procedure: If the state of the weather is coded 2,3,4,8, or 9 (column 2), or if the observation is being taken before 1000 or after $1500 \mathrm{LST}$, the dry-bulb temperature (column 3 ) is entered to the left in that section of the table labeled "cloudy." Otherwise, enter the temperature in the section labeled "sunny." Read the IC at the intersection of the column indexed by the FFM (column 9) and the row indexed by the dry-bulb temperature (column 3); record in column 10.

* If it is raining (state of the weather code 5, 6, or 7) or there is snow or ice on the ground fuels, record a zero (0) in column 10. 


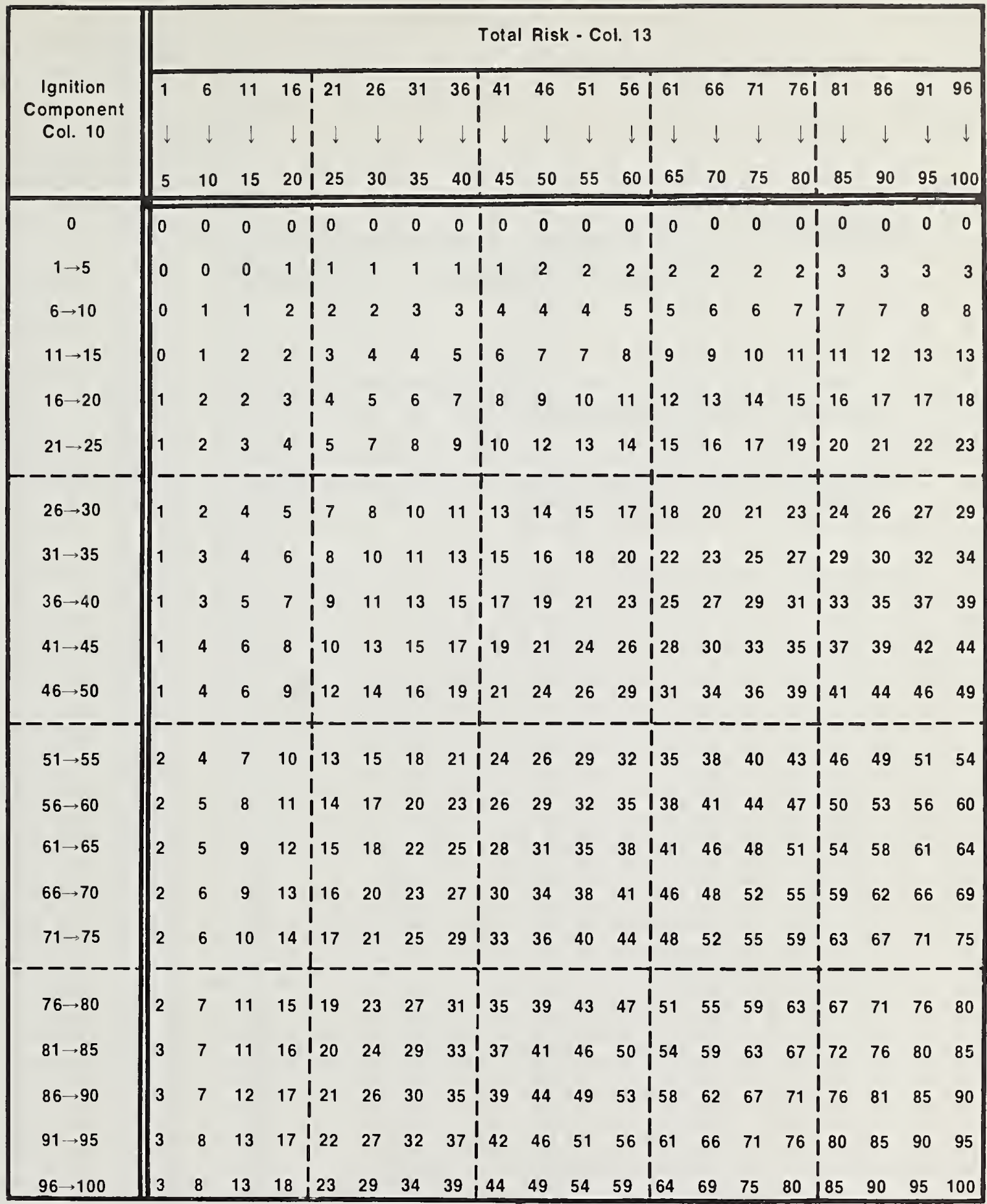

Purpose: To compute a number related to the probable level of fire incidence on the rating area.*

Procedure: At the intersection of the row indexed by the IC (column 10) and the column indexed by total Risk (column 13) is the OI; record in column 14.

* If it is raining (state of weather code 5,6, or 7) or there is snow or ice on the ground fuels, record a zero (0) in column 14. 


\section{Spread Component - Fuel Model H}

Purpose: To compute a number related to the forward rate of spread of the head of a fire burning in fuels represented by this fuel model.*

Procedure: The windspeed (column 16) is entered into the table from the column headed by the slope class assigned to the rating area. At the intersection of this row and the column indexed by the FFM (column 9) is the SC; record in column 18.

* If it is raining (state of weather code 5, 6, or 7) or there is snow or ice on the ground fuels, record a zero (0) in column 18. 
SPREAD COMPONENT - FUEL MODEL H

Col. 18

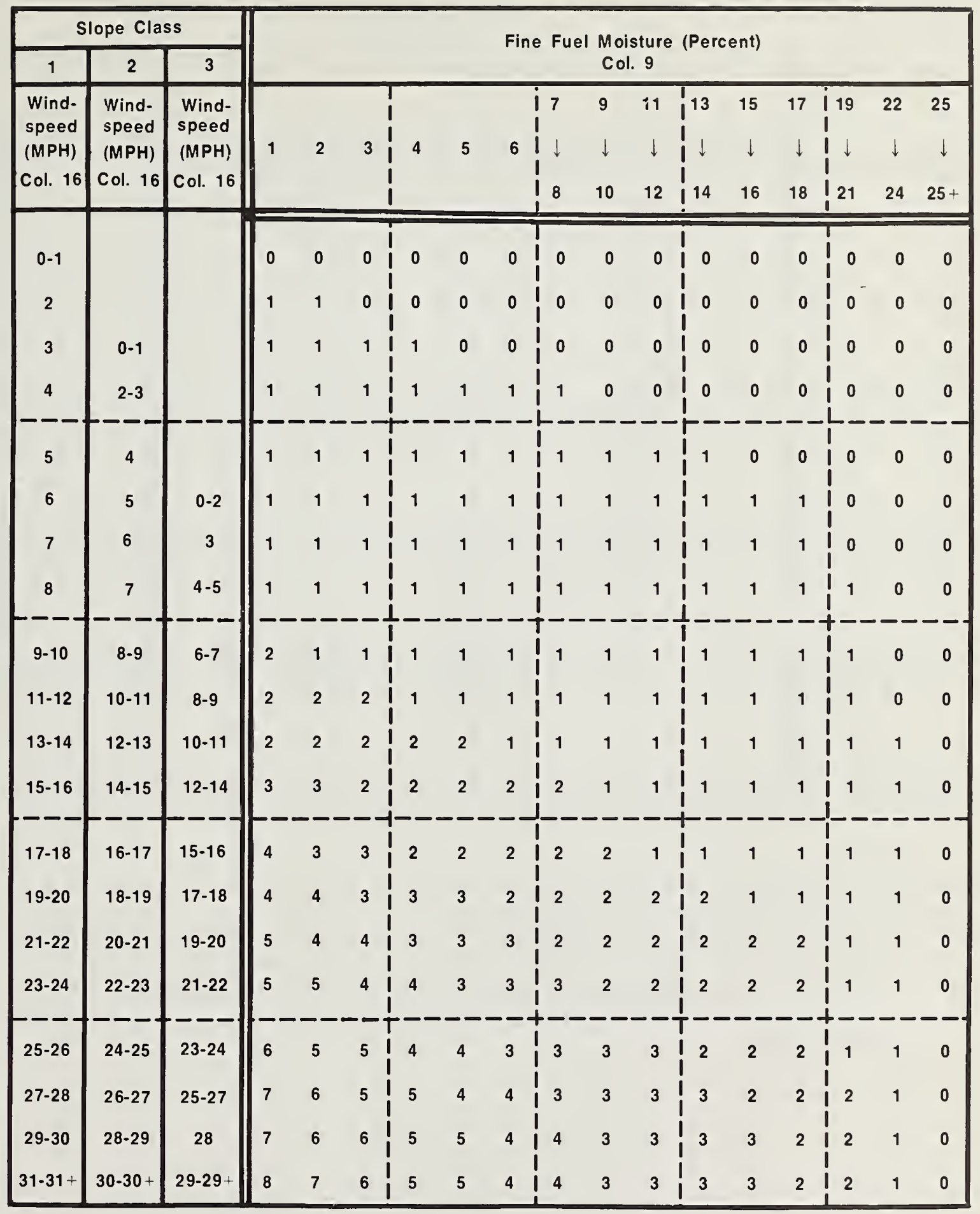


Col. 21

PART A

\begin{tabular}{|c|c|c|c|c|c|c|c|c|c|c|c|c|c|c|c|c|}
\hline \multirow{2}{*}{$\begin{array}{l}\text { 10-Hour TL } \\
\text { Fuel Moisture } \\
\text { (Percent) } \\
\text { Col. } 19\end{array}$} & \multicolumn{16}{|c|}{$\begin{array}{l}\text { Fine Fuel Moisture (Percent) } \\
\text { Col. } 9\end{array}$} \\
\hline & 1 & 2 & 3 & 4 & 5 & 6 & & $\begin{array}{l}7 \\
\downarrow \\
8\end{array}$ & $\begin{array}{c}9 \\
\downarrow \\
10\end{array}$ & $\begin{array}{c}11 \\
\downarrow \\
12\end{array}$ & $\begin{array}{c}13 \\
\downarrow \\
14\end{array}$ & $\begin{array}{c}15 \\
\downarrow \\
16\end{array}$ & $\begin{array}{c}17 \\
\downarrow \\
18\end{array}$ & $\begin{array}{c}19 \\
\downarrow \\
21\end{array}$ & $\begin{array}{c}22 \\
\downarrow \\
24\end{array}$ & $\begin{array}{r}25 \\
\downarrow \\
25+\end{array}$ \\
\hline 1 & A & B & B & C & C & D & & D & $\mathbf{E}$ & $F$ & G & $\mathbf{G}$ & H & 1 & 1 & $J$ \\
\hline 2 & B & B & C & C & D & D & & E & $\mathbf{F}$ & G & G & $H$ & $H$ & 1 & $J$ & $J$ \\
\hline 3 & B & C & C & D & D & E & & E & $\mathbf{F}$ & G & G & $H$ & $\mathbf{H}$ & 1 & $\mathbf{J}$ & $J$ \\
\hline 4 & c & C & D & D & E & E & & $\mathbf{F}$ & G & G & H & $H$ & 1 & 1 & $\mathbf{J}$ & K \\
\hline 5 & C & D & D & E & E & $\mathbf{F}$ & & $\mathbf{F}$ & G & $\mathbf{G}$ & $H$ & $H$ & 1 & $\mathrm{~J}$ & $\mathrm{~J}$ & $\mathbf{K}$ \\
\hline 6 & $D$ & D & $\mathbf{E}$ & $E$ & $\mathbf{F}$ & $\mathbf{F}$ & & $\mathbf{G}$ & $\mathbf{G}$ & $H$ & H & 1 & 1 & $\mathbf{J}$ & $\mathbf{K}$ & $\mathbf{K}$ \\
\hline $7 \rightarrow 8$ & D & $\mathbf{E}$ & E & $\mathbf{F}$ & $F$ & G & & G & H & $H$ & 1 & 1 & $\mathrm{~J}$ & $\mathbf{J}$ & $\mathbf{K}$ & K \\
\hline $9 \rightarrow 10$ & $E$ & $\mathbf{F}$ & $\mathbf{F}$ & G & G & G & & H & H & 1 & I & J & $J$ & K & K & $\mathbf{L}$ \\
\hline $11 \rightarrow 12$ & $F$ & G & G & G & G & $H$ & & H & 1 & 1 & $\mathbf{J}$ & $\mathbf{J}$ & $\mathbf{K}$ & $-\frac{K}{-}$ & $\mathrm{L}$ & $\mathbf{L}$ \\
\hline $13 \rightarrow 14$ & G & $\mathbf{G}$ & $\mathbf{G}$ & H & H & H & & $\overrightarrow{1}$ & 1 & $\mathbf{J}$ & J & $\mathrm{K}$ & $\mathbf{K}$ & $L$ & L & M \\
\hline $15 \rightarrow 16$ & G & H & H & $H$ & H & I & & 1 & $\mathbf{J}$ & $\mathrm{J}$ & K & K & $\mathrm{L}$ & $\mathbf{L}$ & $M$ & $M$ \\
\hline $17 \rightarrow 18$ & H & H & H & I & I & 1 & & $J$ & $J$ & $\mathbf{K}$ & K & $\mathrm{L}$ & $\mathrm{L}$ & $M$ & $M$ & $M$ \\
\hline $19 \rightarrow 21$ & 1 & 1 & I & I & $\mathbf{J}$ & $\mathbf{J}$ & & $J$ & $\mathbf{K}$ & K & $\mathbf{L}$ & $L$ & M & $M$ & $\mathbf{N}$ & $\mathbf{N}$ \\
\hline $22 \rightarrow 24$ & 1 & $\mathbf{J}$ & $J$ & J & $\mathbf{J}$ & $\mathbf{K}$ & & K & $\mathbf{K}$ & $\mathbf{L}$ & $\mathbf{L}$ & $M$ & $M$ & $\mathbf{N}$ & $\mathbf{N}$ & $\mathbf{N}$ \\
\hline $25 \rightarrow 25+$ & $J$ & $\mathrm{~J}$ & $\mathbf{J}$ & K & $K$ & K & & K & $\mathbf{L}$ & $\mathbf{L}$ & M & M & $M$ & $N$ & $\mathbf{N}$ & 0 \\
\hline
\end{tabular}

Procedure: To compute a number related to the rate of combustion at the head of a fire burning in fuels represented by this fuel model.*

Procedure: In Part A-Read the transfer letter at the intersection of the row indexed by the 10-Hr. TL FM (column 19) and the column indexed by the FFM (column 9).

In Part $\mathrm{B}-$-Read the $\mathrm{ERC}$ at the intersection of the row indexed by the 100-Hr. TI, FM (column 20) and the column indexed by the transfer letter from Part $A$; record in column 21 .

* If it is raining (state of weather code 5,6, or 7) or there is snow or ice on the ground fuels, record a zero $(0)$ in column 21 . 
ENERGY RELEASE COMPONENT - FUEL MODEL H

Col. 21

PART B

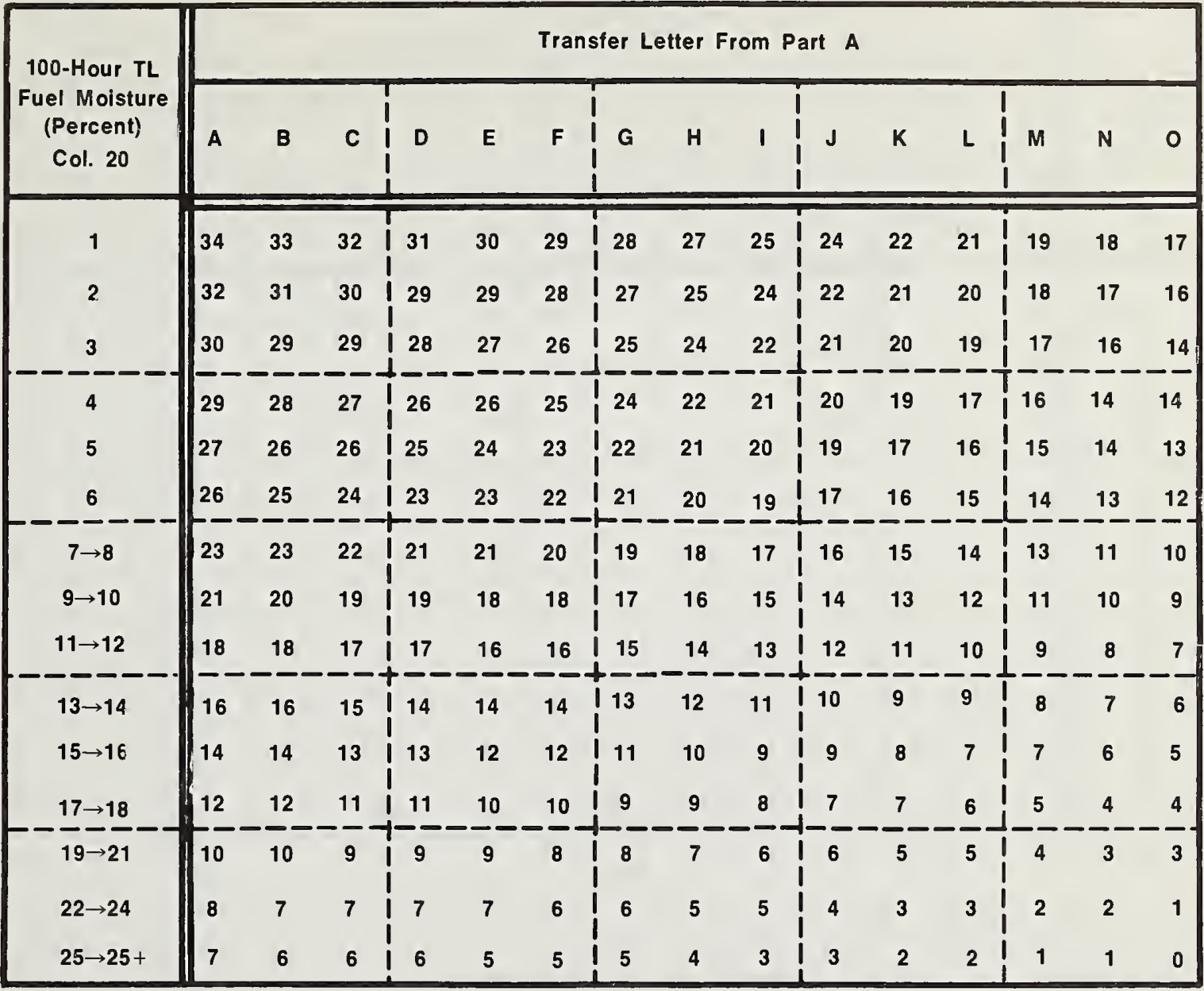


BURNING INDEX - FUEL MODEL H

Col. 22

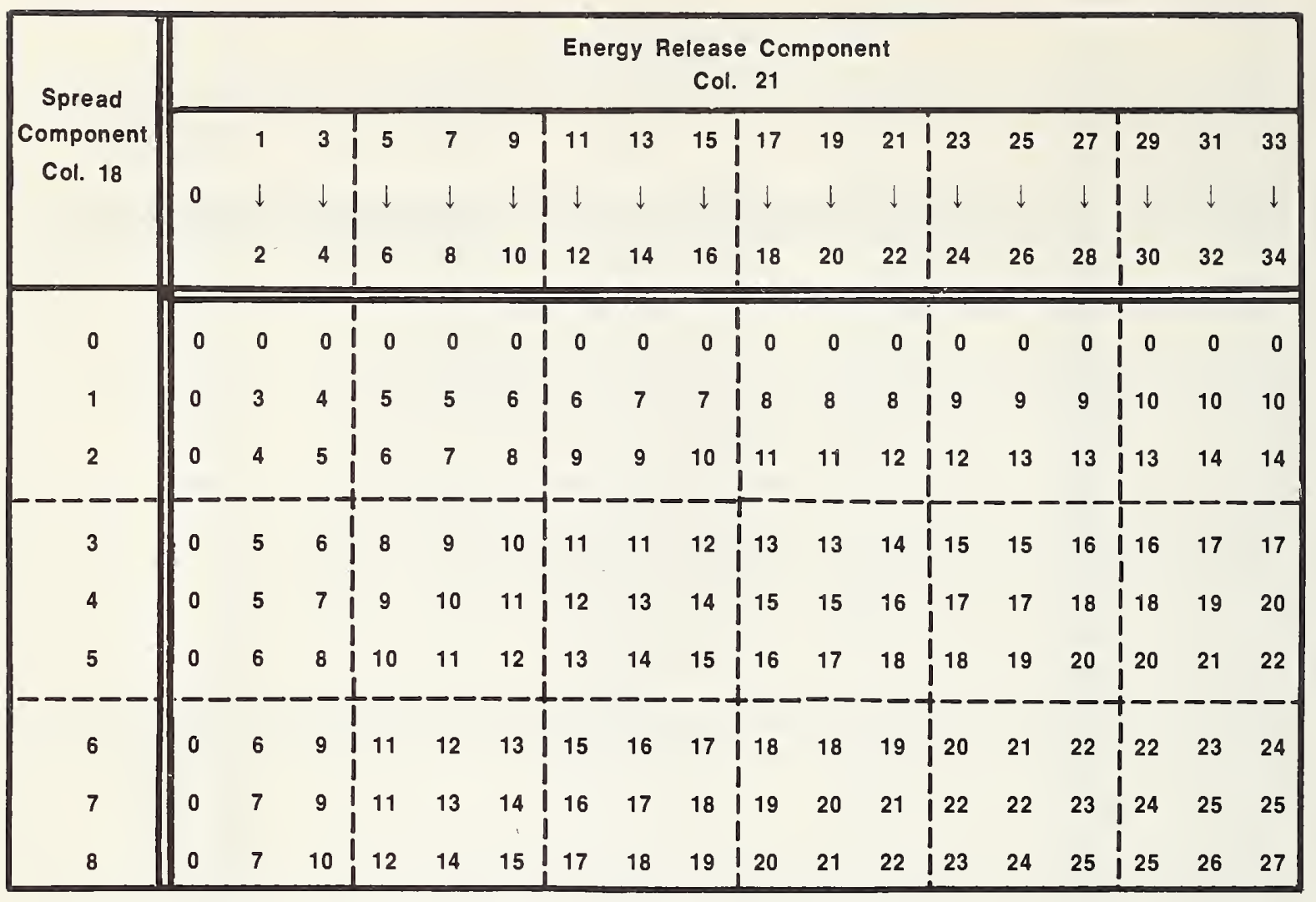

Purpose: To compute a number related to the amount of effort needed to contain a single fire burning in fuels represented by this fuel model.*

Procedure: Read the BI at the intersection of the row indexed by the SC (column 18) and the ERC (column 21); record in column 22.

* If it is raining (state of weather code 5,6, or 7) or there is snow or ice on the ground fuels, record a zero (0) in column 22. 
FIRE LOAD INDEX - FUEL MODEL H

Col. 23

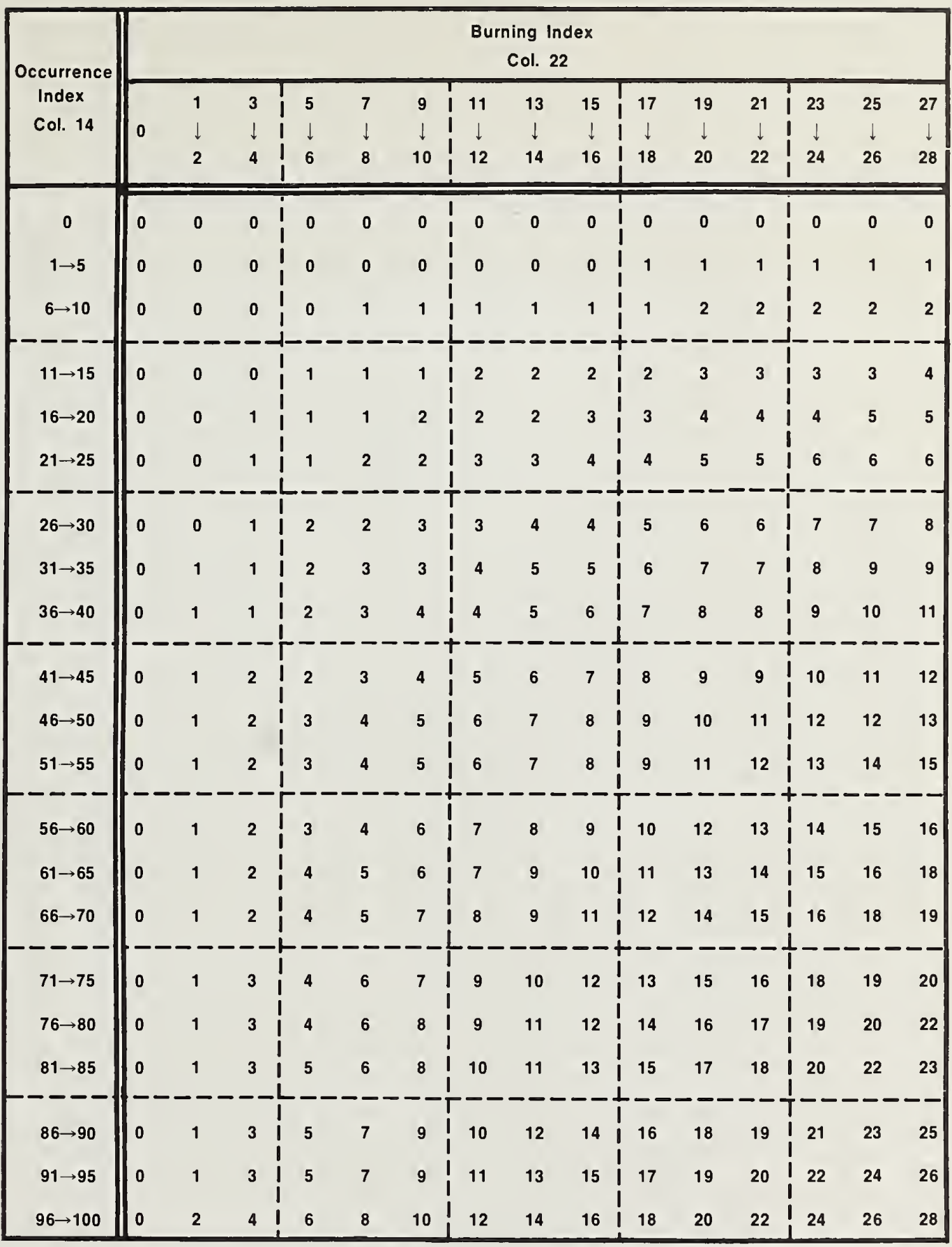

Purpose: To compute a number related to the total effort needed to contain all probable fires on a rating area.*

Procedure: Read the FLI at the intersection of the row indexed by the OI (column 14) and the column indexed by the BI (column 22); record in column 23.

* If it is raining (state of weather code 5, 6, or 7) or there is snow or ice on the ground fuels, record a zero $(0)$ in column 23. 


\section{Fuel Model I}

151 


\section{COMPUTATIONAL FLOW CHART \\ FUEL MODEL I}

(1)

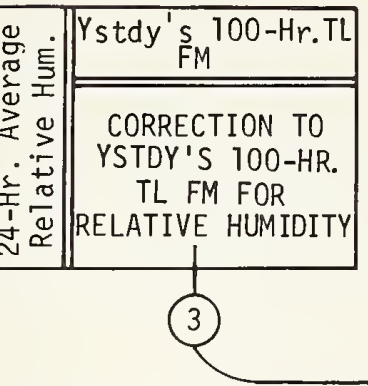

(4)

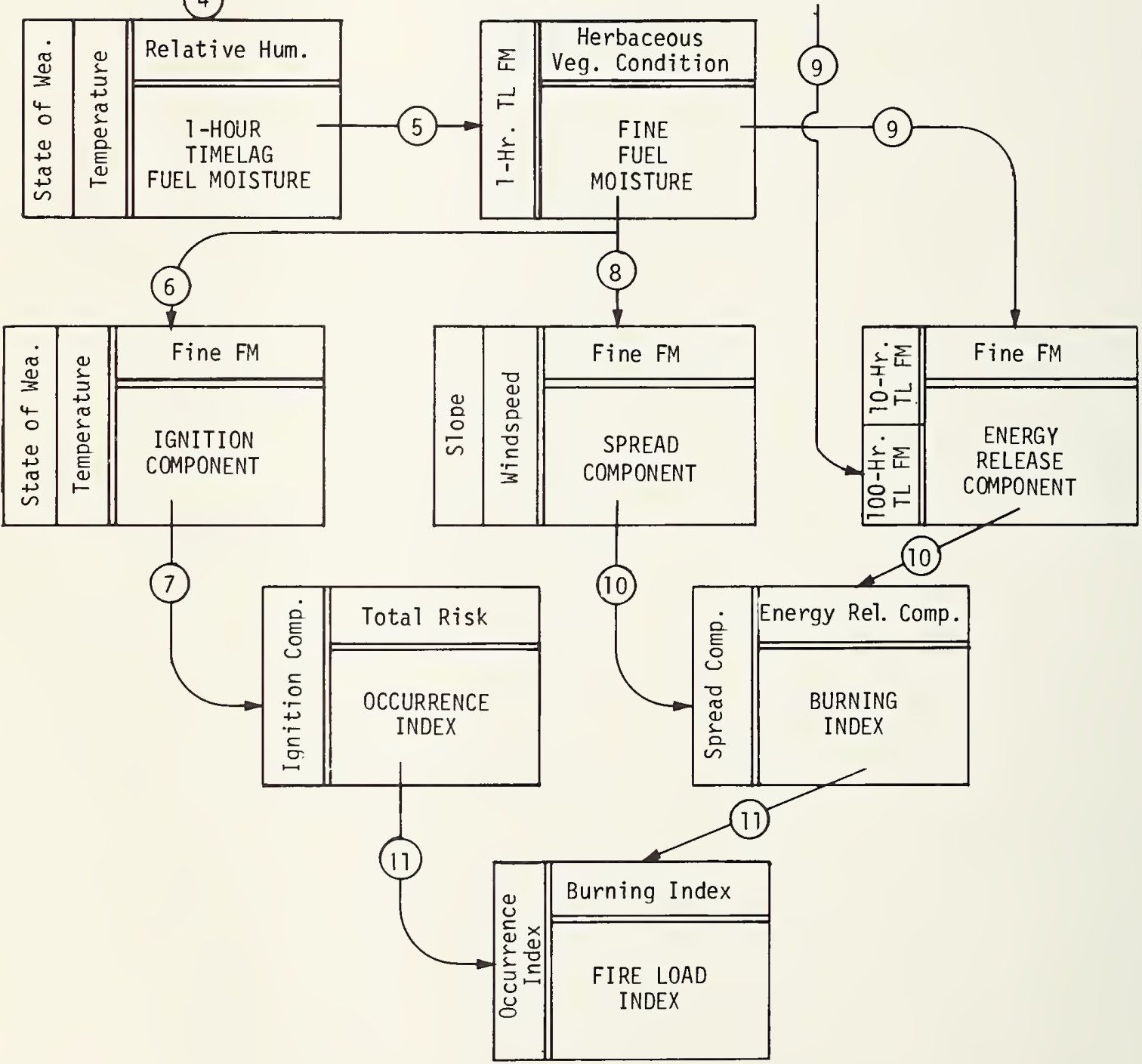

(2)

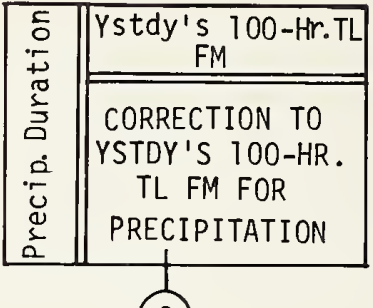

(3)<smiles>[CH]</smiles> 


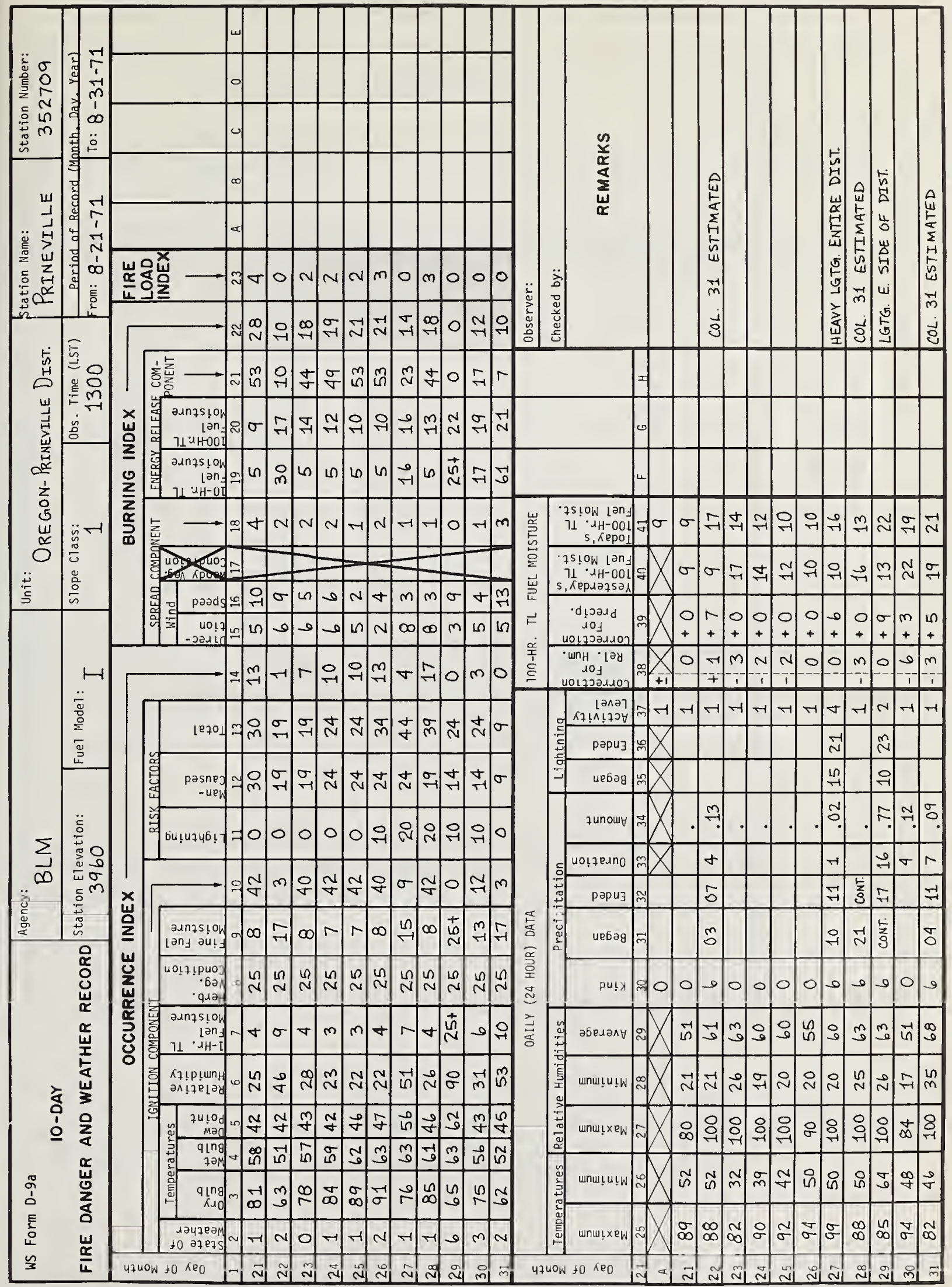




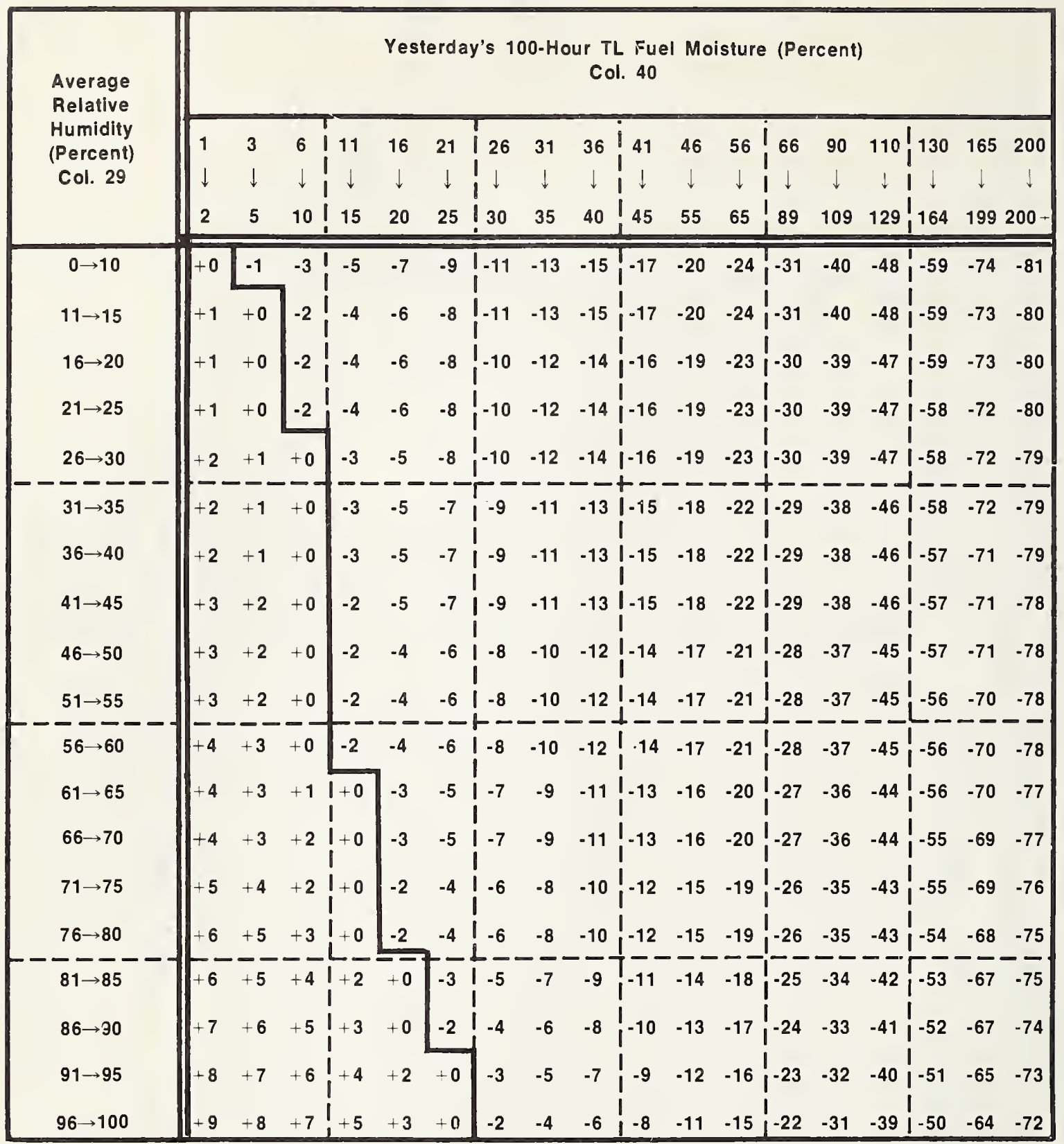

Purpose: To compute the effect of atmospheric humidity (water vapor) since Basic Observation Time yesterday, on the moisture content of the $100-\mathrm{Hr}$. TL fuels.*, **

Procedures: At the intersection of the column indexed by yesterday's 100-Hr. TL, FM (column $40)^{* * *}$ and the row indexed by the 24-hour average relative humidity (column 29) is the correction to the $100-\mathrm{Hr}$. TL FM for relative humidity; record in column 38 .

* Values can be positive (+) or negative (-), record the proper sign.

** If it has rained continuously for the past 24 hours, record a zero (0) in column 38.

*** At the beginning of the fire season, an initial value of 35 percent should be assumed. 


\begin{tabular}{|c|c|c|c|c|c|c|c|c|c|}
\hline \multirow[b]{2}{*}{$\begin{array}{l}\text { Precipitation } \\
\text { Duration } \\
\text { (Hours) } \\
\text { Col. } 33\end{array}$} & \multicolumn{9}{|c|}{$\begin{array}{c}\text { Yesterday's 100-Hour TL Fuel Moisture (Percent) } \\
\text { Col. } 40\end{array}$} \\
\hline & 2 & $\begin{array}{l}3 \\
\downarrow \\
5\end{array}$ & $\begin{array}{c}6 \\
\downarrow \\
10\end{array}$ & $\begin{array}{c}11 \\
\downarrow \\
15\end{array}$ & $\begin{array}{l}16 \\
\downarrow \\
20\end{array}$ & $\begin{array}{c}21 \\
\downarrow \\
25\end{array}$ & $\begin{array}{l}26 \\
\downarrow \\
30\end{array}$ & $\begin{array}{l}31 \\
\downarrow \\
35\end{array}$ & $\begin{array}{c}36 \\
\downarrow \\
36+\end{array}$ \\
\hline $1 \rightarrow 3$ & 8 & 7 & 6 & 4 & 3 & 2 & 1 & 0 & 0 \\
\hline $4 \rightarrow 6$ & 9 & 8 & 7 & 5 & 4 & 3 & 1 & 1 & 1 \\
\hline $7 \rightarrow 9$ & 10 & 9 & 8 & 6 & 5 & 3 & 2 & 1 & 1 \\
\hline $10 \rightarrow 12$ & 11 & 10 & 9 & 7 & 6 & 4 & 2 & 2 & 2 \\
\hline $13 \rightarrow 15$ & 12 & 11 & 10 & 7 & 6 & 5 & 3 & 2 & $\overline{2}$ \\
\hline $16 \rightarrow 18$ & 13 & 13 & 11 & 9 & 7 & 6 & 4 & 3 & 3 \\
\hline $19 \rightarrow 21$ & 15 & 14 & 12 & 10 & 8 & 6 & 5 & 4 & 4 \\
\hline $22 \rightarrow 24$ & 16 & 15 & 14 & 11 & 9 & 7 & 5 & 5 & 4 \\
\hline
\end{tabular}

Purpose: To compute the effect of precipitation occurring since Basic Observation Time yesterday on the moisture content of the $100-\mathrm{Hr}$. TL fuels.*

Procedure: At the intersection of the column indexed by yesterday's 100-Hr. TL FM (column 40) and the row indexed by the precipitation duration (column 33) is the correction to the 100-Hr. TL FM for precipitation; record in column 39.

\section{Computation Of Today's 100-Hour Timelag Fuel Moisture}

Being careful of the arithmetic signs, add the entries in columns 38, 39, and 40 . Enter the results in columns 41 and 20; this is today's 100-Hr. TL FM.

* If no precipitation has occurred in the past 24 hours, record a zero (0) in column 39. 


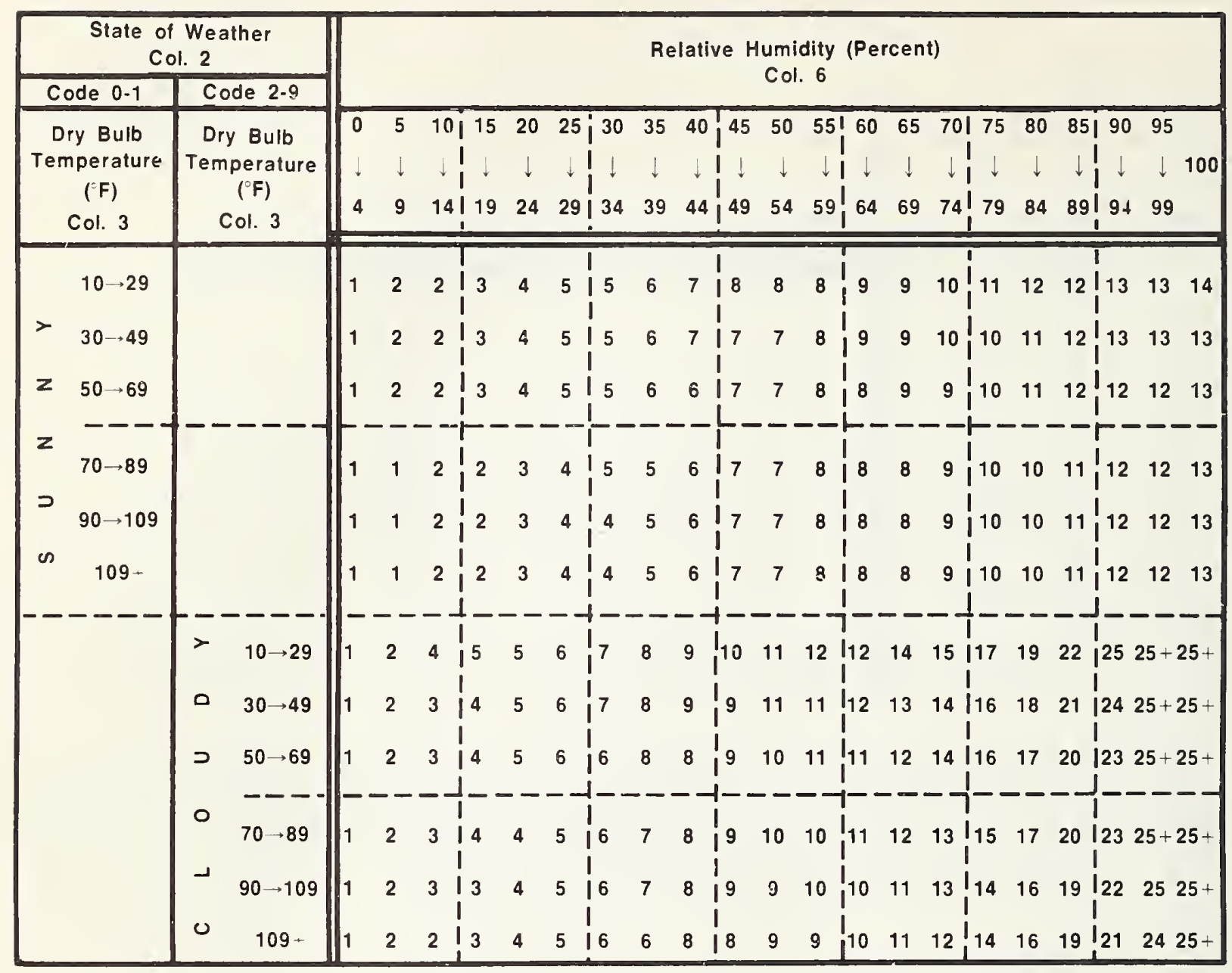

Purpose: To compute the moisture content of dead fuels one-quarter inch and less in diameter.* Procedure: If the state of the weather is coded 2, 3, 4, 8 , or 9 (column 2), or if the observation is being taken before 1000 or after 1500 LST, the dry-bulb temperature is entered to the left in that section of the table labeled "cloudy." Otherwise enter the temperature in the section labeled "sunny." Read the 1-Hr. TL FM at the intersection of this row and the column indexed by the appropriate value for relative humidity (column 6); record in column 7 .

* If it is raining (state of weather codes 5, 6, or 7) or there is snow or ice on the ground fuels, record $25+$ in column 7 . 
FINE FUEL MOISTURE (PERCENT)

Col. 9

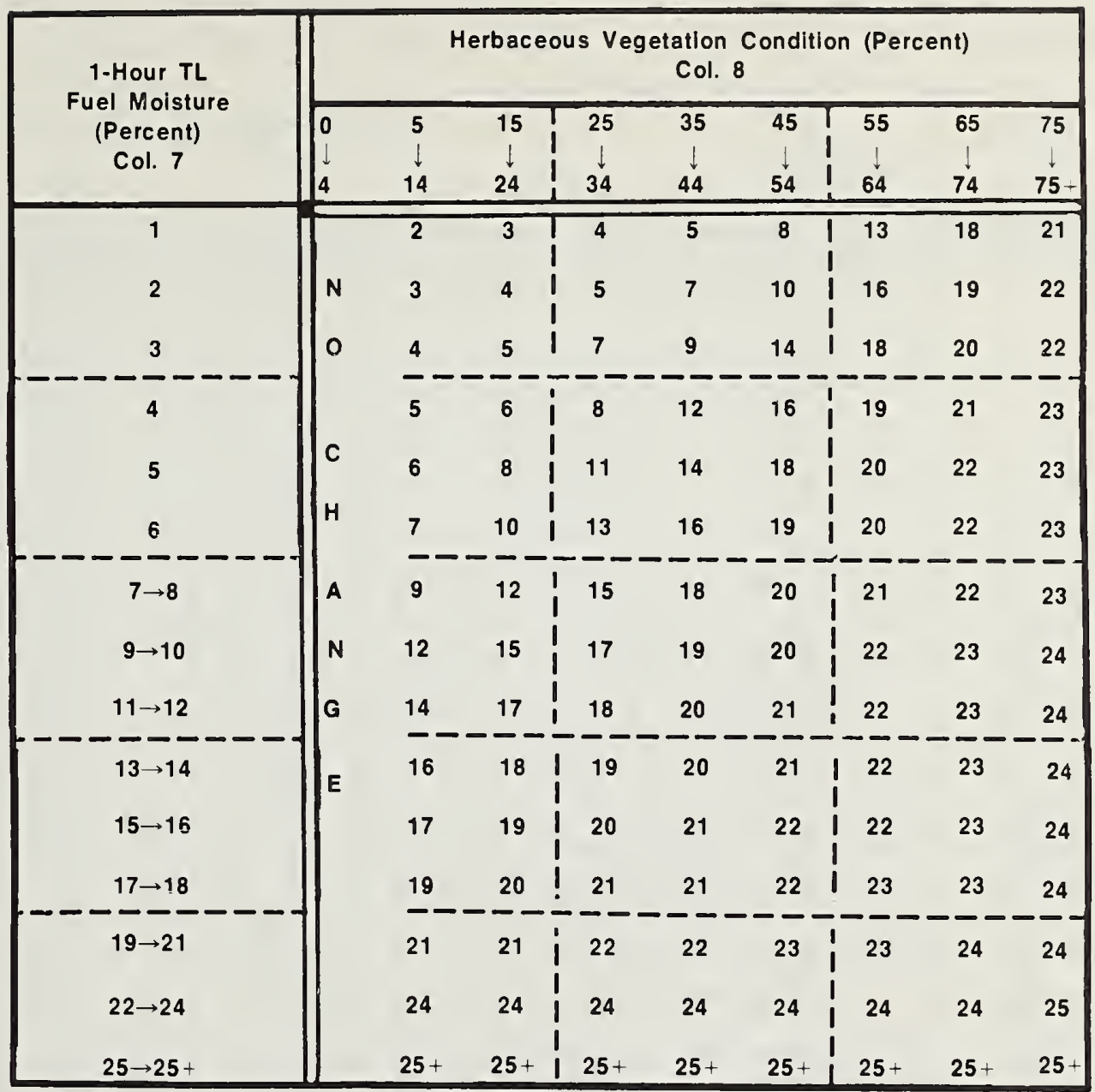

Purpose: To adjust the 1-Hr. TL FM to account for the reduced flammability of the lesser fuels due to the presence of living herbaceous plant material.*

Procedure: Read the FFM at the intersection of the row indexed by the 1-Hr. TL FM (column 7) and the column indexed by herbaceous vegetation condition (column 8 ); record in column 9 .

* If the herbaceous vegetation condition is 4 or less, enter the value of the 1-Hr. TL FM directly into column 9. 


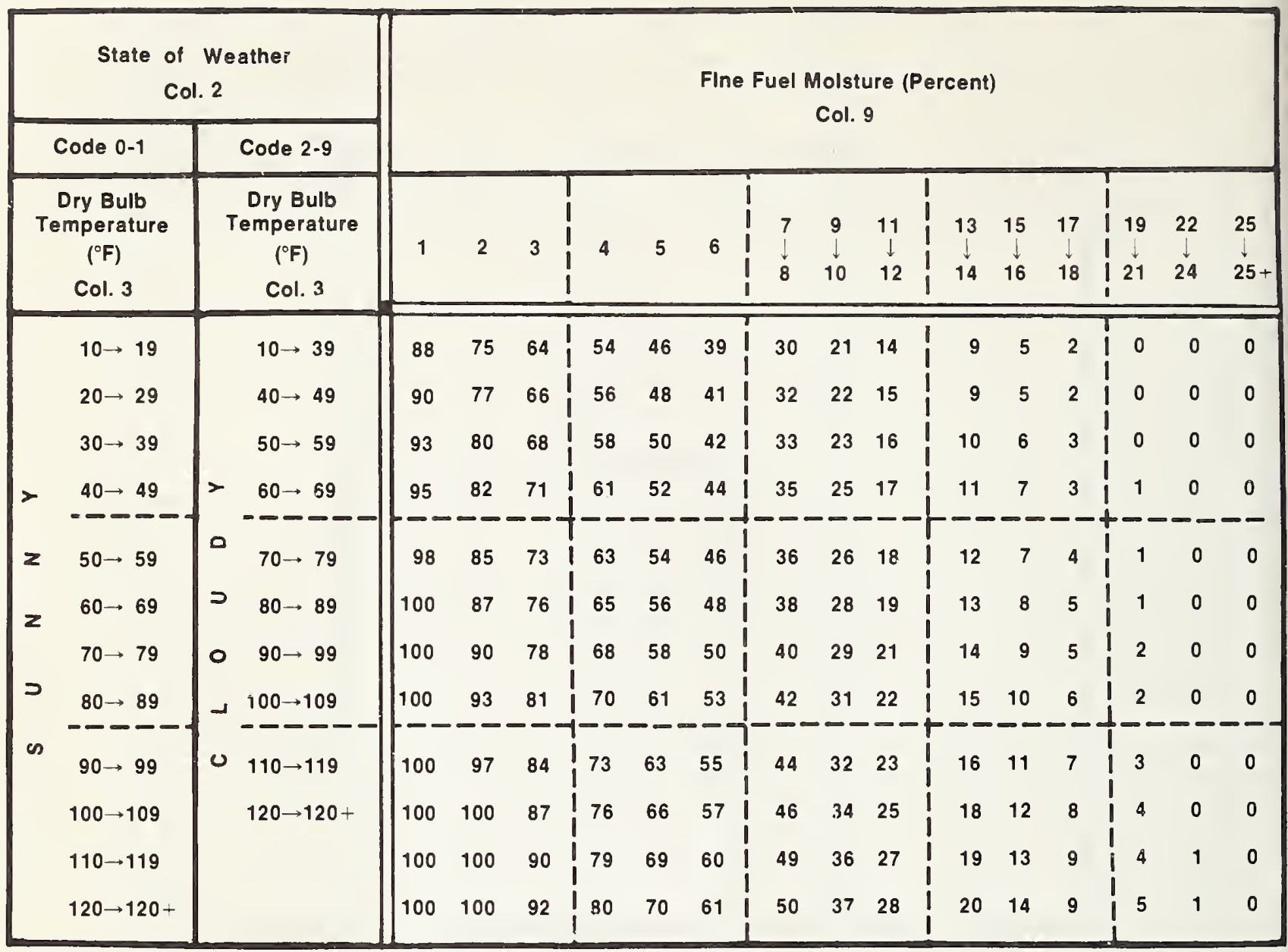

Purpose: To compute a number related to the probability that a fire will result if a firebrand is introduced into the fine fuel complex.*

Procedure: If the state of the weather is coded $2,3,4,8$, or 9 (column 2), or if the observation is being taken before 1000 or after $1500 \mathrm{LST}$, the dry-bulb temperature (coluinn 3) is entered to the left in that section of the table labeled "cloudy." Otherwise, enter the temperature in the section labeled "sunny." Read the IC at the intersection of the column indexed by the FFM (column 9) and the row indexed by the dry-bulb temperature (column 3 ); record in column 10.

* If it is raining (state of the weather code 5,6, or 7) or there is snow or ice on the ground fuels, record a zero (0) in column 10. 
Col. 14

\begin{tabular}{|c|c|c|c|c|c|c|c|c|c|c|c|c|c|c|c|c|c|}
\hline \multirow[b]{2}{*}{$\begin{array}{l}\text { Ignition } \\
\text { Component } \\
\text { Col. } 10\end{array}$} & \multicolumn{17}{|c|}{ Total Risk - Col. 13} \\
\hline & 5 & $\begin{array}{c}6 \\
\downarrow \\
10\end{array}$ & $\begin{array}{c}11 \\
\downarrow \\
15\end{array}$ & \begin{tabular}{l|l}
16 & 21 \\
$\downarrow$ & $\downarrow$ \\
& \\
20 & 25
\end{tabular} & $\begin{array}{c}26 \\
\downarrow \\
30\end{array}$ & $\begin{array}{r}31 \\
\downarrow \\
35\end{array}$ & $\begin{array}{r}36 ! \\
1 \\
1 \\
40 !\end{array}$ & $\begin{array}{c}41 \\
\downarrow \\
45\end{array}$ & $\begin{array}{c}46 \\
\downarrow \\
50 \\
\end{array}$ & $\begin{array}{c}51 \\
\downarrow \\
55 \\
\end{array}$ & 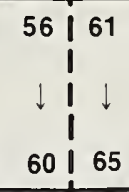 & $\begin{array}{c}66 \\
\downarrow \\
70\end{array}$ & $\begin{array}{r}71 \\
\downarrow \\
75\end{array}$ & 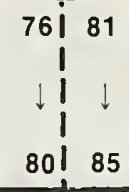 & $\begin{array}{l}86 \\
\downarrow \\
90\end{array}$ & $\begin{array}{c}91 \\
\downarrow \\
95\end{array}$ & $\begin{array}{r}96 \\
\downarrow \\
100\end{array}$ \\
\hline 0 & 0 & 0 & 0 & $0: 0$ & 0 & 0 & 0 & 0 & 0 & 0 & $0: 0$ & 0 & 0 & $0: 0$ & 0 & 0 & 0 \\
\hline $1 \rightarrow 5$ & 0 & 0 & 0 & \begin{tabular}{l|l}
1 & 1
\end{tabular} & 1 & 1 & 1 & 1 & 2 & 2 & $2: 2$ & 2 & 2 & $2: 3$ & 3 & 3 & 3 \\
\hline $6 \rightarrow 10$ & 0 & 1 & 1 & $2: 2$ & 2 & 3 & 3 & 4 & 4 & 4 & $\left.5\right|^{5}$ & 6 & 6 & 7 & 7 & 8 & 8 \\
\hline $11 \rightarrow 15$ & 0 & 1 & 2 & $\left.2\right|^{3}$ & 4 & 4 & 5 & & 7 & 7 & $8: 9$ & 9 & 10 & $\left.11\right|^{11}$ & 12 & 13 & 13 \\
\hline $16 \rightarrow 20$ & 1 & 2 & 2 & $\left.3\right|_{1} ^{4}$ & 5 & 6 & 7 & & 9 & 10 & $\left.11\right|^{12}$ & 13 & 14 & 15 & 17 & 17 & 18 \\
\hline $21 \rightarrow 25$ & 1 & 2 & 3 & $4: 5$ & 7 & 8 & 9 & & 12 & 13 & 14,15 & 16 & 17 & 1920 & 21 & 22 & 23 \\
\hline 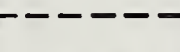 & & & & -1 & & & & & & $=-$ & --1 & 一. & - & -+ & & & \\
\hline $26 \rightarrow 30$ & 1 & 2 & 4 & $\begin{array}{l:l}5 & 7\end{array}$ & 8 & 10 & 11 & & 14 & 15 & & 20 & 21 & & 26 & 27 & 29 \\
\hline $31 \rightarrow 35$ & 1 & 3 & 4 & $6{ }^{6}: 8$ & 10 & 11 & 13 & & 16 & 18 & 2022 & 23 & 25 & $27 \quad 29$ & 30 & 32 & 34 \\
\hline $36 \rightarrow 40$ & 1 & 3 & 5 & $\begin{array}{l:l}7 & 9\end{array}$ & 11 & 13 & 15 & & 19 & 21 & 23 | 25 & 27 & 29 & 3133 & 35 & 37 & 39 \\
\hline $41 \rightarrow 45$ & 1 & 4 & 6 & 8 & 13 & 15 & 17 & & 21 & 24 & $\left.26\right|^{28}$ & 30 & 33 & $35 \mid 37$ & 39 & 42 & 44 \\
\hline $46 \rightarrow 50$ & 1 & 4 & 6 & $9{ }^{12}$ & 14 & 16 & 19 & 1 & 24 & 26 & 29 i 31 & 34 & 36 & 39 & 44 & 46 & 49 \\
\hline$-\pi$ & & & & & & & & & -- & -- & & & & $--1-2$ & & & \\
\hline $51 \rightarrow$ & 2 & 4 & 7 & $\left.10\right|^{13}$ & 15 & 18 & $21 j$ & & 26 & 29 & $\begin{array}{l}32 \\
\mid\end{array}$ & 38 & 40 & $\left.43\right|^{46}$ & 49 & 51 & 54 \\
\hline $56 \rightarrow 60$ & 2 & 5 & 8 & $11 i^{14}$ & 17 & 20 & 231 & & 29 & 32 & $35 !^{38}$ & 41 & 44 & 47 ! 50 & 53 & 56 & 60 \\
\hline $61 \rightarrow 65$ & 2 & 5 & 9 & $12 i^{15}$ & 18 & 22 & $25 !$ & & 31 & 35 & 38 / 41 & 46 & 48 & $51{ }^{54}$ & 58 & 61 & 64 \\
\hline $66 \rightarrow 70$ & 2 & 6 & 9 & $13 i^{16}$ & 20 & 23 & $27 !$ & & 34 & 38 & $41 \int^{46}$ & 48 & 52 & 55 I 59 & 62 & 66 & 69 \\
\hline $\begin{array}{c}71 \rightarrow 75 \\
-----\end{array}$ & 2 & 6 & 10 & $\begin{array}{l}14 L^{17} \\
--L\end{array}$ & 21 & 25 & $29 !$ & & 36 & 40 & $44 I^{48}$ & 52 & 55 & $\begin{array}{lll}59 & 63\end{array}$ & 67 & 71 & $\begin{array}{r}75 \\
--\end{array}$ \\
\hline $76 \rightarrow 80$ & 2 & 7 & 11 & 15 & 23 & 27 & 31 & 35 & 39 & 43 & $\begin{array}{l:l}47 & 51\end{array}$ & 55 & 59 & 63,67 & 71 & 76 & 80 \\
\hline & & & & & & & & & & & & & & & & & \\
\hline $81 \rightarrow 85$ & 3 & 7 & 11 & $16 ?^{20}$ & 24 & 29 & 33 & 37 & 41 & 46 & 50,54 & 59 & 63 & $67 \quad 72$ & 76 & 80 & 85 \\
\hline $86 \rightarrow 90$ & 3 & 7 & 12 & $\left.17\right|^{21}$ & 26 & 30 & 35 & 39 & 44 & 49 & 53 , 58 & 62 & 67 & 7176 & 81 & 85 & 90 \\
\hline $91 \rightarrow 95$ & $3^{3}$ & 8 & 13 & $17: 22$ & 27 & 32 & 37 & 42 & 46 & 51 & $56{ }^{61}$ & 66 & 71 & 76 | 80 & 85 & 90 & 95 \\
\hline $6 \rightarrow 100$ & & 8 & 15 & $\begin{array}{lll}18 & 23 \\
\end{array}$ & 2 & 3 & 39 & 44 & 4 & 5 & & 69 & 75 & & 90 & 95 & 100 \\
\hline
\end{tabular}

Purpose: To compute a number related to the probable level of fire incidence on the rating area.*

Procedure: At the intersection of the row indexed by the IC (column 10) and the column indexed by total Risk (column 13) is the OI; record in column 14.

* If it is raining (state of the weather code 5, 6, or 7) or there is snow or ice on the ground fuels, record a zero $(0)$ in column 14. 


\section{Spread Component - Fuel Model I}

Purpose: To compute a number related to the forward rate of spread of the head of a fire burning in fuels represented by this fuel model.*

Procedure: The windspeed (column 16) is entered into the table from the column headed by the slope class assigned to the rating area. At the intersection of this row and the column indexed by the FFM (column 9) is the SC; record in column 18 .

* If it is raining (state of weather code 5,6, or 7) or there is snow or ice on the ground fuels, record a zero $(0)$ in column 18. 
SPREAD COMPONENT - FUEL MODEL I

Col. 18

\begin{tabular}{|c|c|c|c|c|c|c|c|c|c|c|c|c|c|c|c|c|c|}
\hline \multicolumn{3}{|c|}{ Slope Class } & \multirow{2}{*}{\multicolumn{15}{|c|}{$\begin{array}{l}\text { Fine Fuel Moisture (Percent) } \\
\text { Col. } 9\end{array}$}} \\
\hline 1 & 2 & 3 & & & & & & & & & & & & & & & \\
\hline \multirow{3}{*}{$\begin{array}{l}\text { Wind- } \\
\text { speed } \\
\text { (MPH) } \\
\text { Col. } 16\end{array}$} & \multirow{3}{*}{$\begin{array}{l}\text { Wind- } \\
\text { speed } \\
\text { (MPH) } \\
\text { Col. } 16\end{array}$} & \multirow{3}{*}{$\begin{array}{l}\text { Wind- } \\
\text { speed } \\
\text { (MPH) } \\
\text { Col. } 16\end{array}$} & \multirow{3}{*}{1} & \multirow{3}{*}{2} & \multirow{3}{*}{3} & \multirow{3}{*}{4} & \multirow{3}{*}{5} & \multirow{3}{*}{6} & \multirow{3}{*}{$\begin{array}{l}17 \\
1 \\
1 \\
1 \\
1 \\
1\end{array}$} & \multirow{3}{*}{$\begin{array}{r}9 \\
\downarrow \\
10\end{array}$} & \multirow{3}{*}{\multicolumn{2}{|c|}{ 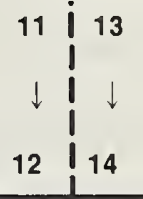 }} & \multirow{3}{*}{$\begin{array}{r}15 \\
\downarrow \\
16 \\
\end{array}$} & \multirow{3}{*}{$\begin{array}{r}17 \\
\downarrow \\
18\end{array}$} & \multirow{3}{*}{$\begin{array}{l}19 \\
\downarrow \\
21\end{array}$} & \multirow{3}{*}{$\begin{array}{r}22 \\
\downarrow \\
24\end{array}$} & \multirow{3}{*}{$\begin{array}{r}25 \\
\downarrow \\
25+\end{array}$} \\
\hline & & & & & & & & & & & & & & & & & \\
\hline & & & & & & & & & & & & & & & & & \\
\hline $0-1$ & & & 1 & 1 & 1 & 1 & 1 & 1 & 1 & 1 & 1 & 1 & 1 & 1 & 0 & 0 & 0 \\
\hline 2 & & & 2 & 1 & 1 & 1 & 1 & 1 & 1 & 1 & 1 & 1 & 1 & 1 & 1 & 0 & 0 \\
\hline 3 & $0-1$ & & 2 & 2 & 2 & 2 & 1 & 1 & 1 & 1 & 1 & 1 & 1 & 1 & 1 & 1 & 0 \\
\hline 4 & $2-3$ & & 3 & 3 & 2 & 2 & 2 & 2 & 2 & 1 & 1 & 1 & 1 & 1 & 1 & 1 & 0 \\
\hline 5 & 4 & $0-1$ & 4 & 3 & 3 & 3 & 2 & 2 & 2 & 2 & 2 & 1 & 1 & 1 & 1 & 1 & 0 \\
\hline 6 & 5 & 2 & 4 & 4 & 3 & 3 & 3 & 3 & 2 & 2 & 2 & 2 & 2 & 1 & 1 & 1 & 0 \\
\hline 7 & 6 & 3 & 5 & 5 & 4 & 4 & 3 & 3 & 3 & 2 & 2 & 2 & 2 & 2 & 1 & 1 & 0 \\
\hline 8 & 7 & $4-5$ & 6 & 5 & 5 & 4 & 4 & 3 & 3 & 3 & 3 & 2 & 2 & 2 & 1 & 1 & 0 \\
\hline $9-10$ & 8-9 & $6-7$ & 7 & 6 & 6 & 5 & 5 & 4 & 4 & 3 & 3 & 3 & 3 & 2 & $?$ & 1 & \\
\hline & & & & & 7 & & & & & & & & & 3 & & & 0 \\
\hline $11-12$ & $10-11$ & $8-9$ & 9 & 8 & 7 & 6 & 6 & 5 & 5 & 4 & 4 & 4 & 3 & 3 & 2 & 1 & 0 \\
\hline $13-14$ & $12-13$ & $10-11$ & 11 & 9 & 8 & 7 & 7 & 6 & 6 & 5 & 5 & 4 & 4 & 3 & 3 & 1 & 0 \\
\hline $15-16$ & $14-15$ & $12-13$ & 13 & 11 & 10 & 9 & 8 & 7 & 6 & 6 & 5 & 5 & 5 & 4 & 3 & 2 & 0 \\
\hline . & & & & & & & & & & & & & & & & & \\
\hline $17-18$ & $16-17$ & $14-15$ & 15 & 13 & 11 & 10 & 9 & 8 & 7 & 7 & 6 & 6 & 5 & 5 & 4 & 2 & 0 \\
\hline $19-20$ & $18-19$ & $16-17$ & 17 & 15 & 13 & 11 & 10 & 9 & 8 & 8 & 7 & 6 & 6 & 5 & 4 & 2 & 0 \\
\hline $21-22$ & $20-21$ & 18-19 & 19 & 16 & 14 & 13 & 12 & 11 & 9 & 8 & 8 & 7 & 7 & 6 & 5 & 2 & 0 \\
\hline 23-24 & $22-23$ & $20-21$ & 21 & 18 & 16 & 14 & 13 & 12 & 11 & 9 & 9 & 8 & 7 & 7 & 5 & 2 & 0 \\
\hline & & & & & & & & & & & & & & & & & \\
\hline $25-26$ & $24-25$ & $22-23$ & 23 & 20 & 18 & 16 & 14 & 13 & 12 & 10 & 10 & 9 & 8 & 7 & 6 & 3 & 0 \\
\hline $27-28$ & 26-27 & $24-25$ & 25 & 22 & 19 & 17 & 16 & 14 & 13 & 11 & 10 & 10 & 9 & 8 & 6 & 3 & 0 \\
\hline $29-30$ & 28 & 26 & 27 & 24 & 21 & 19 & 17 & 15 & 14 & 12 & 11 & 11 & 10 & 9 & 7 & 3 & 0 \\
\hline $31-31+$ & $29-29+$ & $27-27+$ & 28 & 24 & 21 & 19 & 17 & 16 & 14 & 13 & 12 & 11 & 10 & 9 & 7 & 3 & 0 \\
\hline
\end{tabular}




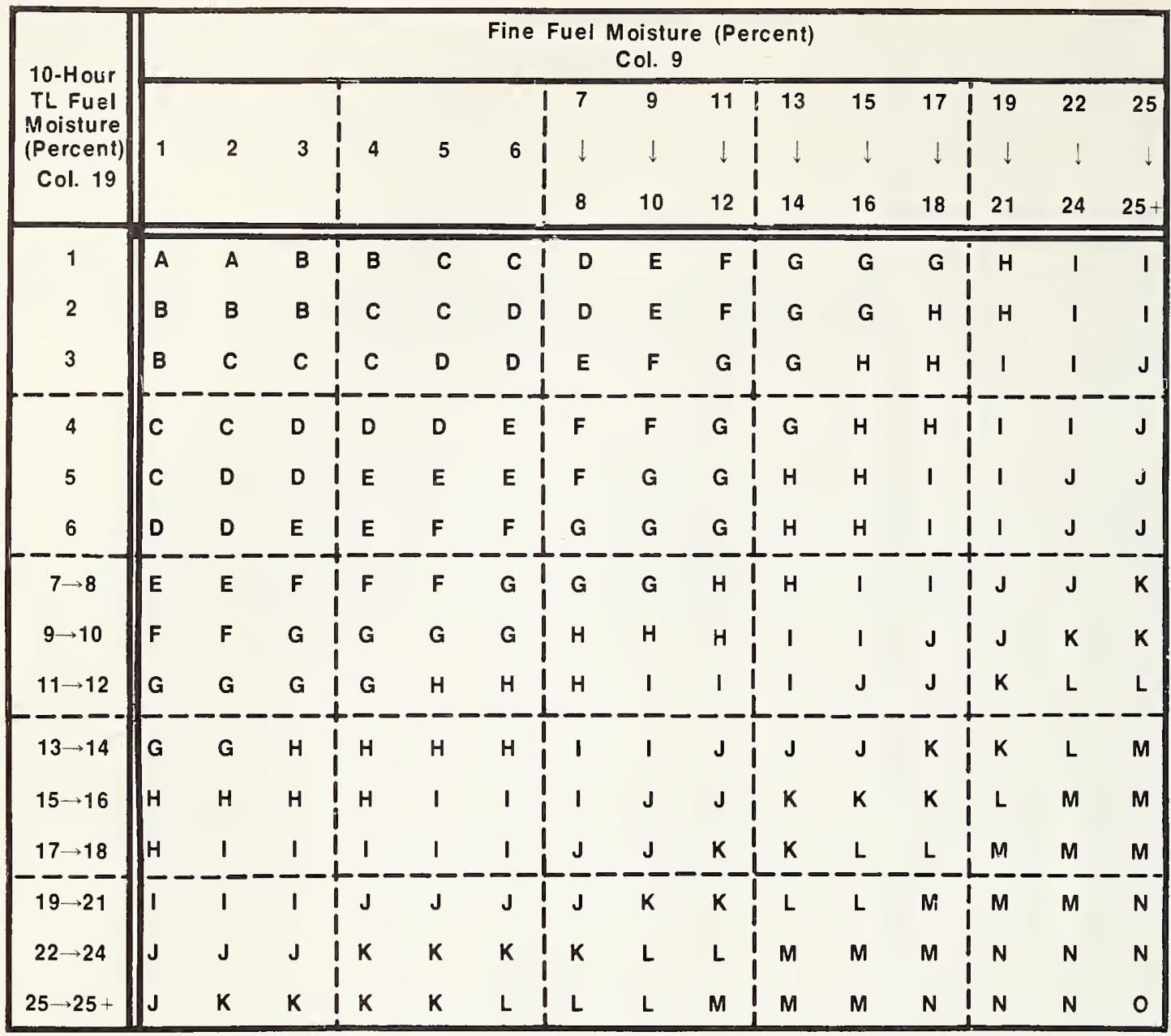

Procedure: To compute a number related to the rate of combustion at the head of a fire burning in fuels represented by this fuel model.*

Procedure: In Part A-Read the transfer letter at the intersection of the row indexed by the 10-Hr. TL FM (column 19) and the column indexed by the FFM (column 9).

In Part B-Read the ERC at the intersection of the row indexed by the $100-\mathrm{Hr}$. TL FM (column 20) and the column indexed by the transfer letter from Part A; record in column 21.

* If it is raining (state of weather code 5,6, or 7) or there is snow or ice on the ground fuels, record a zero (0) in column 21. 
ENERGY RELEASE COMPONENT - FUEL MODEL I

Col. 21

\begin{tabular}{|c|c|c|c|c|c|c|c|c|c|c|c|c|c|c|c|}
\hline \multirow{2}{*}{$\begin{array}{l}\text { 100-Hour } \\
\text { TL Fuel } \\
\text { Moisture } \\
\text { (Percent) } \\
\text { Col. } 20\end{array}$} & \multicolumn{15}{|c|}{ Transfer Letter From Part A } \\
\hline & A & B & C & D & E & $\mathbf{F}$ & G & $H$ & 1 & $\mathbf{J}$ & $\mathbf{K}$ & $\mathbf{L}$ & $M$ & $\mathbf{N}$ & 0 \\
\hline 1 & 96 & 92 & 88 & 84 & 80 & 77 & 72 & 65 & 59 & 54 & 49 & 44 & 38 & 32 & 29 \\
\hline 2 & 92 & 88 & 84 & 81 & 77 & 74 & 69 & 63 & 57 & 51 & 46 & 42 & 36 & 31 & 27 \\
\hline 3 & 89 & 85 & 81 & 78 & 74 & 71 & 6 & 60 & 54 & 49 & 44 & 40 & 35 & 29 & 25 \\
\hline 4 & 85 & 81 & 78 & 74 & 71 & 68 & 63 & 57 & 52 & 47 & 42 & 38 & 33 & 27 & 24 \\
\hline 5 & 82 & 78 & 75 & 71 & 68 & 65 & 6 & 55 & 50 & 45 & 40 & 36 & 31 & 26 & 23 \\
\hline 6 & 79 & 75 & 72 & 68 & 65 & 62 & 58 & 52 & 47 & 43 & 38 & 34 & 29 & 24 & 21 \\
\hline $7 \rightarrow 8$ & 74 & 71 & 67 & 64 & 61 & 58 & 54 & 49 & 44 & 40 & 35 & 32 & 27 & 22 & 19 \\
\hline $9 \rightarrow 10$ & 68 & 65 & 62 & 59 & 56 & 53 & 49 & 45 & 40 & 36 & 32 & 28 & 24 & 19 & 17 \\
\hline $11 \rightarrow 12$ & 62 & 60 & 57 & 54 & 51 & 49 & 45 & 41 & 36 & 32 & 29 & 25 & 21 & 17 & 14 \\
\hline--1 & & & & & & & & - & -1 & - & $=-$ & & & -- & \\
\hline $13 \rightarrow 14$ & 57 & 54 & 52 & 49 & 47 & 44 & 41 & 37 & 33 & 29 & 26 & 22 & 19 & 14 & 12 \\
\hline $15 \rightarrow 16$ & 52 & 50 & 47 & 45 & 43 & 40 & 37 & 33 & 29 & 26 & 23 & 20 & 16 & 12 & 10 \\
\hline $17 \rightarrow 18$ & 48 & 45 & 43 & 41 & 39 & 36 & 3 & 30 & 26 & 23 & 20 & 17 & 14 & 10 & 8 \\
\hline $19 \longrightarrow 21$ & 42 & 40 & 38 & 36 & 34 & 32 & 2 & 26 & 23 & 20 & 17 & 14 & 11 & 7 & 5 \\
\hline $22 \rightarrow 24$ & 37 & 35 & 33 & 31 & 29 & 27 & 2 & 21 & 19 & 16 & 13 & 11 & 8 & 4 & 2 \\
\hline $25 \rightarrow 25+$ & 33 & 31 & 29 & 27 & 26 & 24 & 2 & 19 & 16 & 13 & 11 & 8 & 6 & 2 & 0 \\
\hline
\end{tabular}


BURNING INDEX - FUEL MODEL I

Col. 22

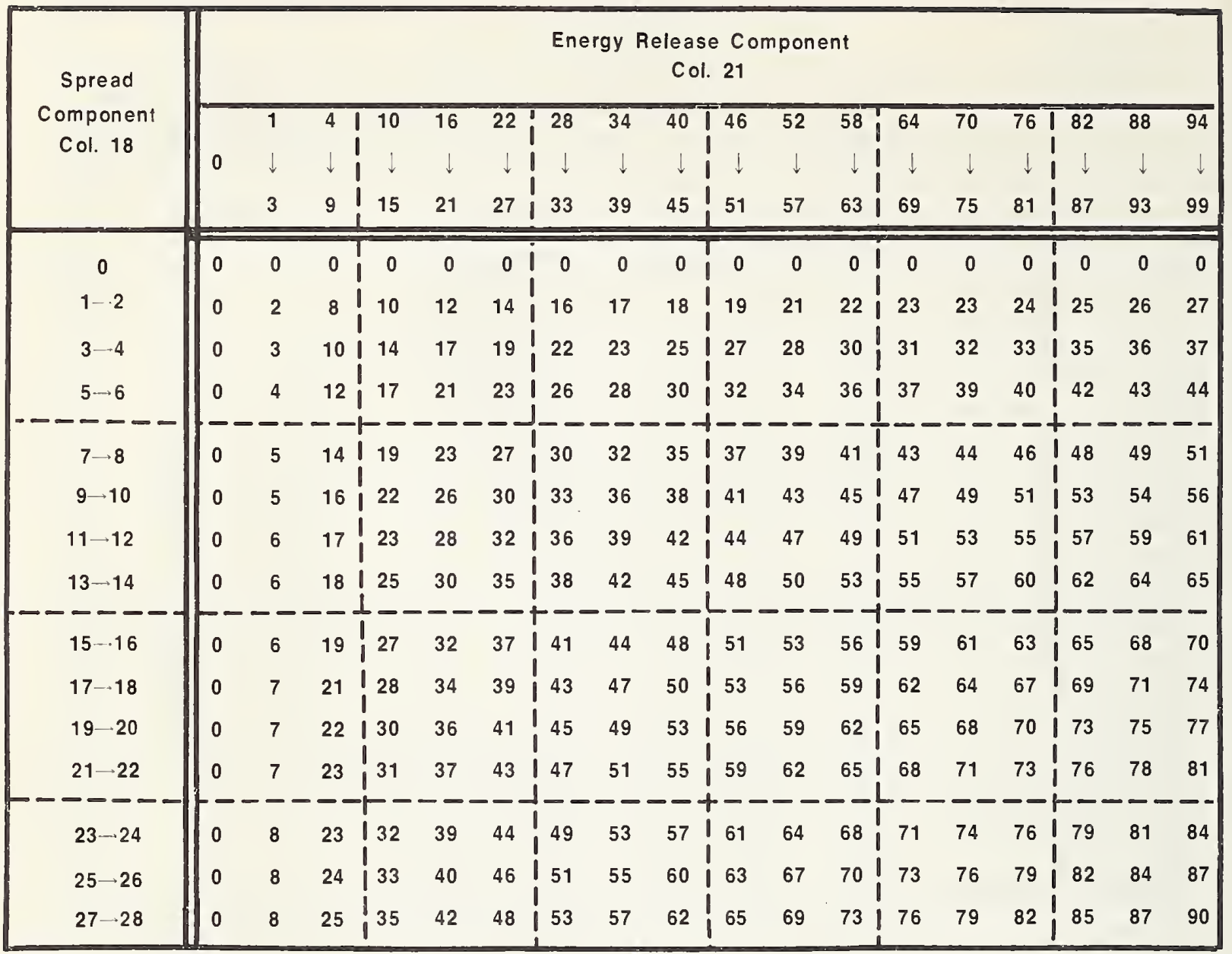

Purpose: To.compute a number related to the amount of effort needed to contain a single fire burning in fuels represented by this fuel model.*

Procedure: Read the BI at the intersection of the row indexed by the SC (column 18) and the ERC (column 21); record in column 22 .

* If it is raining (state of weather code 5,6, or 7) or there is snow or ice on the ground fuels, record a zero (0) in colum 22 
FIRE LOAD INDEX - FUEL MODEL I

Col. 23

\begin{tabular}{|c|c|c|c|c|c|c|c|c|c|c|c|c|c|c|c|c|c|c|c|}
\hline \multirow[b]{2}{*}{$\begin{array}{l}\text { Occurrence } \\
\text { Index } \\
\text { Col. } 14\end{array}$} & \multicolumn{19}{|c|}{$\begin{array}{l}\text { Burning Index } \\
\text { Col. } 22\end{array}$} \\
\hline & 0 & $\begin{array}{l}\downarrow \\
5\end{array}$ & 10 & $\begin{array}{c}11 \\
\downarrow \\
15\end{array}$ & $\left\{\begin{array}{l}16 \\
\downarrow \\
20\end{array}\right.$ & $\begin{array}{l}21 \\
\downarrow \\
25\end{array}$ & $\begin{array}{l}26 \\
\downarrow \\
30\end{array}$ & $\begin{array}{c}31 \\
\downarrow \\
35\end{array}$ & $\begin{array}{l}36 \\
\vdots \\
40 \\
1\end{array}$ & $\begin{array}{c}41 \\
\downarrow \\
45\end{array}$ & $\begin{array}{c}46 \\
\downarrow \\
50\end{array}$ & $\begin{array}{r}51 \\
\downarrow \\
55\end{array}$ & $\begin{array}{c}56 \\
\downarrow \\
60\end{array}$ & $\begin{array}{r}61 \\
\downarrow \\
65\end{array}$ & $\begin{array}{c}66 \\
\downarrow \\
70\end{array}$ & $\begin{array}{r}71 \\
\downarrow \\
75\end{array}$ & $\begin{array}{l}76 \\
\downarrow \\
80\end{array}$ & $\begin{array}{c}81 \\
\downarrow \\
85\end{array}$ & $\begin{array}{c}86 \\
\downarrow \\
90\end{array}$ \\
\hline 0 & 0 & 0 & 0 & 0 & 0 & 0 & 0 & 0 & 0 & 0 & 0 & 0 & 0 & 0 & 0 & 0 & 0 & 0 & 0 \\
\hline $1 \rightarrow 5$ & 0 & 0 & 0 & 0 & 1 & 1 & 1 & 1 & 1 & 1 & 2 & $2 i$ & 2 & 2 & 2 & 2 & 2 & 3 & 3 \\
\hline $6 \rightarrow 10$ & 0 & 0 & 1 & 1 & 2 & 2 & 2 & 3 & 3 & 4 & 4 & 4 & 5 & 5 & 6 & 6 & 7 & 7 & 7 \\
\hline $11 \rightarrow 15$ & 0 & 0 & 1 & 2 & 2 & 3 & 4 & 4 & 5 & 6 & 7 & 7 & 8 & 9 & 9 & 10 & 11 & 11 & 12 \\
\hline $16 \rightarrow 20$ & 0 & 1 & 2 & 2 & 3 & 4 & 5 & 6 & 7 & 8 & 9 & 10 & 11 & 12 & 13 & 14 & 15 & 16 & 17 \\
\hline $21 \rightarrow 25$ & 0 & 1 & 2 & 3 & 4 & 5 & 7 & 8 & 9 & 10 & 12 & 13 & 14 & 15 & 16 & 17 & 19 & 20 & 21 \\
\hline $26 \rightarrow 30$ & $\sigma$ & 1 & 2 & 4 & 5 & 7 & 8 & 10 & 111 & 13 & 14 & -- & 17 & -- & 20 & -- & 23 & 24 & -2 \\
\hline $31 \rightarrow 35$ & 0 & 1 & 3 & 4 & 6 & 8 & 10 & 11 & 13 & 15 & 16 & 18 & 20 & 22 & 23 & 25 & 27 & 29 & 30 \\
\hline $36 \rightarrow 40$ & 0 & 1 & 3 & 5 & 7 & 9 & 11 & 13 & I 15 & 17 & 19 & 21 & 23 & 25 & 27 & 29 & 31 & 33 & 35 \\
\hline $41 \rightarrow 45$ & 0 & 1 & 4 & 6 & 8 & 10 & 13 & 15 & 17 & 19 & 21 & 24 & 26 & 28 & 30 & 33 & 35 & 37 & 39 \\
\hline $46 \rightarrow 50$ & 0 & 1 & 4 & 6 & 9 & 12 & 14 & 16 & 19 & 21 & 24 & 26 & 29 & 31 & 34 & 36 & 39 & 41 & 44 \\
\hline $51 \rightarrow 55$ & 0 & 2 & 4 & 7 & 10 & 13 & 15 & 18 & 21 & 24 & 26 & $29 !$ & 32 & 35 & 38 & 40 & 43 & 46 & 49 \\
\hline $56 \rightarrow 60$ & 0 & 2 & 5 & 8 & & 14 & 17 & 20 & 23 & 26 & 29 & 32 & 35 & 38 & 41 & 44 & 47 & 50 & 53 \\
\hline $61 \rightarrow 65$ & 0 & 2 & 5 & 9 & 12 & 15 & 18 & 22 & 25 & 28 & 31 & $35 !$ & 38 & 41 & 46 & 48 & 51 & 54 & 58 \\
\hline $66 \rightarrow 70$ & 0 & 2 & 6 & 9 & 13 & 16 & 20 & 23 & 27 & 30 & 34 & $38 i$ & 41 & 46 & 48 & 52 & 55 & 59 & 62 \\
\hline $71 \rightarrow 75$ & 0 & 2 & 6 & 10 & 14 & 17 & 21 & 25 & 29 & 33 & 36 & 40 & 44 & 48 & 52 & 55 & 59 & 63 & 67 \\
\hline $76 \rightarrow 80$ & 0 & 2 & 7 & 11 & 15 & 19 & 23 & 27 & 31 & 35 & 39 & 43 & 47 & 51 & 55 & 59 & 63 & 67 & 71 \\
\hline $81 \rightarrow 85$ & 0 & 3 & 7 & 11 & 16 & 20 & 24 & 29 & 33 & 37 & 41 & 46 & 50 & 54 & 59 & 63 & 67 & 72 & 76 \\
\hline-1 & & & & & - & - & 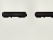 & 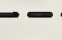 & 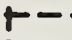 & - & $=$ & & - & - & $=$ & . & -- & - & - \\
\hline $86 \rightarrow 90$ & 0 & 3 & 7 & 12 & 17 & 21 & 26 & 30 & I 35 & 39 & 44 & 49 & 53 & 58 & 62 & 67 & 71 & 76 & 81 \\
\hline $91 \rightarrow 95$ & 0 & 3 & 8 & 13 & 17 & 22 & 27 & 32 & 37 & 42 & 46 & 51 & 56 & 61 & 66 & 71 & 76 & 80 & 85 \\
\hline $96 \rightarrow 100$ & 0 & 3 & 8 & 13 & 18 & 23 & 29 & 34 & 39 & 44 & 49 & 54 & 59 & 64 & 69 & 75 & 80 & 85 & 90 \\
\hline
\end{tabular}

Purpose: To compute a number related to the total effort needed to contain all probable fires on a rating area.*

Procedure: Read the FLI at the intersection of the row indexed by the OI (column 14) and the column indexed by the BI (column 22); record in column 23.

* If it is raining (state of weather code 5, 6, or 7) or there is snow or ice on the ground fuels, record a zero (0) in column 23. 


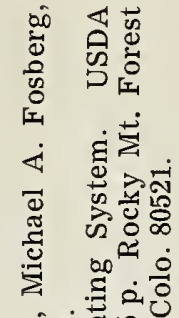

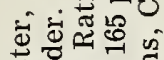

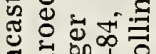
氙 ๑ึ उंक्ष

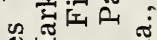
芒芒的

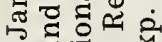
$\therefore$ 西向

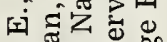
ฐ

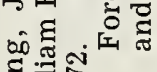
총 نَ

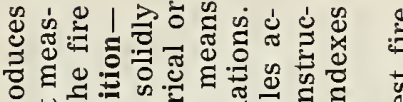
范药. .

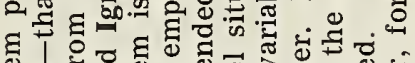

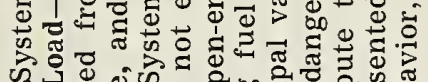

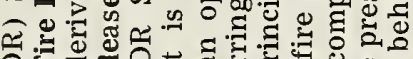

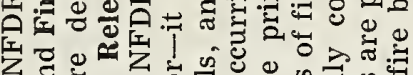

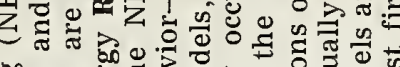
no

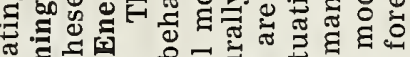

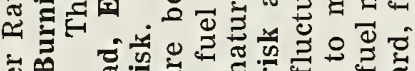

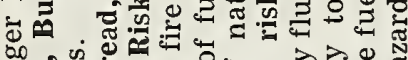

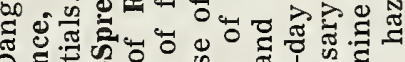
ค1

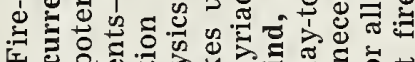
位 శี की

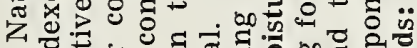

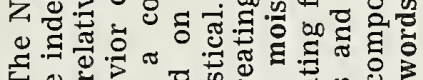

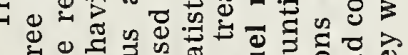

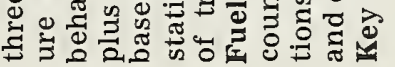

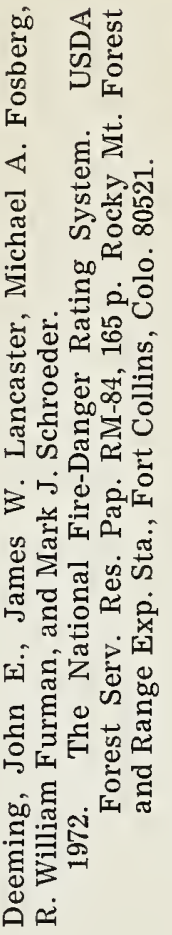

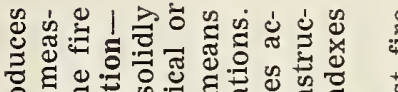

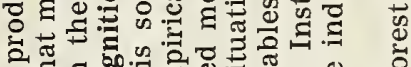

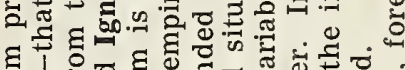

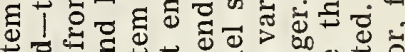
का ส

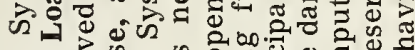

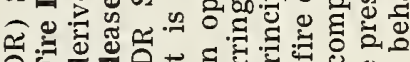

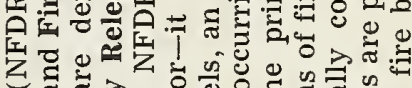
สี สี

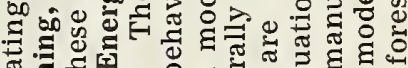

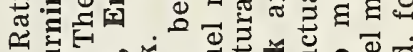

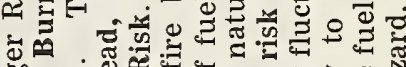
品

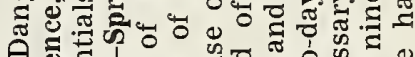

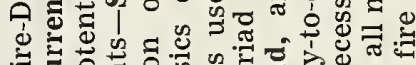

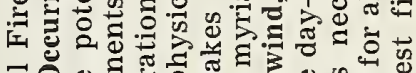
สี I

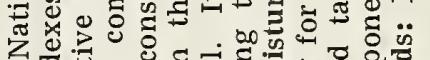

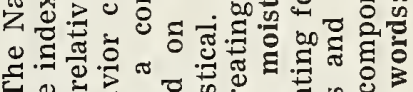

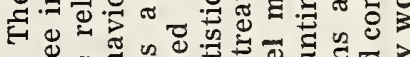

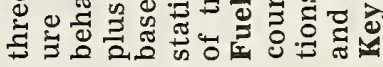

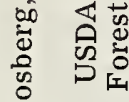 \\ I \\ 安完

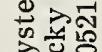

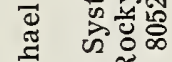 \\ 突 ङ

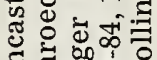 สิ ต以 Bभ. 苛的的

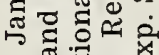 开用

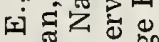

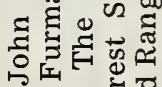

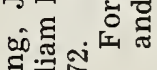 ถัตำ 它}

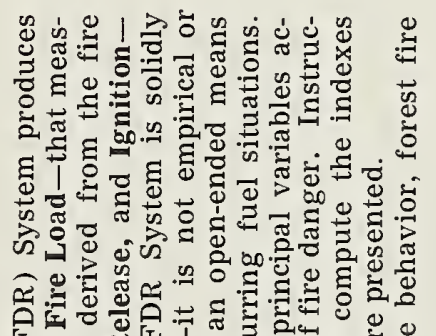

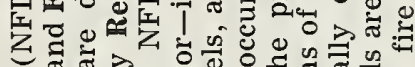
కสี สิ

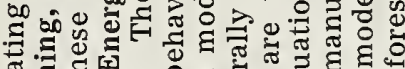
范菲国

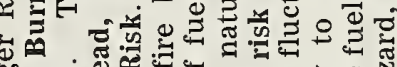

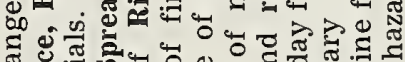
สี

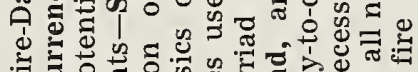

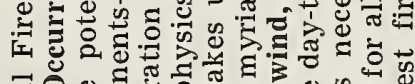

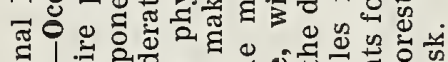

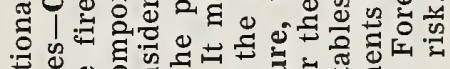

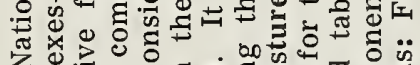

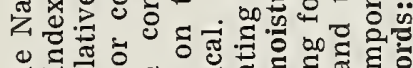

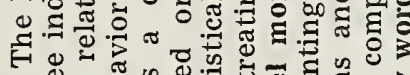

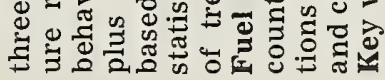

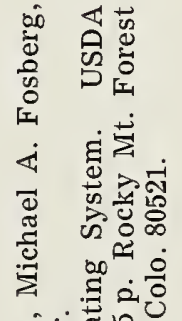
ปे ชू สี

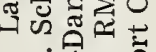
的这

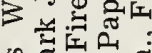
๒ี

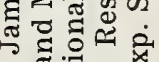

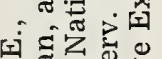
됭 द⿱ है: ค ⿷匚⿱ 口)

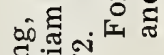
독 政. คे

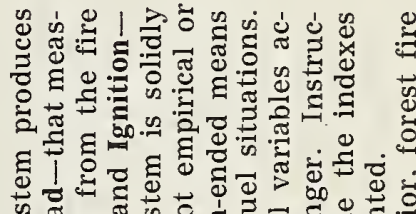
w. के

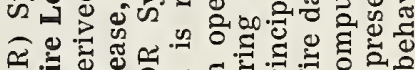

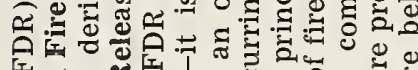

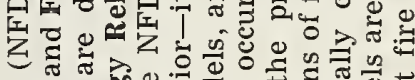
क人

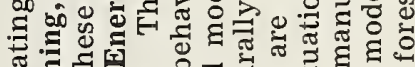
跣.

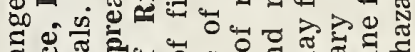

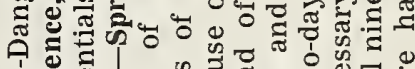
일

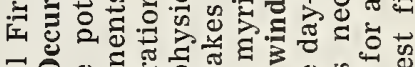
สี I ।

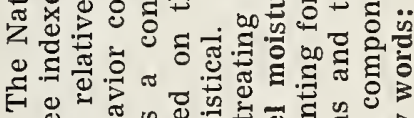

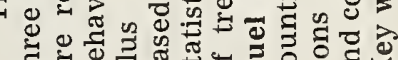





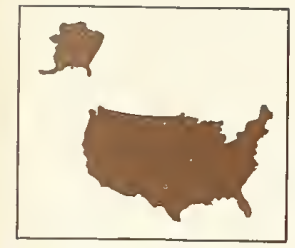

NATIONAL

FIRE-DANGER

RATING SYSTEM
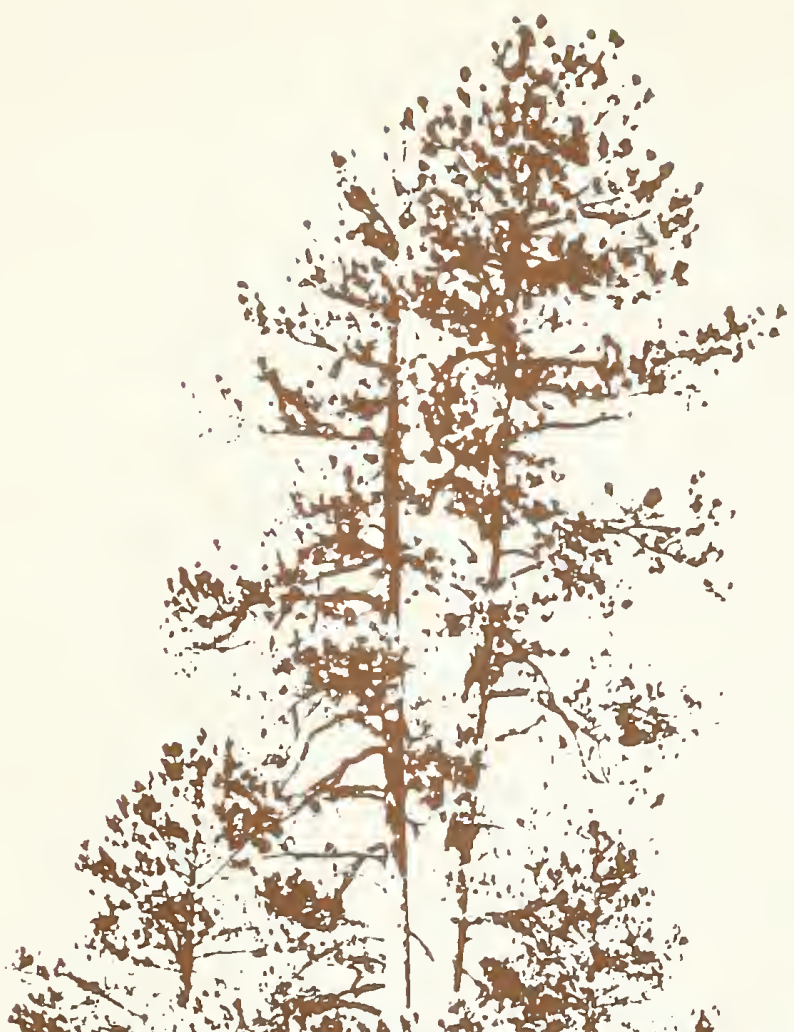

- ton

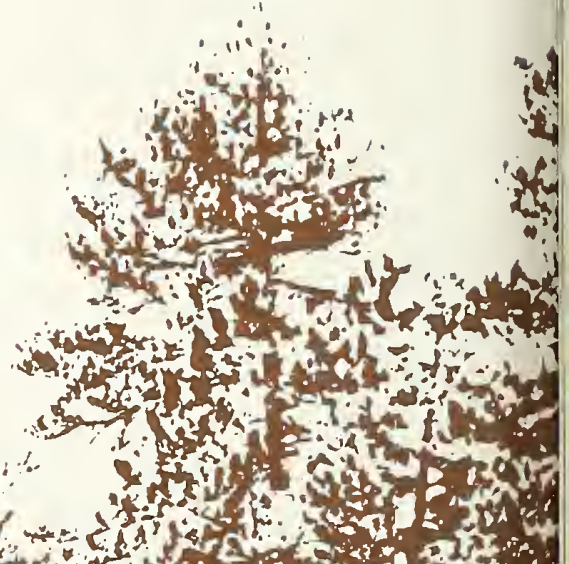

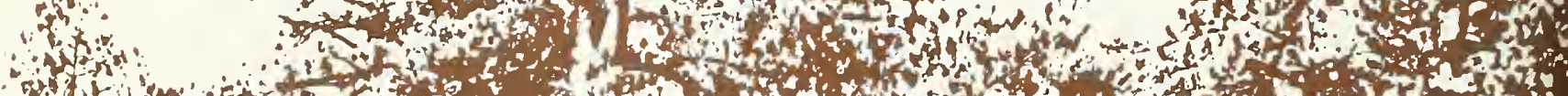

$\therefore$ a

1.

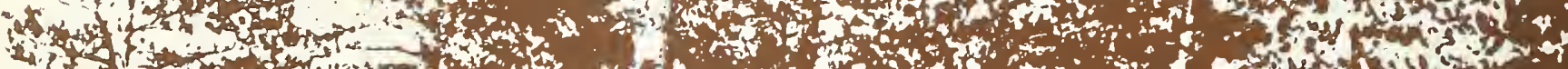

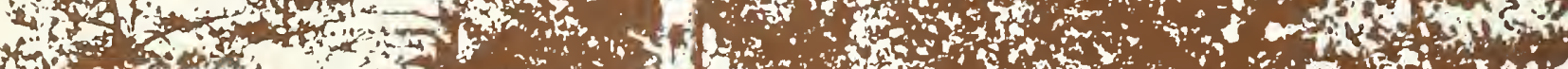

Leto

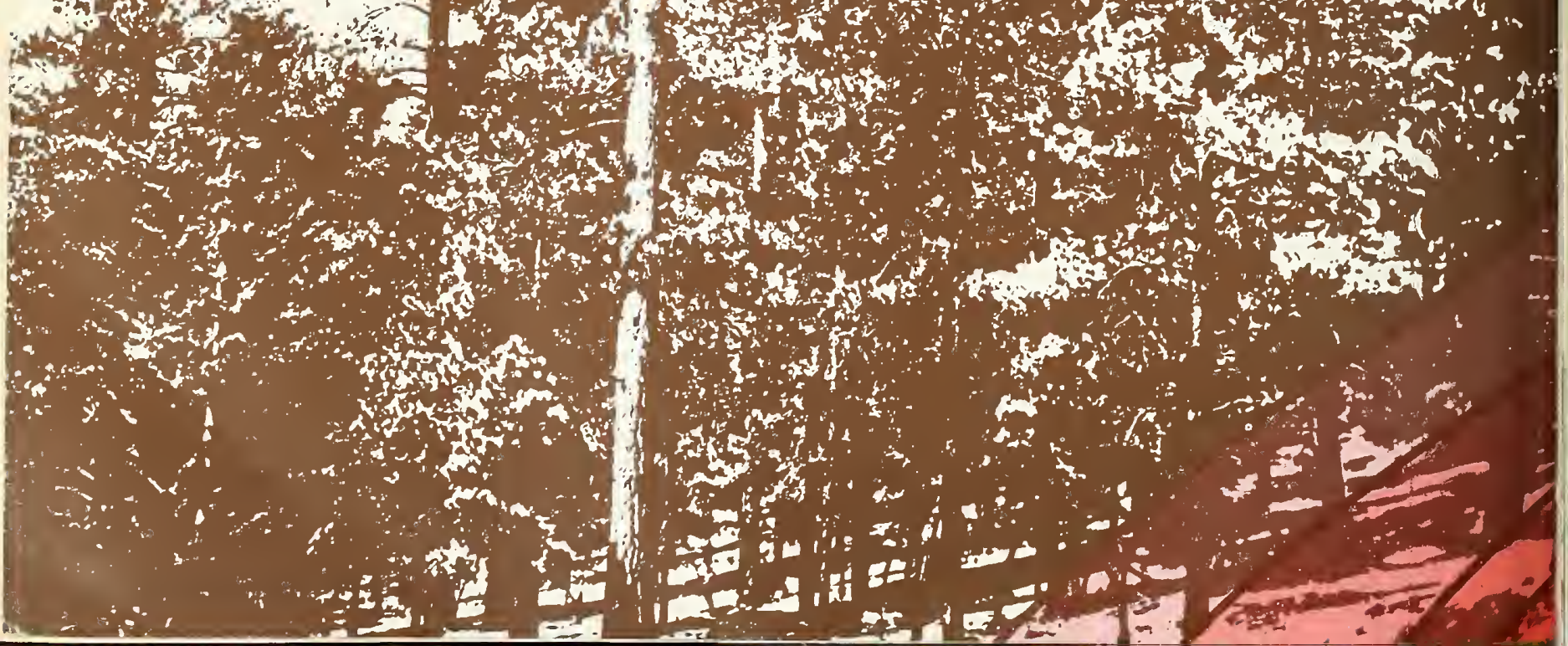

